\title{
Sustainability certification for deforestation-free supply chains: the cases of palm oil and soy
}

\author{
Dissertation \\ to attain the doctoral degree (Dr. sc. agr.) \\ of the Faculty of Agricultural Sciences \\ Georg-August-Universität Göttingen
}

Submitted by

Cordula Verena Maria Hinkes

born in Wiesbaden, Germany

Göttingen, December 2020 
1. Referee: $\quad$ PD Dr. Martin Banse, Thünen Institute of Market Analysis, Braunschweig

2. Referee: Prof. Dr. Achim Spiller, Department of Agricultural Economics and Rural Development, Georg August University of Göttingen

3. Referee: Prof. Dr. Claudia Neu, Department of Agricultural Economics and Rural Development, Georg August University of Göttingen

Date of oral examination: March 4, 2021 
“We must immediately halt deforestation everywhere and grow crops like oil palm and soya only on land that was deforested long ago."

(Sir David Attenborough,

in "A Life on Our Planet", 2020) 


\section{Table of contents}

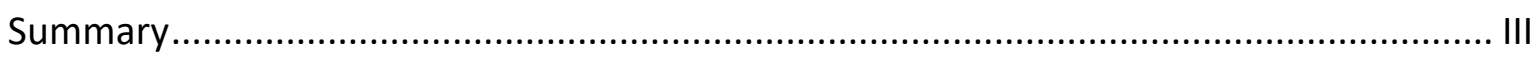

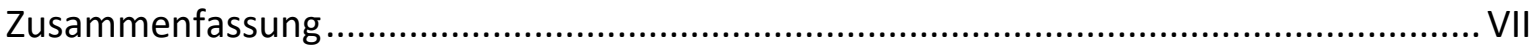

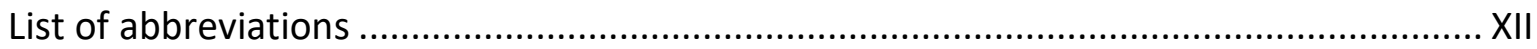

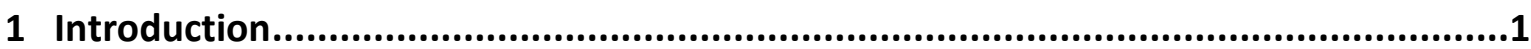

1.1 The role of agriculture and trade in deforestation.............................................. 1

1.2 Zero-deforestation initiatives and policy development ...................................... 3

1.3 Sustainability certification as a potential measure to ensure deforestation-free

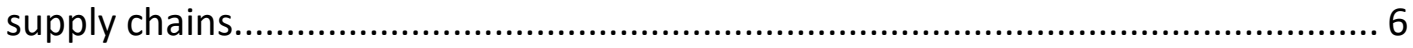

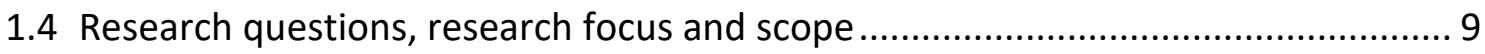

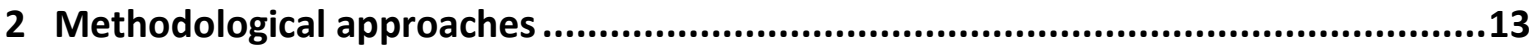

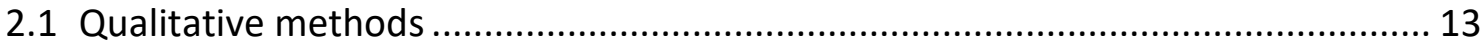

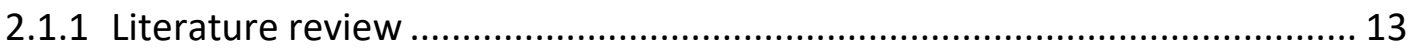

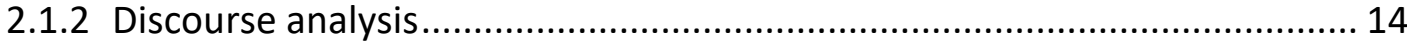

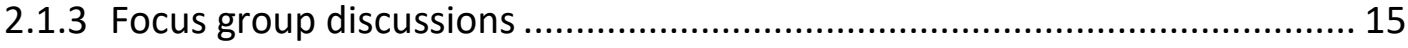

2.1.4 Thematic content analysis and document analysis.................................. 16

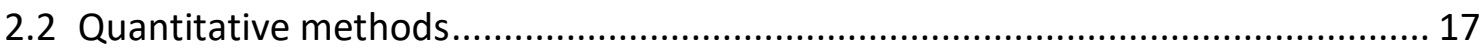

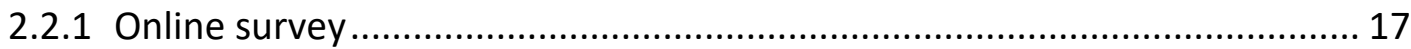

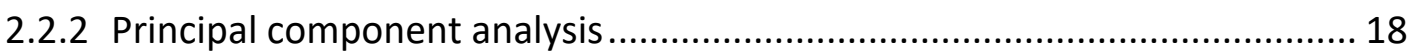

2.2.3 Discrete choice experiment .................................................................... 20

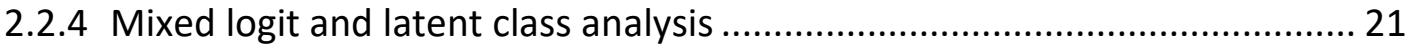

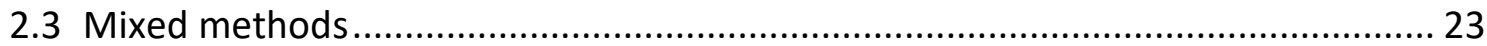

3 Structure and summary of the contributed articles............................................24

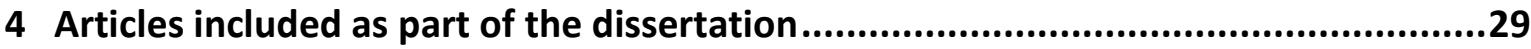

4.1 Adding (bio)fuel to the fire: Discourses on palm oil sustainability in the context of

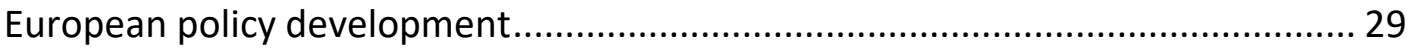

4.2 Consumer attitudes toward palm oil: Insights from focus group discussions ........ 52

4.3 No palm oil or certified sustainable palm oil? Heterogeneous consumer preferences and the role of information.

4.4 Traceability matters: A conceptual framework for deforestation-free supply chains applied to soy certification

5.1 Contribution to the research on deforestation-free supply chains 


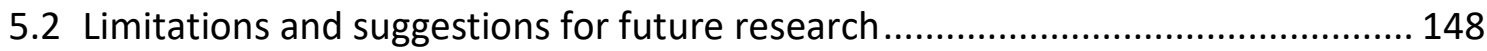

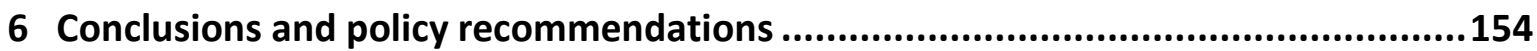

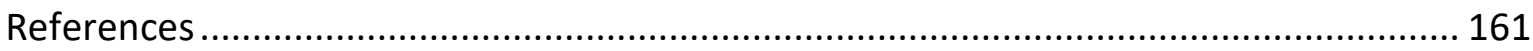

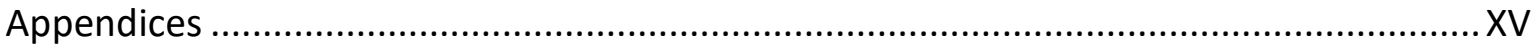

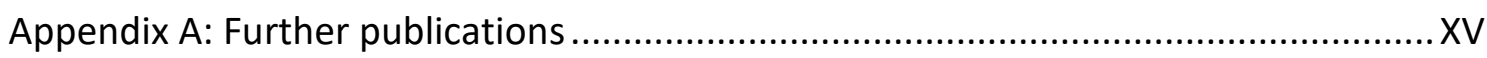

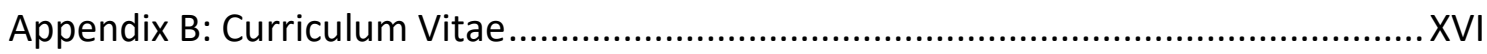

Appendix C: Acknowledgements ............................................................................... 


\section{Summary}

The production of agricultural commodities, such as palm oil or soy, is often linked to the deforestation of biodiversity-rich tropical rainforests with high carbon storage capacities. These so-called forest-risk commodities are traded along international supply chains and primarily consumed as ingredients of food, feed, and fuel in the European Union (EU) and many other countries in the world. Thus, private sector actors as well as the governments of several European countries have acknowledged a shared responsibility for the adverse effects of the demand for forest-risk commodities and established the goal of eliminating deforestation from supply chains. However, due to several obstacles, this goal is still far from being reached. How it can be effectively and efficiently ensured that commodities sourced from distant regions are free from deforestation remains an important, topical question that is being tackled by researchers and policymakers.

This dissertation sets the focus on sustainability certification as one potential instrument to ensure deforestation-free supply chains, because different public and private stakeholders have already been investing resources in promoting certification and developing standards that include forest conservation criteria. The focus is further specified on the geographical level by concentrating on the EU as a major market for forest-risk commodities, and on the commodity level by selecting palm oil and soy, as these are particularly relevant for the EU. Different uses of these commodities (i.e., food, feed, and biofuels) are considered in the analysis. The dissertation is comprised of four articles contributing insights that are relevant for answering the following three research questions (RQs):

I. To what extent is the development of deforestation-free supply chains supported by policy measures in the EU?

II. Which factors influence the demand for certified sustainable, deforestation-free products?

III. Which sustainability certification systems should be supported to ensure deforestationfree supply chains?

With respect to $R Q \mathrm{I}$, the development of relevant EU policies that particularly apply to palm oil is studied by conducting a discourse analysis. This analysis focuses on the European Parliament resolution on palm oil and deforestation of rainforests, and on the EU Renewable Energy Directive II (RED II). The results indicate that these policies promote the view that the sustainability of palm oil currently cannot be ensured by existing voluntary sustainability certification systems. Mandatory sustainability certification according to stricter standards is suggested as a solution in the European Parliament resolution. The RED II classifies palm oil as the 
only high-risk commodity with respect to indirect land-use change (ILUC). Consequently, palm oil will be phased out as a biofuel feedstock in the context of the EU's renewable energy targets, unless certain exception criteria are fulfilled. Actors from Indonesia and Malaysia, the main palm oil producing countries, express opposition to the EU policy development. They argue that palm oil is the most sustainable alternative available. Existing controversies on the sustainability of palm oil have been fueled by discourses related to the development of the new EU policies. Although these policies aim to support the development of deforestation-free supply chains, there are no legally binding regulations for other uses apart from bioenergy yet. Moreover, other forest-risk commodities deserve consideration in future policy development. For policymakers, it is also important to ensure that policy measures are based on empirical evidence to reduce the risk of (trade) conflicts.

Concerning RQ II, it is important to gain knowledge about relevant drivers of demand for certified sustainable products, as this demand is lagging behind supply for several commodities (e.g., palm oil, soy, cocoa). In this context, consumer attitudes and preferences toward (certified) palm oil are a relevant field of interest. In the first step, focus group discussions on palm oil as a food ingredient are conducted with consumers in Germany to gain detailed insights into these aspects. The results of a qualitative content analysis show that respondents are better informed about the disadvantages of palm oil than about its advantages, which influences their attitudes. Most respondents indicate an aversion to palm oil and express their preferences for palm-oil-free products, although they lack knowledge about alternatives to palm oil. Palm oil is not only perceived as unsustainable but also as unhealthy, which is not generally supported by scientific evidence. Neither the Roundtable on Sustainable Palm Oil (RSPO) - a multi-stakeholder initiative defining sustainability standards that include zero-deforestation criteria - nor the respective RSPO product labels are known among respondents. Still, a small price premium for RSPO-certified sustainable palm oil is found to be acceptable if certain conditions are fulfilled, particularly referring to the trustworthiness of the certification system. However, other product attributes as well as personal and situational factors seem more relevant than palm oil in actual purchase and consumption decisions. Particularly the product price, the brand, the taste, the availability, and the time required to search for relevant product information are among the mentioned aspects.

In the second step, a discrete choice experiment with chocolate cookies is implemented as part of a web-based survey conducted in Germany. The purpose is to quantify stated preferences and the willingness to pay for products containing RSPO-certified palm oil, as compared to conventional palm oil and palm-oil-free alternatives. The experiment is split into two parts: before and after providing information on palm oil production and the sustainability labels used in the experiment. On average, respondents prefer palm-oil-free cookies over RSPO-certified 
cookies, while cookies containing exclusively RSPO-certified palm oil ("RSPO certified") are preferred over cookies that may contain both certified and uncertified palm oil ("RSPO mixed"). However, the results of a latent class analysis reveal relevant differences in stated preferences and characteristics between different consumer segments. For instance, one segment clearly avoids palm oil in general, another segment is indifferent, while a third seems to be concerned about sustainability and supports certification. Cheaper products are generally preferred by many respondents, which is in line with the results of the focus group discussions and previous studies. After information provision, preferences for both RSPO-certified and palm-oil-free products increase, with the latter still prevailing. The results suggest that targeted information might help to increase the demand for certified sustainable palm oil among certain consumer segments. Nevertheless, it will probably not be sufficient to achieve a large-scale transformation toward sustainability. Among other aspects, consumers' concerns about potential adverse health aspects of palm oil consumption might also be relevant, but have not been in the focus of this study.

While the RSPO provides the globally predominant certification system for palm oil used in consumer products, the variety of relevant certification systems is much larger for soy, which is mainly used as a feed ingredient in Europe. This variety makes it difficult for policymakers and private sector actors to identify which systems should be supported to achieve zero-deforestation targets. Referring to RQ III, a conceptual framework for the assessment of certification systems in the zero-deforestation context is developed. It comprises three main elements that need to be sufficiently stringent: sustainability standards, assurance systems, and chain-of-custody (CoC) certification. $\mathrm{CoC}$ certification is used to ensure traceability of commodities along the supply chain - an important aspect that had not been sufficiently considered in previous studies. In this framework, it is argued that only segregation and identity preservation are CoC systems that may ensure traceability, because other $\mathrm{CoC}$ systems do not prevent the blending with uncertified commodities. The framework is then applied to assess a sample of 16 soy certification systems. The results suggest that only few certification systems are adequate for ensuring deforestationfree soy supply chains and should be supported: ISCC EU, ISCC PLUS, ProTerra, Donau Soja, Europe Soya, as well as RTRS - provided that an adequate CoC system is used, which is optional for some of these systems. In the case of soy used as feed, certification is not communicated via labels to final consumers of animal products. Thus, the demand for soy certified according to the respective standards would need to be more directly stimulated by soy-sourcing companies.

Overall, this dissertation makes important contributions to policy-relevant research on deforestation-free supply chains by focusing on sustainability certification for two relevant forestrisk commodities and different uses. Further research is required, for instance considering other forest-risk commodities, such as cocoa, as well as the demand and consumption outside the EU. 
Although some progress with respect to achieving zero-deforestation goals can be observed, several obstacles still need to be overcome, for instance related to transaction costs. There is still a significant gap between the supply of and the demand for certified products. This means that certified products have to be sold without a premium, which reduces incentives for producers to achieve certification. Prevailing preferences for palm-oil-free products remain a challenge, as alternatives to palm oil are less efficient in terms of output per production area. Moreover, trade in (unsustainable) palm oil might just be diverted to other import markets. Thus, certification systems and the respective labels should be promoted by providing targeted and easily digestible information to consumers. Consumers' trust in certification should be strengthened by supporting and promoting ambitious certification systems.

Nevertheless, addressing consumer attitudes and preferences alone will most likely not be sufficient to increase the market share of deforestation-free commodities. To address leakage and displacement, certification approaches need to be upscaled by considering various commodities cultivated in certain production areas. Moreover, policies that go beyond nonbinding commitments to support industry initiatives are required. Therefore, mandatory sustainability requirements should be developed to restrict the import of unsustainably produced forest-risk commodities into the EU. In this context, the aspect of traceability also needs to receive more attention in policy and practice. Some of these aspects have already been taken up in recent policy development in the EU, which is still in progress and might be supported by relevant research and public consultation processes. 


\section{Zusammenfassung}

Der Anbau verschiedener Agrarrohstoffe, wie beispielsweise Palmöl und Soja, steht häufig in Verbindung mit der Abholzung von artenreichen tropischen Regenwäldern mit hoher Kohlenstoffspeicherkapazität. Diese sogenannten "Waldrisiko-Rohstoffe“ werden über internationale Lieferketten gehandelt und insbesondere für die Nahrungs- und Futtermittelproduktion sowie als Biokraftstoffe in der Europäischen Union (EU) und anderen Ländern der Welt verwendet. Deshalb haben sowohl privatwirtschaftliche Akteur*innen als auch mehrere europäische Staaten die gemeinsame Verantwortung für negative Auswirkungen der Nachfrage nach Waldrisiko-Rohstoffen anerkannt und sich „entwaldungsfreie Lieferketten“ zum Ziel gesetzt. Dieses Ziel ist jedoch aufgrund verschiedener Hindernisse noch lange nicht erreicht. Wie möglichst effektiv und effizient sichergestellt werden kann, dass importierte Rohstoffe aus weit entfernten Regionen ohne vorherige Entwaldung angebaut wurden, bleibt eine wichtige und aktuelle Frage, die Wissenschaft und Politik beschäftigt.

Diese Dissertation setzt den Fokus auf Nachhaltigkeitszertifizierung als ein mögliches Instrument, um entwaldungsfreie Lieferketten umzusetzen, da verschiedene öffentliche und private Akteur*innen bereits Ressourcen in die Förderung von Zertifizierung und die Entwicklung von Standards, die Waldschutzkriterien beinhalten, investiert haben. Der Fokus wird weiter konkretisiert auf geographischer Ebene durch eine Konzentration auf die EU als einen wichtigen Markt für Waldrisiko-Rohstoffe, und auf Produktebene durch die Auswahl von Palmöl und Soja, da diese besonders relevant für die EU sind. Es werden verschiedene Verwendungsmöglichkeiten (für Nahrungsmittel, Futtermittel, und Biokraftstoffe) berücksichtigt. Die Dissertation besteht aus vier Artikeln, die relevante Erkenntnisse zur Beantwortung der folgenden Forschungsfragen (RQs) beitragen:

I. Inwiefern wird die Entwicklung von entwaldungsfreien Lieferketten durch Politikmaßnahmen in der EU unterstützt?

II. Welche Faktoren beeinflussen die Nachfrage nach nachhaltigen und entwaldungsfreien Produkten, die entsprechend zertifiziert sind?

III. Welche Nachhaltigkeitszertifizierungssysteme sollten unterstützt werden, um entwaldungsfreie Lieferketten zu gewährleisten?

In Bezug auf RQI wird die Entwicklung von relevanten EU-Politikmaßnahmen, die insbesondere Palmöl betreffen, mithilfe einer Diskursanalyse untersucht. Der Fokus dieser Analyse liegt auf der Resolution des Europäischen Parlaments zu Palmöl und der Rodung von Regenwäldern sowie auf der Erneuerbare-Energien-Richtlinie II (RED II). Die Ergebnisse zeigen, dass diese EU-Politikmaßnahmen die Ansicht vertreten, dass die Nachhaltigkeit von Palmöl nicht 
mithilfe von existierenden freiwilligen Zertifizierungssystemen sichergestellt werden kann. Die Resolution des Europäischen Parlaments schlägt verpflichtende Zertifizierung nach strengeren Standards als Lösung vor. In der RED II wird ausschließlich Palmöl als Rohstoff mit hohem Risiko für indirekte Landnutzungsänderungen (ILUC) klassifiziert. Deswegen wird Biokraftstoff aus Palmöl künftig nicht mehr auf Erneuerbare-Energien-Ziele angerechnet, sofern nicht bestimmte Ausnahmekriterien erfüllt werden. Akteur*innen aus Indonesien und Malaysia, den wichtigsten Palmöl-produzierenden Ländern, lehnen die geplanten EU-Politikmaßnahmen ab. Sie argumentieren, dass Palmöl die nachhaltigste verfügbare Option ist. Bestehende Kontroversen um die Nachhaltigkeit von Palmöl wurden durch die geplanten Politikmaßnahmen in der EU verstärkt. Obwohl diese Politikmaßnahmen die Entwicklung entwaldungsfreier Lieferketten unterstützen sollen, gibt es bisher keine verbindlichen Vorschriften für die nichtenergetische Verwendung. Außerdem sollten weitere Waldrisiko-Rohstoffe in Politikmaßnahmen stärker berücksichtigt werden. Politische Entscheidungsträger*innen sollten auch sicherstellen, dass Politikmaßnahmen auf Fakten basieren, um das Risiko von möglichen (Handels-)Konflikten zu reduzieren.

Hinsichtlich RQ II ist es wichtig, Wissen über relevante Einflussfaktoren auf die Nachfrage nach zertifiziert nachhaltigen Produkten zu gewinnen, da diese Nachfrage für einige relevante Rohstoffe (z.B. Palmöl, Soja, Kakao) geringer ist als das Angebot. In diesem Zusammenhang sind die Einstellungen und Präferenzen von Verbraucher*innen ein relevantes Forschungsfeld. Im ersten Schritt werden daher mehrere Gruppendiskussionen zu Palmöl in Lebensmitteln mit Verbraucher*innen in Deutschland durchgeführt, um diese Aspekte detailliert zu untersuchen. Die Ergebnisse der qualitativen Inhaltsanalyse zeigen, dass die Teilnehmenden über die Nachteile von Palmöl besser informiert sind als über dessen Vorteile, was die Einstellungen entsprechend beeinflusst. Die meisten Teilnehmenden äußern eine ablehnende Haltung gegenüber Palmöl und eine Präferenz für palmölfreie Produkte, obwohl sie über Alternativen zu Palmöl wenig informiert sind. Palmöl wird nicht nur als nicht nachhaltig, sondern auch als ungesund wahrgenommen, wobei negative Auswirkungen auf die Gesundheit nicht durch wissenschaftliche Erkenntnisse belegt werden können. Weder der Roundtable on Sustainable Palm Oil (RSPO), der Nachhaltigkeitsstandards für Palmöl mit Kriterien zur "Null-Entwaldung“ entwickelt hat, noch dessen Produktsiegel sind den Teilnehmenden bekannt. Trotzdem wird ein geringer Preisaufschlag für RSPO-zertifiziertes Palmöl als akzeptabel angesehen, sofern bestimmte Bedingungen erfüllt sind; insbesondere in Bezug auf die Vertrauenswürdigkeit des Zertifizierungssystems. Allerdings scheinen andere Produkteigenschaften sowie persönliche und situationsbezogene Faktoren in tatsächlichen Kauf- und Konsumentscheidungen eine größere Rolle zu spielen als Palmöl. Insbesondere der Preis, die (Hersteller-)Marke, der Geschmack, die 
Verfügbarkeit und der benötigte Zeitaufwand für die Suche von relevanten Produktinformationen werden erwähnt.

Im zweiten Schritt wird im Rahmen einer Online-Befragung in Deutschland ein DiscreteChoice-Experiment am Beispiel von Schokoladenkeksen durchgeführt. Das Ziel der Studie ist, die angegebenen Präferenzen und die Zahlungsbereitschaft für Produkte mit RSPO-zertifiziertem Palmöl im Vergleich zu konventionellem Palmöl und palmölfreien Alternativen zu quantifizieren. Das Experiment wird in zwei Teilen durchgeführt; bevor und nachdem die Teilnehmenden Informationen über den Palmölanbau und die verwendeten Nachhaltigkeitssiegel erhalten. Insgesamt bevorzugen die Teilnehmenden palmölfreie Kekse gegenüber Keksen mit RSPOzertifiziertem Palmöl. Kekse, die ausschließlich RSPO-zertifiziertes Palmöl enthalten („RSPO zertifiziert"), werden gegenüber Keksen bevorzugt, die sowohl Anteile von zertifiziertem als auch Anteile von nicht zertifiziertem Palmöl enthalten können („RSPO gemischt“). Allerdings können mithilfe einer Latent-Class-Analyse relevante Unterschiede hinsichtlich der angegebenen Präferenzen und persönlichen Eigenschaften zwischen verschiedenen Personengruppen identifiziert werden. Eine Gruppe beispielsweise vermeidet Palmöl generell, eine andere ist indifferent, während sich eine dritte Gruppe Gedanken um Nachhaltigkeit macht und Zertifizierung unterstützt. Viele Teilnehmende bevorzugen generell preisgünstigere Produkte, was die Ergebnisse aus den Gruppendiskussionen und vorherigen Studien bestätigt. Nach der Bereitstellung von Informationen steigen die angegebenen Präferenzen sowohl für RSPOzertifizierte als auch für palmölfreie Produkte, wobei letztere weiterhin überwiegen. Die Ergebnisse deuten darauf hin, dass zielgerichtete Informationen dabei helfen könnten, die Nachfrage nach zertifiziertem, nachhaltigem Palmöl in bestimmten Zielgruppen zu erhöhen. Trotzdem wird damit alleine vermutlich keine weitreichende Transformation hin zu Nachhaltigkeit erreicht werden. Verbraucherbedenken in Bezug auf mögliche negative gesundheitliche Auswirkungen des Palmölkonsums standen nicht im Fokus dieser Untersuchung, könnten aber neben anderen Aspekten - ebenfalls relevant sein.

Während der RSPO das weltweit wichtigste Zertifizierungssystem für Palmöl in Lebensmitteln ist entwickelt hat, gibt es für Soja - das in Europa hauptsächlich für Futtermittel verwendet wird - eine deutlich größere Anzahl an relevanten Zertifizierungssystemen. Aufgrund dieser Vielfalt ist es für Akteur*innen aus Politik und Wirtschaft schwierig, diejenigen Systeme zu identifizieren, die zur Erreichung von "Null-Entwaldung“ in Lieferketten unterstützt werden sollten. Im Zusammenhang mit RQ III wird deshalb ein Konzept für die Beurteilung von Zertifizierungssystemen mit Fokus auf Kriterien zu Null-Entwaldung entwickelt. Das Konzept besteht aus drei Hauptelementen, die ausreichend hohe Anforderungen stellen müssen: Nachhaltigkeitsstandards, Verifizierungsmechanismen und Chain-of-Custody-Zertifizierung (CoC- 
Zertifizierung). Mit CoC-Zertifizierung soll die Rückverfolgbarkeit von Rohstoffen entlang der Lieferkette gewährleistet werden. Dieser wichtige Aspekt wurde in früheren Studien nicht ausreichend berücksichtigt. In diesem Konzept wird argumentiert, dass nur die CoC-Systeme „Segregation“ und „Identity Preservation“ die Rückverfolgbarkeit entlang der Lieferkette gewährleisten können, weil andere CoC-Systeme die Vermischung mit nicht zertifizierten Rohstoffen nicht verhindern. Das Konzept wird anschließend angewendet, um 16 Zertifizierungssysteme für Soja zu beurteilen. Basierend auf den Ergebnissen sind nur wenige Zertifizierungssysteme für die Sicherstellung von entwaldungsfreien Soja-Lieferketten geeignet und sollten daher unterstützt werden: ISCC EU, ISCC PLUS, ProTerra, Donau Soja, Europe Soya, sowie RTRS. Hierbei wird vorausgesetzt, dass ein geeignetes CoC-System angewandt wird, was bei manchen dieser Systeme optional ist. Bei der Verwendung von Soja für Futtermittel wird den Verbraucher*innen die Zertifizierung nicht in Form von Siegeln auf tierischen Produkten signalisiert. Daher müsste die Nachfrage nach zertifiziertem Soja eher direkt durch Sojaverarbeitende Unternehmen gesteigert werden.

Insgesamt leistet diese Dissertation einen wichtigen, politikrelevanten Forschungsbeitrag zur Umsetzung von entwaldungsfreien Lieferketten, indem das Instrument der Nachhaltigkeitszertifizierung für zwei relevante Waldrisiko-Rohstoffe und verschiedene Verwendungsmöglichkeiten untersucht wird. Zukünftiger Forschungsbedarf besteht unter anderem in Bezug auf weitere Waldrisiko-Rohstoffe - wie beispielsweise Kakao - sowie in Bezug auf die Nachfrage und den Konsum außerhalb der EU. Obwohl Fortschritte hinsichtlich der Erreichung von Null-Entwaldung beobachtet werden können, müssen noch einige Hindernisse überwunden werden; beispielsweise im Zusammenhang mit Transaktionskosten. Es besteht noch immer ein Angebotsüberschuss für zertifizierte Produkte. Das bedeutet, dass zertifizierte Produkte ohne Preisaufschlag verkauft werden müssen, was die Anreize zur Zertifizierung für Produzent*innen verringert. Präferenzen für palmölfreie Produkte stellen weiterhin eine Herausforderung dar, weil Alternativen zu Palmöl weniger effizient in Bezug auf den Ertrag pro Anbaufläche sind. Außerdem könnte es zu einer Verlagerung des Handels von (nicht nachhaltigem) Palmöl in andere importierende Regionen kommen. Daher sollte das Vertrauen der Verbraucher*innen in Zertifizierung gestärkt werden, indem anspruchsvolle Zertifizierungssysteme und deren Siegel gefördert und beworben werden.

Nichtsdestotrotz wird es vermutlich nicht genügen, die Endverbraucher*innen zu informieren, um über veränderte Präferenzen den Marktanteil entwaldungsfreier Rohstoffe zu erhöhen. Um Verdrängungs- und Verlagerungseffekte zu verhindern, müssen Zertifizierungsansätze großflächig umgesetzt werden. Dabei müssen verschiedene Agrarprodukte in einem bestimmten Anbaugebiet berücksichtigt werden. Außerdem sind Politikmaßnahmen 
erforderlich, die über freiwillige Selbstverpflichtungen zur Unterstützung von Initiativen des Privatsektors hinausgehen. Verpflichtende Nachhaltigkeitsanforderungen sollten entwickelt werden, um den Import von nicht nachhaltig produzierten Waldrisiko-Rohstoffen in die EU einzuschränken. In diesem Zusammenhang sollte auch der Aspekt der Rückverfolgbarkeit in Politik und Praxis stärker berücksichtigt werden. Einige dieser Punkte werden aktuell bereits im Rahmen der Entwicklung von EU-Politikmaßnahmen diskutiert. Dieser Entwicklungsprozess könnte durch relevante Forschung und öffentliche Konsultationsprozesse unterstützt werden. 


\section{List of abbreviations}

AAM author accepted manuscript

ADAA argumentative discourse-analytical approach

ADM Archer Daniels Midland

ADP Amsterdam Declarations Partnership

AFi Accounting Framework initiative

AIC Akaike information criterion (used in article 3)

AIC Agricultural Industries Confederation (used in article 4)

ARS Amaggi Responsible Standard

ASC Agricultura Sustenable Certificada

ASEAN Association of Southeast Asian Nations

BFA Belgian Feed Association

BMEL Bundesministerium für Ernährung und Landwirtschaft (English: German Ministry of Food and Agriculture)

CAIC consistent Akaike information criterion

CAQDAS computer-assisted qualitative data analysis software

CAR Cadastro Ambiental Rural (English: Environmental Rural Registry)

CDP Carbon Disclosure Project

CEO Chief Executive Officer

CGF Consumer Goods Forum

$\mathrm{CL} \quad$ conditional logit

$\mathrm{CO}_{2} \quad$ carbon dioxide

$\mathrm{CoC}$ chain of custody / chain-of-custody

CRS Certified Responsible Soya (by Cefetra)

CSR corporate social responsibility

EC European Commission

EFTA European Free Trade Association

e.g. exempli gratia (English: for example)

EM expectation-maximization (algorithm)

EP European Parliament

EPOA European Palm Oil Alliance

EPOC European Palm Oil Conference

ETFRN European Tropical Forest Research Network

EU European Union 
FEFAC Fédération Européenne des Fabricants d'Aliments Composés (English: European Feed Manufacturer's Federation)

FEMAS Feed Materials Assurance Scheme

FERC forest and ecosystem-risk commodity

FGD focus group discussion

FLEGT Forest Law Enforcement, Governance and Trade

FONAP Forum für Nachhaltiges Palmöl (English: Forum for Sustainable Palm Oil)

FQD $\quad$ Fuel Quality Directive

FSMA Food Safety Modernization Act

GAR Golden Agri-Resources

GEWISOLA Gesellschaft für Wirtschafts- und Sozialwissenschaften des Landbaues e.V.

(English: German Society of Economic and Social Sciences in Agriculture)

GFL General Food Law

GHG greenhouse gas

$\mathrm{GM}(\mathrm{O}) \quad$ genetically modified (organism)

GSDR Global Sustainable Development Report

HCS High Carbon Stock

HCV High Conservation Value

IDH Initiatief Duurzame Handel (English: The Sustainable Trade Initiative)

i.e. id est (English: that is; namely)

IIA independence of irrelevant alternatives

ILUC indirect land-use change

ISCC International Sustainability \& Carbon Certification

ISEAL International Social and Environmental Accreditation

ISPO Indonesian Sustainable Palm Oil

ITC International Trade Centre

KMO Kaiser-Meyer-Olkin

Mha million hectares

ML mixed logit

MPIC Malaysian Ministry of Plantation Industries and Commodities

MPOC Malaysian Palm Oil Council

MSA measure of sampling adequacy

MSI multi-stakeholder initiative

MSPO Malaysian Sustainable Palm Oil

NDPE no deforestation, no peat, no exploitation 


\begin{tabular}{|c|c|}
\hline NGO & non-governmental organization \\
\hline NYDF & New York Declaration on Forests \\
\hline PCA & principal component analysis \\
\hline PCE & perceived consumer effectiveness \\
\hline PO & palm oil \\
\hline PPP & public-private partnership \\
\hline QR & Quick Response (code) \\
\hline RED & Renewable Energy Directive \\
\hline RFID & radio-frequency identification \\
\hline $\mathrm{RQ}$ & research question \\
\hline RSPO & Roundtable on Sustainable Palm Oil \\
\hline RSS & Responsible Soybean Standard (by ADM) \\
\hline RTRS & Round Table on Responsible Soy \\
\hline RUT & random utility theory \\
\hline SDG & Sustainable Development Goal \\
\hline SEI & Stockholm Environment Institute \\
\hline SFAP & Sustainable Farming Assurance Programme \\
\hline SSG & Soy Sourcing Guidelines \\
\hline T\&E & Transport \& Environment \\
\hline TCE & transaction cost economics \\
\hline TNC & The Nature Conservancy \\
\hline TRU & traceable resource unit \\
\hline UN & United Nations \\
\hline UNDESA & United Nations Department of Economic and Social Affairs \\
\hline UNFCCC & United Nations Framework Convention on Climate Change \\
\hline UNGA & United Nations General Assembly \\
\hline U.S. & United States \\
\hline USA & United States of America \\
\hline USSEC & U.S. Soybean Export Council \\
\hline U.S. SSAP & U.S. Soy Sustainability Assurance Protocol (by USSEC) \\
\hline VPA & Voluntary Partnership Agreement \\
\hline WTO & World Trade Organization \\
\hline WTP & willingness to pay \\
\hline WWF & World Wide Fund for Nature \\
\hline ZDC & zero-deforestation commitment \\
\hline
\end{tabular}




\section{Introduction}

This dissertation is based on the results of the research project "Accompanying research on the organization of deforestation-free supply chains". This project has been conducted at the Thünen Institute of Market Analysis, one of the specialized research institutes of the (Johann Heinrich von) Thünen Institute based in Braunschweig, Germany. The Thünen Institute, a federal research institute under the auspices of the German Ministry of Food and Agriculture (BMEL), has been funding this project for a duration of 3.5 years (10/2017-03/2021).

The structure of this dissertation is organized as follows: This introductory section (section 1) provides relevant background information on deforestation-free supply chains and sustainability certification. Moreover, it defines the overarching research questions and the focus of this dissertation. Section 2 explains the methods applied in the studies conducted as part of this dissertation. Section 3 provides a structured overview of the articles that are subsequently presented in section 4 . The findings of these articles are discussed in section 5 . Final conclusions and policy recommendations are derived in section 6 .

\subsection{The role of agriculture and trade in deforestation}

Forests are important because they provide habitats for many species as well as crucial ecosystem services, such as carbon sequestration, pest control, pollination, and the provision of biomass (Brockerhoff et al., 2017; FAO, 2020d; Mori et al., 2017). Deforestation, defined as "the conversion of forests to other land use or the permanent reduction of the tree canopy cover below a defined minimum canopy cover threshold" (NYDF Assessment Partners, 2019, p. 10), has substantial adverse effects on biodiversity, climate, and human livelihoods (Betts et al., 2017; Carrasco et al., 2017; Lawrence \& Vandecar, 2015; Pendrill et al., 2019b). While the average annual (net) loss of global forest area has decreased by around 40\% since 1990 to 4.8 million hectares (Mha) per year for the period 2010-2020 (FAO, 2020d; FAO \& UNEP, 2020), the rate of gross tree cover loss not considering reforestation - has still been increasing (FAO \& UNEP, 2020; NYDF Assessment Partners, 2019). It is important to distinguish between naturally regenerating forests (comprising primary forests and other naturally regenerating forests), and planted forests (comprising forest plantations and other planted forests) (FAO \& UNEP, 2020, pp. 15-16). ${ }^{2}$ Primary forests, particularly tropical rainforests, have a higher value in terms of biodiversity, ecosystem services, and carbon stocks than forest plantations (Brockerhoff et al., 2017; FAO, 2020d; Meyfroidt \& Lambin, 2011). In 2019, the loss of primary forests increased by almost three percent compared

\footnotetext{
${ }^{1}$ For comparison: the annual net loss was 7.84 Mha/year for 1990-2000 and 5.17 Mha/year for 2000-2000 (FAO, 2020d; FAO \& UNEP, 2020).

2 For detailed information on forest categories, please refer to FAO \& UNEP (2020, pp. 15-16).
} 
to 2018 (Global Forest Watch, 2020; Trase, 2020). Thus, quantitative indicators such as net loss of global forest area might underestimate sustainability issues linked to deforestation (Meyfroidt et al., 2010).

The expansion of both commercial and subsistence agriculture has been identified in several studies as the major driver of global deforestation (e.g., Busch \& Ferretti-Gallon, 2017; Curtis et al., 2018; Hosonuma et al., 2012). So-called "forest-risk" commodities are linked to a high risk of deforestation, particularly in tropical regions. Timber, pulp and paper, beef (and leather), soy, palm oil ${ }^{3}$, and cocoa are among the most significant forest-risk commodities (Brack \& Bailey, 2013; Henders et al., 2015; Neeff \& Linhares-Juvenal, 2017). Land-use change from forests to palm oil plantations for instance has several adverse environmental effects, such as biodiversity loss, greenhouse gas (GHG) emissions, pollution of water and air, and soil degradation (Gibbs et al., 2015; Grass et al., 2020; Green et al., 2019; Qaim et al., 2020; Vijay et al., 2016). While agricultural development often contributes to socio-economic development, not everyone benefits equally. Conflicts over land-use rights are a relevant problem in different regions. Indigenous communities for instance often lack formal rights and threatened by displacement. Exploitation of workers, forced labor, and inappropriate working conditions have been frequently reported (Moreno-Peñaranda et al., 2015; Orsato et al., 2013; Qaim et al., 2020).

Large volumes of several forest-risk commodities are traded along international supply chains, meaning that importing countries "consume" deforestation and GHG emissions "embodied" in products (European Commission, 2013; Henders et al., 2015; IDH, 2020b; Pendrill et al., 2019b; Pendrill et al., 2019a). The European Union (EU) was the largest import market for embodied (gross) deforestation linked to agricultural commodities in the period 1990-2008 (Brack \& Bailey, 2013; European Commission, 2013), while more recent data shows that China has become the largest market overall for several forest-risk commodities (beef, palm oil, and soy), followed by the EU (Trase, 2020). Within Europe, Germany accounts for the largest volumes of "hidden carbon emissions" linked to imported agricultural commodities (IDH, 2020b). The total amount of embodied deforestation imported into the EU from 1990 to 2008 was estimated at 9 Mha gross (8.4 Mha net considering re-exports) for crop and livestock products within this period. The major part ( $7.4 \mathrm{Mha}$ ) can be attributed to the consumption of crops, particularly oil crops $(70 \%)$. Of those, $82 \%$ were related to soybeans and soy meal, and $17 \%$ to palm oil (European Commission, 2013). Soy is mainly produced in the United States of America (USA), Brazil, and Argentina, which together account for $77 \%$ of the global soybean production (FAO, 2020c). With regard to palm oil, $84 \%$ of the global production takes place in Indonesia and

\footnotetext{
${ }^{3}$ For the sake of brevity, the term "palm oil" is here (if not indicated otherwise) used for both palm oil, which is extracted from the fruit pulp, and palm kernel oil, which is extracted from the fruit kernel.
} 
Malaysia (FAO, 2020b; Oil World, 2019). In the period from 2010 to 2020, Brazil was the country with the highest average annual net loss of forest area in the world, while Indonesia ranked third (FAO, 2020d, p. 18). ${ }^{4}$

\subsection{Zero-deforestation initiatives and policy development}

In reaction to successful campaigns by environmental non-governmental organizations (NGOs) (e.g., Greenpeace, 2006, 2010) and increasing public concerns over the loss of rainforests, several public and private initiatives have been launched since the beginning of the $21^{\text {st }}$ century to reduce deforestation in general and deforestation linked to international supply chains of agricultural forest-risk commodities in particular (Garrett et al., 2019; Lambin et al., 2018; Pirard et al., 2015). The example of moratoria implemented in Brazil illustrates opportunities and challenges of zerodeforestation initiatives that are also relevant for other countries and supply chains.

In 2006, leading soy traders initiated the Soy Moratorium, a voluntary commitment to stop purchasing soy cultivated in previously forested areas in the Brazilian Amazon biome that had been cleared after July 2006, the declared cut-off date ${ }^{5}$ (Gibbs et al., 2015; Nepstad et al., 2014). In the following years, the Soy Moratorium was renewed on an annual basis until 2016, when it was renewed indefinitely as a joint decision by the agribusiness industry, the Brazilian government, and civil society organizations (Kastens et al., 2017). Despite indications of positive effects of the Soy Moratorium (Gibbs et al., 2015; Kastens et al., 2017), there is empirical evidence for continued illegal deforestation associated with exported commodities (Rajão et al., 2020; Trase, 2020). Relevant problems are indirect land-use change (ILUC) and leakage effects that might partly be attributed to the limited scope of the Soy Moratorium, which does not concern any other biomes apart from the Amazon or other agricultural activities besides soy. Policy gaps and deficiencies in the enforcement of national regulations and instruments, such as Brazil's new Forest Code and the rural environmental registry of private properties (CAR), also contribute to these problems (Gibbs et al., 2015; Macedo et al., 2012; Nepstad et al., 2019).

ILUC generally refers to the process of land-use change in one area induced by land-use changes in other areas (Henders \& Ostwald, 2014; Meyfroidt et al., 2014). Leakage is defined as " $a$ geographical displacement of an environmental impact that counteracts the intended effect of a policy" (Henders \& Ostwald, 2014, p. 21; Meyfroidt et al., 2013). Incidents of ILUC can be observed in Brazil, as the expansion of soy cultivation into pasture displaces cattle farming into forest area, inducing deforestation for new pasture (Arima et al., 2011; Macedo et al., 2012; Richards et al., 2014; Trase, 2020). In 2009, meatpacking companies signed the G4 Cattle

\footnotetext{
${ }^{4}$ The Democratic Republic of the Congo ranked second among the countries with the highest average annual net loss of forest area (FAO, 2020d, p. 18).

${ }^{5}$ The cut-off date was later changed to 2008 to be in line with the new Forest Code (Nepstad et al., 2019).
} 
Agreement ${ }^{6}$ to address this issue by stopping to source cattle linked to deforestation in the Amazon. Its success has been limited, though: The CAR does not cover all plots of land and it is difficult to monitor and track cattle, leaving room for leakage, displacement, and cattle laundering from non-compliant to compliant properties (Alix-Garcia \& Gibbs, 2017; Gibbs et al., 2016; le Polain de Waroux et al., 2019; Nepstad et al., 2014). With respect to leakage, the Cerrado savanna, particularly in the so-called Matopiba ${ }^{7}$ region, has become the new deforestation hotspot in Brazil (Gibbs et al., 2015; Nepstad et al., 2019; Soterroni et al., 2019; zu Ermgassen et al., 2020). Despite a voluntary private sector commitment to stop deforestation in the Cerrado (WWF, 2018), the Cerrado is still not covered by the Soy Moratorium and not sufficiently considered in private sector commitments (Nepstad et al., 2019; Soterroni et al., 2019; zu Ermgassen et al., 2020).

Moratoria have also been established in Indonesia, in this case by the government. In 2019, a revolving moratorium on the clearing of primary forests and peatlands was made permanent. Another moratorium on the issuance of new concessions for palm oil plantations was initiated in 2018. However, the effectiveness of these moratoria has been questioned due many revisions that have excluded areas of primary forests from the scope, and due to loopholes created by a lack of data, monitoring, enforcement and sanctions (EIA, 2019; IDH, 2020b; Jong, 2019). These examples demonstrate the complexity of deforestation issues related to agricultural activities, which depends on various geographical, institutional, and economic factors (Busch \& Ferretti-Gallon, 2017; le Polain de Waroux et al., 2019; Lyons-White \& Knight, 2018).

This complexity increases even further considering that "forest-risk" commodities are traded along international supply chains. Both soy and palm oil exports are dominated by few large traders, respectively (Trase, 2020). Still, due to a lack of transparency and traceability, it remains difficult for actors downstream of the supply chain to verify whether a product is "deforestation-free" or not (Gardner et al., 2019; Godar et al., 2016). Since the Consumer Goods Forum (CGF), a global high-level network of many consumer goods retailers and manufacturers, agreed in 2010 on a resolution to achieve zero net deforestation related to relevant forest-risk supply chains by 2020 (CGF, 2010), many large companies have published zero-deforestation commitments (ZDCs). However, these ZDCs differ in the level of ambition, the scope of initiatives, and the instruments used for implementation and monitoring. Progress assessments reveal that in many cases, implementation is not on track (Donofrio et al., 2017; IDH, 2020b; Jopke \&

\footnotetext{
${ }^{6}$ "G4" stands for the signatories of the Cattle Agreement; the four largest Brazilian meatpacking companies at the time (Bertin, Marfrig, Minerva, JBS), and Greenpeace (Alix-Garcia \& Gibbs, 2017). The ambition of this agreement is higher compared to another cattle agreement between the industry and regulators of the same year, which forbids only sourcing from illegally deforested areas (Brandão Jr. et al., 2020).

${ }^{7}$ Matopiba is an acronym for the states Maranhão, Tocantins, Piauí, and Bahia (Nepstad et al., 2019).
} 
Schoneveld, 2018; Lambin et al., 2018). In the case of palm oil, part of the problem can be attributed to the fact that around $40 \%$ of the palm oil production in Indonesia and Malaysia is in the hand of around 3 million independent smallholders, which makes control at the downstream end of the supply chain difficult (ESPO, 2017; Saadun et al., 2018; Trase, 2020).

Besides the necessity of a common definition of forests, it is crucial to distinguish between different understandings of "deforestation-free" or "zero deforestation", and to consider the respective cut-off date. It is usually distinguished between zero illegal deforestation, zero net deforestation, and zero gross deforestation. Zero illegal deforestation refers to the legal regulations in the respective producer country. Zero net deforestation allows for compensation by reforestation in other places, whereas zero gross deforestation does not allow for any conversion of forests (Brown \& Zarin, 2013; Lambin et al., 2018; Neeff \& Linhares-Juvenal, 2017). More ambitious pledges consider not only forests but also other valuable ecosystems, committing to "no deforestation, no peat, no exploitation" (NDPE) (Larsen et al., 2018; Lyons-White \& Knight, 2018). In 2019, the Accountability Framework initiative (AFi) was launched by various stakeholders, with the aim to improve companies' accountability and to agree on definitions (AFi, 2020).

On the political level, several recent agreements, declarations and instruments are directly or indirectly relevant for the zero-deforestation agenda. In 2014, the non-legally binding New York Declaration on Forests (NYDF) set the goal to halve the deforestation rate by 2030 and to stop deforestation by 2030 (NYDF, 2014). The United Nations' 2030 Agenda for Sustainable Development was established in 2015, including the 17 Sustainable Development Goals (SDGs) to be achieved by 2030. Particularly SDG 15 ("Life on Land") contains specific targets related to forest conservation, while other goals are also relevant, such as SDG 12 ("Responsible Consumption and Production"), or SDG 13 (“Climate Action") (UNGA, 2015). In 2016, members of the United Nations Framework Convention on Climate Change (UNFCCC) signed the Paris Agreement aiming at reducing GHG emissions to slow down climate change (UNFCCC, 2015).

These international agreements have contributed to more specific goal-setting in Europe. Two so-called Amsterdam Declarations have so far been signed by Denmark, France, Germany, Italy, Norway, the Netherlands, and the United Kingdom, forming the Amsterdam Declarations Partnership (ADP). The declarations set the (non-binding) goals to make palm oil supply chains fully sustainable (ADP, 2015a), and to eliminate deforestation linked to agricultural supply chains by 2020 (ADP, 2015b). The implementation strategy of the ADP has so far prioritized palm oil, soy, and cocoa because of their relevance with respect to consumption in the EU (ADP, 2016). The palm oil-specific declaration (ADP, 2015a) expresses support for the "Commitment to Support $100 \%$ Sustainable Palm Oil in Europe by 2020", which just had been signed by several European 
national palm oil sustainability initiatives, such as the Forum for Sustainable Palm Oil (FONAP) in Germany (ESPO, 2015). These national initiatives are mostly driven by industry associations as a reaction to pressure by civil society organizations and the media, which had been raising public awareness for sustainability issues related to palm oil production (RSPO, 2020a).

In 2017, the European Parliament called for EU-wide commitments to source only sustainable palm oil (European Parliament, 2017). The new Renewable Energy Directive (RED II) has defined stricter rules for crop-based biofuels based on ILUC risk, resulting in the classification of palm oil as the only crop with high ILUC risk so far (European Union, 2018). In July 2019, the European Commission adopted a communication on "stepping up EU action to protect and restore the world's forests". It stresses the aim to foster the consumption of deforestation-free products, to collaborate with countries producing these products, and to improve the access of information on supply chains, among other aspects (European Commission, 2019a). According to the European Green Deal, which was announced in December 2019, the EU should become climate-neutral by 2050. Among various policies and measures proposed as part of this strategy, it is stressed that deforestation-free products and supply chains shall be promoted (European Commission, 2019b). The Farm to Fork Strategy, an integral part of the European Green Deal, aims at achieving a transition towards sustainability "from farm to fork", referring to food supply chains, which explicitly includes the avoidance of deforestation (European Commission, 2020b).

\subsection{Sustainability certification as a potential measure to ensure deforestation-free supply chains}

Sustainability certification is one relevant instrument among different options for implementing public and private ZDCs (Bager et al., 2020; Garrett et al., 2019; Lambin et al., 2018). Ideally, certification could be used as a "common proxy for eliminating deforestation from supply chains" (Neeff \& Linhares-Juvenal, 2017, p. 2). One of the key actions proposed in the European Commissions' Communication on stepping up EU action to protect and restore the world's forests is to "encourage the strengthening of standards and certification schemes that help to identify and promote deforestation-free commodities through, among other things, studies on their benefits and shortcomings [...]" (European Commission, 2019a, p. 8).

Sustainability certification may be governed by private companies, by NGOs, by governments, or by multi-stakeholder initiatives (MSIs). In general, it can be distinguished between mandatory and voluntary certification. Voluntary certification systems are usually composed of standards, an assurance system, labels and claims, and (optional) chain-of-custody (CoC) systems that shall ensure traceability. Some systems also provide training to producers (Komives \& Jackson, 2014). Sustainability standards usually comprise at least environmental, but 
often also social and economic criteria. As of October 2020, the Sustainability Map by the International Trade Centre (ITC) for instance provides an overview of more than 270 voluntary standards and their various criteria, which also differ in terms of their geographic and productrelated scope (ITC, 2020). As the understanding of sustainability and the ambition of requirements varies greatly between standards, it is difficult to evaluate whether a certified product has really been sustainably produced (IDH, 2020b), which might increase the risk of "greenwashing". Competition between voluntary certification systems might either lead to a "race to the top" (increasing ambition to gain reputation) or a "race to the bottom" (reducing ambition to facilitate implementation) (Lambin \& Thorlakson, 2018). Further challenges remain due to technical and financial barriers to implementation - particularly for smallholders -, resulting in low adoption rates. Moreover, certification is often implemented by producers who are already compliant, or on land that has already been cleared, which might lead to selection bias (Carlson et al., 2018; Glasbergen, 2018; Lambin et al., 2018; van der Ven et al., 2018; Winters et al., 2015). However, voluntary private sustainability certification remains an important measure to close regulatory gaps, as mandatory national or international standards are often not ambitious enough, not sufficiently enforced, or do not even exist (Henson \& Humphrey, 2010; Lambin \& Thorlakson, 2018).

Prominent examples for product-specific MSIs developing relatively wide-spread voluntary sustainability standards are the Roundtable on Sustainable Palm Oil (RSPO) and the Round Table on Responsible Soy (RTRS), which both have been initiated by the World Wide Fund For Nature (WWF) in collaboration with agribusiness companies (Hospes, 2014). Despite criticized weaknesses with respect to inclusiveness (Cheyns, 2014), effectiveness, and control mechanisms (Garrett et al., 2016; Okereke \& Stacewicz, 2018; Ruysschaert \& Salles, 2014), these certification systems still have comparatively high standards, which are revised on a regular basis. Both RSPO and RTRS include zero-deforestation criteria in their most recent versions (RSPO, 2018; RTRS, 2017).

According to IDH - The Sustainable Trade Initiative -, an organization which facilitates public-private partnerships to tackle sustainability issues in various agricultural sectors and countries, $19 \%$ of global palm oil production and only $6 \%$ of global soy production could be regarded "responsible" in 2017. In the case of soy, "responsible" according to the IDH means compliant with the Soy Sourcing Guidelines (SSG) defined by the European Feed Manufacturer's Federation (FEFAC) (IDH, 2020b). With respect to zero-deforestation criteria, these non-binding SSG require only zero illegal deforestation, though (FEFAC, 2016). According to IDH's European Soy Monitor, FEFAC SSG-compliant soy represented only 22\% of the soy used in Europe in 2017 (IDH \& IUCN NL, 2019), and 38\% in 2018 (IDH, 2020a). The IDH also indicates the share of 
deforestation-free soy, estimated as 13\% in 2017 (IDH \& IUCN NL, 2019), and 19\% in 2018 (IDH, 2020a). However, the underlying assessment by Kusumaningtyas and van Gelder (2019) does not consider the aspect of traceability, although IDH emphasizes its importance (IDH, 2020b). Without traceability along the supply chain, it cannot be ensured that a commodity, such as palm oil or soy, used as an ingredient in a certain product has actually been sustainably produced (Mol \& Oosterveer, 2015).

In the case of palm oil, "responsible" refers to certification by the RSPO. The reported share of RSPO-certified palm oil imported for food, feed, and oleochemicals ${ }^{8}$ in Europe ${ }^{9}$ was $74 \%$ in 2017 (IDH, 2020b), and increased to 83\% in 2018 (EPOA, 2020). However, it was reported that only $60 \%$ of the palm oil used by the European food industry and retailers were actually bought as RSPO-certified - and this uptake share has been stagnating since 2016 , when the data was first reported, indicating a persistent demand gap (EPOA, 2020). This gap can also be observed on the global scale, as just about half of the supplied RSPO-certified palm oil volumes are taken up by the market, and basically no progress could be observed over the past six years (RSPO, 2020b). Similar demand gaps are observed also for other commodities. Effectively, this means that producers have to sell certified products at market prices, without a premium (IDH, 2020b).

The European Commission has stressed that the demand for deforestation-free products needs to be increased, for instance by providing relevant information to consumers (European Commission, 2019a, 2020b). The sustainability of a product in general and the "deforestationfree" status in particular are so-called credence qualities. Credence qualities are characteristics related to production processes and supply chains that - in contrast to search qualities and experience qualities - can hardly be assessed by consumers themselves (Darby \& Karni, 1973; Nelson, 1970, 1974). Consumers cannot distinguish between sustainably and unsustainably produced goods because sustainability is a process quality that is not visible and cannot be identified before or after consumption, which leads to problems of information asymmetry. Extrinsic quality cues such as product labels indicating sustainability certification may be used to reduce this information asymmetry by translating sustainability into a search quality (Janßen \& Langen, 2017; Mol \& Oosterveer, 2015; Thøgersen et al., 2010; Vermeir \& Verbeke, 2006).

In theory, consumers who care about sustainability would buy (certified) sustainable products. In practice, however, there are many different factors that might influence attitudes, preferences and behavior, such as personality factors, values, norms, habits, knowledge and experience, contextual factors, and socio-demographic aspects (Gifford, 2014; Grunert et al.,

\footnotetext{
${ }^{8}$ This means that palm oil used in biofuels was not considered (IDH, 2020b).

${ }^{9}$ The report by IDH covers data from 12 European countries that are responsible for the majority of forestrisk commodities imported to Europe (e.g., more than $90 \%$ of net imports for both soy and palm oil). It has to be acknowledged that the available data for some countries is aggregated and in some cases covers only those industries or companies that were willing to participate in this initiative (IDH, 2020b).
} 
2014; Thøgersen et al., 2010; Vermeir \& Verbeke, 2006, 2008). A better understanding of consumers' attitudes and preferences with regard to certain forest-risk commodities and relevant certification systems might help to identify ways to increase the uptake of certified, deforestation-free products. In contrast to RSPO certification for palm oil, which can be communicated via labels on consumer products (RSPO, 2019), soy is mainly indirectly consumed by humans in the form of feed "embedded" in animal products (Heron et al., 2018; Wesseler, 2014). In this case, it is therefore basically impossible for final consumers to evaluate the sustainability of this "hidden" ingredient and to incorporate this aspect in their purchase decisions.

\subsection{Research questions, research focus and scope}

Within the overall context of ZDCs and related initiatives, this dissertation focuses on voluntary sustainability certification, as several public and private stakeholders are already actively involved in certification initiatives and have been investing resources in the development of certification systems. Moreover, sustainability certification has been suggested in several recent policy proposals as an instrument to achieve deforestation-free supply chains. Based on the background information provided in the previous sub-sections, three overarching research questions (RQs) have been identified that require further research to close knowledge gaps by contributing policyrelevant insights:

I. To what extent is the development of deforestation-free supply chains supported by policy measures in the EU?

II. Which factors influence the demand for certified sustainable, deforestation-free products?

III. Which sustainability certification systems should be supported to ensure deforestationfree supply chains?

RQI is relevant because the EU has expressed support for the development of deforestation-free supply chains, following initiative by the ADP countries, but concrete political measures are still being developed, and the consequences for international trade are unclear. RQ II tackles the previously mentioned gap with respect to the uptake of certified products, particularly of palm oil. This gap is problematic, as financial incentives for producers to adopt better agricultural practices and participate in costly certification are needed. RQ III refers to the problem that there are many different sustainability certification systems for different commodities that use different definitions of "deforestation-free" (if at all), which makes it 
difficult for policymakers and supply chain actors to decide which systems to support in order to comply with ZDCs.

These RQs are important but big questions that most likely cannot be conclusively answered in one single research project. Thus, the focus of this dissertation is further specified. Geographically, the focus lies on the EU as a major import market for several forest-risk commodities, because this market relevance means that research supporting the development of sustainable, deforestation-free consumption in Europe should have an effect on production conditions. While the EU supports this development towards sustainability, other relevant markets are still lagging behind (IDH, 2020b; RSPO, 2020a; van der Ven et al., 2018). As public and private zero-deforestation initiatives in several European countries still face challenges with respect to the implementation of their targets, supporting research is required.

Among relevant forest-risk commodities, palm oil and soy have been selected as focus commodities to contribute answers to the RQs. This commodity focus can be justified by several reasons. Palm oil and soy are two out of three commodities that have been prioritized in the implementation strategy of the ADP, because they are particularly relevant from the perspective of EU consumption (ADP, 2016). Soy accounts for the largest net import volumes consumed by European countries. Net imports of palm oil to these countries show a high average growth rate of nearly 10\%, taking into account data from 2011 to 2016 (IDH, 2020b). Moreover, palm oil is globally the most important vegetable oil in terms of global production and consumption volumes (Mielke, 2018; Oil World, 2019). The ADP strategy explains why palm oil is particularly interesting to study: "As the palm oil sector is relatively organised, has an advanced understanding on minimum requirements for sustainability (RSPO or equivalent - as stated in the Amsterdam Declaration of the national initiatives) and is facing considerable public pressure on its environmental and social impact, this value chain has our special interest" (ADP, 2016, p. 2). In line with this argumentation, this dissertation sets an emphasis on palm oil.

Focusing on palm oil and soy also provides the opportunity to consider different sourcing regions (Southeast Asia for palm oil, and South America for soy), and different uses: Soy is primarily used in the form of soy meal for animal feed (Lernoud et al., 2018; Mielke, 2018). Thus, demand for soy is observed mostly indirectly via demand for animal products. Palm oil (including palm kernel oil) is mainly used for cooking and as an ingredient of food products, but it is also relevant for oleochemicals (e.g., cosmetics, soap, detergents), and as a biofuel, while the use for feed is less relevant on the global scale. Palm oil-based biodiesel is particularly relevant in the EU, but less in other regions of the world so far, although demand in other regions is expected to increase (Mielke, 2018; Oil World, 2019; WWF, 2016). In the following, the research focus with respect to each of the overarching RQs is further specified. 
Because of the reasons outlined in the ADP Strategy, recent political discussions on deforestation-free supply chains have concentrated on palm oil. Palm oil is a particularly controversial commodity with respect to sustainability, because it is efficient and versatile and an important source of income for producers, while its production often has adverse social and environmental effects, and its consumption is frequently perceived as unhealthy (e.g., Rival \& Levang, 2014). It is important to understand discourses on the sustainability of palm oil that are reflected in recent EU policy proposals, which in turn have provoked discursive reactions by palm oil producing countries. By analyzing policy discourses, this dissertation aims to contribute relevant insights concerning RQ I. This focus is relevant because it is important for policymakers to understand opposing positions in order to avoid potential trade conflicts. Moreover, discourses that emphasize negative aspects of palm oil production and consumption might influence public perceptions and thereby also reduce the acceptance of certified sustainable palm oil - which interferes with ZDCs. Referring to the European market, the RSPO observes that "misinformation and negative narratives around palm oil have impacted the possibility to effectively communicate the benefits of sustainable palm oil to some audiences" (RSPO, 2020b, p. 55).

This problem is directly connected to RQ II. In this context, it is important to understand final consumers' knowledge, attitudes, and preferences with respect to certain forest-risk commodities in general and certified deforestation-free products in particular. Again, this topic is particularly relevant for palm oil, because the ADP countries have prioritized the aim to achieve sustainable palm oil supply chains (ADP, 2015a, 2016). It is important to focus on food products, because in the EU, the list of ingredients of food products - in contrast to other products - has to specify the types of vegetable oils used (European Union, 2011). Thereby, palm oil becomes "visible" to consumers. As palm oil has received negative attention in NGO campaigns and media contributions focusing on environmental and health aspects (Corciolani et al., 2019; D'Antone \& Spencer, 2015), public perceptions might have been influenced, also because in the recent past, many supermarket products have been advertised with "palm-oil-free" claims (Riganelli \& Marchini, 2017). While several previous studies have analyzed consumer attitudes and preferences with respect to palm oil in different countries (e.g., Disdier et al., 2013; Gassler \& Spiller, 2018; Hartmann et al., 2018), none of these has explicitly studied trade-offs between conventional palm oil, RSPO-certified palm oil, and palm-oil-free alternatives. In this regard, it is also relevant to identify relevant influence factors and to estimate potential market shares. As part of this dissertation, these aspects are explored in Germany, as Germany is a major palm-oilconsuming country within Europe which has committed to sustainable sourcing of palm oil (ADP, 2015a; IDH, 2020b). 
To tackle RQ III, a conceptual assessment framework is required as a decision-support tool for evaluating certification systems. Such a framework needs to consider relevant zerodeforestation criteria and should be applicable to certification systems for different forest-risk commodities and their supply chains. Unlike in the case of palm oil, the variety of voluntary certification systems is quite large for soy (ITC, 2019, 2020), which makes soy certification systems particularly relevant to assess. In previous studies dealing with similar assessments (Hargita et al., 2018; Kusumaningtyas \& van Gelder, 2019), the aspect of traceability has not been sufficiently considered. Without traceability, however, the link between production and consumption gets lost. Thus, all relevant components of certification systems, including $\mathrm{CoC}$ systems to ensure traceability, need to be considered in the framework to be developed. Based on this framework, soy certification systems that are relevant for the European feed market (FEFAC, 2016; ITC, 2019) should be assessed.

Section 1 has explained the role agriculture plays in deforestation and introduced the topic of sustainability certification in the context of deforestation-free supply chains. Based on the identified research problems, three overarching research questions have been defined and the research scope has been determined. The following section 2 will introduce the different research methods that have been applied to find answers to the three research questions. 


\section{Methodological approaches}

Different research methods have been applied to contribute answers to the research questions posed in section 1.4. Research methods are usually classified as either qualitative or quantitative, although it has been argued that such a clear distinction is often not possible (Allwood, 2012; Creswell, 2009, p. 3). Qualitative methods are relatively open, usually characterized by interaction between researchers and participants, interpretation, and the elicitation of non-numerical data. They are usually oriented toward deriving general theories from particular cases, which is particularly relevant for research topics that are not well explored yet. Quantitative methods are characterized by the use of standardized instruments that allow for the elicitation of numerical data. Larger samples are used to study relationships between relevant variables, to test research hypotheses, and to relate these results to the population of interest (Creswell, 2009, p. 4; Kuckartz, 2014, p. 28). Mixed methods are often regarded as a third category that involves the integration of both qualitative and quantitative methods (Creswell \& Plano Clark, 2011; Kuckartz, 2014 , p. 33). Both qualitative and quantitative methods can be further classified as either data collection methods or data analysis methods, while the separation between the two phases is not always clear-cut for qualitative methods.

The following sub-sections describe the main characteristics of the research methods applied in this dissertation and provide reasons for their selection.

\subsection{Qualitative methods}

\subsubsection{Literature review}

Literature reviews are conducted as part of many research projects - in different forms and with varying degrees of detail. Condensed reviews of relevant literature may serve the purpose of providing an overview of the topic of interest to describe and discuss the state of knowledge and identify research gaps, whereas a more comprehensive literature review that follows clear procedures can be a type of scientific article on its own. Narrative reviews, systematic reviews, and meta-analyses are examples for different forms of literature review articles (Grant \& Booth, 2009; Jesson et al., 2011; Torraco, 2016). While this dissertation does not include a review article per se, reviews of the current state of research are part of each contribution, and two of the articles explicitly use literature reviews as part of the methods applied to answer the research questions.

Among the various literature review approaches the integrated literature review was chosen. Integrated literature reviews are defined as " $a$ form of research that reviews, critiques, and synthesizes representative literature on a topic in an integrated way such that new 
frameworks and perspectives on the topic are generated" (Torraco, 2005, p. 356). Similar to systematic literature reviews, this approach involves a description of the strategy used to select literature to be considered in the review, including databases and keywords used for searching. The selected literature is analyzed to identify relevant topics and categories. Different forms of synthesis are possible, such as a research agenda, a taxonomy, or a conceptual framework (Torraco, 2005, 2016). Compared to other literature review methods, this approach was found to be particularly suitable for the purpose of this dissertation because it helped to develop a conceptual framework to identify sustainability certification systems that are adequate for ensuring deforestation-free supply chains.

\subsubsection{Discourse analysis}

Discourse analysis is an umbrella term for different qualitative approaches to study how (spoken or written) language is used to frame and give meaning to issues in a certain social context (Richardson, 1996; Salkind, 2010, p. 367). There are many different definitions and interpretations of the term discourse. The philosophers Jürgen Habermas and Michel Foucault promoted different understandings of discourses that form the basis for a broad categorization of discourse concepts. Habermas studied discourses from a rather normative point of view and focused rather on the aspect of language itself. In contrast, Foucault followed the social-constructivist idea that discourses can hardly be evaluated on a normative basis - as there is no objective 'truth' -, but they provide insights about the socio-political context of discourses and about the actors that spread and shape them (Hajer \& Versteeg, 2005; Richardson, 1996). Foucault's poststructuralist approach to discourse analysis is useful for understanding the reciprocal relationships between different discourses and policies (Feindt \& Oels, 2005; Hajer \& Versteeg, 2005; Sharp \& Richardson, 2001).

Maarten Hajer has developed a so-called argumentative discourse-analytical approach (ADAA) in the Foucauldian tradition that is particularly targeted at analyzing discourses concerning environmental policies (Hajer, 1995). Several previous studies on other environmental policy discourses have used Hajer's ADAA (e.g., Cotton et al., 2014; Elgert, 2012; Ferns \& Amaeshi, 2017; Soini \& Birkeland, 2014). Therefore, this approach has been selected to analyze discourses in the context of palm-oil-related policy development in the European Union as part of this dissertation. Hajer defines a discourse as "a specific ensemble of ideas, concepts, and categorizations that are produced, reproduced, and transformed in a particular set of practices and through which meaning is given to physical and social realities" (Hajer, 1995, p. 44). Analyzing discourses according to Hajer's ADAA involves the identification of storylines, emblems, and discourse coalitions. 
Storylines can be understood as narratives on the subject of interest that are developed and spread by discourse coalitions. Emblems are often used as examples in storylines to illustrate and emphasize the relevance of the issue at stake. They might be used to represent the complex of environmental problems in a certain period (Hajer, 1995, pp.19-20). A discourse coalition consists of actors that may follow different agendas but promote the same storyline. Referring to a storyline of deforestation, Hajer explains the concept of a discourse coalition as follows: „All actors speak about the rainforest but mean (slightly) different things. [...], but they all help to sustain, in their own particular way, the story-line of the destruction of the rainforests in environmental politics" (Hajer, 1995, p. 13).

\subsubsection{Focus group discussions}

Focus group discussions are a popular qualitative data collection method that is characterized by interactions within the focus group, which is a group of respondents sampled according to the purpose of the respective study. Focus group discussions provide insights on the range of different opinions and attitudes regarding the issue of interest, which is more difficult to achieve (and more expensive) with individual qualitative interviews (Cyr, 2016; Finch \& Lewis, 2003; Gaiser, 2008; Lamnek, 2010). This method has been used in several previous studies in similar research fields (e.g., Barrios \& Costell, 2004; Macdiarmid et al., 2016; Sirieix et al., 2013; Zepeda et al., 2013). The discussion usually follows a questioning route and is managed by at least one moderator. There are no strict rules with respect to the size and the composition of a focus group, but it should be large enough to keep the discussion going and not too large to be managed by the moderator. Six to eight participants are recommended by Lamnek (2010) and K. Stewart and Williams (2005). Focus group discussions are particularly suitable for exploratory studies to develop research hypotheses on topics that have not previously been qualitatively analyzed in detail. However, the sample is usually not sufficiently large and representative to generalize conclusions for the population of interest (Barrios \& Costell, 2004; Gaiser, 2008; Johnson et al., 2007; Palinkas et al., 2015).

While focus group discussions are still usually conducted face-to-face, the advancement of technology has led to the development of different computer-mediated discussion settings. Using appropriate chat tools or web conferencing software, focus group discussions can also be conducted via the internet (Franklin \& Lowry, 2001). Online focus groups have several advantages compared to face-to-face focus groups. For instance, it is possible to connect respondents from different places or people who are immobile, at very low costs compared to face-to-face focus group discussions (e.g., Lobe, 2017; Stewart \& Shamdasani, 2017; Woodyatt et al., 2016). In times of physical distancing requirements (i.e., due to the COVID-19 coronavirus pandemic beginning in 2019/2020), online research methods have become even more relevant. Synchronous online 
focus group discussions that allow for real-time interactions between participants can be either text-, audio-, or video-based, while the latter option also includes sound. Particularly text-based online focus groups allow for the discussion of sensitive topics due to the higher degree of anonymity (Lamnek, 2010; Reid \& Reid, 2005). Transcription costs can be saved because the text is immediately available. However, important contextual information might get lost due to the lack of vocal and visual cues (Holt, 2010). Additional disadvantages of online focus groups are the requirement of technical infrastructure and skills as well as difficulties in remotely moderating the discussion (Brüggen \& Willems, 2009). Particularly text-based discussions bear the risk of conversation threading, the problem of parallel discussion threads sidetracked from the main discussion (Franklin \& Lowry, 2001; Gaiser, 2008; Stewart \& Williams, 2005).

Previous studies provide more detailed information on the benefits and weaknesses of face-to-face and online focus group discussions (e.g., Gaiser, 2008; Reid \& Reid, 2005; Schneider et al., 2002; Stewart \& Shamdasani, 2017). For this dissertation project, both face-to-face and online focus group discussions were conducted, using the same semi-structured questioning route in order to utilize the benefits of both methods while offsetting their weaknesses. Due to a higher risk of technical issues with video- or audio-based online focus groups, the text-based synchronous format was chosen. Methodological lessons learned from the organization and implementation of the text-based synchronous online focus groups have been published in a research note (Hinkes, 2020). In particular, it was recognized that this mode of discussion allows participants to use a web-based search engine to search for answers to the questions discussed in the focus groups, which might lead to biased statements.

\subsubsection{Thematic content analysis and document analysis}

Different forms of qualitative content analysis can be applied to analyze data collected in focus group discussions or by using other qualitative data collection methods. Some examples are evaluative qualitative content analysis, summative content analysis, typological analysis, and thematic (content) analysis (Braun \& Clarke, 2006; Hsieh \& Shannon, 2005; Kuckartz, 2016; Mayring, 2000; Schreier, 2014). It was decided to analyze the transcripts from the face-to-face and online focus group discussions using thematic content analysis ${ }^{10}$ according to Braun and Clarke (2006) and Kuckartz (2016) because it fits to the research purpose and is relatively flexible to apply. This is because thematic content analysis is not bound to a specific theoretical framework, and it is rather a category of analytic approaches than a single method (Braun et al., 2019; Braun \& Clarke, 2006). In contrast to other approaches, there are no strict rules with respect to the deductive or inductive development of the codebook, the extraction of data from

\footnotetext{
${ }^{10}$ Braun and Clarke (2006) refer to "thematic analysis" but later explain that the term "thematic content analysis" may be used interchangeably (Braun et al., 2019).
} 
the available materials, or the quantification of the identified aspects (Braun \& Clarke, 2006; Kuckartz, 2016; Schreier, 2014). This flexibility is particularly appropriate for the exploration of rather new research questions for which no theory on relevant categories exists yet, leaving room for development and interpretation by the researcher (Braun et al., 2019).

Thematic content analysis is characterized by multi-stage coding of the data to develop thematic categories or themes, which aim at "reflecting a pattern of shared meaning" (Braun et al., 2019, p. 845). Both inductive coding (i.e., deriving codes from the material) and deductive coding (i.e., applying codes based on research hypotheses and the questioning route) can be used. The resulting coding system consists of thematic (main) categories and usually at least one level of sub-categories (Braun \& Clarke, 2006; Kuckartz, 2016). Nowadays, coding and memo writing is usually performed using computer-assisted qualitative data analysis software (CAQDAS). MAXQDA Analytics Pro 2018 was used for the thematic content analysis in this research project. The thematic main categories have primarily been developed based on the thematic sections of the semi-structured questioning route used for the focus group discussions (deductive coding), while the sub-categories and supplementary topics that came up in the discussions have primarily been derived from the transcribed material (inductive coding). The codebook and the results of the analysis have been intensively discussed with fellow researchers.

For the qualitative analysis of different types of documents as part of the integrated literature review and the discourse analysis conducted, guidelines for document analysis have been considered. Document analysis according to Bowen (2009) is an analysis method similar to thematic content analysis that can be applied to all kinds of documents in addition to scientific or grey literature. The selected documents are iteratively analyzed by inspecting the documents first superficially and then in more detail, before critically interpreting the content in consideration of contextual aspects (Bowen, 2009).

\subsection{Quantitative methods}

\subsubsection{Online survey}

A survey is a data collection method that can be implemented in different forms: as personal faceto-face interviews, via telephone or mail, or in web-based formats. Over the past 15 years, online (or web-based) surveys have become increasingly popular and are nowadays frequently applied in marketing and consumer research (Evans \& Mathur, 2018). Online surveys are usually implemented to collect primarily quantitative data, using a standardized questionnaire that can be accessed on a website. The web-based format has several advantages over paper-based questionnaires: it offers many design options, time and costs can be saved, and the data is directly available for analysis and does not have to be manually entered into a computer system. 
Moreover, self-administration via the internet increases flexibility for respondents, while biases such as social desirability bias - might be reduced when interviewers are absent. Items can be presented in a randomized order, which also helps to reduce bias. There are many different webbased survey tools offering various dynamic features as well as the integration of experiments (Evans \& Mathur, 2018; Vehovar \& Lozar Manfreda, 2008).

Potential problems of surveys in general - irrespective of the mode of implementation are related to different types of errors that might lead to biased results. Among the most relevant errors are measurement error, sampling error, coverage error, and nonresponse error. Measurement error refers to differences between the measured responses and the true values, which might for instance result from deficiencies in the questionnaire design or implementation, or respondents' lack of understanding, motivation, or protest responses (Couper, 2000; Evans \& Mathur, 2018; Fricker, R.D., Jr., 2008; Vehovar \& Lozar Manfreda, 2008). Cognitive pretesting of the questionnaire is recommended to reduce errors related to a potential lack of understanding (Lenzner et al., 2016). Thus, cognitive pretests have been conducted in the preparatory phase of the online survey implemented as part of this dissertation. Coverage error results from discrepancies between the target population (which is to be studied) and the frame population (which can be accessed to select the sample). An example for coverage error in online surveys is the exclusion of people without internet access.

Sampling error results from differences between the sample and the frame population. There are two main categories of sampling approaches: probability-based sampling and nonprobability sampling. Strictly speaking, only probability-based sampling can be used for statistical inference because with non-probability sampling, the probability of selection is not known. However, probability-based sampling is difficult to achieve, particularly with web-based surveys. Non-response error occurs if invited respondents decide against participation or do not complete the survey. Item non-response error refers to skipping questions within the survey. This problem can relatively easily be avoided in web-based surveys by defining questions as mandatory. To reduce non-response bias in general, incentives might be offered to respondents (Couper, 2000; Evans \& Mathur, 2018; Fricker, R.D., Jr., 2008; Vehovar \& Lozar Manfreda, 2008).

For the purpose of studying consumer preferences for palm oil as part of this dissertation, it was decided to implement a web-based survey with a quota-based non-probability sample recruited from an volunteer online panel, which is common in market research and relatively efficient in terms of cost and time (Evans \& Mathur, 2018; Fricker, R.D., Jr., 2008).

\subsubsection{Principal component analysis}

Often many different items are included in a survey questionnaire, and it is hardly possible to include and interpret all of them as single variables in the data analysis. Principal component 
analysis (PCA) and factor analysis (also known as common factor analysis, principal axis factoring, or principal factor analysis) are two very similar methods that can be used for reducing the number of variables based on correlations while minimizing information loss (Sarstedt \& Mooi, 2019, pp. 259-262; Widaman, 1993). Sometimes different terminologies are used in the literature, which might lead to confusion. Hair et al. (2019, pp. 139-140) for instance summarize both (common) factor analysis and PCA under the category of exploratory factor analysis ${ }^{11}$. Factor analysis and PCA differ in their underlying assumptions and objectives. PCA aims at reproducing a data structure while reducing the number of components as far as possible. Factor analysis tries to explain the relationship between variables based on identified underlying factors. In contrast to PCA, which assumes that the total variance of a variable is shared with the other variables, factor analysis assumes that there is also unique variance, which cannot be reproduced (Sarstedt \& Mooi, 2019, pp. 266-267; Widaman, 1993). In this dissertation, it was decided to use PCA to identify components based on the items of the questionnaire, as the purpose was rather to aggregate the items to components than to explain latent structures, and because PCA has been frequently used in market research (Sarstedt \& Mooi, 2019, p. 266). Nevertheless, it was also checked whether factor analysis would result in different factors, which was not the case.

Before conducting a PCA, the items' adequacy for conducting a PCA (or factor analysis) has to be assessed. Therefore, the each variable's measure of sampling adequacy (MSA) according to Kaiser and Rice (1974) is examined. The MSA indicates how well the respective variable can be explained by the other variables based on common variance. Each MSA value should exceed 0.5 (with values exceeding 0.8 indicating high sampling adequacy), otherwise it is recommended to exclude the item from the analysis. The overall sampling adequacy is indicated by the KaiserMeyer-Olkin (KMO) criterion, which is the overall mean of the MSA values and is evaluated based on the same threshold values (Hair et al., 2019, pp.135-137; Kaiser \& Rice, 1974; Sarstedt \& Mooi, 2019, pp. 264-265). The items used in the online survey implemented as part of this dissertation have been assessed in a pre-test for their adequacy to conduct a PCA. In this pre-test, a sample of 150 respondents evaluated the respective survey items using the defined 7-point Likert scale. Based on the results, the MSA and KMO values were found to be adequate for conducting a PCA. The adequacy was later again tested and confirmed for the results of the full study.

When the adequacy has been confirmed, the PCA can be conducted. The number of factors (or components) to be extracted can be determined based on different criteria: Kaiser criterion, scree plot, explained variance, parallel analysis, and prior information. A rotational

\footnotetext{
${ }^{11}$ While exploratory factor analysis is used if the structure of components or factors is unknown, confirmatory factor analysis might for instance be used in case of well-known structures, such as existing scales tested in previous studies (Sarstedt \& Mooi, 2019, p. 260).
} 
method can be applied to improve the interpretability of the factors. Depending on the assumption on relations between the factors, either an orthogonal method (assuming no relation between the factors) or an oblique method (assuming some relation between the components) is applied. Based on factor loadings, each variable is assigned to a factor, which has to be interpreted, labeled, and extracted as a new variable for the purpose of including it in further analyses. The internal consistency of a scale (i.e., the items aggregated to a factor) can be assessed by different measures, the most popular one being Cronbach's alpha. Usually, Cronbach's alpha values exceeding 0.7 are deemed favorable, while 0.6 is an acceptable lower limit for exploratory studies (Hair et al., 2019, p. 140ff.; Sarstedt \& Mooi, 2019, p. 267ff.; Tavakol \& Dennick, 2011).

\subsubsection{Discrete choice experiment}

Consumer preferences for goods or services can be quantified by using different methods for measuring the perceived value or the utility of the good or service from the consumers' point of view. In monetary terms, this perceived value or utility is expressed as willingness to pay (WTP), which is the maximum price a consumer is willing to pay for the good or service (Breidert, 2006, pp. 23-29). Different methods for estimating WTP can be classified into two main categories: revealed preference methods and stated preference methods.

Revealed preference methods are observations of either market data or (field) experiments. Stated preference methods can be categorized as either direct or indirect surveys. Due to their relative flexibility and cost-effectiveness as compared to revealed preference methods, they are often applied in marketing research on new products and various attribute combinations. Disadvantages are potentially lower reliability and validity due to the creation of hypothetical markets and difficulties in modeling real market constraints (Breidert, 2006, pp. 3855; Louviere et al., 2000, pp. 228-231). Discrete choice experiments belong to the group of indirect survey methods, meaning that respondents are not directly asked for their WTP but asked to choose between different product variants at different prices. This approach is preferable to direct surveys which are more prone to biased results (Breidert, 2006, pp. 48-55). Different instruments may be used to further reduce biases, such as a cheap talk script, solemn oath, or honesty priming, although the empirical evidence for their effectiveness seems mixed (deMagistris et al., 2013; Howard et al., 2017; Tonsor \& Shupp, 2011).

The underlying theoretical framework of discrete choice experiments is mainly based on Lancaster's characteristics theory of value (Lancaster, 1966) and McFadden's random utility theory (RUT) (McFadden, 1974). Lancaster suggests that the different characteristics of a good (i.e., attributes and their levels) and not the good itself provide utility to the individual (Lancaster, 1966). McFadden divides the individual's utility function into an observable non-stochastic 
(systematic) component reflecting utility derived from the characteristics, and an unobservable stochastic component or (random) error term reflecting idiosyncrasies ${ }^{12}$ (Louviere et al., 2000, p. 38; McFadden, 1974). It is assumed that the individual consumer - in consideration of a restricted budget - chooses the alternative whose characteristics provide him or her the highest total utility (Lancaster, 1966; McFadden, 1974).

A discrete choice experiment usually has three main phases: experimental design, implementation, and analysis (Hensher et al., 2015; Louviere et al., 2000). Concerning the design, researchers have to decide on the attributes and levels of the alternatives, the number of alternatives per choice set, the number of choice sets presented to each respondent in the implementation phase (e.g., as part of a survey), and whether the design is labeled or unlabeled. The inclusion of an opt-out ("no choice") or status quo option allows for more realistic choice scenarios (and, consequently, a more realistic estimation of utility parameters), if in real-life choice situations it would also be possible to decide against the alternatives offered. If the total number of possible attribute combinations is very high, it is recommendable to use a reduced design which maximizes efficiency in terms of minimizing standard errors of the parameters estimated in the analysis phase (i.e., a so-called D-efficient design). D-efficient designs are superior to orthogonal designs if any information on the parameters to be estimated is available prior to the implementation (Bliemer \& Rose, 2011; Hensher et al., 2015; Johnson et al., 2013; Louviere et al., 2000). Different software tools nowadays provide solutions to create such Defficient choice designs. For the choice experiment implemented as part of this dissertation, the software Ngene by ChoiceMetrics was used to create a D-efficient design based on coefficient priors obtained from a pilot study conducted with 57 respondents.

\subsubsection{Mixed logit and latent class analysis}

Depending on the underlying assumptions, different models can be used to analyze data obtained from a discrete choice experiment, such as multinomial logit, conditional logit, mixed logit (or random parameter logit), nested logit, and latent class models (Hauber et al., 2016; Hensher et al., 2015; Louviere et al., 2000; McFadden, 1974, 1986)..$^{13}$ Multinomial and conditional logit models are based on strong assumptions that are violated in many cases, in particular the assumption of the independence of irrelevant alternatives (IIA) (Luce, 1959), which requires that the random utility components are independently and identically distributed (Hensher et al.,

\footnotetext{
${ }^{12}$ Potential error sources are omitted variables, measurement inaccuracies, or inconsistent choice behavior (Adamowicz et al., 1998, p. 9).

${ }^{13}$ Originally, the multinomial logit model considered only characteristics of the individual, while the conditional logit model introduced characteristics of the alternatives (Hoffman \& Duncan, 1988; McFadden, 1974). Nowadays, researchers often refer to multinomial logit models when they actually mean conditional logit models (Hauber et al., 2016).
} 
2015, p. 93ff.; Louviere et al., 2000, p.44ff.; McFadden, 1974). To account for preference heterogeneity among respondents, mixed logit, nested logit, or latent class models are suitable options.

A nested logit model may be used if it can be assumed that product alternatives can be classified into different segments (or nests), based on correlations between the random components. While it is not necessary that the respondents' decision-making process follows a hierarchical decision tree, assumptions on a hierarchical decision process might help to identify the structure of a nested logit model. However, nested logit models do not account for heterogeneity derived from the respondents' characteristics (Hensher et al., 2015, p. 102ff.; Louviere et al., 2000, p. 144ff.). Mixed logit models allow (some) parameters to be randomly distributed. They are usually estimated using maximum simulated likelihood estimation. ${ }^{14}$ In addition to the attribute coefficients, also the respective standard deviations of these mean effects are provided for the parameters that are specified as randomly distributed. A statistically significant standard deviation can be interpreted as an indicator for relevant preference heterogeneity, confirming that the assumption of a random distribution is adequate (Hauber et al., 2016; Hensher et al., 2015, p. 106ff.; McFadden \& Train, 2000). For the choice experiment implemented as part of this dissertation, first a mixed logit model was used to identify the mean utility associated with the different product attributes by the overall sample, and to check for preference heterogeneity, which could be confirmed by the results.

However, to identify the sources of preference heterogeneity, either interaction effects with socio-economic and/or psychometric attributes have to be estimated, or a latent class model can be estimated instead. Interaction effects might be difficult to interpret in case of many variables. With latent class models (also known as finite mixture models), observations are grouped into classes based on estimated membership probabilities, and segment-specific utility parameters are estimated for the product attributes. The classes are called latent because the assignment to a segment cannot be directly observed, but is based on latent constructs (i.e., the socio-economic and/or psychometric attributes that might be operationalized using survey items or aggregated factors). In the standard latent class model, the estimated parameters within a latent class (or segment) are fixed, but differ between classes (Boxall \& Adamowicz, 2002; Hensher et al., 2015, p. 706ff.; Swait, 1994).

Consequently, latent class models are useful for market segmentation studies and allow for more straightforward interpretation compared to complex mixed logit models with interaction effects. It was therefore decided to conduct a latent class analysis in addition to the mixed logit model that accounted only for main effects. The number of latent classes is not determined by

\footnotetext{
${ }^{14}$ Maximum simulated likelihood is also known as simulated maximum likelihood (Munkin \& Trivedi, 1999).
} 
the model, but has to be decided by the researcher based on different criteria, usually considering at least model fit and interpretability (Collins \& Lanza, 2010, pp. 81-89). There are different approaches to latent class analysis. The approach applied in this dissertation uses the expectation-maximization algorithm, which is more stable than other algorithms in terms of achieving convergence, and allows for considering panel data structure (Bhat, 1997; Pacifico \& Yoo, 2013; Yoo, 2019).

\subsection{Mixed methods}

Qualitative and quantitative social research methods can be combined in a so-called mixed methods study in order to explore certain research questions in depth, thereby getting a better understanding of complex issues. Different types of mixed methods designs can be applied for different purposes. These types can be mainly distinguished according to their implementation sequence and their emphasis on either the qualitative or the quantitative part (Creswell \& Plano Clark, 2011; Johnson et al., 2007; Kuckartz, 2014). Creswell and Plano Clark (2011) distinguish between convergent, explanatory, exploratory, embedded, transformative, and multiphase designs. As part of this dissertation, a mixed methods study based on an exploratory design was implemented to study consumer attitudes and preferences toward palm oil (articles 2 and 3, respectively).

Exploratory designs are defined as the sequential implementation of qualitative data collection and analysis methods in the first phase followed by quantitative data collection and analysis methods in the second phase. Results of the first phase are used to further develop research hypotheses and instruments to be tested in the second phase in order to generalize the findings. Depending on the focus, an exploratory design can be implemented either as theorydevelopment variant (prioritizing the qualitative phase) or as instrument-development variant (prioritizing the quantitative phase) (Creswell \& Plano Clark, 2011, p. 90).

In the case of this research project, consumers' attitudes toward palm oil had not been qualitatively explored in Germany before. Thus, the results from the focus group discussions (qualitative) were used to develop both research hypotheses as well as psychometric scales to be tested in a subsequent online survey that involved a discrete choice experiment (quantitative). The purpose was to find out to what extent the exploratory results of the discussions could be generalized for the population of interest. As the quantitative part of the analysis was emphasized, this mixed methods study can be classified as using an instrument-development exploratory design, or in mixed methods design notation: qual $\rightarrow$ QUANT $^{15}$ (Kuckartz, 2014, p. 59; Morse, 1991).

\footnotetext{
${ }^{15}$ According to this notation, the arrow indicates the implementation sequence, while the capitalization indicates which part is emphasized in the study (Kuckartz, 2014; Morse, 1991).
} 


\section{Structure and summary of the contributed articles}

This dissertation is composed of four articles that aim at contributing answers to the research questions defined in section 1.4 by applying the methods explained in section 2 . Table 1 provides an overview of these articles, which all have been published in peer-reviewed scientific journals. Appendix A provides a list of further publications, of which two are particularly worth mentioning: The first is a working paper dealing with a comprehensive assessment of soy certification systems (Hargita et al., 2018, 2019), which inspired the development of article (4) with a specific and more detailed focus on traceability. The second is a research note on the method of synchronous textbased online focus groups, which has been applied in the qualitative study described in article (2) (Hinkes, 2020).

Table 1. List of contributed articles

\begin{tabular}{|c|c|c|c|}
\hline Article & Authors & Title & Journal \\
\hline (1) & $\begin{array}{l}\text { C. Hinkes } \\
\text { (2020) }\end{array}$ & $\begin{array}{l}\text { Adding (bio)fuel to the fire: } \\
\text { Discourses on palm oil } \\
\text { sustainability in the context of } \\
\text { European policy development }\end{array}$ & $\begin{array}{l}\text { Environment, Development and } \\
\text { Sustainability, 22, 7661-7682. } \\
\text { https://doi.org/10.1007/s10668- } \\
\text { 019-00541-y }\end{array}$ \\
\hline (2) & $\begin{array}{l}\text { C. Hinkes, } \\
\text { I. Christoph- } \\
\text { Schulz (2019) }\end{array}$ & $\begin{array}{l}\text { Consumer attitudes toward palm } \\
\text { oil: Insights from focus group } \\
\text { discussions }\end{array}$ & $\begin{array}{l}\text { Journal of Food Products } \\
\text { Marketing, 25(9), 875-895. } \\
\text { https://doi.org/10.1080/10454446. } \\
\text { 2019.1693468 }\end{array}$ \\
\hline (3) & $\begin{array}{l}\text { C. Hinkes, } \\
\text { I. Christoph- } \\
\text { Schulz (2020) }\end{array}$ & $\begin{array}{l}\text { No palm oil or certified } \\
\text { sustainable palm oil? } \\
\text { Heterogeneous consumer } \\
\text { preferences and the role of } \\
\text { information }\end{array}$ & $\begin{array}{l}\text { Sustainability, 12(18), Article 7257, } \\
\text { https://doi.org/10.3390/ } \\
\text { su12187257 }\end{array}$ \\
\hline (4) & $\begin{array}{l}\text { C. Hinkes, } \\
\text { G. Peter (2020) }\end{array}$ & $\begin{array}{l}\text { Traceability matters: } \\
\text { A conceptual framework for } \\
\text { deforestation-free supply chains } \\
\text { applied to soy certification }\end{array}$ & $\begin{array}{l}\text { Sustainability Accounting, } \\
\text { Management and Policy Journal, } \\
\text { 11(7), 1159-1187. } \\
\text { https://doi.org/10.1108/SAMPJ-04- } \\
\text { 2019-0145 }\end{array}$ \\
\hline
\end{tabular}

The four articles included in this dissertation cover different aspects of sustainability certification in the context of deforestation-free supply chains. Figure 1 visualizes the relationship between the articles with respect to the scope of this dissertation. The first three articles focus on palm oil, while the fourth article concerns soy. Article (1) deals with an analysis of discourses on palm oil that are reflected in the recent development of policy measures in the EU. One major focus lies on the use of palm oil as a biofuel feedstock. Articles (2) and (3) explore consumers' attitudes and preferences toward palm oil as a food ingredient using qualitative (2) and quantitative (3) methods. In article (4), an assessment of zero-deforestation criteria with a focus on traceability along the supply chain is performed for several soy certification systems. The 
following paragraphs provide a summary of each of the four contributions. The full articles are presented in section 4.

\begin{tabular}{|c|c|c|c|c|}
\hline Topic & \multicolumn{4}{|c|}{ Sustainability certification for deforestation-free supply chains } \\
\hline Commodity & \multicolumn{3}{|c|}{ Palm oil } & Soy \\
\hline Use & Fuel & \multicolumn{2}{|c|}{ Food } & Feed \\
\hline Perspective & Policy measures & \multicolumn{2}{|c|}{ Consumer attitudes \& preferences } & Supply chain \\
\hline \multirow[t]{3}{*}{ Article } & (1) & (2) & (3) & (4) \\
\hline & $\begin{array}{l}\text { Methods: } \\
\text { - Literature review } \\
\text { - Discourse analysis }\end{array}$ & $\begin{array}{l}\text { Methods: } \\
\text { - Face-to-face \& } \\
\text { online focus group } \\
\text { discussions } \\
\text { - Thematic content } \\
\text { analysis (qualitative) }\end{array}$ & $\begin{array}{l}\text { - Wethods: } \\
\text { - Web survey with } \\
\text { choice experiment } \\
\text { Mixed logit \& } \\
\text { Latent class analysis } \\
\text { (quantitative) }\end{array}$ & $\begin{array}{l}\text { Methods: } \\
\text { - Literature review } \\
\text { - Document analysis }\end{array}$ \\
\hline & $\begin{array}{l}\text { - Dample/Data: } \\
\text { documentypes of } \\
\text { - European Palm Oil } \\
\text { Conference } 2017\end{array}$ & $\begin{array}{c}\text { Sample/Data: } \\
\text { - } 66 \text { respondents in } \\
\text { eight focus groups }\end{array}$ & $\begin{array}{c}\text { - } \begin{array}{c}\text { Sample/Data: } \\
\text { (quota-based) }\end{array} \\
\text { (quota-bondents }\end{array}$ & 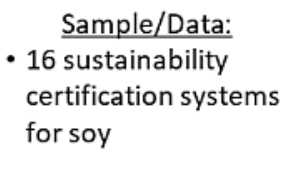 \\
\hline
\end{tabular}

Figure 1. Conceptual overview of the scope of the dissertation

In article (1), the argumentative discourse-analytical approach (ADAA) according to Hajer (1995) is adopted to analyze discourses on the sustainability of palm oil in the context of the development of policies on the EU level. The aim of this study is to provide insights into the views and arguments promoted by different actors in palm oil producing and consuming countries that might influence trade relations. A literature review is conducted to develop a conceptual framework for analyzing palm-oil-related discourses. It considers the three pillars of sustainability as well as three discursive levels: the product level, the mode of production level, and the institutional level. Two policy documents are in the focus of the analysis: the European Parliament resolution of 4 April 2017 on palm oil and deforestation of rainforests, and the revised EU Renewable Energy Directive (RED II). Qualitative data is extracted from official policy documents, scientific literature, media reports, press releases, as well as speeches held at an industry-driven palm oil conference. As a result of the discourse analysis, three main positions on the sustainability of palm oil are identified:

1. There is no sustainable palm oil available on the market yet.

2. Certified sustainable palm oil is the solution.

3. Palm oil is the most sustainable alternative available.

The different elements of the ADAA (storylines, emblems, and discourse coalitions) are analyzed for each of these positions. The two EU policy documents represent mainly the first and 
- partly - the second position. Stricter, mandatory sustainability requirements for palm oil are developed. In contrast, reactions to this policy development from the main producer countries Indonesia and Malaysia refer to storylines related to the third position, emphasizing the aspect of land use efficiency. The discourse analysis identifies an intensification of controversies in the context of regulations on bioenergy and reveals that storylines are partly influenced by selected framing and misconceptions of facts. The findings of this study are particularly relevant for policymakers who need to understand regulatory gaps and potential sources of conflict between discourse coalitions to avoid trade-related conflicts.

It is also important to understand to what extent public discourses and other factors might affect consumers' attitudes and preferences, which again might influence the demand for sustainable, deforestation-free products. Article (2) covers the first, qualitative part of a mixed methods approach. Four face-to-face and four text-based synchronous focus group discussions are conducted with a total sample of 66 consumers in Germany. The composition of the focus groups is relatively heterogeneous in terms of different socio-economic criteria. The moderated discussions follow a semi-structured questioning route and have a duration of 60 to 90 minutes. Pictures of a palm-oil-free hazelnut spread product and two different RSPO labels ("RSPO certified" and "RSPO mixed") are used as discussion stimuli. "RSPO certified" means that the product contains only RSPO-certified palm oil. "RSPO mixed" means that a mass balance approach is applied, which allows for mixing certified with uncertified palm oil. After the discussions, the transcribed audio protocols and chat protocols are qualitatively analyzed according to the thematic content analysis method by using the software MAXQDA.

The results show that the respondents know more about potential disadvantages of palm oil than about its advantages compared to alternatives. The identified prevailing aversion to palm oil is based on discourses on sustainability issues and health aspects. Among the respondents, nobody had heard of RSPO certification prior to the discussion. Overall, stated preferences for palm-oil-free hazelnut spread are predominant. Still, most respondents express their willingness to pay a small premium for "RSPO certified" palm oil (but not for the "RSPO mixed" variant), as compared to uncertified palm oil. Several aspects are mentioned as preconditions, such as the effectiveness and reliability of the certification system. Despite preferences for palm-oil-free products, many respondents lack knowledge about potential alternatives to palm oil. In general, palm oil is not perceived as a major decision-relevant factor in real consumption decisions. Various aspects are regarded as more important, such as the product price, the taste, brand loyalty, and availability. The time required to search for product information is identified as a potential barrier to sustainable consumption in general. 
Building up on these exploratory results, research hypotheses and questionnaire items are developed to be tested in the second, quantitative part of the mixed methods study. Article (3) deals with a web-based survey including a discrete choice experiment that involves fictitious chocolate cookie products. The aim of this study is to quantify stated preferences and WTP for RSPO-certified products, as compared to palm-oil-free products and products containing conventional palm oil. In this regard, potential sources of preference heterogeneity as well as effects of information provision on preferences shall be analyzed. The survey sample selected according to socio-demographic quota consists of 1,000 consumers in Germany. The analysis is divided into two parts: before and after the provision of information on palm oil and different certification systems. Mixed logit models and latent class models are estimated using Stata. ${ }^{16}$

The results show that cookies with a "palm-oil-free" claim are generally preferred over RSPO-certified cookies both before and after information provision. However, the mixed logit analysis reveals evidence for preference heterogeneity and statistically significant differences between the two parts of the experiment. Before information provision, stated preferences for palm-oil-free cookies exceed those for cookies carrying the "RSPO certified" label. Preferences for "RSPO mixed"-labeled cookies are statistically insignificant. After information provision, significantly positive preferences are identified for all three alternatives, as compared to uncertified palm oil. However, palm-oil-free products still provide the highest mean utility.

A latent class analysis considering socio-demographic attributes and psychometric factors is conducted to explore potential sources of preference heterogeneity. Six consumer segments of different sizes are identified for part 1 of the experiment. One segment for instance avoids palm oil (14\% of the sample), another segment is indifferent about palm oil (20\%), while a third supports certification (16\%). Several segments are considerably price-sensitive. The participants seem more likely to choose certified palm oil if they have trust in certification and are concerned about sustainability, for instance. After information provision, the indifferent segment dissolves, and its members split up into other segments. Although the share of respondents who support RSPO certification increases, overall preferences for palm-oil-free products increase, too. Thus, the provision of information to consumers might help to influence preferences for certified palm oil, but it might also have unintended effects and will probably not be sufficient.

Concerning the credibility and effectiveness of certification systems, article (4) deals with an assessment of sustainability certification systems for soy with respect to the question on which systems may be suitable to ensure zero deforestation. In a first step, a conceptual framework for the assessment is developed based on a literature review. This framework consists of three main

\footnotetext{
${ }^{16}$ Those respondents who always choose the opt-out option throughout the experiment are excluded from further analysis, which leaves a sample of 956 respondents.
} 
elements: i) sustainability standards that define forests, zero deforestation, and the respective ecosystems to be protected; ii) assurance systems that specify required controls and certification procedures; iii) mandatory or optional chain-of-custody certification systems. It is argued that among different chain-of-custody systems, only "segregation" and "identity preservation" are able to ensure traceability. "Mass balance", "area mass balance" and "book \& claim" are not suitable, because these systems cannot ensure that a product contains only certified produce. In the second step, the framework is used to assess 16 soy certification systems that have been selected based on their compliance with the FEFAC SSG. With respect to elements i) and ii), information is mainly retrieved from two previous studies. Concerning element iii), the most recent standard documents for the different certification systems are analyzed. The results of the assessment indicate that only few soy certification systems fulfill the zero-deforestation criteria according to the framework: ISCC EU, ISCC PLUS, ProTerra, Donau Soja, Europe Soya, as well as RTRS. Thus, these systems should be prioritized by policymakers and supply chain actors supporting zero-deforestation targets. In this regard, relevant opportunities and threats with respect to the effective implementation of deforestation-free supply chains are briefly discussed. 


\section{$4 \quad$ Articles included as part of the dissertation}

\subsection{Adding (bio)fuel to the fire: Discourses on palm oil sustainability in the context of European policy development}

Cordula Hinkes

Environment, Development and Sustainability (2020), 20: 7661-7682.

DOI: https://doi.org/10.1007/s10668-019-00541-y

Permission to reproduce this article in its final published version as part of this dissertation has been granted by the publisher Springer Nature B.V.

The final authenticated version published in Environment, Development and Sustainability is available online at: https://doi.org/10.1007/s10668-019-00541-y.

Declaration of originality:

All tasks related to research planning, data collection, data analysis, drafting and revising the manuscript were performed by the author. 


\title{
Adding (bio)fuel to the fire: discourses on palm oil sustainability in the context of European policy development
}

\author{
Cordula Hinkes $^{1}$
}

Received: 7 February 2019 / Accepted: 26 November 2019 / Published online: 3 December 2019

(C) Springer Nature B.V. 2019

\begin{abstract}
Palm oil is highly versatile, efficient, and cheap - and the most consumed vegetable oil globally. However, the expansion of industrial palm oil production has adverse environmental and social effects that have contributed to the development of discourses questioning the sustainability of palm oil. Discourses have the power to influence environmental policy and may induce change in production, consumption, and trade relations. Contributing to research on palm oil-related discourses, the aim of this study is to analyze discourses in the context of the recent development of European policies. Adopting an argumentative discourse-analytical approach, we analyze discourses on palm oil within and around two relevant policies: the European Parliament resolution on palm oil and deforestation of rainforests, and the revised Renewable Energy Directive II of the European Union (EU). Although the sustainability of palm oil has been contested between palm oil-producing and palm oil-consuming countries for decades, we show how these two policies have added fuel to the fire. While the EU frames palm oil as a "forest-risk" and "high ILUC-risk" commodity and thereby contradicts previous EU support for palm oil-based biofuels, the governments of Indonesia and Malaysia describe the policy development as a "ban on palm oil", "crop apartheid" and the starting point of a potential "trade war". Both sides disseminate storylines that are partly biased by a misinterpretation of facts. By providing a classification of relevant discourses that are discussed in the political context, this article facilitates a better understanding of discursive struggles on palm oil.
\end{abstract}

Keywords Biofuel · Certification · Discourse analysis · European Union · Indirect land use change $\cdot$ Palm oil

\section{Introduction}

Environmental policymaking is influenced by discourses and, vice versa, shapes discourses (Feindt and Oels 2005). Discourse coalitions lobby for their interests by promoting certain storylines on an issue at stake - which might result in the development of policies or institutional change (Hajer 1995; Schmidt 2008, 2010; Béland 2009). Policy discourse analysis

Cordula Hinkes

cordula.hinkes@thuenen.de

1 Thuenen Institute of Market Analysis, Bundesallee 63, 38116 Braunschweig, Germany 
facilitates a better understanding of political discussions and motivations of different actors (Schmidt 2008). The current political debate on the sustainability of palm oil between the European Union and major palm oil-producing countries is an interesting and topical case for policy discourse analysis. Policies that aim at supporting the sustainable development of the palm oil sector need to consider trade-offs between environmental, social, and economic aspects (Hansmann et al. 2012).

Globally, palm oil is the most consumed oil among the major vegetable oils and animal fats. Indonesia and Malaysia are currently responsible for around $83 \%$ of the global palm oil production. As the second largest import market for palm oil, the European Union (EU) is connected via international supply chains to Southeast Asian producers (Mielke 2018; Oil World 2018). While palm oil is primarily used for cooking and as an ingredient in processed food, it is also highly relevant for other industries, such as cosmetics and bioenergy (Rival and Levang 2014; WWF 2016a; Hunsberger and Alonso-Fradejas 2016; Mielke 2018). The use as biofuel has become increasingly important. In 2017, the EU used $47 \%$ of imported palm oil as biofuel (ESPO 2019). Palm oil is not only more versatile, but also more efficient and cheaper to produce than alternative oils (WWF 2016a; Rival and Levang 2014). Due to its versatility, the oil palm has been framed as a "multipurpose plant" (Rival and Levang 2014) or "flex crop" (Hunsberger and Alonso-Fradejas 2016; Pye 2019; Borras et al. 2015).

But the industrial production of palm oil has adverse social and environmental effects that have been frequently criticized, particularly in campaigns by non-governmental organizations (NGOs) (Dauvergne 2017). Land use change for the establishment of oil palm monoculture plantations in previously forested areas causes biodiversity loss, soil erosion, waste, as well as reduced air and water quality (Moreno-Peñaranda et al. 2015; Vijay et al. 2016; Fitzherbert et al. 2008; Guillaume et al. 2018; Jiwan 2013; Koh and Wilcove 2008). The practice of slash and burn to clear land as well as peatland drainage is not only threatening ecological systems and many species but also causing forest fires and the release of carbon dioxide into the atmosphere, which drives climate change (Pacheco and Komarudin 2017; Varkkey 2013; Miettinen et al. 2016). The resulting haze leads to respiratory problems and other human health issues (Pye 2019; Larsen et al. 2018; Goldstein 2015). While the engagement in palm oil production provides opportunities for poverty alleviation and economic growth (Azhar et al. 2017; McCarthy and Cramb 2009), there are also adverse social effects, such as exploitation and forced labor, conflicts over land rights and resources, and reduced economic resilience and food sovereignty of local communities (Moreno-Peñaranda et al. 2015; Goldstein 2015; Byerlee and Rueda 2015; McCarthy et al. 2012; Brad et al. 2015; Colchester 2016; Gaveau et al. 2016; Jiwan 2013). These effects can be particularly attributed to large-scale, industrial monoculture palm oil production, whereas smallholdings are much less problematic (Lee et al. 2014).

Responding to these issues, the Roundtable on Sustainable Palm Oil (RSPO) has been formed in 2004 to establish voluntary sustainability certification systems and to improve the reputation of the sector (Schouten and Glasbergen 2011; Boons and Mendoza 2010; Hospes 2014). However, the industry-dominated RSPO has been criticized for a lack of effectiveness in the enforcement of standards and in resolving problems inherent to industrial palm oil production (Schouten and Glasbergen 2012; Oosterveer 2015; Colchester 2016; Jiwan 2013; Ruysschaert and Salles 2014). Large-scale palm oil production continues to expand under the disguise of the "industry narrative" of sustainable palm oil (Dauvergne 2018). Certification has primarily been implemented in areas that already have low forest cover (Carlson et al. 2018), and certified sustainable palm oil is still linked to deforestation (Cazzolla Gatti et al. 2019). 
The legitimacy of the RSPO as a form of market-based governance has been further questioned, as particularly smallholders, indigenous peoples, and governments have not been sufficiently represented and involved (Oosterveer 2015; Cheyns 2011, 2014; Colchester 2016). Due to economic and institutional barriers, independent smallholders are effectively excluded from certification and international markets (Ruysschaert and Salles 2014; Ruysschaert 2016; Glasbergen 2018), although small-scale production has a higher potential to achieve conservation targets (Azhar et al. 2017; Brandi et al. 2015). In an attempt to reclaim sovereignty in terms of standard setting, producer countries recently introduced national mandatory regulations: the Indonesian Sustainable Palm Oil (ISPO) and Malaysian Sustainable Palm Oil (MSPO) standards (Wijaya and Glasbergen 2016; Pacheco and Komarudin 2017; Larsen et al. 2018; Astari and Lovett 2019; Hospes 2014).

Different actors frame issues related to palm oil in different ways, as the interpretation of sustainability is contested and depends on context and perspective (Corciolani et al. 2019; Cheyns 2011; Azhar et al. 2017; Boons and Mendoza 2010; Ruysschaert 2016). Consequently, the range of storylines on palm oil sustainability disseminated by different actors is broad: from a "miracle plant" to a "serious ecological threat" (Rival and Levang 2014), a "forest-risk commodity" (Henders et al. 2015) or "conflict palm oil" (Rainforest Action Network 2013). Many previous studies have directly or indirectly focused on discourses with respect to palm oil properties (e.g., Hunsberger and Alonso-Fradejas 2016; Othman et al. 1993) as well as the conditions of palm oil production and its effects on environmental and social sustainability (e.g., Susanti and Maryudi 2016). Particularly the RSPO (e.g., Orsato et al. 2013; Pye 2019; Schouten and Glasbergen 2011; Moreno-Peñaranda et al. 2015; Cheyns 2011; Ruysschaert and Salles 2014, 2016; Dauvergne 2018) and national mandatory standards (e.g., Astari and Lovett 2019; Hospes 2014; Dauvergne 2018) have been subject of institutional discourse analyses.

However, although the relevance of European policies for the palm oil sector has been stressed before (Larsen et al. 2018; Astari and Lovett 2019; D’Antone and Spencer 2015; Stattman et al. 2018), to the best of our knowledge no study has focused on discourses related to this aspect yet. The aim of this discourse analysis is therefore to contribute to closing this research gap. Following Hajer's (1995) argumentative discourse-analytical approach, we examine official policy documents, presentations, press releases, and media articles to explore which discourses on palm oil sustainability have influenced relevant EU policies, and which are reflected in reactions by actors from Indonesia and Malaysia. Thereby, this article contributes insights into the development of palm oil-related discourses that are relevant for policymakers, researchers, and stakeholders of global palm oil supply chains.

The remainder of this article is structured as follows. Section 2 provides information on the European policies that are in the focus of this discourse analysis. Section 3 defines and explains the conceptual framework, methods, and data used. Section 4 analyzes discourses on palm oil sustainability in the context of the selected European policies. In Sect. 5, the results are discussed and conclusions are derived.

\section{European commitments and policies concerning palm oil}

Following the aim to save resources and reduce greenhouse gas emissions, the EU Renewable Energy Directive (2009/28/EC) (RED) has facilitated a global bioenergy boom since its implementation (Wolf et al. 2018). The RED set the binding target for EU member 


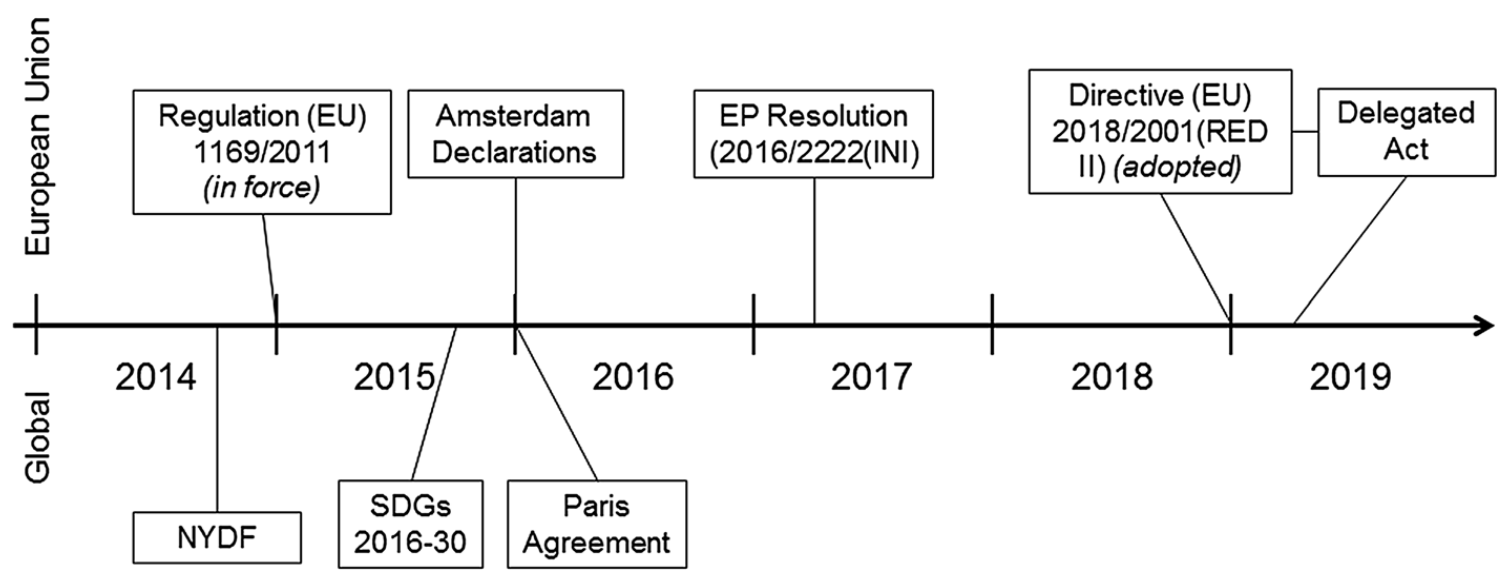

Fig. 1 European policies and commitments affecting the palm oil sector (2014-2019). Source: own contribution

states to achieve a renewable energy rate of at least $20 \%$ of total energy consumption and $10 \%$ for the transport sector by 2020 . Bioenergy has been framed as sustainable energy suitable to save $\mathrm{CO}_{2}$ emissions compared to fossil fuels (Roth et al. 2018), and palm oilbased biodiesel has been promoted as a cheap energy source (Oosterveer 2015). European demand for biofuels has contributed to the expansion of palm oil production in Indonesia and Malaysia, which has triggered increasing concerns about adverse effects (Boons and Mendoza 2010; Jiwan 2013).

Although sustainability criteria are defined in the form of a "meta-standard" in the RED, they have been criticized as being too lax (Stattman et al. 2018). The environmental sustainability of biofuel production has been questioned due to indirect land use change (ILUC). Biofuel production contributes to the displacement of food crops to other areas of high carbon stock value (Valin et al. 2015; Henders and Ostwald 2014; Chiavari 2013; Oosterveer 2015; Fargione et al. 2008). Land conversion may induce a "biofuel carbon debt," as carbon released from soil and biomass exceeds emission savings compared to the use of fossil fuels (Fargione et al. 2008). Moreover, socioeconomic consequences of increasing demand for biofuel crops have not been adequately considered in the RED (Chiavari 2013). The so-called food vs. fuel trade-off has negative effects on livelihoods. As more palm oil is used to produce crops for bioenergy, food prices increase and self-sufficiency is reduced (Susanti and Maryudi 2016; Boons and Mendoza 2010; Hunsberger and Alonso-Fradejas 2016; Dauvergne and Neville 2010).

Recent policy development reflects the topicality and importance of emerging discourses on sustainable palm oil. We focus on current discussions in the multilateral political context, acknowledging that other initiatives also deserve further analysis, as for instance private sector commitments to achieve "deforestation-free" supply chains (Pacheco and Komarudin 2017; Donofrio et al. 2017) and national mandatory sustainability standards (e.g., Astari and Lovett 2019; Hospes 2014). Figure 1 shows a timeline of international and European policy development for the period from 2014 to 2019 that we identified as directly or indirectly relevant for the aggravation of political disputes on palm oil production, consumption, and trade.

On the global scale, mainly the New York Declaration on Forests (NYDF), the Sustainable Development Goals (SDGs), and the Paris Agreement have influenced the development of more specific policies in the EU since 2014. The NYDF as one important outcome of the UN Climate Summit in 2014 has established the goal of ending global deforestation 
by 2030. One of the ten NYDF goals focuses explicitly on deforestation for palm oil production (NYDF 2014). Several SDGs affect palm oil supply chains, particularly Goal 12 ("Responsible Consumption and Production"), Goal 13 ("Climate Action"), and Goal 15 ("Life on Land"). The signatory countries to the Paris Agreement pledged to develop and implement "nationally determined contributions" (NDCs) to halt climate change. Indonesia's first NDC for instance includes targets to increase the use of renewable energies (Republic of Indonesia 2016), contributing to increasing national demand for palm oilbased biodiesel (Nangoy and Jensen 2018).

Within the EU, Regulation (EU) No. 1169/2011 on the provision of food information to consumers has made the specific declaration of vegetable oils (e.g., palm oil) on the list of ingredients mandatory for food products, thereby increasing the visibility of palm oil. In December 2015, two so-called Amsterdam Declarations were signed. One follows the overarching aim of stopping deforestation linked to agricultural supply chains by 2020, and the other explicitly focuses on achieving sustainability in palm oil supply chains (Amsterdam Declaration 2015a, b). The Amsterdam Declarations Partnership (ADP) currently involves Denmark, France, Germany, Italy, the Netherlands, Norway, and the UK. However, these commitments are voluntary, without any direct implications for production or consumption.

The non-binding European Parliament (EP) resolution of 4 April 2017 on palm oil and deforestation of rainforests (2016/2222(INI)) has called for the development of European minimum sustainability criteria for imported palm oil and the appropriate consideration of adverse effects of palm oil production in the planned revision of the RED. The revised Renewable Energy Directive (EU) 2018/2001 (RED II) for the period from 2021 to 2030 limits the use of crop-based biofuels. It has entered into force in December 2018. Particularly the EP resolution and the RED II, supplemented by a delegated act, have contributed to the political dispute between the EU and palm oil-producing countries, as they impose restrictions on palm oil for the European market that contradict previous demand. These two European policies have therefore been set in the focus of further analysis.

\section{Methodology, methods, and data}

\subsection{Conceptual framework for the policy discourse analysis}

According to discursive institutionalism, discourses are formed by ideas, structure, and context, and they require agency and interaction (Schmidt 2008, 2010). They have the power to induce institutional or policy change, provided that institutional barriers can be overcome (Béland 2009; Schmidt 2010). Discourse analysis helps to understand how certain storylines on environmental problems are institutionalized in policies (Hajer and Versteeg 2005; Hajer 1995; Dryzek 2005; Ockwell and Rydin 2010). Poststructuralist approaches to discourse analysis in the tradition of Foucault aim at understanding how competing discourses struggle for power and hegemony and thereby shape politics (Hajer and Versteeg 2005; Sharp and Richardson 2001; Ockwell and Rydin 2010). They support the social-constructivist view that discourses provide insights about the sociopolitical context in which they evolve (Hajer and Versteeg 2005; Richardson 1996).

We apply Maarten Hajer's argumentative discourse-analytical approach (ADAA), which has been developed for the analysis of discourses in the context of environmental policies 
(Hajer 1995). ${ }^{1}$ The ADAA has been applied in several recent discourse-analytical studies on other topics before (e.g., Cotton et al. 2014; Elgert 2012; Soini and Birkeland 2014; Ferns and Amaeshi 2017; Ockwell and Rydin 2010). As a Foucauldian concept, Hajer's approach emphasizes the importance of analyzing the institutional context in which environmental policies emerge in response to environmental problems that are perceived and framed by different actors. Hajer defines discourse as "a specific ensemble of ideas, concepts, and categorizations that are produced, reproduced, and transformed in a particular set of practices and through which meaning is given to physical and social realities" (Hajer 1995).

The main elements of Hajer's ADAA are storylines, emblems, and discourse coalitions. A storyline is defined as "a generative sort of narrative that allows actors to draw upon various discursive categories to give meaning to specific physical or social phenomena" (Hajer 1995). As a kind of "metaphor" used for communication, emblems are issues repeatedly utilized to represent a category of environmental problems that are relevant in a specific period. Discourse coalitions are formed by different actors that distribute the same storylines for their own interests, while their interpretation might differ for different members of the same discourse coalition (Hajer 1995). When storylines are being reproduced by different actors, they might over time become accepted as facts. Hajer (1995) defines this process as "discursive closure", the first step of a policymaking process, in which the policy problem is being defined.

In his research, Hajer (1995) has shown that discourses on acid rain-an emblem for transnational environmental pollution in the 1980s-were linked to the concept of ecological modernization. This concept is understood as a "technocratic approach" (Hajer 1995) to solving environmental problems resulting from excessive consumption of resources by increasing efficiency, without initiating radical change of the existing socioeconomic system (Hajer 1995; Dryzek 2005; Hajer and Versteeg 2005; Langhelle 2000). In this respect, ecological modernization differs from sustainable development, as it does not sufficiently consider planetary boundaries (Langhelle 2000; Dryzek 2005).

\subsection{Methods and elements of the policy discourse analysis}

As a preparatory step to the policy discourse analysis, we conducted a literature review of scientific articles dealing with discourses on palm oil. Using the search engine Google Scholar, we searched for "palm oil", combined with "discourse", "dispute", "controversial", "narrative", "storyline", and related keywords to identify relevant articles. In this way we identified more than 30 scientific articles explicitly focusing on different aspects of palm oil-related discourses. We found that discourses on palm oil focus on one or several aspects of sustainability or on health aspects, while on the vertical dimension discourses may concern different levels: palm oil as a product, the mode of production, and governance by public or private institutions, such as the RSPO (see Fig. 2). When analyzing discourses, it is important to distinguish between these different levels and to consider diverging perceptions of sustainability by different stakeholders. In a comprehensive media analysis on palm oil for the period from 1979 to 2017, Corciolani et al. (2019) identified

\footnotetext{
1 Another approach to discourse analysis of environmental policies is provided by Dryzek (2005), who follows the tradition of Habermas and his normative understanding of discourse that focuses rather on language itself than on power and knowledge inherent in discourses (see also Hajer and Versteeg 2005; Ockwell and Rydin 2010).
} 


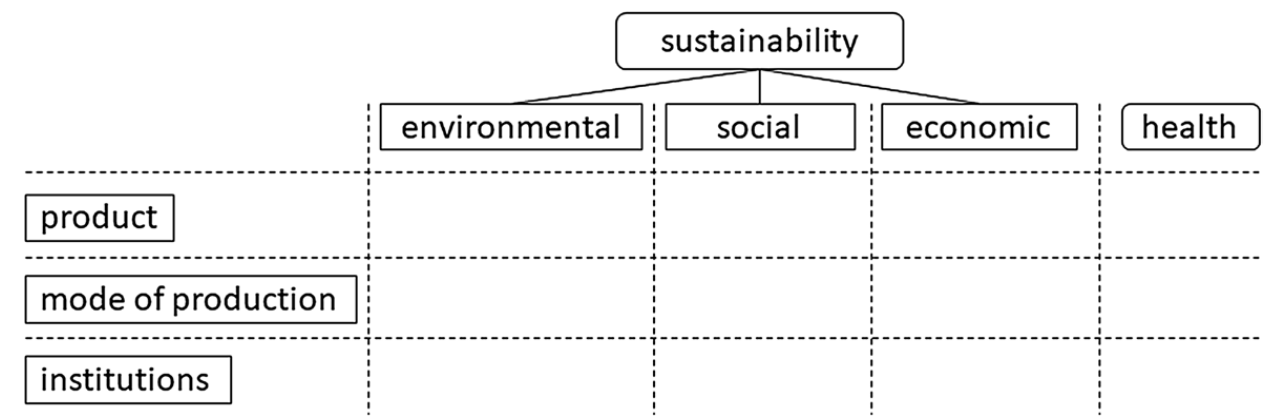

Fig. 2 Conceptual scheme of discursive levels for palm oil-related discourses. Source: own contribution

a discursive shift over time: While health issues significantly decreased and economic themes first decreased but have been increasing again since 2010, environmental and social themes have become more relevant.

As explained in Sect. 2, this study focuses on the analysis of discourses on palm oil sustainability in the context of recent policy development in Europe. Therefore, storylines have been compiled mainly from official policy documents. Relevant secondary literature, particularly online articles and press releases on reactions by policy actors and stakeholders in producer countries, has been identified by using the search engines of Google Search and Google News. In addition, we have applied Karlsen's (2018) "discourse approach to an event" to the case of the European Palm Oil Conference (EPOC) 2017, which took place in Brussels in November 2017. Similar to previous approaches (e.g., by Ockwell and Rydin (2010)), this method involves the qualitative analysis of data produced and collected during a conference.

The EPOC 2017 was selected as a relevant and interesting case for research on palm oil-related discourses because it involved a variety of actors and took place at a time when the development of new European policies dealing with palm oil had just become subject of public discussions. It was organized by the European Palm Oil Alliance (EPOA), an initiative of major players in the international palm oil business as well as associations and lobby organizations from producer countries. The EPOA aims to "engage with and educate stakeholders on the full palm oil story" (EPOA 2018). The overall theme was "Taking responsibility in sustainability". All EPOA members are also engaged in the RSPO. Data were retrieved from observation and personal notes taken during the conference as well as from recorded side interviews and presentation material that was made publicly available after the conference. The main source of data was derived from 19 speeches by stakeholders from producer countries, the palm oil industry and the food and retail industry, nongovernmental organizations, as well as by members of the European Parliament and the European Commission.

\section{Analysis of discourses on palm oil related to European policy development}

\subsection{The EP resolution on palm oil and deforestation of rainforests}

The EP resolution on palm oil and deforestation of rainforests (2016/2222(INI)) of 4 April 2017 (European Parliament 2017) promotes the aim of achieving "[...] an EU-wide 
national commitment of sourcing $100 \%$ certified sustainable palm oil by 2020 ". Considering the conceptual scheme for palm oil-related discourses presented in Fig. 2 (Sect. 3.2), different aspects of sustainability at different levels are covered by the resolution. However, it has a clear focus on framing palm oil as a "forest-risk commodity".

At the product level, the resolution acknowledges advantages of palm oil, in particular the productivity and versatility. The efficiency of palm oil production is emphasized by claiming that "[...] replacing palm oil with other vegetable oils would create a need for more land for cultivation". With respect to the cost advantage of palm oil, it is however stated that this " $[\ldots]$ is made possible by the increase in the number of oil palm plantations in deforested areas". This phrasing leaves room for interpretation: Is the cost efficiency of palm oil contingent upon deforestation? Or does the large number of plantations lead to an oversupply and resulting low price of palm oil, which would be rather detrimental to cost efficiency? A clear, data-based explanation is missing — a finding that is symptomatic for the whole document.

At the "mode of production" level, the environmental frame mainly refers to the destruction of habitats for endangered species due to deforestation. Health aspects are only mentioned as a negative consequence of slash-and-burn practices resulting in wildfires and smoke emissions. Pointing to trade-offs between environmental conservation and economic development, the resolution calls for "[...] better integration of conservation issues into development cooperation". Discourses on "land grabbing" related to palm oil expansion are taken up, referring to the "global rush for land" and "speculation on land and agricultural commodities". Although beef and soy imported into the EU have contributed more to deforestation than imported palm oil has (European Commission 2013), the resolution itself focuses on palm oil only. In this respect, palm oil is used as an emblem for deforestation linked to agricultural activities in general.

While the resolution approves private sector "zero deforestation" commitments, the need for unambiguous definitions of "forest" and "deforestation-free" is emphasized. The lack of a common understanding of these concepts contributes to discourses on palm oil. Existing private sector commitments often refer to "zero net deforestation", which means that deforestation can be compensated by afforestation elsewhere. This target usually goes beyond achieving "zero illegal deforestation", but is less ambitious than "zero gross deforestation", which does not allow for afforestation as compensation (Brown and Zarin 2013; Pirard et al. 2015; WWF 2016b; Neeff and Linhares-Juvenal 2017). The overall ambition of the resolution with respect to "deforestation-free" or sustainable palm oil is not clarified.

At the institutional level, the EP resolution emphasizes the "shared global responsibility" for issues related to palm oil and the need for a "global solution". In this respect, the need for cooperation between palm oil-producing and palm oil-consuming countries is stressed. To what extent producing countries might have been consulted on the draft of this resolution is not explained, though. The resolution calls for the development of a single, mandatory certification system for palm oil entering the EU market, supplemented by a comprehensible product label and information campaigns to improve consumer awareness and acceptance. The resolution further asks for minimum sustainability criteria for imported palm oil, while it remains unclear whether the mandatory certification scheme to be developed shall be based on these minimum criteria or go beyond. Existing voluntary certification systems, such as RSPO, ISPO, and MSPO, are criticized as insufficient for ensuring sustainable and deforestation-free palm oil production. Only RSPO NEXT, an advanced add-on to RSPO certification, is regarded as sufficiently ambitious.

Several strong statements on palm oil production and consumption in the resolution are presented as "facts" and supported by descriptive statistics, but only very few references 
to the respective data sources are provided. Interestingly, at the same time the lack of reliable data in producer countries is criticized. The references include no peer-reviewed scientific articles, but mostly studies commissioned by the EU and reports by different NGOs, such as Amnesty International, FERN, Rainforest Action Network, or WWF. According to a typology by Ruysschaert and Salles (2016), the WWF is regarded as "collaborative" with respect to engagement with the RSPO, while other NGOs are rather "opposing" or "skeptic". This selection of sources indicates which stakeholders might have influenced the development of the resolution. The following two examples on deforestation illustrate that the lack of references hinders the verification of claims on which political statements are based on, increasing the risk of data manipulation, misinterpretation, and the development of "alternative facts" on palm oil.

First, point 4 of the "General considerations" of the EP resolution states that "[...] $40 \%$ of global deforestation [are] caused by conversion to large-scale monocultural oil palm plantations", referring to a report by the European Commission (2013). Baron et al. (2017) point out that this "fact" is not true. Instead, the report states that in the period from 1990 to 2008 , " $40 \%$ of the deforestation attributed to the crop sector [in Indonesia] is associated directly or indirectly with oil palm production" (European Commission 2013). Thus, it refers only to Indonesian deforestation associated with crop production within a certain time frame. As further explained by Baron et al. (2017), the numbers provided by the report show that only $2.3 \%$ of global deforestation in the given period can be attributed to palm oil.

Second, point 14 refers to "[...] the fact that around half of the area of forests cleared illegally was used for palm oil production for the EU market". The context of this number is not further specified, though, and again no references are provided. As such, the sentence might be understood as referring to the total amount of illegally cleared forests globally, which-considering the data in European Commission (2013) — cannot be correct. Both examples of data misrepresentation had already been taken up by the press (Press Club Brussels Europe 2018; Baron et al. 2017), demonstrating how biased storylines on palm oil are disseminated.

In the final part, the EP resolution refers to the use of palm oil in the form of biodiesel and its effects on sustainability, particularly emphasizing the aspect of ILUC. The "biofuel carbon debt" (Fargione et al. 2008) of palm oil is indirectly mentioned. The EP asks the European Commission "[...] to take measures to phase out the use of vegetable oils that drive deforestation, including palm oil, as a component of biofuels, preferably by 2020", thereby referring to the revised Renewable Energy Directive (RED II) to be developed. Again the land use efficiency of palm oil compared to other crop-based biofuels is emphasized, stressing that a potential replacement by other tropical oils would not be a suitable solution. Instead, the resolution "[...] recommends finding and promoting more sustainable alternatives for biofuel use, such as European oils produced from domestically cultivated rape and sunflower seeds".

\subsection{Reactions to the EP resolution on palm oil and deforestation of rainforests}

Representatives of the palm oil industry and policymakers of palm oil-producing countries have responded very critically to the recent policy development in Europe. With respect to the EP resolution, reactive discourses have focused explicitly on the aspect of deforestation. In his speech at the EPOC 2017, the CEO of the Malaysian Palm Oil Council (MPOC) referred to the exploitation of forests and peatlands in Europe centuries 
ago. Moreover, he criticized that the ratio of certified sustainable timber in Europe is still far too low. Requesting less developed countries to conserve their resources at the expense of economic development while Europe failed to comply with their own expectations is regarded as hypocrisy. It was further questioned whether the EU and Western NGOs use correct numbers when they talk about deforestation, also referring to diverging definitions of forest and deforestation. With respect to greenhouse gas emissions, the MPOC frames palm oil plantations as important carbon sinks (MPOC 2018). Other speakers at the EPOC 2017 also complained about the proliferation of "misinformation" and "alternative facts" on palm oil.

The Secretary-General of the Malaysian Ministry of Plantation Industries and Commodities (MPIC) directly addressed the EP resolution:

These [r] esolutions, if adopted as regulations, may impede market access and in the longer term negate economic growth in the palm oil producing countries. [...] this decision is also inconsistent with the EU and WTO principles of non-discrimination [...] the environmental footprint and impact of palm oil is far smaller than [that of] other vegetable oils (Yogeesvaran 2017).

Throughout his speech, he framed palm oil positively, focusing on versatility and efficiency, opportunities for economic development, employment, and smallholder livelihoods. By drawing on development narratives, palm oil is framed as a "driver of development" (Rival and Levang 2014) or "development engine" (Pye 2019). He further stressed that palm oil trade provides "mutual benefits to both exporting and importing countries" (Yogeesvaran 2017).

Most stakeholders at the EPOC 2017 shared the opinion that "sustainable palm oil is possible", as expressed by a representative of the environmental NGO Conservation International. As the majority of participants are engaged in the RSPO, the prevalence of a "pro sustainable palm oil" discourse is not surprising. One of the main messages underlining the shared beliefs was that "palm oil can be produced in a way that is sustainable and doesn't need further expansion". Considering the globally increasing demand for palm oil (Oil World 2018), this might only be achieved by improving the efficiency of palm oil production. It was not discussed, however, how a significant increase in efficiency should be achieved.

With respect to the suggested mandatory palm oil certification system for the EU market, the participants of the conference had diverging opinions. Food industry actors stressed that the success of their efforts toward achieving sustainable palm oil is limited by a missing business case for certification. Currently, only around half of the RSPO-certified palm oil volumes are sold as certified (RSPO 2018), indicating a bottleneck on the demand side. Even if products contain certified sustainable palm oil, the respective labels are not always attached to the products because of consumers' concerns about palm oil, which might outweigh their positive perceptions of sustainability certification (Giam et al. 2016; D'Antone and Spencer 2015; Cova and D'Antone 2016). Several speakers at the EPOC 2017 therefore called on European policymakers to make sustainability certification mandatory. They further expressed their concern about recent practices to promote food products by using "palm oil-free" labels and claims on products. These were framed as discriminatory or even illegal because they would wrongfully indicate to consumers that palm oil is a harmful product in itself. The CEO of the MPOC claimed that such labels would reinforce the "negative myth" of unsustainable palm oil, without distinguishing between different modes of production. At the same time, stakeholders from producer countries expressed their concerns about mandatory EU certification, arguing that there are already ambitious systems 
in place, and that such a regulation would discriminate against smallholders, who might get excluded from markets.

\subsection{The revised Renewable Energy Directive II}

The EP resolution on palm oil and deforestation of rainforests has influenced the development of the revised RED II, particularly by suggesting the phase-out of biofuels made from "forest-risk" commodities. The initial proposal for this binding regulation by the European Commission (EC) in November 2016 set a new renewable energy target of at least $27 \%$ of the final energy consumption in the EU by 2030. Moreover, it stipulated that crop-based biofuels in general should contribute not more than $3.8 \%$ to the renewable energy target of the EU. The justification for the suggested reduction is that crop-based biofuels are highly inefficient in terms of greenhouse gas emission savings because of ILUC effects.

As part of the EU legislative procedure, the EP voted on the proposed revision in January 2018 and proposed stricter requirements: Palm oil should be excluded from the accounting of gross final consumption of energy from renewable energy sources by 2021, and the overall renewable energy target should be set to $35 \%$. In contrast to the originally proposed RED II by the EC, the EP thereby distinguished palm oil from other crops, referring to the EP resolution on palm oil and deforestation of rainforests. The decision to treat palm oil differently than other crop-based biofuels with high ILUC risk was not clearly justified (European Parliament 2018).

In December 2018, after further consultations and changes, the Council of the EU adopted the revised proposal as Directive (EU) 2018/2001, with an overall renewable energy target of at least $32 \%$ and a biofuel target of at least $14 \%$ for the transport sector. All crop-based biofuels with high ILUC risk - not only palm oil-are to be phased out by 2030. This decision implies the need for a procedure to evaluate ILUC risk. In March 2019, a delegated act was adopted by the EC for the implementation of the RED II. This delegated act, supplemented by a report (European Commission 2019), focuses mainly on the determination of ILUC risk and on the certification of "low ILUC-risk" biofuels, which should still be eligible to count toward the renewable energy targets of the EU. Thereby, discourses on the sustainability of palm oil are complemented by the dichotomy of "high ILUC-risk" versus "low ILUC-risk" biofuels.

According to definitions and a formula for determining high ILUC risk provided in Article 3 and the Annex of the delegated act, currently only palm oil is regarded as "high ILUC-risk" feedstock, while all other crops considered do not exceed the defined thresholds. To qualify as having low ILUC risk, biofuels have to fulfill so-called additionality criteria. These additionality criteria are defined as sustainable measures that lead to a productivity increase, while at the same time being financially attractive. Two relevant exceptions to financial additionality are made: biofuels made from crops produced on previously abandoned land or produced by smallholders. Smallholders are defined as independent producers that own an agricultural area below two hectares. A clear procedure for the certification of "low ILUC-risk" biofuels is still to be published.

\subsection{Reactions to the revised Renewable Energy Directive II}

The revised RED II has been subject of heated political discussions. Particularly the vote by the European Parliament in 2018 to explicitly exclude palm oil from counting toward renewable energy targets has sparked outrage among Southeast Asian producer countries. 
Arguing that the EU unfairly discriminates against palm oil, the government of Indonesia has repeatedly announced to file a complaint with the World Trade Organization (WTO) (Keating 2019; Suroyo and Nangoy 2019), while the Malaysian government has threatened the EU with boycotts against European products (Tan 2019; Reuters 2018a). The Malaysian Minister of Plantation Industries and Commodities described the policy development as a form of "crop apartheid" (Spross 2018; Reuters 2018a). In this regard, he referred to discourses on "green neo-colonialism" and the perception that Europe uses concerns about sustainability as a pretext for supporting their agricultural sectors (Risso and Lim 2010).

Golden Agri-Resources (GAR), one of the world's largest palm oil companies, published a statement in reaction to the EP vote on the draft RED II, claiming that "[b]y excluding only palm oil, the EU treats this oil unfairly compared to other vegetable oils" and that "[...] millions of smallholders [...] will be hardest hit by the EU's decision to phase out palm oil in the biofuels market" (GAR 2017). GAR further warns about the risk of displacement and leakage:

While the EU has the right to pursue policy initiatives to halt deforestation, it also needs to avoid a blunt-instrument approach that will divert commodities and products linked to deforestation to other less discerning and stringent markets. (GAR 2017)

Effectively, the exception for smallholders made in the delegated act to the RED II might be attributed to successful lobbying and the public dissemination of storylines on trade discrimination and smallholder livelihoods by palm oil-producing countries. Still, in the final version of the RED II, palm oil remains the only feedstock classified as "high ILUC-risk". Ongoing diplomatic disputes on palm oil were also one reason why the negotiations on the planned free trade agreement between Indonesia and the European Free Trade Association (EFTA) could not be settled (Reuters 2018b), and why trade relations between the EU and the Association of Southeast Asian Nations (ASEAN) have been impaired (Deringer et al. 2019). Producing countries continue to promote storylines on the "ban on palm oil" (Ooi 2019) and accuse the EU of initiating a "palm oil trade war" (CNA 2019).

But the RED II has not only fueled trade disputes between palm oil-producing countries and the EU. Criticism has also emerged from within the EU, though for other reasons. The European association of farmers and cooperatives (Copa-Cogeca) for instance complained about "loopholes" in the Directive, particularly referring to the exceptions for smallholders (OFI 2019). Also referring to "loopholes", the NGO umbrella organization Transport \& Environment (T\&E) stated that "there is no such thing as green palm oil or soy biodiesel", criticizing also the fact that soy has not been classified as "high ILUC-risk" feedstock in the delegated act (T\&E 2019).

\subsection{Classification of palm oil-related discourses}

To summarize the findings described before, discourses on palm oil in the context of recent European policy development can be categorized by applying Hajer's (1995) ADAA, as shown in Table 1. We focus mainly on the two policies considered, but also take into account the broader context, acknowledging previous research on palm oil-related discourses referred to in the previous sections. The main controversial question is whetherand under which conditions-palm oil is perceived as sustainable. This controversy is reinforced by the complex concept of sustainability and its trade-offs between environmental, economic, and social aspects. We find that storylines on the sustainability of palm oil can be condensed into three main positions. 


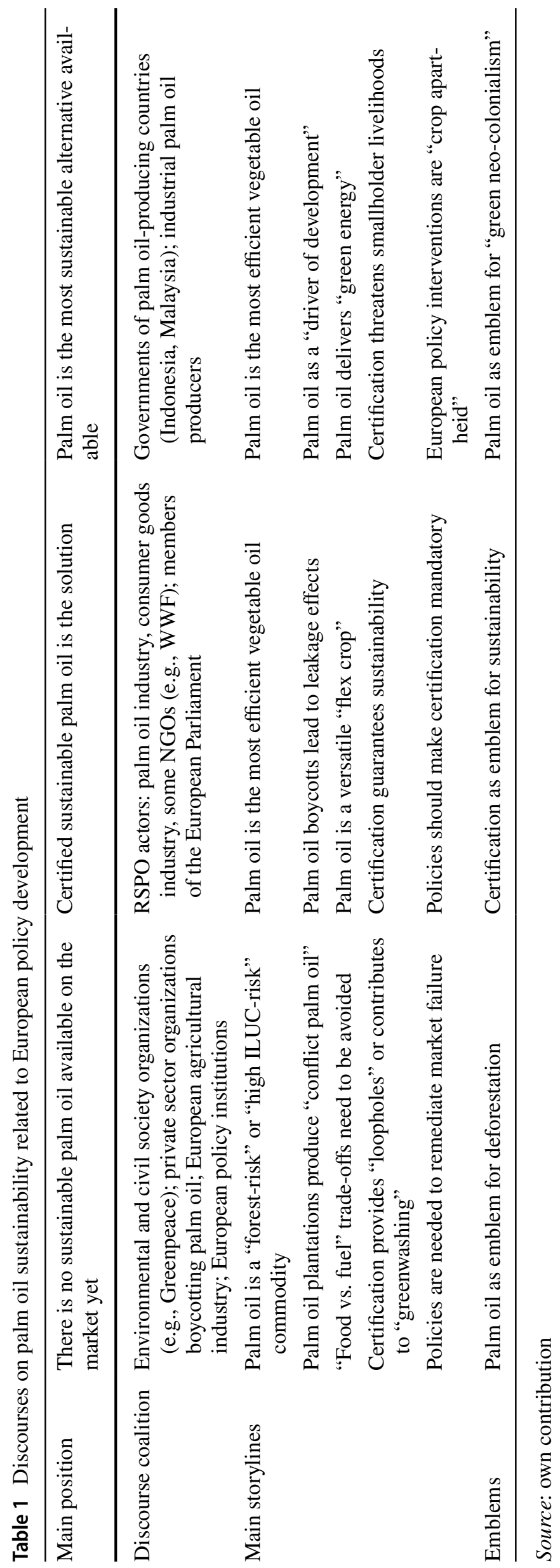


The first position can be subsumed as "there is no sustainable palm oil available on the market yet". Referring to the "mode of production" level, social and environmental conflicts resulting from the expansion of palm oil plantations are emphasized. This position explicitly criticizes existing sustainability certification systems as neither strict nor effective enough. The discourse coalition promoting this position consists for instance of RSPO-critical environmental and human rights NGOs, but also involves private sector organizations promoting palm oil-free products. It is partly reflected in the European Parliament resolution, which refers to different aspects and storylines on palm oil sustainability. A common feature of storylines related to this position is the use of palm oil as an emblem for deforestation linked to agriculture in general. This means that although the expansion of other crops or animal production systems also contributes to the loss of rainforests or other valuable ecosystems, palm oil is the commodity in focus of discourses on deforestation. Going beyond direct deforestation, storylines on ILUC reflected in the RED II can also be classified into this first position. Here, palm oil is generally framed as a "high ILUC-risk" feedstock that should be phased out as biofuel. For certain NGOs as well as European agricultural and biofuel producers, the provisions made in the RED II are not comprehensive or strict enough, as exceptions and the opportunity for "low ILUC-risk" certification would provide "loopholes". This example also illustrates the meaning of discourse coalitions according to Hajer (1995): Different actors support an overarching position to exercise discursive power over opposing positions, but at the same time they might follow different motivations and disseminate different storylines that frame an issue from a certain perspective.

Proponents of the second position acknowledge the adverse effects of industrial palm oil production emphasized by the first discourse coalition. However, they set the institutional level in focus, asserting that "certified sustainable palm oil is the solution" to social and environmental problems. In this regard, certification is used as an emblem for sustainability by using "certified palm oil" as a synonym for "sustainable palm oil". Described by Dauvergne (2018) as "industry narrative", storylines related to this position support ecological modernization, as defined in Sect. 3.1. This discourse coalition mainly consists of members and supporters of the RSPO who also spread positive storylines on palm oil during the EPOC 2017. Again, members of this discourse coalition might follow different agendas and definitions of sustainable palm oil, but they are all pro-certification. While RSPO members emphasize the benefits and achievements of RSPO certification, others agree that certification is the solution, but so far not effectively implemented. This position is reflected in the EP resolution, which calls for the development of a more ambitious and mandatory certification system for the European market. Referring to the prevailing demand gap for certified palm oil (RSPO 2018), this coalition demands to make certification mandatory. It furthermore warns about a boycott of palm oil, referring to the lower efficiency of alternative oils and potential risks of displacement and leakage.

The third position that "palm oil is the most sustainable alternative available" can be regarded as a counter-discourse to the other two positions that both (more or less) criticize unsustainable palm oil production. It is particularly promoted by different governmental institutions of Malaysia and Indonesia, but also by the palm oil industry. According to this discourse coalition that rather refers to the product level of discourses, palm oil is the most efficient alternative, delivers "green energy", and is a "driver of development". Regarding the trade relations with Europe, palm oil is seen as an emblem for "green neo-colonialism", the discourse on exploitation and discrimination of less developed countries by Europe. This discourse coalition claims that the improvement of smallholder livelihoods, employment opportunities, and economic development are valuable benefits of the growing 
market for palm oil. National mandatory certification systems, such as ISPO and MSPO, are promoted as an alternative to the RSPO, which is imposed by the "Global North" and criticized as unfeasible to be implemented by smallholders. Although lobbyism by this discourse coalition has successfully contributed to the development of exception rules for smallholders, the provisions of the RED II are still perceived as unfair and exploitive, as described in the storyline of "crop apartheid".

\section{Discussion and conclusions}

In the pursuit of sustainable development, policymakers in palm oil-producing and palm oil-consuming countries have to deal with trade-offs between environmental conservation, social inclusion, and economic growth. Discursive struggles resulting from diverging perceptions of palm oil sustainability have at first led to the establishment of voluntary private certification systems, particularly the RSPO. But this development has certainly not solved all problems, while discourses on the sustainability of palm oil have been extended to the level of private governance and its legitimacy (e.g., Schouten and Glasbergen 2012). Previous discourse-analytical studies have shown that the industrial mode of production is rather reinforced than challenged by industry-dominated private governance (Dauvergne 2018; Ruysschaert and Salles 2016). On the regulatory side, two major processes have recently started to influence the palm oil sector as well as discourses on the sustainability of palm oil: the development of mandatory standards in palm oil-producing countries (e.g., Astari and Lovett 2019; Hospes 2014), and the development of stricter regulation in the EU as a major importer of palm oil.

Contributing to previous research on palm oil-related discourses, we have analyzed discourses in the context of two major policies: the European Parliament resolution on palm oil and deforestation of rainforests, and the revised RED II of the European Union. Adopting Hajer's argumentative discourse-analytical approach (Hajer 1995), we have structured and aggregated relevant discourses to three main positions, distinguished according to their framing of the sustainability of palm oil:

1. "There is no sustainable palm oil available on the market yet."

2. "Certified sustainable palm oil is the solution."

3. "Palm oil is the most sustainable alternative available."

The EP resolution on palm oil and deforestation of rainforests frames palm oil as "forestrisk commodity," thereby partly referring to flawed data. It contributes to the first position, but also to the second position, as it calls for the introduction of a single, mandatory certification scheme for the European market that should be more ambitious than established private certification systems, which fail to keep their promises. The revised RED II can be associated with the first position, as it aims to phase out palm oil-based biofuel as a contributor to EU renewable energy targets due to high ILUC risk. With the RED II, the discursive "dichotomy of unsustainable and sustainable palm oil" (Dauvergne 2018) has developed into a dichotomy of "high ILUC-risk" and "low ILUC-risk" palm oil in the context of biofuels targeted at the EU market. While the EU policies emphasize adverse effects related to the large-scale, industrial mode of palm oil production, the governments of Indonesia and Malaysia mainly respond in two ways. First, they promote storylines that focus on advantages of palm oil, emphasizing efficiency and livelihood opportunities for 
smallholders. Second, they directly refer to the EU policies by dismissing them as discriminatory, neo-colonial initiatives framed as "crop apartheid". These storylines can be mainly allocated to the third position, although national regulatory efforts to implement mandatory sustainability certification might be linked to the second position.

Although tensions between the EU and palm oil-producing countries have existed and developed for many years, the recent development of European policies has led to an intensification of discursive struggles. We argue that particularly the new regulation on biofuels has added fuel to the fire. Malaysian government officials have repeatedly referred to a "trade war" in this context. Producer countries' rather aggressive, political storylines on neo-colonialism have to be understood in the historical context. In the nineteenth century, Dutch and British colonialists brought the oil palm from Africa to Southeast Asia. The exploitation of workforce for the development and operation of palm oil plantations can be traced back to the colonial period (McCarthy and Cramb 2009). Later, the same European countries that have cleared large areas of their own forested landscapes and contributed to resource exploitation in the former colonies began to impose sustainability standards on products imported from these regions. At the same time, the EU stipulated demand for palm oil-based biofuels based on the provisions made in the original RED, which might also have contributed to "land grabbing" for the expansion of palm oil production (Goldstein 2015). Now with the RED II, the EU sends reversed market signals to producer countries, imposing again stricter sustainability requirements for palm oil.

However, four main points have to be considered with respect to the implications of the RED II: First, the RED II in its final version does not explicitly single out palm oil, although currently only palm oil exceeds the thresholds defined for classification as "high ILUC-risk" biofuel. Second, the RED II only concerns the use of palm oil as biofuel, not the use as an ingredient of food, feed, or oleochemicals. Third, "high ILUC-risk" biofuels are not "banned" from the EU market, but they are just not allowed to be counted toward the renewable energy target anymore and therefore are not eligible for subsidies. Fourth, there are still exceptions to this rule, particularly for smallholders. But these exceptions are still subject to certain conditions that currently seem to be ignored in public discourses. In particular, smallholders are only exempt from complying with the "financial additionality" criterion, but not from complying with requirements with respect to sustainable production, characterized by improved agricultural practices. It remains to be decided how exactly the planned certification for "low ILUC-risk" feedstock shall be implemented.

This discourse analysis has certainly its limitations. Due to its focus on two European policies and related reactions by certain actors, it is clearly limited in scope and scale and mainly tackles the aspects of deforestation, indirect land use change, and certification, while leaving out other relevant concerns and stakeholders. Furthermore, it has to be acknowledged that it is impossible to provide a fully objective view on discourses, as framing also takes place at the level of the analyst. Other researchers would probably have considered other sources or would have interpreted the same material in a different way. The identified three discursive positions on the sustainability of palm oil are aggregated and not unambiguous. Particularly the borders between the first and the second position are not always clearly marked. Nevertheless, we argue that this classification provides a structured overview of storylines promoted by different discourse coalitions. It should be useful for policymakers, researchers, and stakeholders of palm oil value chains, who aim at understanding discursive struggles on palm oil. Thus, this article contributes to closing a relevant research gap by adding important insights on policy discourses to previous discourse-analytical research on palm oil. 
According to projections, the global consumption of palm oil is expected to grow further, particularly in emerging economies of Asia and South America (Oil World 2018; Mielke 2018), while efforts to improve sustainability will probably slow down the growth in production (OECD/FAO 2017). Nevertheless, additional direct and indirect land conversion for palm oil production is expected (Mielke 2018; Vijay et al. 2016; Fitzherbert et al. 2008). It remains to be seen to what extent European policies, in particular the RED II, will have positive effects on the sustainability of the palm oil sector or rather contribute to displacement and leakage.

We recommend that policymakers take storylines on palm oil, their underlying arguments, and potential flaws into account, because this information should facilitate decisions with respect to implementing measures that affect the sustainability of the palm oil sector. Policies should effectively address the problems identified in this discourse analysis and prevent opposing discourse coalitions from taking advantage of "alternative facts" and developing their counter-discourses as an antithesis. It is crucial to ensure that discursive closure is not based on misunderstandings or incorrect data representation.

So far, we have analyzed discourses in the context of certain European policies that concern the consumption of palm oil at a political level and rather deal with the use of palm oil as biofuel. For future research, we aim to focus on the analysis of consumers' attitudes and perceptions toward palm oil, which is also used as an ingredient in many processed products. We regard it crucial to analyze to what extent attitudes and consumption decisions might be influenced by certain storylines on palm oil. Relevant insights into this aspect have been provided for instance by Cova and D'Antone (2016) and D'Antone and Spencer (2015), focusing on French consumers. Further research involving other consumer markets would be useful to gain knowledge on the dissemination of discourses on palm oil at the consumer level, which would be relevant for policymakers, but also for the agri-food industry. In addition, we suggest analyzing discourses on other relevant "forest-risk" commodities, such as soy or cocoa, in order to facilitate a better understanding of the commodityspecific issues that currently might hinder the development of "deforestation-free" supply chains.

\section{Compliance with ethical standards}

Conflict of interest The author declares that he/she has no conflict of interests.

\section{References}

Amsterdam Declaration. (2015b). Towards eliminating deforestation from agricultural commodity chains with European countries. The Hague: Dutch Ministry of Foreign Affairs. Retrieved April 1, 2019, from https://www.euandgvc.nl/binaries/euandgvc/documents/publications/2015/december/7/decla rations/Amsterdam+Declaration+Deforestation+\%26+Agro-commodity+chains.pdf.

Amsterdam Declaration. (2015a). The Amsterdam declaration in support of a fully sustainable palm oil supply chain by 2020. The Hague: Dutch Ministry of Foreign Affairs. Retrieved April 1, 2019, from https ://www.euandgvc.nl/documents/publications/2015/december/7/declarations-palm-oil.

Astari, A. J., \& Lovett, J. C. (2019). Does the rise of transnational governance 'hollow-out' the state? Discourse analysis of the mandatory Indonesian sustainable palm oil policy. World Development, 117, $1-12$. 
Azhar, B., Saadun, N., Prideaux, M., \& Lindenmayer, D. B. (2017). The global palm oil sector must change to save biodiversity and improve food security in the tropics. Journal of Environmental Management, 203(Pt 1), 457-466.

Baron, V., Rival, A., \& Marichal, R. (2017). No, palm oil is not responsible for $40 \%$ of global deforestation. The Conversation. Retrieved April 4, 2018, from https://theconversation.com/no-palm-oil-is-notresponsible-for-40-of-global-deforestation-78482.

Béland, D. (2009). Ideas, institutions, and policy change. Journal of European Public Policy, 16(5), 701-718.

Boons, F., \& Mendoza, A. (2010). Constructing sustainable palm oil: How actors define sustainability. Journal of Cleaner Production, 18(16-17), 1686-1695.

Borras, S. M., Franco, J. C., Isakson, S. R., Levidow, L., \& Vervest, P. (2015). The rise of flex crops and commodities: Implications for research. The Journal of Peasant Studies, 43(1), 93-115.

Brad, A., Schaffartzik, A., Pichler, M., \& Plank, C. (2015). Contested territorialization and biophysical expansion of oil palm plantations in Indonesia. Geoforum, 64, 100-111.

Brandi, C., Cabani, T., Hosang, C., Schirmbeck, S., Westermann, L., \& Wiese, H. (2015). Sustainability standards for palm oil: Challenges for smallholder certification under the RSPO. The Journal of Environment \& Development, 24(3), 292-314.

Brown, S., \& Zarin, D. (2013). Environmental science. What does zero deforestation mean? Science, 342(6160), 805-807.

Byerlee, D., \& Rueda, X. (2015). From public to private standards for tropical commodities: A century of global discourse on land governance on the forest frontier. Forests, 6(4), 1301-1324.

Carlson, K. M., Heilmayr, R., Gibbs, H. K., Noojipady, P., Burns, D. N., Morton, D. C., et al. (2018). Effect of oil palm sustainability certification on deforestation and fire in Indonesia. Proceedings of the National Academy of Sciences of the United States of America, 115(1), 121-126.

Cazzolla Gatti, R., Liang, J., Velichevskaya, A., \& Zhou, M. (2019). Sustainable palm oil may not be so sustainable. The Science of the Total Environment, 652, 48-51.

Cheyns, E. (2011). Multi-stakeholder initiatives for sustainable agriculture: Limits of the 'inclusiveness' paradigm. In S. Ponte, J. Vestergaard, \& P. Gibbon (Eds.), Governing through standards: Origins, drivers and limits (pp. 318-354). London: Palgrave.

Cheyns, E. (2014). Making "minority voices" heard in transnational roundtables: The role of local NGOs in reintroducing justice and attachments. Agriculture and Human Values, 31(3), 439-453.

Chiavari, J. (2013). EU biofuel policies and their implications for Southeast Asia. In O. Pye \& J. Bhattacharya (Eds.), The palm oil controversy in Southeast Asia: A transnational perspective (pp. 199-219). Singapore: ISEAS Publishing.

CNA. (2019). Malaysia minister accuses EU of palm oil 'trade war'. Channel News Asia (CNA). Retrieved July 6, 2019, from https://www.channelnewsasia.com/news/asia/malaysia-minister-accuses-eu-ofpalm-oil-trade-war-11508990?cid=h3_referral_inarticlelinks_24082018_cna.

Colchester, M. (2016). Do commodity certification systems uphold indigenous peoples' rights? Lessons from the Roundtable on Sustainable palm Oil and Forest Stewardship Council. IUCN Policy Matters, 21, 149-165.

Corciolani, M., Gistri, G., \& Pace, S. (2019). Legitimacy struggles in palm oil controversies: An institutional perspective. Journal of Cleaner Production, 212, 1117-1131.

Cotton, M., Rattle, I., \& van Alstine, J. (2014). Shale gas policy in the United Kingdom: An argumentative discourse analysis. Energy Policy, 73, 427-438.

Cova, B., \& D’Antone, S. (2016). Brand iconicity vs. anti-consumption well-being concerns: The Nutella palm oil conflict. Journal of Consumer Affairs, 50(1), 166-192.

D’Antone, S., \& Spencer, R. (2015). Organising for sustainable palm oil consumption: A market-based approach. Consumption Markets \& Culture, 18(1), 55-71.

Dauvergne, P. (2017). Is the power of brand-focused activism rising? The case of tropical deforestation. The Journal of Environment \& Development, 26(2), 135-155.

Dauvergne, P. (2018). The global politics of the business of "sustainable" palm oil. Global Environmental Politics, 18(2), 34-52.

Dauvergne, P., \& Neville, K. J. (2010). Forests, food, and fuel in the tropics: The uneven social and ecological consequences of the emerging political economy of biofuels. The Journal of Peasant Studies, 37(4), 631-660.

Deringer, H., Lee-Makiyama, H., \& Murty, D. (2019). Europe and South-East Asia: Shifting from diplomacy to unilateralism. ECIPE Policy Brief 01/2019. Brussels: European Centre for International Political Economy (ECIPE). Retrieved July 5, 2019, from https://ecipe.org/publications/europe-asiashifting-unilateralism/. 
Donofrio, S., Rothrock, P., \& Leonard, J. (2017). Supply change: Tracking corporate commitments to deforestation-free supply chains. Washington, DC: Forest Trends. Retrieved October 31, 2018, from https ://www.forest-trends.org/wp-content/uploads/2017/03/2017SupplyChange_FINAL.pdf.

Dryzek, J. S. (2005). The politics of the earth: Environmental discourses (2nd ed.). Oxford: Oxford University Press.

Elgert, L. (2012). Certified discourse? The politics of developing soy certification standards. Geoforum, 43(2), 295-304.

EPOA. (2018). The palm oil story. Zoetermeer, the Netherlands: European Palm Oil Alliance (EPOA). Retrieved December 20, from https://www.palmoilandfood.eu/en.

ESPO. (2019). Choosing sustainable palm oil: Progress report on the import and use of sustainable palm oil in Europe. Zoetermeer, the Netherlands: European Sustainable Palm Oil (ESPO) secretariat. Retrieved April 1, 2019, from https://www.idhsustainabletrade.com/publication/choosing-sustainabl e-palm-oil/.

European Commission. (2013). The impact of EU consumption on deforestation. Technical Report. Brussels: European Commission. Retrieved October 12, 2017, from http://ec.europa.eu/environment/fores ts/pdf/1.\%20Report\%20analysis\%20of\%20impact.pdf.

European Commission. (2019). Report from the Commission to the European Parliament, the Council, the European Economic and Social Committee and the Committee of the Regions on the status of production expansion of relevant food and feed crops worldwide. Brussels: European Commission. Retrieved March 13, 2019, from https://eur-lex.europa.eu/legal-content/EN/TXT/?uri=COM:2019:142:FIN.

European Parliament. (2017). European Parliament resolution of 4 April 2017 on palm oil and deforestation of rainforests (2016/2222(INI)). Strasbourg: European Parliament. Retrieved March 13, 2019, from http://www.europarl.europa.eu/sides/getDoc.do?type=TA\&reference=P8-TA-2017-0098\&langu age $=$ EN\&ring $=$ A8-2017-0066.

European Parliament. (2018). Amendments adopted by the European Parliament on 17 January 2018 on the proposal for a directive of the European Parliament and of the Council on the promotion of the use of energy from renewable sources (recast) (COM(2016)0767-C8-0500/2016-2016/0382(COD)). Strasbourg: European Parliament. Retrieved July 4, 2019, from http://www.europarl.europa.eu/doceo/ document/TA-8-2018-0009_EN.html.

Fargione, J., Hill, J., Tilman, D., Polasky, S., \& Hawthorne, P. (2008). Land clearing and the biofuel carbon debt. Science, 319(5867), 1235-1238.

Feindt, P. H., \& Oels, A. (2005). Does discourse matter? Discourse analysis in environmental policy making. Journal of Environmental Policy \& Planning, 7(3), 161-173.

Ferns, G., \& Amaeshi, K. (2017). Struggles at the summits: Discourse coalitions, field boundaries, and the shifting role of business in sustainable development. Business and Society, 20, 000765031770188.

Fitzherbert, E. B., Struebig, M. J., Morel, A., Danielsen, F., Brühl, C. A., Donald, P. F., et al. (2008). How will oil palm expansion affect biodiversity? Trends in Ecology \& Evolution, 23(10), 538-545.

GAR. (2017). GAR Statement on ENVI Committee Decision to exclude palm oil from EU biofuels. Singapore: Golden Agri-Resources Ltd. (GAR). Retrieved October 28, 2018, from https://goldenagri.com. sg/wp-content/uploads/2017/10/GAR-Statement-on-ENVI-Committee-Decision-to-exclude-palm-oilfrom-EU-biofuels.pdf.

Gaveau, D. L. A., Sheil, D., Husnayaen, Salim, M. A., Arjasakusuma, S., Ancrenaz, M., et al. (2016). Rapid conversions and avoided deforestation: Examining four decades of industrial plantation expansion in Borneo. Scientific Reports, 6, 32017.

Giam, X., Mani, L., Koh, L. P., \& Tan, H. T. W. (2016). Saving tropical forests by knowing what we consume. Conservation Letters, 9(4), 267-274.

Glasbergen, P. (2018). Smallholders do not eat certificates. Ecological Economics, 147, 243-252.

Goldstein, J. E. (2015). Knowing the subterranean: Land grabbing, oil palm, and divergent expertise in Indonesia's peat soil. Environment and Planning A, 48(4), 754-770.

Guillaume, T., Kotowska, M. M., Hertel, D., Knohl, A., Krashevska, V., Murtilaksono, K., et al. (2018). Carbon costs and benefits of Indonesian rainforest conversion to plantations. Nature Communications, 9(1), 2388.

Hajer, M. A. (1995). The politics of environmental discourse: Ecological modernization and the policy process. Oxford: Oxford University Press.

Hajer, M., \& Versteeg, W. (2005). A decade of discourse analysis of environmental politics: Achievements, challenges, perspectives. Journal of Environmental Policy \& Planning, 7(3), 175-184.

Hansmann, R., Mieg, H. A., \& Frischknecht, P. (2012). Principal sustainability components: Empirical analysis of synergies between the three pillars of sustainability. International Journal of Sustainable Development and World Ecology, 19(5), 451-459. 
Henders, S., \& Ostwald, M. (2014). Accounting methods for international land-related leakage and distant deforestation drivers. Ecological Economics, 99, 21-28.

Henders, S., Persson, U. M., \& Kastner, T. (2015). Trading forests: Land-use change and carbon emissions embodied in production and exports of forest-risk commodities. Environmental Research Letters, 10(12), 125012.

Hospes, O. (2014). Marking the success or end of global multi-stakeholder governance? The rise of national sustainability standards in Indonesia and Brazil for palm oil and soy. Agriculture and Human Values, 31(3), 425-437.

Hunsberger, C., \& Alonso-Fradejas, A. (2016). The discursive flexibility of 'flex crops': Comparing oil palm and jatropha. The Journal of Peasant Studies, 43(1), 225-250.

Jiwan, N. (2013). The political ecology of the Indonesian palm oil industry: A critical analysis. In O. Pye \& J. Bhattacharya (Eds.), The palm oil controversy in Southeast Asia: A transnational perspective (pp. 48-75). Singapore: ISEAS Publishing.

Karlsen, A. (2018). Framing industrialization of the offshore wind value chain-A discourse approach to an event. Geoforum, 88, 148-156.

Keating, D. (2019). EU labels biofuel from palm oil as unsustainable, bans subsidies. Forbes. Retrieved July 5, 2019, from https://www.forbes.com/sites/davekeating/2019/03/14/eu-labels-biofuel-from-palm-oilas-unsustainable-bans-subsidies/.

Koh, L. P., \& Wilcove, D. S. (2008). Is oil palm agriculture really destroying tropical biodiversity? Conservation Letters, 1(2), 60-64.

Langhelle, O. (2000). Why ecological modernization and sustainable development should not be conflated. Journal of Environmental Policy \& Planning, 2(4), 303-322.

Larsen, R. K., Osbeck, M., Dawkins, E., Tuhkanen, H., Nguyen, H., Nugroho, A., et al. (2018). Hybrid governance in agricultural commodity chains: Insights from implementation of 'No Deforestation, No Peat, No Exploitation' (NDPE) policies in the oil palm industry. Journal of Cleaner Production, 183, 544-554.

Lee, J. S. H., Abood, S., Ghazoul, J., Barus, B., Obidzinski, K., \& Koh, L. P. (2014). Environmental impacts of large-scale oil palm enterprises exceed that of smallholdings in Indonesia. Conservation Letters, $7(1), 25-33$.

McCarthy, J. F., \& Cramb, R. A. (2009). Policy narratives, landholder engagement, and oil palm expansion on the Malaysian and Indonesian frontiers. The Geographical Journal, 175(2), 112-123.

McCarthy, J. F., Vel, J. A. C., \& Afiff, S. (2012). Trajectories of land acquisition and enclosure: Development schemes, virtual land grabs, and green acquisitions in Indonesia's Outer Islands. The Journal of Peasant Studies, 39(2), 521-549.

Mielke, T. (2018). World markets for vegetable oils and animal fats: Dynamics of global production, trade flows, consumption and prices. In M. Kaltschmitt \& U. Neuling (Eds.), Biokerosene: Status and prospects (pp. 147-188). Berlin: Springer.

Miettinen, J., Shi, C., \& Liew, S. C. (2016). Land cover distribution in the peatlands of Peninsular Malaysia, Sumatra and Borneo in 2015 with changes since 1990. Global Ecology and Conservation, 6, 67-78.

Moreno-Peñaranda, R., Gasparatos, A., Stromberg, P., Suwa, A., Pandyaswargo, A. H., \& Puppim de Oliveira, J. A. (2015). Sustainable production and consumption of palm oil in Indonesia: What can stakeholder perceptions offer to the debate? Sustainable Production and Consumption, 4, 16-35.

MPOC. (2018). $\mathrm{CO}_{2}$ removal through oil palm plantations contributes significantly to Malaysia's carbon sink status. Petaling Jaya, Malaysia: Malaysian Palm Oil Council (MPOC). Retrieved December 20, 2018, from http://www.mpoc.org.my/CO2_Removal_Through_Oil_Palm_Plantations_Contributes_ Significantly_to_Malaysia's_Carbon_Sink_Status.aspx.

Nangoy, F., \& Jensen, F. (2018). Indonesia bets big on biodiesel to limit costs of oil imports. Reuters. Retrieved June 25, 2019, from https://www.reuters.com/article/us-indonesia-biodiesel/indonesia-betsbig-on-biodiesel-to-limit-costs-of-oil-imports-idUSKBN1KS0CC.

Neeff, T., \& Linhares-Juvenal, T. (2017). Zero deforestation initiatives and their impacts on commodity supply chains: Discussion paper prepared for the 57th Session of the FAO Advisory Committee on Sustainable Forest-based Industries. Rome: Food and Agriculture Organization of the United Nations (FAO). Retrieved November 1, 2018, from http://www.fao.org/3/a-i6857e.pdf.

NYDF. (2014). New York declaration on forests: Declaration and action agenda. New York City, NY: United Nations Development Programme (UNDP). Retrieved December 18, 2018, from http://www. undp.org/content/dam/undp/library/Environment\%20and\%20Energy/Forests/New\%20York\%20Dec laration\%20on\%20Forests_DAA.pdf.

Ockwell, D. G., \& Rydin, Y. (2010). Analysing dominant policy perspectives-The role of discourse analysis. In D. G. Ockwell \& J. C. Lovett (Eds.), A handbook of environmental management (pp. 168-197). Cheltenham: Edward Elgar Pub. Ltd. 
OECD/FAO. (2017). OECD-FAO agricultural outlook 2017-2026. Paris: OECD Publishing. Retrieved January 22, 2019, from http://www.fao.org/3/a-i7465e.pdf.

OFI. (2019). EC delegated act classifies palm oil as unsustainable but leaves 'loopholes'. Redhill, UK: Oils \& Fats International (OFI). Retrieved July 6, 2019, from https://www.ofimagazine.com/news/ec-deleg ated-act-classifies-palm-oil-as-unsustainable-but-leaves-loopholes.

Oil World. (2018). Oil world annual 2018. Hamburg: ISTA Mielke GmbH.

Ooi, T. C. (2019). Indonesia and Malaysia unite to fight EU's ban on palm oil. New Straits Times. Retrieved July 6, 2019, from https://www.nst.com.my/business/2019/04/477092/indonesia-and-malaysia-unite -fight-eus-ban-palm-oil.

Oosterveer, P. (2015). Promoting sustainable palm oil: Viewed from a global networks and flows perspective. Journal of Cleaner Production, 107, 146-153.

Orsato, R. J., Clegg, S. R., \& Falcão, H. (2013). The political ecology of palm oil production. Journal of Change Management, 13(4), 444-459.

Othman, J. B., Houston, J. E., \& Mclntosh, C. S. (1993). Health issue commodity promotion. Food Policy, 18(3), 214-223.

Pacheco, P., \& Komarudin, H. (2017). Implementing commitments in the Indonesian palm oil sector. In ETFRN (Ed.), Zero deforestation: A commitment to change. ETFRN News (Vol. 58, pp. 184-190). Wageningen.

Pirard, R., Fishman, A., Gnych, S., Obidzinski, K., \& Pacheco, P. (2015). Deforestation-free commitments: The challenge of implementation-An application to Indonesia. Working Paper. Bogor, Indonesia: Center for International Forestry Research (CIFOR). Retrieved November 26, 2018, from http://www. cifor.org/publications/pdf_files/WPapers/WP181Pirard.pdf.

Press Club Brussels Europe. (2018). The social and environmental impacts of EU palmoil policies. Brussels: Press Club Brussels Europe. Retrieved December 20, 2018, from https://www.pressclub. be/event/the-social-and-environmental-impacts-of-eu-palmoil-policies/.

Pye, O. (2019). Commodifying sustainability: Development, nature and politics in the palm oil industry. World Development, 121, 218-228.

Rainforest Action Network. (2013). Conflict palm oil: How U.S. snack food brands are contributing to orang utan extinction, climate change and human rights violations. San Francisco, CA: Rainforest Action Network. Retrieved December 17, 2018, from https://www.ran.org/conflict_palm_oil/.

Republic of Indonesia. (2016). First nationally determined contribution: Republic of Indonesia. Bonn, Germany: United Nations Framework Convention on Climate Change (UNFCCC) Secretariat. Retrieved June 25, 2019, from https://www4.unfccc.int/sites/ndcstaging/PublishedDocuments/ Indonesia\%20First/First\%20NDC\%20Indonesia_submitted\%20to\%20UNFCCC\%20Set_Novem ber\%20\%202016.pdf.

Reuters. (2018a). European move to ban palm oil from biofuels is 'crop apartheid'-Malaysia. Reuters. Retrieved December 20, 2018, from https://www.reuters.com/article/malaysia-palmoil-eu/europ ean-move-to-ban-palm-oil-from-biofuels-is-crop-apartheid-malaysia-idUSL3N1PD1NJ.

Reuters. (2018b). Indonesia, EFTA sign long delayed free trade deal. Reuters. Retrieved December 20, 2018, from https://www.reuters.com/article/us-indonesia-efta-trade/indonesia-efta-sign-long-delay ed-free-trade-deal-idUSKBN1OF0EU.

Richardson, T. (1996). Foucauldian discourse: Power and truth in urban and regional policy making. European Planning Studies, 4(3), 279-292.

Risso, S., \& Lim, K. Y. (2010). Counting the cost of palm oil. Politico. Retrieved January 2, 2019, from https://www.politico.eu/article/counting-the-cost-of-palm-oil/.

Rival, A., \& Levang, P. (2014). Palms of controversies: Oil palm and development challenges. Bogor, Indonesia: Center for International Forestry Research (CIFOR). Retrieved November 6, 2018, from hhttps://www.cifor.org/library/4860/.

Roth, A., Riegel, F., \& Batteiger, V. (2018). Potentials of biomass and renewable energy: The question of sustainable availability. In M. Kaltschmitt \& U. Neuling (Eds.), Biokerosene: Status and prospects (pp. 95-122). Berlin: Springer.

RSPO. (2018). RSPO impact report 2018. Kuala Lumpur: Roundtable on Sustainable Palm Oil (RSPO). Retrieved March 22, 2019, from https://rspo.org/resources/rspo-reports/impact-reports.

Ruysschaert, D. (2016). The impact of global palm oil certification on transnational governance, human livelihoods and biodiversity conservation. IUCN Policy Matters, 21, 45-58.

Ruysschaert, D., \& Salles, D. (2014). Towards global voluntary standards: Questioning the effectiveness in attaining conservation goals. Ecological Economics, 107, 438-446.

Ruysschaert, D., \& Salles, D. (2016). The strategies and effectiveness of conservation NGOs in the global voluntary standards: The case of the Roundtable on Sustainable Palm Oil. Conservation and Society, 14(2), 73. 
Schmidt, V. A. (2008). Discursive institutionalism: The explanatory power of ideas and discourse. Annual Review of Political Science, 11(1), 303-326.

Schmidt, V. A. (2010). Analyzing ideas and tracing discursive interactions in institutional change: From historical institutionalism to discursive institutionalism. Paper prepared for presentation for the panel: "Ideas, Power and Public Policy". Washington, DC: Annual Meetings of the American Political Science Association, Sept. 2-5, 2010. Retrieved May 14, 2019, from https://ssrn.com/ abstract $=1642947$.

Schouten, G., \& Glasbergen, P. (2011). Creating legitimacy in global private governance: The case of the Roundtable on Sustainable Palm Oil. Ecological Economics, 70(11), 1891-1899.

Schouten, G., \& Glasbergen, P. (2012). Private multi-stakeholder governance in the agricultural market place: An analysis of legitimization processes of the Roundtables on Sustainable Palm Oil and Responsible Soy. International Food and Agribusiness Management Review, 15(Special Issue B), 63-88.

Sharp, L., \& Richardson, T. (2001). Reflections on Foucauldian discourse analysis in planning and environmental policy research. Journal of Environmental Policy \& Planning, 3(3), 193-209.

Soini, K., \& Birkeland, I. (2014). Exploring the scientific discourse on cultural sustainability. Geoforum, $51,213-223$.

Spross, H. (2018). Does EU biofuel deal compromise the environment for trade with Southeast Asia? Deutsche Welle. Retrieved December 23, 2018, from, https://p.dw.com/p/305XJ.

Stattman, S., Gupta, A., Partzsch, L., \& Oosterveer, P. (2018). Toward sustainable biofuels in the European Union? Lessons from a decade of hybrid biofuel governance. Sustainability, 10(11), 4111.

Suroyo, G., \& Nangoy, F. (2019). Indonesia to challenge 'discriminative' EU directive on palm oil. Reuters. Retrieved July 5, 2019, from https://www.reuters.com/article/us-indonesia-eu-palmoil-idUSK CN1PP0VW.

Susanti, A., \& Maryudi, A. (2016). Development narratives, notions of forest crisis, and boom of oil palm plantations in Indonesia. Forest Policy and Economics, 73, 130-139.

T\&E. (2019). Palm oil is not a green fuel, says EU. Brussels: Transport \& Environment (T\&E). Retrieved July 6, 2019, from https://www.transportenvironment.org/news/palm-oil-not-green -fuel-says-eu.

Tan, T. (2019). Stop palm oil discrimination. The Star. Retrieved July 5, 2019, from https://www.thest ar.com.my/news/nation/2019/03/21/stop-palm-oil-discrimination/.

Valin, H., Peters, D., van den Berg, M., Frank, S., Havlik, P., Forsell, N., et al. (2015). The land use change impact of biofuels consumed in the EU: Quantification of area and greenhouse gas impacts. Utrecht, The Netherlands: ECOFYS Netherlands B.V. Retrieved February 22, 2018, from https://ec.europa.eu/ energy/sites/ener/files/documents/Final\%20Report_GLOBIOM_publication.pdf.

Varkkey, H. (2013). Patronage politics, plantation fires and transboundary haze. Environmental Hazards, 12(3-4), 200-217.

Vijay, V., Pimm, S. L., Jenkins, C. N., \& Smith, S. J. (2016). The impacts of oil palm on recent deforestation and biodiversity loss. PLOS ONE, 11(7), e0159668.

Wijaya, A., \& Glasbergen, P. (2016). Toward a new scenario in agricultural sustainability certification? The response of the Indonesian national government to private certification. The Journal of Environment \& Development, 25(2), 219-246.

Wolf, V., Dehoust, J., \& Banse, M. (2018). World markets for cereal crops: Global trends for production, consumption, trade and prices. In M. Kaltschmitt \& U. Neuling (Eds.), Biokerosene: Status and prospects (pp. 123-145). Berlin: Springer.

WWF. (2016a). Auf der Ölspur: Berechnungen zu einer palmölfreieren Welt. Berlin: World Wide Fund for Nature (WWF) Germany. Retrieved November 4, 2017, from http://www.wwf.de/fileadmin/fm-wwf/ Publikationen-PDF/WWF-Studie_Auf_der_OElspur.pdf.

WWF. (2016b). Deforestation-free supply chains-Concepts and implications. Berlin: World Wide Fund for Nature (WWF) Germany. Retrieved November 4, 2017, from https://mobil.wwf.de/fileadmin/fmwwf/Publikationen-PDF/WWF-Study_Deforestation-Free_Supply_Chains.pdf.

Yogeesvaran, K. (2017). Speech by secretary general, ministry of plantation industries and commodities. European Palm Oil Conference 2017. Solvay Library, Brussels. Zoetermeer, the Netherlands: European Palm Oil Alliance (EPOA). Retrieved December 20, 2018, from https://www.palmoilandfood. eu/sites/default/files/02.\%20Keynote\%20address $\% 20$ by $\% 20$ Secretary $\% 20$ General $\% 2$ C $\% 20 \mathrm{MPIC} \% 20$ for\%20EPOC\%202017.pdf.

Publisher's Note Springer Nature remains neutral with regard to jurisdictional claims in published maps and institutional affiliations. 


\subsection{Consumer attitudes toward palm oil: Insights from focus group discussions}

Cordula Hinkes, Inken Christoph-Schulz

Journal of Food Products Marketing (2019), 25(9): 875-895.

DOI: https://doi.org/10.1080/10454446.2019.1693468

Due to Taylor \& Francis' academic embargo (18 months from the date of publication), permission has been granted to include the "Original Manuscript" version of this article (before peer-review). As a minor revision was performed after peer-review, there are minor differences between the "Original Manuscript" version and the published "Version of Record". ${ }^{17}$

The final version (Version of Record) published by Taylor \& Francis Group in Journal of Food Products Marketing on November 20, 2019 is available online:

https://doi.org/10.1080/10454446.2019.1693468.

\section{Declaration of originality:}

The semi-structured questioning route used in the focus group discussions was developed by the author and revised by the co-author Dr. Inken Christoph-Schulz. The participants of the focus groups were recruited by an external market research agency. The face-to-face focus group discussions were jointly planned by the author and Dr. Inken Christoph-Schulz. Three of four faceto-face focus group discussions were jointly moderated by the author and Dr. Inken ChristophSchulz; the fourth was jointly moderated by the author and Dr. Anja-Karolina Rovers. The four online focus group discussions were planned and conducted by the author. The analysis of the resulting material was performed by the author and discussed with Dr. Inken Christoph-Schulz. The manuscript was written by the author and reviewed by Dr. Inken Christoph-Schulz.

\footnotetext{
${ }^{17}$ In addition, two editorial changes have been implemented. The expression "palm oil-free" has been changed to "palm-oil-free" throughout the manuscript for reasons of consistency, and one duplicate sentence that had been overlooked in the revision process has been deleted.
} 


\title{
Consumer attitudes toward palm oil: Insights from focus group discussions
}

Cordula Hinkes $^{\mathrm{a} *}$ and Inken Christoph-Schulz ${ }^{\mathrm{a}}$

${ }^{a}$ Thuenen Institute of Market Analysis, Bundesallee 63, 38116 Braunschweig, Germany

*corresponding author

e-mail: cordula.hinkes@thuenen.de

\begin{abstract}
Palm oil is an ingredient of many food products. Despite its advantages, palm oil has been associated with adverse environmental, social, and health effects. The Roundtable on Sustainable Palm Oil (RSPO) promotes certified sustainable palm oil, but demand for RSPO-certified palm oil is relatively low. To gain insights into consumer attitudes with respect to palm oil, we conducted online and face-to-face focus group discussions in Germany. Results indicate knowledge gaps and predominantly negative attitudes toward palm oil. Products without palm oil seem to be preferred over products that contain RSPO-certified palm oil. But palm oil is not among the most important factors affecting consumption decisions, and the majority of discussants were uninformed about alternatives to palm oil. Consumers need reliable and easily accessible information on palm oil and certification systems. "Palm-oil-free" labels might attract concerned consumers. However, replacing palm oil with less efficient alternatives might counteract sustainable development goals.
\end{abstract}

Keywords attitude, certification, focus group, palm oil, sustainability

\section{Introduction}

Produced mainly in Indonesia and Malaysia, palm oil ${ }^{18}$ is the most consumed vegetable oil globally (Oil World, 2018). Palm oil has important advantages over other vegetable oils: it is cheap, most efficient in terms of yield per hectare, and highly versatile (Rival \& Levang, 2014; WWF, 2016). The largest share is used for cooking and as ingredient of food and feed, followed by industrial use for cosmetics, detergents and cleaning products. The use for bioenergy is relatively small, but

\footnotetext{
${ }^{18}$ Two different oils are derived from the fruits of the oil palm: palm kernel oil is obtained from crushing the kernel, and palm oil is extracted from the pulp. Composition and uses are different, but discourses on palm oil usually do not distinguish between the two. Therefore, "palm oil" is used as an umbrella term for both oils in this article.
} 
growing (Oil World, 2018; WWF, 2016). Despite its advantages, palm oil has become a subject of controversial discussions on health issues and sustainability.

Concerning health issues, palm oil is rich in saturated fatty acids whose consumption might be linked to increased risk of cardiovascular disease, although there is still no clear evidence for such effects (Chowdhury et al., 2014; Rival \& Levang, 2014). In contrast to alternative oils, palm oil does not need to get hydrogenated for further processing. Hydrogenation leads to the formation of trans fatty acids, whose consumption is associated with increased health risks (Rival \& Levang, 2014; WHO, 2015). With respect to sustainability, land-use change for palm oil plantations has been associated with deforestation of rainforests, biodiversity loss, and resulting negative effects on climate and the environment (Carlson et al., 2012; Guillaume et al., 2018; Koh \& Wilcove, 2008; Oosterveer, 2015; Rival \& Levang, 2014). Moreover, socio-economic problems related to smallholder livelihoods, exploitation of workers, and land tenure conflicts have been identified (Byerlee \& Rueda, 2015; Goldstein, 2015; Moreno-Peñaranda et al., 2015; Pye, 2019). To improve this situation, the Roundtable on Sustainable Palm Oil (RSPO) has developed voluntary certification systems including social and environmental standards for palm oil production. However, the effectiveness of this initiative is still being questioned (Colchester, 2016; Dauvergne, 2018; Oosterveer, 2015).

The European Union (EU) is the second largest importer of palm oil, after India (Oil World, 2018). Acknowledging responsibility for deforestation associated with agricultural commodities consumed in Europe, two "Amsterdam Declarations" have been signed by the governments of several European countries in 2015. One declaration sets the target to source only sustainable palm oil by 2020 , while the other one aims at ending deforestation related to certain agricultural supply chains by 2020 . In 2017 , around $74 \%$ of palm oil for food imported into Europe were certified according to RSPO standards (ESPO, 2019). However, the demand for certified sustainable palm oil is still far below supply: The global uptake rate of RSPO-certified palm oil was around 52\% in 2017 (RSPO, 2018). This means that a significant part could not be sold as certified palm oil. This gap might be explained by a lack of willingness to pay a premium for certified palm oil.

For policymakers, supply chain actors and marketers it is important to improve the understanding of potential demand side barriers that hinder a sustainable development of the palm oil sector. If demand continues to lag behind supply, sustainability initiatives like the RSPO might fail. Concerned consumers might exert pressure on companies by choosing products that contain certified sustainable palm oil (D'Antone \& Spencer, 2015; Larsen et al., 2018; Raynaud et al., 2016). However, RSPO labels are sometimes not attached to certified products, as they make consumers aware of undesired palm oil content (Larsen et al., 2018). Since the implementation of 
EU Regulation (1169/2011) on the provision of food information to consumers in December 2014, the list of ingredients of food products sold within the EU has to specify the type of vegetable oils used. Before, palm oil was usually hidden under the common umbrella of "vegetable oils" (Riganelli \& Marchini, 2017). Reacting to negative public discourses on palm oil, some European retailers, such as REWE in Austria and Iceland in the United Kingdom, have recently decided to ban palm oil for their own-brand products (Iceland Foods Ltd., 2018; REWE Group, 2017). "Palmoil-free" claims are increasingly attached to food and non-food products to increase consumer awareness.

Several standardized, quantitative studies have analyzed consumer attitudes and preferences for palm oil so far. In Singapore, Giam et al. (2016) identified a premium WTP of 8.29.9\% for certified sustainable palm oil. In the United Kingdom, Bateman et al. (2010) found that the WTP for certified sustainable palm oil depends on the product quality and the level of information provided. Ostfeld et al. (2019) conducted an online survey with British consumers. Only five percent of respondents indicated to know the RSPO label. In France, Disdier et al. (2013) applied an experimental auction approach to quantify WTP for palm oil versus alternative oils. They found that additional information provided to consumers affects their preferences. Hartmann et al. (2018) found that consumers considered products with "palm-oil-free" labels healthier than unlabeled products. Verneau et al. (2019) identified health concerns as the main factor that motivates consumers to avoid palm oil, while environmental concerns were also relevant. A discrete choice experiment conducted by Gassler and Spiller (2018) is the only relevant study conducted in Germany to date. The authors identified significant preferences for RSPOcertified palm oil. However, the study did not involve any product options without palm oil, except for a generic "no choice" option.

Overall, a lack of detailed, qualitative research on these issues has been identified. Aguiar et al. (2018) conducted means-end laddering interviews and found that palm oil was positively perceived as a natural product because it is free of trans fatty acids. The overall awareness of palm oil as a product ingredient was low, though. The present study aims to find out which attitudes consumers in Germany express toward palm oil, and which factors might influence consumers' preferences. Are consumers concerned about palm oil as an ingredient, or does palm oil not have any influence on consumption decisions? Do consumers rather prefer products that contain certified sustainable palm oil, or rather products without palm oil? To answer these questions, an exploratory qualitative analysis of online and face-to-face focus group discussions with consumers in Germany has been conducted. 


\section{Methodology, methods and data}

\subsection{Theoretical framework on certification and preferences}

Sustainability is a so-called "credence quality" (Darby \& Karni, 1973): For consumers, it is impossible to assess the sustainability of certain product ingredients, even after they have purchased and consumed the product. Certification labels attached to products might reduce this information asymmetry by converting sustainability into a "search quality" (Darby \& Karni, 1973; Thøgersen et al., 2010). Several conceptual frameworks explain relevant factors determining whether consumers pay attention to sustainability labels and adopt them in a purchase situation (Grunert et al., 2014; Thøgersen, 2000; Thøgersen et al., 2010). According to these models, consumers consciously purchase products with a sustainability label only if they are motivated. They need to be concerned about sustainability issues and strive for sustainable development. Moreover, they need to be convinced that purchasing certified sustainable products contributes to achieving this goal.

Additional motivational and perceptional factors are required for consumers to pay attention to respective labels in a purchase situation. One relevant factor is perceived consumer effectiveness (PCE): consumers need to be convinced that they are able to make a difference with their consumption decisions. Moreover, they need to trust the respective certification systems. Trust is influenced by knowledge and understanding of sustainability and of the respective labels and certification requirements. Previous positive or negative experience with other labels might also influence trust. Motivation, knowledge as well as availability of certified products influence each other and determine awareness to labels in the purchase situation. Finally, paying attention to labeled products is a necessary, but not sufficient condition for the actual purchase decision. Several previous studies have identified a gap between attitudes toward sustainability and actual purchase behavior that may result from different barriers (e.g., Grunert, 2011; Grunert et al., 2014; Thøgersen, 2000; Thøgersen et al., 2010; Young et al., 2009). Among these barriers are: time and cognitive effort required, product price, lack of information, misinterpretation, and trade-offs with other priorities affecting the purchase decision. Qualitative research methods may be used to gain insights into decision-relevant factors for a given research question.

\subsection{Face-to-face and online focus group discussions}

Focus group discussions (FGDs) are a suitable data collection method for exploratory analyses. FGDs are useful to gain insights into a broad range of opinions. They can be implemented at relatively low costs and provide the opportunity to study group interaction (Finch \& Lewis, 2003; Gaiser, 2008). As a qualitative method, FGDs are not suitable to extrapolate findings to the 
population of interest in general (Barrios \& Costell, 2004; Palinkas et al., 2015). However, they may be used to develop and refine research hypotheses that might then be tested with quantitative methods (Johnson et al., 2007; Kuckartz, 2014). FGDs have been used in several previous exploratory studies on consumer attitudes and preferences with respect to food (e.g., Barrios \& Costell, 2004; Velema et al., 2019), particularly considering aspects of food sustainability (e.g., Macdiarmid et al., 2016), or perceptions of sustainability labels (e.g., Sirieix et al., 2013).

For this study both synchronous, text-based online FGDs and face-to-face FGDs were conducted in order to exploit advantages of the two methodologies. The synchronous chat format allows participants to comment simultaneously (Gaiser, 2008; Lamnek, 2010). Participants from different locations can join online FGDs without incurring any travel costs. Moreover, the lack of direct face-to-face interaction in text-based online FGDs creates "psychological distance" (Reid \& Reid, 2005). Conformity pressure and resulting social desirability bias might thereby be reduced (Lamnek, 2010). Major weaknesses of online FGDs are comparatively short answers, conversation threading, the lack of visual cues, and the lack of control of the environment. Detailed information on advantages and disadvantages of online and face-to-face FGDs are for instance provided by Gaiser (2008), Lamnek (2010), Reid and Reid (2005), Schneider et al. (2002), as well as Stewart and Shamdasani (2017).

\section{Implementation and analysis}

\subsection{Sample selection}

Considering empirical guidance by Guest et al. (2017) on the required number of focus groups, it was decided to implement four online FGDs, followed by four face-to-face FGDs. In line with methodological suggestions (Barbour, 2007; Finch \& Lewis, 2003), each face-to-face focus group should comprise four to eight discussants. Due to the synchronous discussion format, online FGDs can be implemented with more participants, thereby compensating for shorter and less detailed comments (Lamnek, 2010; Oringderff, 2004; Schneider et al., 2002). Participants for both online and face-to-face FGDs were recruited and incentivized by a market research institute. Aiming to collect a diverse range of opinions, a purposeful sampling strategy was applied to achieve a relatively heterogeneous participant structure (Gaiser, 2008; Palinkas et al., 2015). In order to cover different geographic areas in Germany, each online focus group should include at least one participant from the geographical North, South, West and East, respectively. ${ }^{19}$

\footnotetext{
${ }^{19}$ The geographic areas were defined according to federal states.

North: Schleswig-Holstein, Mecklenburg-Vorpommern, Bremen, Lower Saxony, Hamburg;

East: Brandenburg, Berlin, Saxony-Anhalt, Thuringia, Saxony; South: Baden-Württemberg, Bavaria; West: North Rhine-Westphalia, Hesse, Rhineland-Palatinate, Saarland.
} 
Two screening questions were used to assess involvement with respect to product ingredients and sustainability. On a 5-point Likert scale (1: never; 5: always), potential participants had to rate how often they read the list of ingredients when they shop for groceries. Moreover, they were asked how important they regard sustainability in the context of food (1: not important at all; 5: very important). Overall, the sample involved 66 participants, thereof 47 in online focus groups (10-13 participants per group) and 19 in face-to-face focus groups (4-6 participants per group). Variations in group size between groups of the same type resulted from over-recruitment and last-minute cancellations. Table 1 shows the participant characteristics.

Table 1. Characteristics of the focus group participants

\begin{tabular}{|c|c|c|c|}
\hline & & Online focus groups & $\begin{array}{c}\text { Face-to-face focus } \\
\text { groups }\end{array}$ \\
\hline & & $(n=47)$ & $(n=19)$ \\
\hline \multirow[t]{2}{*}{ Sex } & male & 32 & 9 \\
\hline & female & 15 & 10 \\
\hline \multirow[t]{2}{*}{ Age } & mean & 47.2 & 42.3 \\
\hline & range & $19-65$ & $18-64$ \\
\hline \multirow[t]{4}{*}{ Employment status } & full-time & 26 & 11 \\
\hline & part-time & 8 & 6 \\
\hline & retired & 3 & 1 \\
\hline & Other & 10 & 1 \\
\hline Involvement & ingredients & 3.47 & 4.05 \\
\hline (mean) & sustainability & 3.98 & 4.26 \\
\hline \multirow[t]{4}{*}{ Geographic distribution } & North & 11 & \\
\hline & East & 18 & \\
\hline & South & 5 & \\
\hline & West & 13 & \\
\hline
\end{tabular}

\subsection{Set-up and discussion procedure}

The same semi-structured questioning route was used for both online and face-to-face FGDs to ensure comparability. The online FGD format was pre-tested in July 2018 with the main purpose of testing the questioning route as well as the features of the software Adobe Connect used for the chats. The online FGDs were conducted in August 2018, followed by the face-to-face FGDs implemented in two German cities in October 2018 (two groups in Braunschweig and two groups in Berlin). In all focus groups, participants had been advised to use only their first name or any preferred pseudonym to ensure protection of privacy. The moderator started the discussions by providing information on the protection of data privacy to receive participants' prior informed 
consent with respect to the audio recording and analysis of the discussion. With respect to discussion rules, online FGDs allowed for simultaneous answers, while face-to-face FGDs did not. The discussion time for each of the four focus groups was between 60 and 90 minutes.

The discussions started with an "icebreaker question" on the participants' weekly grocery shopping frequency. Afterwards, a hazelnut spread product picture was shown to avoid an abstract discussion on palm oil. Nutella, the probably most popular hazelnut spread brand in the world, contains palm oil and therefore has been subject to public criticism (Cova \& D'Antone, 2016). Other brands have recently reacted to increasing consumer concerns and introduced palmoil-free alternatives. Nudossi for instance is a German hazelnut spread that usually contains palm oil. In 2017, a palm-oil-free version that shows a large "palm-oil-free" claim on the front side was introduced to the market. This product example was used for the discussion, after having replaced the brand name with a generic term for hazelnut spread (Figure 1).

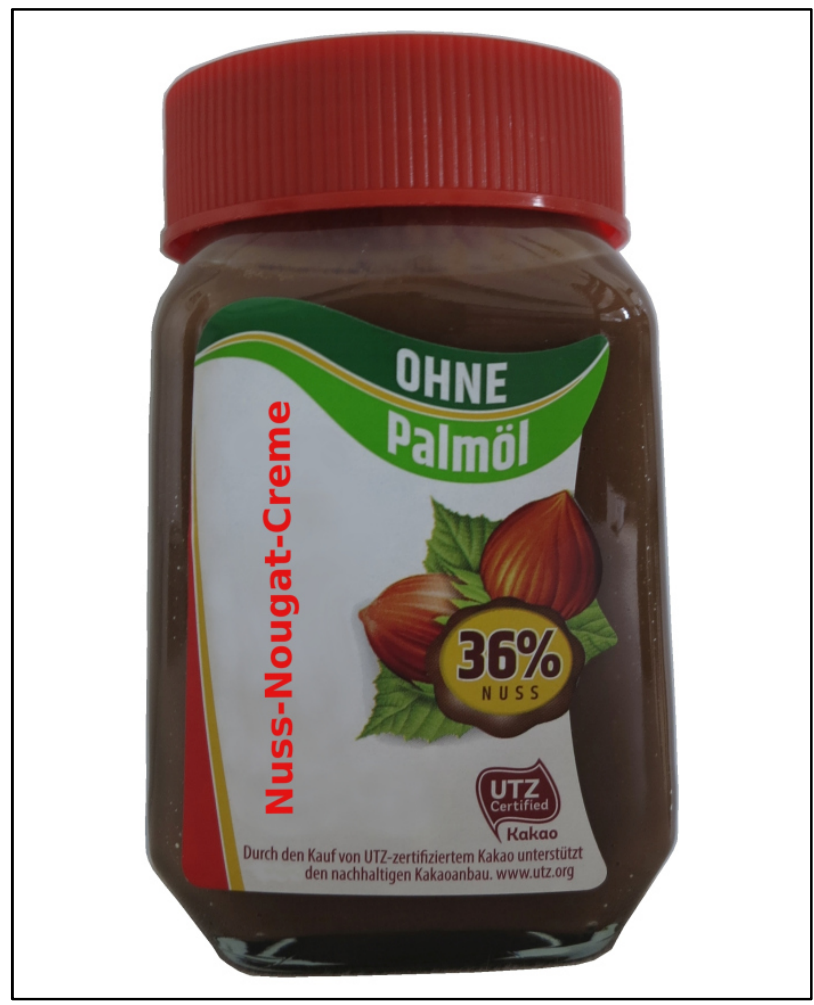

Figure 1. Hazelnut spread picture used as a stimulus for online focus groups

Source: own contribution; computer-modified photograph of a real product (Nudossi)

The questioning route was structured according to different thematic blocks. In the first block, advantages and disadvantages of palm oil were discussed in order to gain insights into the discussants' knowledge, awareness and attitudes. In the second block, knowledge, awareness and attitudes with respect to sustainability certification of palm oil were assessed. In this context, participants were asked whether they know any certification system for sustainable palm oil, 
before showing a picture of two RSPO labels for further discussion. One of the labels signalized $100 \%$-certified and segregated palm oil described as "certified", the other label showed a claim for "mixed" palm oil. This claim refers to the chain-of-custody system of mass balance, which allows for blending RSPO-certified with uncertified palm oil. Preferences for palm oil were assessed in two steps. First, participants discussed preferences for products containing certified palm oil versus products containing uncertified palm oil. Second, preferences for palm-oil-free products were discussed in comparison with products that contain certified palm oil. Finally, motivational factors with respect to sustainable consumption were discussed.

\section{$\underline{3.3 \text { Data analysis }}$}

Audio recordings of the face-to-face FGDs were transcribed verbatim by an external service provider. All transcriptions were reviewed, anonymized and checked for accuracy by the main moderator of the discussions. The online FGDs generated chat protocols that required no further transcription. Following Braun and Clarke (2006) and Kuckartz (2016), a thematic content analysis of the discussions was conducted. Thematic content analysis is a flexible and comprehensible qualitative data analysis method that has been widely used in focus group studies (Macdiarmid et al., 2016; Velema et al., 2019). MAXQDA Analytics Pro 2018 was used for memo writing and coding of the data material. Deductive coding was used to develop the main thematic categories derived from the questions included in the semi-structured questioning route. In addition, inductive coding was applied to identify additional relevant issues and patterns derived from the discussions themselves. The code book and the coded data material were discussed in a peer consultation among colleagues experienced with qualitative methods and revised considering to the feedback received.

\section{Results}

\subsection{Knowledge and awareness of palm oil and certification}

Most discussants noticed the "palm-oil-free" claim on the product picture and clearly stated that this claim shall address consumers' environmental awareness. In this context, the most frequently mentioned disadvantage of palm oil was the deforestation of rainforests associated with palm oil plantations. Several persons used emotive language, such as "destruction", "elimination" or "attack" on rainforests as the "green lung" of the planet. Biodiversity loss and other environmental consequences of palm oil monocultures were mentioned relatively often, although the aspect of monoculture was not further explained. Moreover, the issue of international transport of palm oil was mentioned, particularly referring to $\mathrm{CO}_{2}$ emissions that contribute to 
climate change.

Socio-economic aspects of palm oil production were less often mentioned. Some discussants criticized working conditions and the exploitation of smallholders by large corporations, as well as food security issues resulting from the occupation of arable land. Furthermore, palm oil was frequently perceived as "unhealthy". In most cases, it was not further specified why palm oil might be unhealthy. Some discussants mentioned the relatively high ratio of saturated fats. A few persons thought that palm oil is carcinogenic. One participant claimed that palm oil ensures that the feeling of satiety is delayed, resulting in weight gains. Related to this aspect, a few statements described palm oil as "low-quality" or "cheap" fat.

Regarding potential advantages of palm oil, almost every discussant mentioned the cheap price compared to alternatives. Interestingly, several discussants framed the cost aspect explicitly as a benefit to the industry, not to themselves as consumers: "I only see the advantages for the producer $=$ particularly cheap". In this respect, it was also noted that oil palms are probably easy to cultivate and the fruits easy to process. However, only a few discussants reflected on the efficiency of palm oil compared to alternatives. Texture and neutral flavor of palm oil were also mentioned as advantages. In two instances, it was noted that palm oil contributes to longer shelf life. Aspects of availability and versatility were inferred from the perception that palm oil is an ingredient of many different products.

Awareness with respect to palm oil as an ingredient in products was relatively heterogeneous, although discussants seemed to be more aware of and concerned about palm oil in food products than in non-food products. Asked for products that might contain palm oil, the majority of discussants first mentioned processed food products, particularly sweets. Several discussants were unaware of any other products or uses of palm oil, besides processed food. Some had heard of other uses, such as cosmetics, but often they were unsure whether their answer is correct. A few times the German brand Palmin was associated with palm oil, although Palmin products are made of coconut fat. The use of palm oil for biofuels seemed to be relatively unknown.

When discussants were asked whether they are aware of any sustainability certification system for palm oil, neither RSPO nor any other system was mentioned. Nobody was able to describe the RSPO labels before the respective pictures were presented to the groups. Looking at the labels, only three discussants across all groups claimed to have seen them on products before. The majority of all participants stated that they had not actively searched for information on palm oil prior to the discussion. Several discussants indicated that NGO campaigns, documentaries or reports on palm oil had made them aware of palm oil issues. Some referred to information by friends or family members avoiding palm oil, which had influenced their awareness and attitudes. 


\subsection{Attitudes and preferences toward palm oil and alternatives}

The majority of participants indicated their willingness to pay a premium for hazelnut spread that contains RSPO-certified palm oil as compared to uncertified palm oil. The indicated willingness-topay (WTP) values were mostly in the range between $10 \%$ and $20 \%$. However, apart from the participants' attitude toward palm oil as well as financial considerations, different aspects have been identified as relevant requirements for a general WTP for certified palm oil:

- the relevance of the product type to the consumer,

- taste, habits and potential brand loyalty,

- the usual consumption frequency,

- the relevance of palm oil as an ingredient of the respective product,

- and trust in the respective certification system.

Several discussants stated that they do not consume hazelnut spread, so they felt unable to discuss any preferences related to this product type. Others revealed their brand loyalty toward Nutella and argued that no other hazelnut spread could compete with its taste. One person admitted: "In the end, taste defeats conscience." A few participants stated that their WTP also depends on the relative amount of palm oil compared to other ingredients of the product: if it is only a minor ingredient, it is less relevant and the WTP is accordingly lower or even zero.

One person argued that recognizing the RSPO label on a product would make her aware that it contains palm oil and therefore deter her from purchasing. Another one claimed to have seen the RSPO label before, but perceived it as "somehow not reliable" because it is generally not well-known. It was furthermore remarked that "this is again only something for educated people", referring to the English word "sustainable" printed on the label. Some discussants explained that they do not trust any labels at all because there are so many different certification systems and certification criteria are not made transparent. The label for "mixed" palm oil certified according to the mass balance system was in several cases perceived as "greenwashing" and not supported by the discussants.

Overall, the majority of discussants demonstrated a rather negative attitude toward palm oil and declared to prefer the palm-oil-free option due to a lack of trust in certification. But most of the participants had never questioned whether a replacement of palm oil would automatically be more sustainable. Some discussants admitted that they actively try to avoid products that contain palm oil as they had heard that palm oil is "bad", but without knowing any particular reasons. The most frequently mentioned preferable alternatives to palm oil were oil from sunflower, rapeseed, or coconut. Sunflower and rapeseed oil were suggested mainly because they are produced in Europe. Regionally produced food was preferred because of shorter transport 
distance, knowledge of the origin of products and economic support of regional producers. In general, the discussion on alternatives to palm oil revealed relevant knowledge gaps. One person stated that "[...] for coconut oil, you don't have to cut down the tree, but only harvest [the fruits]." Coconut oil was also described as healthier than palm oil by different discussants. In one of the online focus groups, several discussants mentioned that they prefer certified organic products, indicating that according to their understanding, palm oil cannot be certified as organic.

\section{$\underline{4.3 \text { Barriers to sustainable consumption }}$}

The discussions revealed different personal, situational and product-related factors that might prevent consumers from purchasing products they regard as more sustainable. One situational factor is the availability of sustainable alternatives: some discussants stressed the difficulty to find more palm-oil-free products in their current shopping venue. The lack of time was identified as another major constraint to sustainable consumption. First, consumers need time to search for information on relevant ingredients before they go shopping. Second, they need time to read the list of ingredients of different products available at the point of sale. Concerning product-related constraints, several discussants complained about the difficulty to find out whether cosmetics or other non-food products contain palm oil. As the list of ingredients shows mainly Latin names, the identification of palm oil derivatives is experienced as complicated. Moreover, it was criticized by different persons that the font size of the list of ingredients is usually too small.

The FGDs indicated that the presence of too many certification systems and labels leads to information overload and confusion and a resulting lack of trust. On the one hand, discussants expressed their doubt on the credibility of sustainability labels that are attached to cheap products sold in discounters, while on the other hand they requested more information on certification criteria and standard providers that would justify the premium for certified products. In this regard, some discussants stated that they cannot afford to purchase only sustainable products considering their budget.

Moreover, discussants explained that they can hardly avoid all potentially problematic product ingredients. They face trade-offs between different factors: "[...] there are many other things [besides palm oil] one needs to consider at the same time and that are also somehow not good [...], and I find that frustrating". Several discussants stated that they would prefer organic vegetables, as they regard them as more sustainable. But these are often wrapped in plastic, as opposed to the conventional alternatives. Trying to decide for the "lesser of two evils", some indicated to prefer the non-organic products without plastic foil. Some discussants expressed reluctance to surrender food they regard as unsustainable or unhealthy: "I don't eat this on a daily basis, but sometimes I need it. And then it doesn't matter to me." 
Perceived consumer effectiveness seems to play a role as well. Although this aspect was not discussed in detail, several participants stated that consumers - not as individuals, but collectively - have the power to induce change through their consumption behavior, for instance by boycotting certain brands or product ingredients. Some persons acknowledged their responsibility as consumers, whereas others blamed primarily the private sector for unsustainable production.

\section{Discussion}

This qualitative analysis of FGDs with consumers in Germany adds to previous research on consumer attitudes and preferences toward palm oil by providing insights into prevailing knowledge gaps and concerns. Moreover, it contributes findings on preferences between products that contain certified palm oil versus palm-oil-free products. Different personal, situational and product-related factors that are relevant for actual consumption decisions have been identified.

In contrast to final products involved in other studies on consumer preferences (e.g., Thøgersen et al. (2010), Grunert et al. (2014)), palm oil is usually not purchased as a product on its own but included as one of many ingredients in processed products. This fact makes purchase decisions involving palm oil even more complex. The results of this analysis suggest that consumers rather care about palm oil in food than in any other kind of products. Not everybody is even aware that palm oil is also used for other purposes than as ingredient in food. One reason might be found in the EU Regulation (1169/2011) mentioned in the introduction, which does not affect non-food products, which often contain palm oil derivatives that are hidden behind scientific names and can hardly be identified by consumers.

Thøgersen (2000) expected that increased prevalence of certified products would contribute to knowledge on certification and labels as well as to perceived consumer effectiveness. The results of this study indicate that this development has rather contributed to information overload and reduced trust in certification systems. These findings confirm the results of previous studies (e.g., Grunert, 2011; Sirieix et al., 2013; Thøgersen et al., 2010). In line with Gassler and Spiller (2018) as well as Ostfeld et al. (2019), RSPO certification systems were found to be basically unknown among consumers. RSPO labels might increase awareness of palm oil and thereby discourage those consumers who do not believe that palm oil can be produced in a sustainable manner, as explained by Larsen et al. (2018). The RSPO "mixed" label was perceived as less credible by several participants, supporting findings by Gassler and Spiller (2018). It remains to be further explored whether the indicated lack of trust in certification is really a major 
reason for consumers not to buy certified products, or whether it is used as a socially accepted excuse.

The majority of discussants indicated to prefer products without palm oil. Emerging "palm-oil-free" labeling of products might have influenced consumer attitudes and preferences. As suggested by Hartmann et al. (2018), consumers might prefer palm-oil-free products simply because they think that the absence of palm oil is beneficial for health or other reasons and therefore advertised by the respective brand. In the present study, coconut oil was often suggested as a healthier alternative to palm oil in the discussions, although composition and properties are quite similar (Rival \& Levang, 2014). The discussions did not reveal any support for the findings by Aguiar et al. (2018) with respect to consumers' perceptions of palm oil as a more natural product.

Two different forms of focus groups were used in this study: synchronous, text-based online focus groups and traditional face-to-face focus groups. As expected, the number of comments per discussant was larger in online focus groups, while each comment was significantly shorter compared to face-to-face focus groups. While the two forms differ in their implementation, no major differences in the discussion process and the stated attitudes and preferences could be identified between the two forms. However, the analysis revealed one relevant limitation of text-based online focus groups that to the best of our knowledge has not been considered in previous studies. In one of the chats, one discussant made a statement that was later identified as copied from a website of a palm oil documentary. During the content analysis, the wording, correct orthography and case sensitivity of this comment seemed unusual compared to the other chat comments. The analysts then used the Google search engine to check this statement and found the original source. In this case, the statement was used as an answer to a question on the participants' prior knowledge on palm oil. Consequently, this example shows that online focus groups are rather unsuitable for assessing knowledge, as participants might be tempted to compensate their lack of knowledge through a quick search on the internet.

Common limitations of stated preference techniques, such as hypothetical bias and social desirability bias, may lead to a significant gap between stated preferences and actual behavior, implying a tendency to overstate preferences and WTP for sustainably produced goods (Fisher, 1993; Murphy et al., 2005; Vermeir \& Verbeke, 2006). These biases remain relevant as long as no real money has to be spent. Although the participants rated their involvement with respect to product ingredients and sustainability as relatively high on average, only a few claimed to actually search for information on the list of ingredients when they shop for groceries. Therefore, stated preferences for palm-oil-free products have to be interpreted with caution. The identified decision-relevant factors might act as barriers to sustainable consumption and explain a potential 
attitude-behavior gap at least to some extent. Other factors, such as price, taste, and brand, were found to be more relevant in consumption decisions. In accordance with findings by Cova and D'Antone (2016), the focus group discussions revealed brand loyalty toward Nutella. Some of these factors have also been identified in previous studies, for instance by Grunert (2011) and Young et al. (2009).

Qualitative studies with small samples are usually not representative and therefore do not allow for drawing conclusions for the whole population. In this case, purposeful sampling was applied to recruit participants who are relatively concerned about sustainability and product ingredients in general, so the results might probably overestimate concern about palm oil due to selection bias. Following a mixed methods approach (Johnson et al., 2007; Kuckartz, 2014), the results of this analysis will be used to develop an online survey including a choice experiment to quantitatively analyze attitudes and preferences of German consumers toward palm oil. The main novelties compared to the study by Gassler and Spiller (2018) will be the inclusion of a specific alternative oil as a product attribute in the choice experiment, and the consideration of psychometric scales as potential influence factors.

For future research, it will also be essential to get a better understanding of consumer preferences in emerging palm oil-importing economies with less strict requirements on certification, such as India or China. It remains questionable how palm oil can become sustainable if overall production continues to grow, inducing further land-use change (Dauvergne, 2018). The trend toward advertising palm-oil-free products might also be problematic, considering the competitive advantage of palm oil compared to alternative oils and fats in terms of efficiency. If we maintain consumption levels while replacing palm oil by other vegetable oils, we might end up with even more environmental problems (Rival \& Levang, 2014; WWF, 2016). Thus, policymakers should take undesirable consequences of increasing use of alternative oils into account, and accordingly support communication to the public. Environmentally conscious consumers should rather be advised to reduce their consumption of processed food and non-food products instead of switching to "palm-oil-free" alternatives. For marketing purposes, however, the use of "palmoil-free" labels on products might be a valuable strategy to increase the awareness of consumers who are concerned about sustainability or health related to palm oil.

\section{Conclusions}

The results of this exploratory qualitative analysis of consumer attitudes and stated preferences suggest that German consumers tend to have negative attitudes toward palm oil and are more concerned about palm oil in food than in non-food products. A lack of knowledge on palm oil, certification, and alternative vegetable oils has been identified. The majority of focus group 
discussants indicated to prefer products without palm oil over products that contain RSPOcertified palm oil. One of the main reasons provided was a lack of trust in certification systems. However, it was revealed that palm oil is overall not a major factor influencing actual purchase decisions. There are personal, situational and product-related factors that might play a more important role, such as taste, time, availability and price. Further quantitative analyses involving largely representative samples will be required to test the findings. Indicated preferences for palm-oil-free products might be problematic, as alternative vegetable oils are not necessarily more sustainable than palm oil. Only a reduction in the overall consumption of processed, not a mere replacement of ingredients, might contribute to sustainable development in the long run. Therefore, relevant information needs to be provided to consumers to close knowledge gaps with respect to benefits and problems of palm oil and its alternatives.

\section{Declarations of interest}

The authors have no conflicts of interest to declare.

\section{Funding}

This research did not receive any specific grant from funding agencies.

\section{References}

Aguiar, L. K., Martinez, D. C., \& Caleman, S. M. Q. (2018). Consumer awareness of palm oil as an ingredient in food and non-food products. Journal of Food Products Marketing, 24(3), 297-310. https://doi.org/10.1080/10454446.2017.1266559.

Barbour, R. (2007). Doing focus groups. In U. Flick, S. Kvale, M. V. Angrosino, R. S. Barbour, M. Banks, G. Gibbs, \& T. Rapley (Eds.), The SAGE Qualitative Research Kit (Vol. 4, pp. 1-174). London: SAGE Publications.

Barrios, E. X., \& Costell, E. (2004). Review: Use of methods of research into consumers' opinions and attitudes in food research. Food Science and Technology International, 10(6), 359-371. https://doi.org/10.1177/1082013204049386.

Bateman, I. J., Fisher, B., Fitzherbert, E., Glew, D., \& Naidoo, R. (2010). Tigers, markets and palm oil: Market potential for conservation. Oryx, 44(2), 230-234. https://doi.org/10.1017/S0030605309990901.

Braun, V., \& Clarke, V. (2006). Using thematic analysis in psychology. Qualitative Research in Psychology, 3(2), 77-101. https://doi.org/10.1191/1478088706qp063oa.

Byerlee, D., \& Rueda, X. (2015). From public to private standards for tropical commodities: A century of global discourse on land governance on the forest frontier. Forests, 6(4), 13011324. https://doi.org/10.3390/f6041301.

Carlson, K. M., Curran, L. M., Ratnasari, D., Pittman, A. M., Soares-Filho, B. S., Asner, G. P., Trigg, S. N., Gaveau, D. A., Lawrence, D., \& Rodrigues, H. O. (2012). Committed carbon emissions, deforestation, and community land conversion from oil palm plantation expansion in West 
Kalimantan, Indonesia. Proceedings of the National Academy of Sciences, 109(19), 7559-7564. https://doi.org/10.1073/pnas.1200452109.

Chowdhury, R., Warnakula, S., Kunutsor, S., Crowe, F., Ward, H. A., Johnson, L., Franco, O. H., Butterworth, A. S., Forouhi, N. G., Thompson, S. G., Khaw, K.-T., Mozaffarian, D., Danesh, J., \& Di Angelantonio, E. (2014). Association of dietary, circulating, and supplement fatty acids with coronary risk: A systematic review and meta-analysis. Annals of Internal Medicine, 160(6), 398-406. https://doi.org/10.7326/M13-1788.

Colchester, M. (2016). Do commodity certification systems uphold indigenous peoples' rights? Lessons from the Roundtable on Sustainable Palm Oil and Forest Stewardship Council. IUCN Policy Matters, 21, 149-165. Retrieved from http://www.forestpeoples.org/index.php/es/node/6197 on May 15, 2018.

Cova, B., \& D'Antone, S. (2016). Brand iconicity vs. anti-consumption well-being concerns: The Nutella palm oil conflict. Journal of Consumer Affairs, 50(1), 166-192. https://doi.org/10.1111/joca.12082.

D'Antone, S., \& Spencer, R. (2015). Organising for sustainable palm oil consumption: A marketbased approach. Consumption Markets \& Culture, 18(1), 55-71. https://doi.org/10.1080/10253866.2014.899217.

Darby, M. R., \& Karni, E. (1973). Free competition and the optimal amount of fraud. The Journal of Law and Economics, 16(1), 67-88. https://doi.org/ 10.1086/466756.

Dauvergne, P. (2018). The global politics of the business of "sustainable" palm oil. Global Environmental Politics, 18(2), 34-52. https://doi.org/10.1162/glep_a_00455.

Disdier, A.-C., Marette, S., \& Millet, G. (2013). Are consumers concerned about palm oil? Evidence from a lab experiment. Food Policy, 43, 180-189. https://doi.org/10.1016/j.foodpol.2013.09.003.

ESPO (2019). Choosing sustainable palm oil: Progress report on the import and use of sustainable palm oil in Europe. Zoetermeer, The Netherlands: European Sustainable Palm Oil (ESPO) secretariat. Retrieved from https://www.idhsustainabletrade.com/publication/choosingsustainable-palm-oil/ on April 1, 2019.

Finch, H., \& Lewis, J. (2003). Focus groups. In J. Ritchie \& J. Lewis (Eds.), Qualitative research practice: A guide for social science students and researchers (pp. 170-198). London: SAGE Publications.

Fisher, R. J. (1993). Social desirability bias and the validity of indirect questioning. Journal of Consumer Research, 20(2), 303-315. https://doi.org/10.1086/209351.

Gaiser, T. J. (2008). Online focus groups. In Fielding, N., Lee, R.M., Blank, G. (Ed.), The SAGE handbook of online research methods (pp. 290-306). London: SAGE Publications.

Gassler, B., \& Spiller, A. (2018). Is it all in the MIX? Consumer preferences for segregated and mass balance certified sustainable palm oil. Journal of Cleaner Production, 195, 21-31. https://doi.org/10.1016/j.jclepro.2018.05.039.

Giam, X., Mani, L., Koh, L. P., \& Tan, H. T.W. (2016). Saving tropical forests by knowing what we consume. Conservation Letters, 9(4), 267-274. https://doi.org/10.1111/conl.12209.

Goldstein, J. E. (2015). Knowing the subterranean: Land grabbing, oil palm, and divergent expertise in Indonesia's peat soil. Environment and Planning A, 48(4), 754-770. https://doi.org/10.1177/0308518X15599787. 
Grunert, K. G. (2011). Sustainability in the food sector: A consumer behaviour perspective. International Journal on Food System Dynamics, 2(3), 207-218.

https://doi.org/10.18461/ijfsd.v2i3.232.

Grunert, K. G., Hieke, S., \& Wills, J. (2014). Sustainability labels on food products: Consumer motivation, understanding and use. Food Policy, 44, 177-189.

https://doi.org/10.1016/j.foodpol.2013.12.001.

Guest, G., Namey, E., \& McKenna, K. (2017). How many focus groups are enough? Building an evidence base for nonprobability sample sizes. Field Methods, 29(1), 3-22. https://doi.org/10.1177/1525822X16639015.

Guillaume, T., Kotowska, M. M., Hertel, D., Knohl, A., Krashevska, V., Murtilaksono, K., Scheu, S., \& Kuzyakov, Y. (2018). Carbon costs and benefits of Indonesian rainforest conversion to plantations. Nature Communications, 9, Article no. 2388. https://doi.org/10.1038/s41467-01804755-y.

Hartmann, C., Hieke, S., Taper, C., \& Siegrist, M. (2018). European consumer healthiness evaluation of 'free-from' labelled food products. Food Quality and Preference, 68, 377-388. https://doi.org/10.1016/j.foodqual.2017.12.009.

Iceland Foods Ltd. (2018). Iceland to be the UK's first major supermarket to remove palm oil from own label food: Collapse in orangutan population provides urgent need for action. Deecide, UK: Iceland Foods Ltd. Retrieved from https://about.iceland.co.uk/wpcontent/uploads/2018/04/Iceland-to-be-the-UKs-first-major-supermarket-to-remove-palm-oilfrom-own-label-food-10.4.18.pdf on January 10, 2019.

Johnson, R. B., Onwuegbuzie, A. J., \& Turner, L. A. (2007). Toward a definition of mixed methods research. Journal of Mixed Methods Research, 1(2), 112-133. https://doi.org/10.1177/1558689806298224.

Koh, L. P., \& Wilcove, D. S. (2008). Is oil palm agriculture really destroying tropical biodiversity? Conservation Letters, 1(2), 60-64. https://doi.org/10.1111/j.1755-263X.2008.00011.x.

Kuckartz, U. (2014). Mixed Methods: Methologie, Forschungsdesigns und Analyseverfahren. Wiesbaden, Germany: Springer Fachmedien.

Kuckartz, U. (2016). Qualitative Inhaltsanalyse: Methoden, Praxis, Computerunterstützung ( ${ }^{\text {rd }}$ ed.). Grundlagentexte Methoden. Weinheim, Germany: Beltz Juventa.

Lamnek, S. (2010). Qualitative Sozialforschung ( $5^{\text {th }}$ ed.). Weinheim, Germany: Beltz Verlag.

Larsen, R. K., Osbeck, M., Dawkins, E., Tuhkanen, H., Nguyen, H., Nugroho, A., Gardner, T. A., Zulfahm, \& Wolvekamp, P. (2018). Hybrid governance in agricultural commodity chains: Insights from implementation of 'No Deforestation, No Peat, No Exploitation' (NDPE) policies in the oil palm industry. Journal of Cleaner Production, 183, 544-554. https://doi.org/10.1016/j.jclepro.2018.02.125.

Macdiarmid, J. I., Douglas, F., \& Campbell, J. (2016). Eating like there's no tomorrow: Public awareness of the environmental impact of food and reluctance to eat less meat as part of a sustainable diet. Appetite, 96, 487-493. https://doi.org/10.1016/j.appet.2015.10.011.

Moreno-Peñaranda, R., Gasparatos, A., Stromberg, P., Suwa, A., Pandyaswargo, A. H., \& Puppim de Oliveira, J. A. (2015). Sustainable production and consumption of palm oil in Indonesia: What can stakeholder perceptions offer to the debate? Sustainable Production and Consumption, 4, 16-35. https://doi.org/10.1016/j.spc.2015.10.002. 
Murphy, J. J., Allen, P. G., Stevens, T. H., \& Weatherhead, D. (2005). A meta-analysis of hypothetical bias in stated preference valuation. Environmental and Resource Economics, 30(3), 313-325. https://doi.org/10.1007/s10640-004-3332-z.

Oil World. (2018). Oil World Annual 2018. Hamburg, Germany: ISTA Mielke GmbH.

Oosterveer, P. (2015). Promoting sustainable palm oil: Viewed from a global networks and flows perspective. Journal of Cleaner Production, 107, 146-153. https://doi.org/10.1016/j.jclepro.2014.01.019.

Oringderff, J. (2004). "My Way": Piloting an online focus group. International Journal of Qualitative Methods, 3(3), 69-75. https://doi.org/10.1177/160940690400300305.

Ostfeld, R., Howarth, D., Reiner, D., \& Krasny, P. (2019). Peeling back the label - exploring sustainable palm oil ecolabelling and consumption in the United Kingdom. Environmental Research Letters, 14(1), Article 014001. https://doi.org/10.1088/1748-9326/aaf0e4.

Palinkas, L. A., Horwitz, S. M., Green, C. A., Wisdom, J. P., Duan, N., \& Hoagwood, K. (2015). Purposeful sampling for qualitative data collection and analysis in mixed method implementation research. Administration and Policy in Mental Health and Mental Health Services Research, 42(5), 533-544. https://doi.org/10.1007/s10488-013-0528-y.

Pye, O. (2019). Commodifying sustainability: Development, nature and politics in the palm oil industry. World Development, 121, 218-228. https://doi.org/10.1016/j.worlddev.2018.02.014.

Raynaud, J., Fobelets, V., Georgieva, A., Joshi, S., Kristanto, L., Groot Ruiz, A. de, Bullock, S., \& Hardwicke, R. (2016). Improving business decision making: Valuing the hidden costs of production in the palm oil sector: A study for The Economics of Ecosystems and Biodiversity for Agriculture and Food (TEEBAgriFood) Program. Retrieved from http://www.teebweb.org/agriculture-and-food/palm-oil/ on January 1, 2018.

Reid, D. J., \& Reid, F. J. M. (2005). Online focus groups: An in-depth comparison of computermediated and conventional focus group discussions. International Journal of Market Research, 47(2), 131-162. https://doi.org/10.1177/147078530504700204.

REWE Group (2017). Es geht auch ohne Palmöl!: Ja! Natürlich Vorreiter beim Einsatz von PalmölAlternativen. Wiener Neudorf: REWE International AG. Retrieved from https://www.rewegroup.at/de/newsroom/pressemitteilungen/janatuerlich-1711-palmoel-alternative/ on March 6, 2019.

Riganelli, C., \& Marchini, A. (2017). Governance and quality disclosure: The palm oil issue. British Food Journal, 119(8), 1718-1731. https://doi.org/10.1108/BFJ-11-2016-0566.

Rival, A., \& Levang, P. (2014). Palms of controversies: Oil palm and development challenges. Bogor, Indonesia: Center for International Forestry Research (CIFOR). Retrieved from https://www.cifor.org/library/4860/ on November 6, 2018.

RSPO (2018). RSPO Impact Report 2018. Kuala Lumpur: Roundtable on Sustainable Palm Oil (RSPO). Retrieved from https://rspo.org/resources/rspo-reports/impact-reports on March 22, 2019.

Schneider, S. J., Kerwin, J., Frechtling, J., \& Vivari, B. A. (2002). Characteristics of the discussion in online and face-to-face focus groups. Social Science Computer Review, 20(1), 31-42. https://doi.org/10.1177/089443930202000104. 
Sirieix, L., Delanchy, M., Remaud, H., Zepeda, L., \& Gurviez, P. (2013). Consumers' perceptions of individual and combined sustainable food labels: A UK pilot investigation. International Journal of Consumer Studies, 37(2), 143-151. https://doi.org/10.1111/j.1470-6431.2012.01109.x.

Stewart, D. W., \& Shamdasani, P. (2017). Online focus groups. Journal of Advertising, 46(1), 4860. https://doi.org/10.1080/00913367.2016.1252288.

Thøgersen, J. (2000). Psychological determinants of paying attention to eco-labels in purchase decisions: Model development and multinational validation. Journal of Consumer Policy, 23(3), 285-313. https://doi.org/10.1023/A:1007122319675.

Thøgersen, J., Haugaard, P., \& Olesen, A. (2010). Consumer responses to ecolabels. European Journal of Marketing, 44(11/12), 1787-1810. https://doi.org/10.1108/03090561011079882.

Velema, E., Vyth, E. L., \& Steenhuis, I. H. M. (2019). "I've worked so hard, I deserve a snack in the worksite cafeteria": A focus group study. Appetite, 133, 297-304. https://doi.org/10.1016/j.appet.2018.11.027.

Vermeir, I., \& Verbeke, W. (2006). Sustainable food consumption: Exploring the consumer "attitude - behavioral intention" gap. Journal of Agricultural and Environmental Ethics, 19(2), 169-194. https://doi.org/10.1007/s10806-005-5485-3.

Verneau, F., La Barbera, F., Amato, M., \& Sodano, V. (2019). Consumers' concern towards palm oil consumption. British Food Journal, 121(9), 1982-1997. https://doi.org/10.1108/BFJ-10-20180659.

WHO (2015). Eliminating trans fats in Europe: A policy brief. Copenhagen: World Health Organization (WHO) Regional Office for Europe. Retrieved from http://www.euro.who.int/_data/assets/pdf_file/0010/288442/Eliminating-trans-fats-inEurope-A-policy-brief.pdf on December 11, 2018.

WWF (2016). Auf der Ölspur: Berechnungen zu einer palmölfreieren Welt. Berlin: World Wide Fund for Nature (WWF) Germany. Retrieved from http://www.wwf.de/fileadmin/fmwwf/Publikationen-PDF/WWF-Studie_Auf_der_OElspur.pdf on November 4, 2017.

Young, W., Hwang, K., McDonald, S., \& Oates, C. J. (2009). Sustainable consumption: Green consumer behaviour when purchasing products. Sustainable Development, 37(2), 20-31. https://doi.org/10.1002/sd.394. 


\subsection{No palm oil or certified sustainable palm oil? Heterogeneous consumer preferences and the role of information}

Cordula Hinkes, Inken Christoph-Schulz

Sustainability (2020), 12(18): 7257.

DOI: https://doi.org/10.3390/su12187257

This article has been published in the Special Issue "Food Quality, Price and Consumer Choices".

Copyright is retained by the authors. Articles published in Sustainability are licensed under an open access Creative Commons CC BY 4.0 license.

\section{Declaration of originality:}

The idea, the research questions, and the concept for the study were developed by the author. The questionnaire for the survey was drafted by the author and revised by Dr. Inken ChristophSchulz, with additional helpful feedback received by several participants in pre-tests and consultations among colleagues. The choice design was created by the author. The recruitment of participants and the technical implementation of the survey were performed by a contracted service provider. The implementation was tested by the author and Dr. Inken Christoph-Schulz. The data analysis was performed by the author. Dr. Inken Christoph-Schulz provided helpful feedback on the data analysis, particularly on the principal component analysis. The manuscript was written by the author and reviewed by Dr. Inken Christoph-Schulz. 


\title{
Article \\ No Palm Oil or Certified Sustainable Palm Oil? Heterogeneous Consumer Preferences and the Role of Information
}

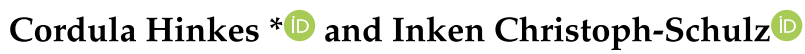 \\ Thuenen Institute of Market Analysis, Bundesallee 63, 38116 Braunschweig, Germany; \\ inken.christoph@thuenen.de \\ * Correspondence: cordula.hinkes@thuenen.de
}

Received: 7 August 2020; Accepted: 2 September 2020; Published: 4 September 2020

\begin{abstract}
Public concerns about the adverse effects of palm oil production and consumption have contributed both to the development of certification standards for sustainable palm oil and to the promotion of palm-oil-free products. While research on consumer preferences for palm oil is growing, potential trade-offs between these two options-products containing certified palm oil versus palm-oil-free products-are still largely unexplored. Focusing on this research gap, a discrete choice experiment involving chocolate cookies was implemented as part of a web survey among consumers in Germany. Results indicate that consumers on average prefer palm-oil-free cookies, although a latent class analysis identifies several consumer segments that differ in terms of preferences, attitudes, and characteristics. Many respondents are highly price-sensitive. After the provision of additional information, stated preferences for certified palm oil increase, but four out of five consumer segments still prefer palm-oil-free products. Prevailing health concerns and a potential lack of trust in certification might explain this choice behavior. As alternatives to palm oil are not necessarily more sustainable, initiatives supporting the uptake of certified sustainable palm oil should be further strengthened. Targeted information campaigns might be a suitable instrument to raise awareness and increase knowledge about palm oil.
\end{abstract}

Keywords: certification; choice experiment; consumer behavior; deforestation; food; label; latent class analysis; RSPO; stated preferences; sustainability

\section{Introduction}

The expansion of oil palm cultivation can contribute to socio-economic development but often has significant adverse social and environmental effects [1]. Particularly in Indonesia and Malaysia, which together account for around 84 percent of global palm oil production [2,3], huge areas of tropical forests have been cleared and peatlands have been drained and burned for oil palms [4-7]. Among other problems, land-use change processes related to the expansion of oil palm cultivation induce biodiversity loss [8-10] and greenhouse gas emissions [11,12]. Moreover, land tenure conflicts and exploitation of workers, as well as problems related to the livelihoods of smallholders and indigenous communities, have been reported $[13,14]$.

Addressing problems related to unsustainable palm oil production, two main trends can be observed in the market: the development of sustainability standards for palm oil, and the replacement of palm oil with alternative oils and fats $[15,16]$. The most popular voluntary sustainability standards for palm oil have been developed by the Roundtable on Sustainable Palm Oil (RSPO) and are updated on a regular basis [17]. The RSPO supply chain certification is advertised to consumers in the form of product labels and claims. For instance, if a final food product contains only palm oil that has been 
certified and segregated from uncertified palm oil along the whole supply chain, it can be labeled as "RSPO certified". Generally, palm oil labeled as "RSPO certified" should be $100 \%$ certified. In practice, RSPO currently requires a certified content of at least $95 \%$, a justification, and compensation in the form of RSPO credits for any remaining non-certified content [18]. If a certain amount of certified palm oil is bought and used as an ingredient, but mixed with uncertified palm oil along the supply chain, an "RSPO mixed" label can be used. According to the "mass balance" approach, it has to be ensured that the total amount of "RSPO mixed" palm oil does not exceed the total amount of actually certified palm oil; it is not guaranteed that the labeled final product actually contains any certified palm oil $[18,19]$.

With respect to the replacement of palm oil, it has been argued that there is currently no technically suitable and economically viable alternative that would be more sustainable. Palm oil is not only particularly versatile with respect to different uses [20], but also the most productive among relevant vegetable or exotic oils and fats, meaning that it requires less land for the same amount of output [20-22]. Still, comprehensive life cycle assessments are required to take into account trade-offs between land use and other aspects, such as greenhouse gas emissions or water use [23].

Currently, 19 percent of the global palm oil production is RSPO-certified, but not even half of the certified volumes are taken up by the market, so there is a significant demand gap [24,25]. Interestingly, products that contain RSPO-certified palm oil are often not labeled accordingly. This indicates that consumer goods manufacturers and retailers might rather tend to hide palm oil as an ingredient than to advertise certified sustainable palm oil, assuming negative attitudes toward palm oil in general [26-28]. Buying products that contain only certified sustainable palm oil has been rated as most effective among different actions aimed at reducing the adverse effects of palm oil production [29]. As the second-largest import market for palm oil globally [3], the European Union has acknowledged responsibility for deforestation linked to imported commodities and products and called for action to support sustainable consumption [30,31]. Palm oil has been prioritized by the Amsterdam Declarations Partnership (ADP), a small group of European countries aiming at eliminating deforestation from agricultural supply chains [32,33].

The focus of this analysis is on Germany, as this country is a member of the ADP, consumes a large share of palm oil volumes imported to Europe, and supports sustainability certification of palm oil via the Forum for Sustainable Palm Oil (FONAP) [34]. Acknowledging the influence of political consumerism [35], this article shall contribute answers to the following research questions:

- Do consumers tend to prefer products containing certified sustainable palm oil or rather palm-oil-free products, if they care at all?

- Which socio-economic or attitudinal factors might influence consumer preferences for palm oil?

- How does the provision of information to consumers affect their preferences?

This article proceeds as follows. Section 2 provides a literature overview of relevant scientific articles on consumer attitudes and preferences toward palm oil and defines the research hypotheses to be tested in this study. The methods used for data collection and analysis are described in Section 3. The results of the analysis are presented in Section 4 and discussed in Section 5. Finally, conclusions are drawn in Section 6.

\section{Conceptual Framework and Research Hypotheses}

\subsection{Consumer Attitudes, Preferences, and Behavior in the Context of Sustainability}

According to the theory of planned behavior, the most relevant factors that influence behavioral intentions are attitudes, subjective norms, and perceived behavioral control [36,37]. In line with this concept, economic choice theory suggests that attitudes and perceptions influence preferences, which have an effect on behavioral intentions. These latent, unobservable constructs are influenced by information on product attributes, markets, and external factors. Using a decision protocol, consumers 
make choices based on the principle of utility maximization under the consideration of a restricted budget and other potential constraints [38]. This framework has been further developed for the more specific case of behavioral intentions toward sustainable consumption behavior. The sustainability of a product is a so-called credence quality that can hardly be assessed by consumers before or even after consumption and, therefore, leads to information asymmetry [39]. Sustainability certification and product labeling are used to reduce this information asymmetry $[40,41]$.

Vermeir and Verbeke [41,42] identified positive effects of involvement with sustainability, certainty (or confidence), and perceived consumer effectiveness (PCE) on attitudes. Involvement is influenced by values, needs and motivations, while certainty (or confidence) is derived from information and knowledge [41,42]. PCE refers to people's perception of their ability to contribute to alleviating social or environmental issues with their consumption decisions [41,43]. Attitudes again influence the intention to buy sustainable food, but not necessarily actual purchase behavior. In addition to personal factors, contextual factors such as situational (e.g., time, availability), economic (e.g., budget), or institutional (e.g., general availability) constraints might act as barriers to pro-environmental behavior $[41,42,44]$. The actual use of sustainability labels in purchase decisions depends not only on consumers' motivation and understanding with respect to sustainability, but also on knowledge, previous experience, and trust with respect to the respective certification systems and labels $[40,45,46]$.

\subsection{Development of Hypotheses Based on a Literature Overview}

Various studies on consumers' perceptions, attitudes, and preferences toward palm oil have been conducted in different countries. The majority of studies use quantitative approaches based on web-based surveys [16,26,29,47-52] or face-to-face surveys [28,53,54]. Only few use qualitative approaches [55] or mixed methods [29,56]. Some studies focus on palm oil in general, others consider (certified) sustainable palm oil and/or no palm oil. A further distinction can be made with respect to whether a study takes health and/or sustainability aspects into account.

Aguiar et al. [55] and Guadalupe et al. [54] study consumers' awareness and perceptions of palm oil as an ingredient, without considering certification. Both studies have methodological limitations. Aguiar et al. [55] use means-end laddering in interviews with only 25 respondents. They find that respondents are unaware of palm oil as a product ingredient, seem to be concerned about social and environmental issues, but perceive palm oil as "natural", which is interpreted as valuable for health. The small sample size and the exploratory character of the study do not allow for drawing conclusions on the attitudes of a wider population. Guadalupe et al. [54] conduct a face-to-face survey using a short questionnaire. Based on identified negative perceptions of Spanish consumers with respect to health and environmental effects of palm oil, the authors recommend replacing palm oil. In opposition to scientific evidence, health issues related to palm oil consumption seem to be accepted as facts, while sustainability advantages of palm oil in terms of productivity are neglected by the authors. Respondents' willingness to pay (WTP) is assessed with a simple closed-ended question, which bears the risk of substantially biased results.

Preferences for palm-oil-free products have been studied with different approaches and methods $[16,47,48,50-52,57]$. The results suggest that consumers lack knowledge about palm oil $[47,51]$ and tend to be concerned about sustainability and/or health effects of palm oil $[48,50,52,57]$. Such concerns or general perceptions of palm oil do not always influence preferences and behavioral intentions, though [16,47]. Borrello et al. [47] and Hartmann et al. [50] conclude that consumers' perceptions of "palm-oil-free" products as healthier results from a so-called "health halo effect", meaning that "free from" product claims suggest the absence of unhealthy ingredients [58].

Different specifications of sustainability have been used in studies on preferences for (certified) sustainable palm oil, such as "tiger-friendly" palm oil [53], "deforestation-free" palm oil [28], sustainable palm oil in general without a specific certification [16,56], and RSPO-certified palm oil [26,49]. The study by Gassler and Spiller [49] is particularly interesting, as it is based on a discrete choice experiment with consumers in Germany that distinguishes between preferences for 100\% RSPO-certified and 
mixed RSPO-certified palm oil. The results indicate that consumers derive utility from both labels, but segregation is preferred. However, the study does not consider trade-offs between products that contain RSPO-certified palm oil and palm-oil-free products. The largest consumer segment identified in the latent class analysis preferred opting out rather than choosing a product with conventional palm oil, and more than 15 percent of the sample chose the opt-out option in all choice tasks. It remains unclear whether the reason might be a rejection of palm oil, a distaste for the respective product category, or other factors influencing preferences. Moreover, psychometric factors were measured by only one statement, respectively.

The study by Vergura et al. [16] seems to be the only one so far that examined consumer attitudes and preferences for products with sustainable palm oil as compared to "palm-oil-free" products and products without any palm-oil-related claim. The respondents showed a higher risk perception toward prepackaged cookies showing a "with sustainable palm oil" claim as compared to products with a "palm-oil-free" claim. The product evaluation was also better for "palm-oil-free" products. However, no significant differences with respect to stated WTP could be identified, not even compared to products without any claim. Respondents were assigned to different treatment groups and directly asked to indicate their willingness-to-pay, so the elicitation method as well as the rather small convenience sample (191 respondents split up into six groups) might have played a role in this case.

To gain first qualitative insights into attitudes and preferences with respect to palm oil in general as well as certified palm oil and palm-oil-free alternatives, we conducted several online and face-to-face focus group discussions with consumers in Germany prior to this study. The majority of participants indicated to prefer palm-oil-free products for different reasons, such as assumed negative health effects of palm oil consumption, or a lack of trust in certification. Still, the discussions also revealed some reasons why consumers might not pay attention to palm oil or labels when shopping for groceries, such as a lack of time to read the list of ingredients (see reference [59] for detailed results).

Considering the findings from previous studies and the focus group discussions, research hypotheses on palm-oil-related consumer attitudes and preferences to be tested in this study have been developed. Although further research is needed, several studies indicate that consumers prefer both certified sustainable palm oil and alternatives to palm oil over conventional palm oil, if they have a choice (e.g., [47,49,57]). Furthermore, based on the findings by Vergura et al. [16], it might be expected that consumers prefer palm-oil-free products over products containing RSPO-certified palm oil. The study by Gassler and Spiller [49] as well as the focus group discussions [59] suggest that consumers prefer products with an "RSPO certified" label over products with an "RSPO mixed" label. Based on preparatory research for this study in German supermarkets, it was found that RSPO-labeled products usually also carry labels of other certification systems. While studies focusing, for instance, on preferences for Fairtrade and EU organic labels exist (e.g., [60,61]), there is a lack of research on consumers' preferences for RSPO certification for the case that a product carries such labels in addition. This aspect deserves further investigation.

Referring to the conceptual framework presented in Section 2.1, it is expected that different socio-demographic and psychometric criteria might influence consumer preferences. Mixed results were found with respect to socio-economic characteristics. Some studies did not find any statistically significant effects $[47,53,57]$. In contrast, other studies identified significant effects of variables such as age, gender, education, or income-but the results are inconsistent and difficult to compare across studies $[26,48,50,51]$. Concerning psychometric factors, knowledge on palm oil has shown significant effects on attitudes and preferences for palm oil [47,51,62]. Attitudes toward palm oil differ between countries and are not necessarily negative (e.g., [28,56]). PCE was identified as a significant driver of preference heterogeneity in the study by Gassler and Spiller [49], but measured not as a tested scale but using a single item. Verneau et al. [52] found that sustainability concerns increased consumers' intention to consume palm-oil-free products, whereas Borrello et al. [47] identified a negative effect of sustainability concern on the purchase frequency. Engaging in information-seeking behavior related to food and palm oil, in particular, was also found to be a relevant predictor $[47,48,50,52]$. Some studies 
have investigated the influence of additional factors, such as health concerns or interest $[47,50]$ or trust in the food system and in product claims [49]. Further research is required to validate evidence from previous studies. Interestingly, there seems to be no prior research on attitudes toward sustainability certification as a potential driver of preferences for certified palm oil.

Attitudes and preferences might be influenced by information provided to consumers. Disdier et al. [57], for instance, found that the provision of additional information on environmental and health effects of palm oil increased respondents' stated WTP for palm-oil-free products. Similarly, Bateman et al. [53] show that marketing information can be used to boost WTP for (tiger-friendly) palm oil. In line with these studies, it is expected that consumer preferences for both "palm-oil-free"-labeled and RSPO-certified products increase if consumers are provided with additional information on palm oil and certification.

To summarize, the following research hypotheses on consumers' attitudes and preferences shall be tested in this study:

Hypothesis (H1). Consumers, on average, prefer palm-oil-free products and products containing certified sustainable palm oil over unlabeled products that contain conventional palm oil.

Hypothesis (H2). Consumers, on average, prefer palm-oil-free products over products containing RSPO-certified palm oil.

Hypothesis (H3). Consumers, on average, prefer products with an "RSPO certified" label over products with an "RSPO mixed" label.

Hypothesis (H4). Consumer preferences for product attributes and ingredients (such as palm oil) are heterogeneous and differ according to socio-demographic and psychometric aspects.

Hypothesis (H5). The provision of information on palm oil and certification will positively affect preferences for both palm-oil-free products and products containing certified sustainable palm oil, as compared to conventional palm oil.

\section{Materials and Methods}

\subsection{Discrete Choice and Latent Class Approach}

According to the characteristics theory of value by Lancaster [63], the utility of a good is determined by the utility consumers obtain from the combination of its characteristics. These characteristics can be described as product attributes and their respective levels. McFadden's [64] random utility theory adds that an individual's utility function consists of a non-stochastic part that can be estimated based on revealed preferences, and a stochastic part that includes unobserved aspects. The conditional logit (CL) model as a basic form of choice models is based on the assumption of independence of irrelevant alternatives (IIA) [38,64]. The IIA assumption refers to Luce's choice axiom postulating that the odds ratio between two alternatives does not change if, for instance, a third alternative is added $[65,66]$. It has been shown that the IIA is likely to be violated in choice experiments that involve an opt-out ("no choice") option, as respondents who would rather opt out are more likely to choose the least unattractive option instead of choosing randomly in forced-choice situations $[67,68]$. A latent class approach instead allows for explaining preference heterogeneity without requiring the IIA assumption to hold [69]. Latent class analysis assigns respondents to latent segments, which are estimated based on psychographic and socio-demographic variables, so that the members of a segment are relatively homogeneous in their characteristics [69,70].

Following Boxall and Adamowicz [69] and Swait [70], the probability $\pi_{n}(i)$ that individual $n$ of the sample choses alternative $i$ among different alternatives $\mathrm{k}$ of a choice set $\mathrm{C}$ is defined as:

$$
\pi_{n}(i)=\sum_{s=1}^{S} \pi_{n s} \pi_{n \mid s}(i)
$$


where $\pi_{n s}$ is the probability that individual $n$ belongs to segment (or latent class) $s$, and $\pi_{n \mid s}(i)$ is the probability that individual $n$ belonging to segment $s$ chooses alternative $i$. This product of probabilities can be further expressed as:

$$
\pi_{n}(i)=\sum_{s=1}^{S}\left[\frac{\exp \left(\alpha \lambda_{s} Z_{n}\right)}{\sum_{s=1}^{S} \exp \left(\alpha \lambda_{s} Z_{n}\right)}\right]\left[\frac{\exp \left(\mu_{s} \beta_{s} Z_{i}\right)}{\sum_{k \in C} \exp \left(\mu_{s} \beta_{s} X_{k}\right)}\right],
$$

where $Z_{n}$ is a vector of individual-specific characteristics that may include psychometric attributes and/or socio-demographic attributes, $\lambda_{s}$ is the respective segment-specific parameter vector, $Z_{i}$ is a vector of attributes of alternative $i, \beta_{s}$ is the vector of segment-specific utility parameters, and $\alpha$ and $\mu_{s}$ are scale parameters that both have to be set equal to 1 (otherwise it would not be possible to estimate the segment-specific utility parameters).

Apart from the selection of relevant attributes, a major difficulty of latent class analysis lies in determining the number of classes. This decision can be based on different criteria, such as absolute or relative model fit, parsimony, and interpretability, often leading to ambiguous conclusions [71].

\subsection{Choice Design}

Chocolate cookies were chosen as product example because they are rather popular, inexpensive, usually available in German supermarkets, and often contain palm oil. Moreover, no particular brand is associated with this type of product. Table 1 shows the product attributes and their levels that have been included in the choice experiment, as well as the coding of the respective variables. The chocolate content was included as a product attribute because this aspect is a relevant feature of chocolate cookies that is prominently advertised on the packages. Dummy coding was used instead of effects coding for the categorical variables in order to facilitate the interpretation of coefficients in relation to the respective reference level and the calculation of meaningful values for WTP after estimation. In general, it is also possible to transform the parameter values to another coding scheme after estimation [72]. The levels of the price attribute and the chocolate content attribute are based on a preparatory market survey conducted in German supermarkets and discounters, considering variations in other product attributes. Two different RSPO labels have been considered. One-hundred percent RSPO-certified palm oil ("RSPO certified") indicates that all of the palm oil used for the product has been certified, while the "mixed" version ("RSPO mixed") allows for blending with uncertified palm oil.

Table 1. Product attributes, levels, and coding.

\begin{tabular}{ccc}
\hline Product Attribute & Levels & Variable Coding \\
\hline price (€ per 200 g unit) & $\begin{array}{c}0.79,1.49,2.49,3.99 \\
\text { conventional palm oil, } \\
\text { "mixed" RSPO-certified palm oil, } \\
100 \% \text { RSPO-certified palm oil, } \\
\text { "palm-oil-free" labeled }\end{array}$ & $\begin{array}{c}\text { continuous } \\
\text { reference level: conventional palm oil }\end{array}$ \\
EU organic certification & yes, no & $\begin{array}{c}\text { dummy coding; } \\
\text { reference level: no } \\
\text { dummy coding; }\end{array}$ \\
Fairtrade certification & yes, no & $\begin{array}{c}\text { reference level: no } \\
\text { dummy coding; } \\
\text { chocolate content }\end{array}$ \\
reference level: $20 \%$
\end{tabular}

RSPO—Roundtable on Sustainable Palm Oil.

An unlabeled D-efficient choice design was created using the software Ngene 1.2 (ChoiceMetrics Pty Ltd, Sydney) [73]. To obtain priors for the choice design, a pilot study was conducted with a convenience sample of 57 respondents. The final D-efficient choice design generated two blocks of eight choice sets, respectively. Each choice set consisted of two product alternatives and one opt-out option ("I choose neither of the two alternatives."), as shown in the example in Figure 1, which has 
been translated from the German original. The RSPO labels were used in their German versions shown in Figure 1; "gemischt" meaning "mixed", and "zertifiziert" meaning "certified". Permission to use the different labels for the purpose of the study was granted in advance. The data analysis was performed using Stata 16 (StataCorp LLC, College Station, Texas).
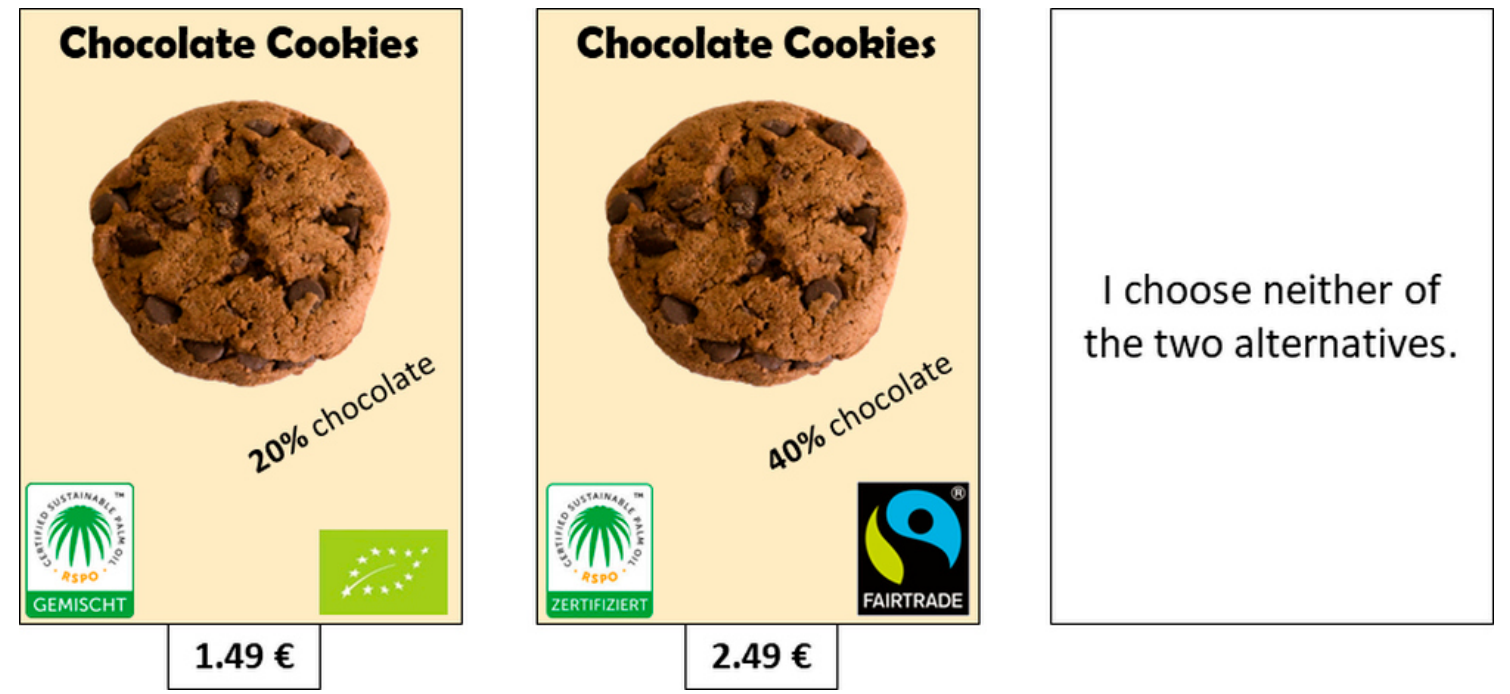

Figure 1. Example of a choice task.

\subsection{Questionnaire Design}

The questionnaire was structured into different parts. First, respondents had to answer questions related to their socio-economic characteristics. The second part comprised questions related to shopping behavior and preferences, focusing on the example of chocolate cookies as well as on sustainability certification. Respondents were, for instance, asked to assess different statements concerning their perception of sustainability certification. Next, respondents had to complete the first part of the choice experiment. They were randomly assigned to one of the two choice blocks consisting of eight choice sets. The order of choice sets within the block was also randomly determined. Prior to the first task, a so-called "cheap talk script" was presented to the respondents. Cheap talk scripts have originally been introduced by Cummings and Taylor [74] as an ex-ante calibration method for mitigating hypothetical bias that might result in an overstated willingness to pay [75]. The script used in this study has been inspired by cheap talk scripts applied in previous studies (e.g., [76,77]). The translated version of the script is provided in Appendix A. In contrast to the study by Gassler and Spiller [49], no additional background information on palm oil and the different certification systems was provided prior to the choice experiment in order to imitate a real shopping situation.

The next part of the questionnaire concerned knowledge and attitudes. Respondents were asked to provide a self-assessment of their knowledge on palm oil adopted from Schmitt et al. [62]. Attitudes were measured using several statements on palm oil that had been derived from the focus group discussions [59]. Before the second part of the choice experiment, background information on palm oil and the different labels of RSPO, Fairtrade, and EU organic was provided. The translated version of the text is provided in Appendix B. A comprehension question was used to test understanding of the information provided. The correct answer was provided to all respondents. As Howard et al. [78] found that the effectiveness of cheap talk scripts might diminish over time, a brief reminder script was used. Respondents were allocated to the choice block they had not yet answered in the first part. Afterward, respondents were asked to evaluate statements related to psychometric scales that had been adapted from previous studies, measuring concern about sustainability issues [45] and PCE [43]. The last part involved statements with respect to respondents' information-seeking behavior. 
The questionnaire was pretested at different stages. Cognitive pretests were conducted to identify and revise potentially problematic questions and items. The technical implementation of the online survey was pretested to verify functionality and usability.

\section{Results}

\subsection{Characteristics of the Sample}

The survey was implemented in April 2020 with a quota-based sample of 1000 respondents, recruited from the online panel of a market research organization, which also provided the web implementation of the questionnaire. Quotas were determined based on official statistics of the German population with respect to age, gender, education level, employment status, household size, net household income, and geographic distribution according to federal states [79]. The age range was set to 18-70 years, as this is a typical range available in online panels that allows for meeting quota requirements [80]. Table 2 shows the distribution of selected characteristics of the sample in comparison to the German population. The indicated mean and median age were approximated based on the year of birth. Intervals are indicated for some attributes, as the available statistics used different age ranges (e.g., 20-64 years or 15 years onwards). People with higher education levels are overrepresented, but otherwise, the sample is well aligned with population statistics.

Table 2. Selected socio-demographic characteristics of the sample.

\begin{tabular}{|c|c|c|c|}
\hline$(n=1000)$ & & Sample & Population $^{1}$ \\
\hline \multirow{2}{*}{ Age } & year of birth (range) & 1948-2001 & 1948-2001 \\
\hline & age (mean/median) & $46 / 47$ & $45 / 46$ \\
\hline \multirow{3}{*}{ Gender $(\%)$} & female & 50.3 & 49.54 \\
\hline & male & 49.5 & 50.46 \\
\hline & diverse & 0.2 & no official data \\
\hline \multirow{4}{*}{ Education level (school) (\%) } & no school leaving diploma or still in school & 0.8 & $4-7$ \\
\hline & primary or lower secondary school & 12.2 & $22-30$ \\
\hline & secondary school or equivalent & 37.7 & $23-27$ \\
\hline & higher education entrance qualification & 49.3 & $32-40$ \\
\hline \multirow{2}{*}{ University/college degree (\%) } & yes & 26.1 & $18-20$ \\
\hline & no & 73.9 & $80-82$ \\
\hline \multirow{4}{*}{ Monthly net household income (\%) } & $<€ 1300$ & 20.8 & 19.4 \\
\hline & $€ 1300-2599$ & 38.5 & 37.4 \\
\hline & $€ 2600-4499$ & 28.4 & 28.3 \\
\hline & $\geq € 4500$ & 12.3 & 14.9 \\
\hline \multirow{4}{*}{ Geographic location (\%) } & North & 17.8 & 18.0 \\
\hline & East & 17.4 & 17.3 \\
\hline & South & 29.5 & 29.3 \\
\hline & West & 35.3 & 35.4 \\
\hline
\end{tabular}

${ }^{1}$ The population statistics are based on Destatis' extrapolations from the most recent census data for Germany (2011) to the most recent valuation date (31 December 2018) [79].

\subsection{Principal Component Analysis}

Principal component analysis (PCA) was conducted to summarize several 7-point Likert scale items to factors to be included in the choice analysis. Two scales were adopted, slightly modified and translated to German from the literature: concern about sustainability issues [45] and PCE [43]. The English versions of all items included in the PCA are presented in Appendix C. The number of retained factors was determined based on the consideration of different criteria: Kaiser criterion, scree plot, parallel analysis, percentage of explained variance, and the interpretability of the factors [81]. Oblique factor rotation according to the Promax method was applied if more than one factor was identified due to the underlying assumption that the factors are related [81]. This assumption was confirmed by analyzing the correlation between the resulting factors. Table 3 shows the results and the indicators for sampling adequacy and reliability. 
Table 3. Principal component analysis (PCA) results.

\begin{tabular}{ccccc}
\hline Scale/Set of Items & $\begin{array}{c}\text { Kaiser-Meyer-Olkin } \\
\text { (KMO) Measure }\end{array}$ & Retained Factors & No. of Items & Cronbach's Alpha \\
\hline $\begin{array}{c}\text { trust in certification, } \\
\begin{array}{c}\text { perceptions of palm oil, } \\
\text { interest in product information }\end{array}\end{array}$ & 0.863 & $\begin{array}{c}\text { certification support } \\
\text { certification skepticism } \\
\text { informed consumption } \\
\text { palm oil objection }\end{array}$ & 4 & 0.813 \\
\hline $\begin{array}{c}\text { concern about } \\
\text { sustainability issues }\end{array}$ & 0.962 & sustainability concern & 15 & 0.733 \\
\hline $\begin{array}{c}\text { perceived consumer } \\
\text { effectiveness (PCE) }\end{array}$ & 0.698 & PCE & 5 & 0.848 \\
\hline
\end{tabular}

The Kaiser-Meyer-Olkin (KMO) measure of sampling adequacy clearly exceeds 0.5 , which is regarded as the minimum threshold of acceptance [81,82]. The item-specific measures of sampling adequacy (MSAs) - which are not shown here for the sake of brevity-also exceed this threshold, with no MSA value below 0.6. The factor "certification support" is associated with statements that express general support toward sustainability certification, while "certification skepticism" comprises statements that express skepticism with respect to the reliability and effectiveness of sustainability certification. The factor "informed consumption" summarizes statements that are related to the perceived importance of information and respondents' information-seeking behavior. The factor "palm oil objection" includes statements that express rejection of palm oil. Reliability is measured by Cronbach's alpha, which should exceed 0.6 (better: $>0.7$ ) [81,83]. Based on this criterion, all retained factors are sufficiently reliable, although "palm oil objection" just meets the threshold.

\subsection{Results of the Choice Analysis}

Among the sample, 44 respondents always chose the opt-out option in both parts of the choice experiment. Asked for their reason for always opting out, the majority of respondents indicated to dislike chocolate cookies in general. It was decided to exclude these observations from the analysis because they would not provide any useful insights on preferences for the product attributes. Thus, the sample size for subsequent analyses was reduced to 956. The choice data were analyzed using Stata 16 . The Hausman test $[84,85]$ confirmed that a conditional logit model was inappropriate due to the violation of the IIA assumption. Thus, mixed logit (ML) models were estimated using the mixlogit module for Stata [86] to check for preference heterogeneity. All product-related variables were specified as having random effects. One model was estimated based on the data for the first part of the choice experiment, and one model for the second part after information provision. The results are presented in Table 4.

With respect to the hypotheses developed in Section 2.2, H1, H2, and H3 can be confirmed for part 2 of the choice experiment, as the variable palm-oil-free has the largest coefficient, followed by RSPO certified and RSPO mixed. All three coefficients are positive and highly significant, meaning that the respective claims are all preferred over conventional palm oil. For part 1, the three hypotheses can only be partly confirmed, considering that RSPO mixed is not significant. On average, respondents in both parts preferred cheaper cookies with $40 \%$ chocolate content, and derived utility from EU organic and Fairtrade certification. However, the standard deviations of several coefficients indicate that there is indeed preference heterogeneity (H4). Moreover, there are significant differences between the two parts, indicating that information provision might affect preferences. Particularly the coefficients of the two RSPO labels and for the palm-oil-free claim all strongly increased compared to the reference level, supporting $\mathbf{H 5}$. The large negative coefficient for the opt-out variable indicates that respondents on average tend to prefer a cookie product. However, a relevant disadvantage of dummy coding is that the alternative-specific constant for the opt-out option is confounded with the reference level of the product attributes [87]. To test the coding effect on the opt-out coefficient, the models were estimated 
again using effects coding. The results showed that the opt-out coefficient was larger but still negative and highly significantly negative in both parts ( -2.696 vs. -2.337$)$.

Table 4. Mixed logit results for both parts of the choice experiment.

\begin{tabular}{ccccc}
\hline ( $n$ = 956) & \multicolumn{2}{c}{ Part 1 } & \multicolumn{2}{c}{ Part 2 } \\
\hline mean & coeff. & (std. err.) & coeff. & (std. err.) \\
\hline opt-out & $-4.267^{* * *}$ & 0.164 & $-3.137^{* * *}$ & 0.154 \\
price & $-1.324^{* * *}$ & 0.053 & $-1.263^{* * *}$ & 0.051 \\
RSPO certified & $0.146^{*}$ & 0.063 & $0.928^{* * *}$ & 0.066 \\
RSPO mixed & $0.036^{* *}$ & 0.061 & $0.464^{* * *}$ & 0.062 \\
palm-oil-free & $0.451^{* * *}$ & 0.076 & $1.799^{* * *}$ & 0.086 \\
EU organic & $0.412^{* * *}$ & 0.038 & $0.357^{* * *}$ & 0.038 \\
Fairtrade & $0.754^{* * *}$ & 0.066 & $0.626^{* * *}$ & 0.068 \\
$40^{*}$ chocolate & $0.798^{* * *}$ & 0.055 & $0.640^{* * *}$ & 0.053 \\
\hline standard deviation & coeff. & (std. err.) & coeff. & (std. err.) \\
\hline opt-out & $3.283^{* * *}$ & 0.186 & $3.338^{* * *}$ & 0.147 \\
price & $1.098^{* * *}$ & 0.048 & $1.060^{* * *}$ & 0.044 \\
RSPO certified & $0.151^{*}$ & 0.093 & 0.034 & 0.098 \\
RSPO mixed & $0.260^{*}$ & 0.113 & 0.032 & 0.164 \\
palm-oil-free & $0.078^{* *}$ & 0.167 & $1.110^{* * *}$ & 0.101 \\
EU organic & $0.005^{* *}$ & 0.140 & 0.014 & 0.088 \\
Fairtrade & $0.532^{* * *}$ & 0.095 & $0.700^{* * *}$ & 0.091 \\
$40^{*}$ chocolate & $-0.818^{* * *}$ & 0.065 & $0.733^{* * *}$ & 0.073 \\
\hline
\end{tabular}

Note: ${ }^{* *} ; * * *$ denote significance at $p<0.001 ; p<0.01 ; p<0.05$, respectively.

In the next step, latent class analyses were conducted to explore preference heterogeneity in more detail. The lclogit2 module for Stata developed by Yoo [88] as an update to lclogit [89] was used for this purpose. This module uses the expectation-maximization (EM) algorithm according to Bhat [90]. In addition to the factors resulting from the PCA described in Section 4.2, a variable for the self-assessed knowledge on palm oil as well as socio-demographic variables for age, gender, household income, and educational level were included in the model as individual-specific characteristics. Separate models for the two parts of the choice experiment were estimated with varying number of classes (2-7).

The model fit was evaluated based on the Bayesian information criterion (BIC) [91] and the consistent Akaike information criterion (CAIC) [92], with the lowest values indicating the best model fit. Nylund et al. [93] have shown that the Akaike information criterion (AIC) [94] is less accurate and tends to overestimate the number of classes. Table 5 shows the information criteria, the log-likelihood at convergence (LL), and the number of parameters (n.p.) for the different models. For comparison, Table 5 also includes the respective statistics for the conditional logit (CL) and mixed logit (ML) models that do not include individual-specific variables. The results suggest a six-classes solution for part 1 and a five-classes solution for part 2.

Table 5. Model fit comparison.

\begin{tabular}{cccccccccc}
\hline & \multicolumn{9}{c}{ Part 1 } \\
\hline Classes & n.p. & LL & AIC & CAIC & BIC & LL & AIC & CAIC & BIC \\
\hline $1(\mathrm{CL})$ & 8 & -7031 & 14,077 & 14,124 & 14,116 & -7414 & 14,844 & 14,891 & 14,883 \\
$1(\mathrm{ML})$ & 16 & -5832 & 11,697 & 11,792 & 11,775 & -6107 & 12,246 & 12,340 & 12,324 \\
\hline 2 & 30 & -6294 & 12,648 & 12,824 & 12,794 & -6676 & 13,411 & 13,587 & 13,557 \\
3 & 52 & -5734 & 11,572 & 11,877 & 11,825 & -5858 & 11,820 & 12,125 & 12,073 \\
4 & 74 & -5631 & 11,410 & 11,844 & 11,770 & -5694 & 11,536 & 11,970 & 11,896 \\
5 & 96 & -5524 & 11,232 & 11,795 & 11,699 & -5599 & 11,390 & 11,953 & 11,857 \\
6 & 118 & -5411 & 11,058 & 11,750 & 11,632 & -5529 & 11,294 & 11,986 & 11,868 \\
7 & 140 & -5372 & 11,024 & 11,845 & 11,705 & -5462 & 11,203 & 12,024 & 11,884 \\
\hline
\end{tabular}

$\mathrm{CL}$-conditional logit, ML-mixed logit, n.p.-number of parameters, LL-log-likelihood at convergence, AIC-Akaike information criterion, CAIC - consistent Akaike information criterion, BIC-Bayesian information criterion. 
Table 6 shows the results of the latent class analysis for part 1 of the choice experiment. The indicated class share is the mean posterior probability of class membership over all respondents. The latent classes have been labeled to describe the characteristics and preferences of their members. The coefficients for the membership variables have to be interpreted in relation to class 6 , which is the reference class for the estimated model determined by Stata. In general, a significant positive (negative) coefficient of a membership variable means that-all else being equal—an increase in that variable increases (decreases) the likelihood of membership of the respective class, as compared to the reference class. To get a complete picture, the models have been estimated several times to obtain results for all possible reference classes. The variables that showed insignificant coefficients for all groups in all estimated model variants are highlighted in light-grey color. For part 1, this concerns the gender dummy female and the factor for palm oil (PO) objection.

The characteristics of the identified latent classes are described in the following paragraphs. The "palm oil avoiders" in class 1 have high preferences for PO-free products and insignificant preferences for the two forms of RSPO certification (RSPO certified; RSPO mixed). The coefficients for Fairtrade certification and $40 \%$ chocolate are highly significant and positive. "Palm oil avoiders" express a higher involvement with respect to information-seeking behavior compared to the reference class, as indicated by the level of informed cons(umption). This is also the case if the reference class is set to the "plain cookie eaters" or the "chocolate lovers". Members of class 1 tend to express a lower level of cert(ification) skepticism and PO knowledge compared to the reference class. The "plain cookie eaters" (class 2) are the largest segment comprising nearly one-third of all respondents. They are highly price-sensitive and clearly reject RSPO mixed, PO-free, and EU organic labels. As none of the attributes is associated with positive utility, they seem to prefer cheap, plain cookies. With respect to the membership variables, this segment is not clearly distinguishable from the "cheap shoppers", although the product preferences are quite different. The only significant variables are age and high income, but the significance of both coefficients is not very high. Analyzing variants of the model it was found that it is less likely that individuals with high PCE, sust(ainability concern), or informed consumption are in the class of "plain cookie eaters" compared with the class of "concerned consumers", for instance.

Class 3 has been labeled "palm oil neutrals" because the coefficients for all three palm-oil-related variables are insignificant. The members show highly significant preferences for EU organic and Fairtrade certification. Compared to the reference, they are more concerned about sustainability issues, tend to support sustainability certification, and believe in sustainability certifications' effectiveness. They are also more likely to engage in informed consumption behavior. However, they rate their PO knowledge lower than the members of class 6 . This group seems to be much more involved and interested in sustainable consumption behavior than the reference class. The "chocolate lovers" (class 4) are the smallest segment. They show a strong preference for higher chocolate content, while the coefficients for all other product attributes are insignificant. They are only slightly price-sensitive and are more likely to have a higher household income than the "cheap shoppers". Among the psychometric membership variables, only the positive sustainability concern is significant.

The "concerned consumers" in class 5 are characterized by highly significant preferences for cookies with RSPO certified, PO-free, EU organic, and Fairtrade labels. It is the only segment with significant preferences for RSPO-certified cookies, but they still prefer the palm-oil-free alternative. The appreciation for these credence attributes is also reflected in the lack of price-sensitivity. Compared to the reference class, this segment seems to care most about sustainability and certification, as the coefficients for certification support, certification skepticism, sustainability concern, and informed consumption indicate. PCE has no significant coefficient in this model variant, but comparisons with other reference segments showed that respondents with high PCE values are more likely to be "concerned consumers" than "palm oil neutrals" or "plain cookie eaters". Higher income increases the likelihood to be a member of this class. The reference group of "cheap shoppers" (class 6) is very price-sensitive. However, its members show significantly positive and relatively high preferences 
for higher chocolate content as well as RSPO mixed and Fairtrade certification. It is the only class that associates a positive utility with RSPO mixed certification, while the coefficient for RSPO certified remains insignificant. These counterintuitive preferences cannot be rationally explained. Compared to classes 2 to 5, "cheap shoppers" are more likely to be older and less likely to have a high income.

Table 6. Latent class analysis for part 1 of the choice experiment.

\begin{tabular}{|c|c|c|c|c|c|c|}
\hline Latent Class & Class 1 & Class 2 & Class 3 & Class 4 & Class 5 & Class 6 \\
\hline Label & $\begin{array}{l}\text { Palm Oil } \\
\text { Avoiders }\end{array}$ & $\begin{array}{l}\text { Plain } \\
\text { Cookie } \\
\text { Eaters }\end{array}$ & $\begin{array}{l}\text { Palm Oil } \\
\text { Neutrals }\end{array}$ & $\begin{array}{l}\text { Chocolate } \\
\text { Lovers }\end{array}$ & $\begin{array}{l}\text { Concerned } \\
\text { Consumers }\end{array}$ & $\begin{array}{l}\text { Cheap } \\
\text { Shoppers }\end{array}$ \\
\hline class share & $13.5 \%$ & $31.7 \%$ & $19.7 \%$ & $7.4 \%$ & $16.4 \%$ & $11.4 \%$ \\
\hline \multicolumn{7}{|c|}{ product variables: coefficient (standard error) } \\
\hline opt-out & $\begin{array}{l}0.849^{* * *} \\
(0.211)\end{array}$ & $\begin{array}{l}-10.291 \text { *** } \\
(0.917)\end{array}$ & $\begin{array}{l}-2.734^{\text {**** }} \\
(0.279)\end{array}$ & $\begin{array}{l}-1.481^{* *} \\
(0.537)\end{array}$ & $\begin{array}{l}-1.523^{* * *} \\
(0.326)\end{array}$ & $\begin{array}{l}-2.704 \\
(0.393)\end{array}$ \\
\hline price & $\begin{array}{l}-0.584^{* * *} \\
(0.096)\end{array}$ & $\begin{array}{l}-2.588^{* * *} \\
(0.208)\end{array}$ & $\begin{array}{l}-0.823^{* * *} \\
(0.077)\end{array}$ & $\begin{array}{l}-0.362 * \\
(0.156)\end{array}$ & $\begin{array}{l}-0.109 \\
(0.096)\end{array}$ & $\begin{array}{l}-3.161 \\
(0.399)\end{array}$ \\
\hline RSPO certified & $\begin{array}{l}0.131 \\
(0.178)\end{array}$ & $\begin{array}{l}-0.448 \\
(0.277)\end{array}$ & $\begin{array}{l}0.201 \\
(0.134)\end{array}$ & $\begin{array}{l}-0.257 \\
(0.310)\end{array}$ & $\begin{array}{l}0.438^{* *} \\
(0.145)\end{array}$ & $\begin{array}{l}0.524 \\
(0.293)\end{array}$ \\
\hline RSPO mixed & $\begin{array}{l}-0.211 \\
(0.203)\end{array}$ & $\begin{array}{l}-1.409 \text { *** } \\
(0.368)\end{array}$ & $\begin{array}{l}0.151 \\
(0.139)\end{array}$ & $\begin{array}{l}-0.611 \\
(0.346)\end{array}$ & $\begin{array}{l}0.037 \\
(0.147)\end{array}$ & $\begin{array}{l}0.791 \text { ** } \\
(0.304)\end{array}$ \\
\hline PO-free & $\begin{array}{l}0.966^{* * *} \\
(0.182)\end{array}$ & $\begin{array}{l}-1.264 \text { * } \\
(0.517)\end{array}$ & $\begin{array}{l}-0.116 \\
(0.161)\end{array}$ & $\begin{array}{l}-0.428 \\
(0.528)\end{array}$ & $\begin{array}{l}0.943^{* * *} \\
(0.195)\end{array}$ & $\begin{array}{l}0.567 \\
(0.387)\end{array}$ \\
\hline EU organic & $\begin{array}{l}0.151 \\
(0.125)\end{array}$ & $\begin{array}{l}-0.837^{* *} \\
(0.289)\end{array}$ & $\begin{array}{l}0.507^{* * *} \\
(0.097)\end{array}$ & $\begin{array}{l}-0.192 \\
(0.290)\end{array}$ & $\begin{array}{l}0.723 * * * \\
(0.106)\end{array}$ & $\begin{array}{l}0.266 \\
(0.196)\end{array}$ \\
\hline Fairtrade & $\begin{array}{l}0.804 * * * \\
(0.174)\end{array}$ & $\begin{array}{l}-0.760 \\
(0.399)\end{array}$ & $\begin{array}{l}0.644^{* * *} \\
(0.130)\end{array}$ & $\begin{array}{l}-0.353 \\
(0.371)\end{array}$ & $\begin{array}{l}1.496 * * * \\
(0.187)\end{array}$ & $\begin{array}{l}0.860^{*} \\
(0.333)\end{array}$ \\
\hline $40 \%$ chocolate & $\begin{array}{l}0.913 * * * \\
(0.172)\end{array}$ & $\begin{array}{l}-0.212 \\
(0.321)\end{array}$ & $\begin{array}{l}0.006 \\
(0.123)\end{array}$ & $\begin{array}{l}3.187^{* * *} \\
(0.510)\end{array}$ & $\begin{array}{l}0.565^{* * *} \\
(0.129)\end{array}$ & $\begin{array}{l}1.473^{* * *} \\
(0.249)\end{array}$ \\
\hline \multicolumn{7}{|c|}{ membership variables: coefficient (standard error) } \\
\hline age & $\begin{array}{l}-0.021 \\
(0.013)\end{array}$ & $\begin{array}{l}-0.027^{*} \\
(0.010)\end{array}$ & $\begin{array}{l}-0.068^{* * *} \\
(0.013)\end{array}$ & $\begin{array}{l}-0.035^{*} \\
(0.014)\end{array}$ & $\begin{array}{l}-0.051^{* * *} \\
(0.013)\end{array}$ & \\
\hline female & $\begin{array}{l}0.151 \\
(0.182)\end{array}$ & $\begin{array}{l}0.168 \\
(0.143)\end{array}$ & $\begin{array}{l}0.297 \\
(0.181)\end{array}$ & $\begin{array}{l}0.31 \\
0(0.192)\end{array}$ & $\begin{array}{l}0.100 \\
(0.175)\end{array}$ & \\
\hline high education & $\begin{array}{l}0.058 \\
(0.272)\end{array}$ & $\begin{array}{l}-0.208 \\
(0.225)\end{array}$ & $\begin{array}{l}-0.121 \\
(0.276)\end{array}$ & $\begin{array}{l}-0.302 \\
(0.314)\end{array}$ & $\begin{array}{l}-0.323 \\
(0.272)\end{array}$ & \\
\hline medium education & $\begin{array}{l}-0.636 \text { * } \\
(0.268)\end{array}$ & $\begin{array}{l}-0.093 \\
(0.203)\end{array}$ & $\begin{array}{l}-0.556 \text { * } \\
(0.276)\end{array}$ & $\begin{array}{l}0.013 \\
(0.293)\end{array}$ & $\begin{array}{l}-0.161 \\
(0.260)\end{array}$ & \\
\hline high income & $\begin{array}{l}0.406 \\
(0.298)\end{array}$ & $\begin{array}{l}0.557^{*} \\
(0.241)\end{array}$ & $\begin{array}{l}0.600^{*} \\
(0.284)\end{array}$ & $\begin{array}{l}0.738^{*} \\
(0.303)\end{array}$ & $\begin{array}{l}0.891 \text { ** } \\
(0.281)\end{array}$ & \\
\hline medium income & $\begin{array}{l}0.296 \\
(0.237)\end{array}$ & $\begin{array}{l}0.091 \\
(0.189)\end{array}$ & $\begin{array}{l}0.121 \\
(0.235)\end{array}$ & $\begin{array}{l}-0.060 \\
(0.251)\end{array}$ & $\begin{array}{l}0.467 \\
(0.231)\end{array}$ & \\
\hline cert. support & $\begin{array}{l}0.324 \\
(0.203)\end{array}$ & $\begin{array}{l}0.275 \\
(0.157)\end{array}$ & $\begin{array}{l}0.764^{* * *} \\
(0.205)\end{array}$ & $\begin{array}{l}0.432 \\
(0.218)\end{array}$ & $\begin{array}{l}0.944^{* * *} \\
(0.204)\end{array}$ & \\
\hline cert. skepticism & $\begin{array}{l}-0.379 * \\
(0.191)\end{array}$ & $\begin{array}{l}-0.216 \\
(0.150)\end{array}$ & $\begin{array}{l}-0.572 \text { ** } \\
(0.193)\end{array}$ & $\begin{array}{l}-0.178 \\
(0.204)\end{array}$ & $\begin{array}{l}-0.470 * \\
(0.181)\end{array}$ & \\
\hline PO objection & $\begin{array}{l}0.052 \\
(0.197)\end{array}$ & $\begin{array}{l}0.133 \\
(0.165)\end{array}$ & $\begin{array}{l}-0.112 \\
(0.194)\end{array}$ & $\begin{array}{l}-0.090 \\
(0.213)\end{array}$ & $\begin{array}{l}0.053 \\
(0.189)\end{array}$ & \\
\hline PO knowledge & $\begin{array}{l}-0.283^{*} \\
(0.130)\end{array}$ & $\begin{array}{l}-0.189 \\
(0.103)\end{array}$ & $\begin{array}{l}-0.384 \\
(0.126)\end{array}$ & $\begin{array}{l}-0.162 \\
(0.135)\end{array}$ & $\begin{array}{l}-0.123 \\
(0.125)\end{array}$ & \\
\hline PCE & $\begin{array}{l}0.430 \\
(0.263)\end{array}$ & $\begin{array}{l}0.010 \\
(0.194)\end{array}$ & $\begin{array}{l}-0.053 \\
(0.259)\end{array}$ & $\begin{array}{l}-0.108 \\
(0.272)\end{array}$ & $\begin{array}{l}0.396 \\
(0.248)\end{array}$ & \\
\hline sust. concern & $\begin{array}{l}0.454 \\
(0.246)\end{array}$ & $\begin{array}{l}0.298 \\
(0.184)\end{array}$ & $\begin{array}{l}0.579 * \\
(0.243)\end{array}$ & $\begin{array}{l}0.570^{*} \\
(0.266)\end{array}$ & $\begin{array}{l}0.885^{* * *} \\
(0.250)\end{array}$ & \\
\hline informed cons. & $\begin{array}{l}0.667^{*} \\
(0.271)\end{array}$ & $\begin{array}{l}-0.349 \\
(0.211)\end{array}$ & $\begin{array}{l}0.896^{* *} \\
(0.271)\end{array}$ & $\begin{array}{l}-0.048 \\
(0.295)\end{array}$ & $\begin{array}{l}0.581 * \\
(0.274)\end{array}$ & \\
\hline _constant & $\begin{array}{l}0.498 \\
(0.279) \\
\end{array}$ & $\begin{array}{l}1.354^{* * *} \\
(0.237) \\
\end{array}$ & $\begin{array}{l}0.817^{* *} \\
(0.286) \\
\end{array}$ & $\begin{array}{l}0.036 \\
(0.332) \\
\end{array}$ & $\begin{array}{l}0.208 \\
(0.289) \\
\end{array}$ & \\
\hline
\end{tabular}

Note: ${ }^{* * *} ; * * *{ }^{*}$ denote significance at $p<0.001 ; p<0.01 ; p<0.05$, respectively. PO-palm oil.

Table 7 shows the latent classes after information provision (part 2). Based on the coefficients and class shares, the results were compared with part 1 to identify relevant changes. The results suggest that the "palm oil neutrals" have split up into other segments. The "palm oil avoiders" gained class 
share, although not as much as the "concerned consumers". The class share of the largest segment, the "plain cookie eaters", has only marginally changed. However, its members now express significant and strong preferences for the RSPO certified attribute, while still no positive utility is derived from any other product attributes. It has to be considered that this group is still highly price-sensitive, so the support for RSPO-certified palm oil does not automatically translate into the willingness to pay a high premium for this attribute. Except for the "chocolate lovers", all segments now express significantly positive preferences for the RSPO certified label.

Table 7. Latent class analysis for part 2 of the choice experiment.

\begin{tabular}{|c|c|c|c|c|c|}
\hline Latent Class & Class 1 & Class 2 & Class 3 & Class 4 & Class 5 \\
\hline Label & $\begin{array}{l}\text { Palm Oil } \\
\text { Avoiders }\end{array}$ & $\begin{array}{l}\text { Plain Cookie } \\
\text { Eaters }\end{array}$ & $\begin{array}{l}\text { Concerned } \\
\text { Consumers }\end{array}$ & $\begin{array}{l}\text { Chocolate } \\
\text { Lovers }\end{array}$ & $\begin{array}{l}\text { Cheap } \\
\text { Shoppers }\end{array}$ \\
\hline class share & $21.2 \%$ & $31.6 \%$ & $27.5 \%$ & $7.2 \%$ & $12.5 \%$ \\
\hline \multicolumn{6}{|c|}{ product variables: coefficient (standard error) } \\
\hline opt-out & $\begin{array}{l}1.216^{* * *} \\
(0.178)\end{array}$ & $\begin{array}{l}-8.456^{* * *} \\
(0.572)\end{array}$ & $\begin{array}{l}-1.517^{* * *} \\
(0.205)\end{array}$ & $\begin{array}{l}0.272 \\
(0.315)\end{array}$ & $\begin{array}{l}-2.642^{* * *} \\
(0.386)\end{array}$ \\
\hline price & $\begin{array}{l}-0.677^{* * *} \\
(0.083)\end{array}$ & $\begin{array}{l}-2.278^{* * *} \\
(0.138)\end{array}$ & $\begin{array}{l}-0.191 \\
(0.060)\end{array}$ & $\begin{array}{l}-0.394^{* * *} \\
(0.106)\end{array}$ & $\begin{array}{l}-2.731^{* * *} \\
(0.472)\end{array}$ \\
\hline RSPO certified & $\begin{array}{l}1.171^{* * *} \\
(0.175)\end{array}$ & $\begin{array}{l}0.515^{* *} \\
(0.183)\end{array}$ & $\begin{array}{l}1.039^{* * *} \\
(0.096)\end{array}$ & $\begin{array}{l}0.213 \\
(0.270)\end{array}$ & $\begin{array}{l}0.662 \text { * } \\
(0.284)\end{array}$ \\
\hline RSPO mixed & $\begin{array}{l}0.006 \\
(0.218)\end{array}$ & $\begin{array}{l}-0.114 \\
(0.194)\end{array}$ & $\begin{array}{l}0.482^{* * *} \\
(0.096)\end{array}$ & $\begin{array}{l}0.594^{*} \\
(0.280)\end{array}$ & $\begin{array}{l}0.397 \\
(0.275)\end{array}$ \\
\hline PO-free & $\begin{array}{l}2.717^{* * *} \\
(0.193)\end{array}$ & $\begin{array}{l}0.116 \\
(0.233)\end{array}$ & $\begin{array}{l}1.537^{* * *} \\
(0.129)\end{array}$ & $\begin{array}{l}0.745^{*} \\
(0.340)\end{array}$ & $\begin{array}{l}0.980 * \\
(0.466)\end{array}$ \\
\hline EU organic & $\begin{array}{l}0.236 * \\
(0.099)\end{array}$ & $\begin{array}{l}-0.295 \\
(0.171)\end{array}$ & $\begin{array}{l}0.456^{* * *} \\
(0.060)\end{array}$ & $\begin{array}{l}-0.558^{* *} \\
(0.208)\end{array}$ & $\begin{array}{l}0.034 \\
(0.167)\end{array}$ \\
\hline Fairtrade & $\begin{array}{l}0.664^{* * *} \\
(0.142)\end{array}$ & $\begin{array}{l}-0.861 \\
(0.239)\end{array}$ & $\begin{array}{l}0.894^{* * *} \\
(0.109)\end{array}$ & $\begin{array}{l}-0.068 \\
(0.253)\end{array}$ & $\begin{array}{l}-0.063 \\
(0.346)\end{array}$ \\
\hline $40 \%$ chocolate & $\begin{array}{l}0.325^{* *} \\
(0.122)\end{array}$ & $\begin{array}{l}-0.6022^{* *} \\
(0.220)\end{array}$ & $\begin{array}{l}0.181 \text { * } \\
(0.080)\end{array}$ & $\begin{array}{l}2.847^{* * *} \\
(0.299)\end{array}$ & $\begin{array}{l}0.870^{* * *} \\
(0.224)\end{array}$ \\
\hline \multicolumn{6}{|c|}{ membership variables: coefficient (standard error) } \\
\hline age & $\begin{array}{l}-0.004 \\
(0.011)\end{array}$ & $\begin{array}{l}-0.037^{* * *} \\
(0.010)\end{array}$ & $\begin{array}{l}-0.043^{* * *} \\
(0.010)\end{array}$ & $\begin{array}{l}-0.020 \\
(0.014)\end{array}$ & \\
\hline female & $\begin{array}{l}0.306 \text { * } \\
(0.154)\end{array}$ & $\begin{array}{l}0.205 \\
(0.134)\end{array}$ & $\begin{array}{l}0.163 \\
(0.144)\end{array}$ & $\begin{array}{l}0.137 \\
(0.185)\end{array}$ & \\
\hline high education & $\begin{array}{l}-0.136 \\
(0.231)\end{array}$ & $\begin{array}{l}-0.010 \\
(0.203)\end{array}$ & $\begin{array}{l}-0.208 \\
(0.222)\end{array}$ & $\begin{array}{l}0.188 \\
(0.313)\end{array}$ & \\
\hline medium education & $\begin{array}{l}-0.257 \\
(0.218)\end{array}$ & $\begin{array}{l}-0.147 \\
(0.187)\end{array}$ & $\begin{array}{l}-0.025 \\
(0.206)\end{array}$ & $\begin{array}{l}0.176 \\
(0.298)\end{array}$ & \\
\hline high income & $\begin{array}{l}-0.030 \\
(0.251)\end{array}$ & $\begin{array}{l}0.306 \\
(0.211)\end{array}$ & $\begin{array}{l}0.554 \text { * } \\
(0.224)\end{array}$ & $\begin{array}{l}0.487 \\
(0.274)\end{array}$ & \\
\hline medium income & $\begin{array}{l}0.226 \\
(0.204)\end{array}$ & $\begin{array}{l}-0.010 \\
(0.176)\end{array}$ & $\begin{array}{l}0.112 \\
(0.191)\end{array}$ & $\begin{array}{l}-0.124 \\
(0.246)\end{array}$ & \\
\hline cert. support & $\begin{array}{l}0.483 * * \\
(0.177)\end{array}$ & $\begin{array}{l}0.352 * \\
(0.152)\end{array}$ & $\begin{array}{l}0.830^{* * *} \\
(0.170)\end{array}$ & $\begin{array}{l}0.594^{* *} \\
(0.217)\end{array}$ & \\
\hline cert. skepticism & $\begin{array}{c}-0.314 \\
(0.160)\end{array}$ & $\begin{array}{l}-0.150 \\
(0.141)\end{array}$ & $\begin{array}{l}-0.470 \\
(0.152)\end{array}$ & $\begin{array}{c}-0.254 \\
(0.198)\end{array}$ & \\
\hline PO objection & $\begin{array}{l}0.383^{*} \\
(0.170)\end{array}$ & $\begin{array}{l}0.208 \\
(0.157)\end{array}$ & $\begin{array}{l}0.377^{*} \\
(0.163)\end{array}$ & $\begin{array}{l}-0.019 \\
(0.216)\end{array}$ & \\
\hline PO knowledge & $\begin{array}{l}-0.152 \\
(0.111)\end{array}$ & $\begin{array}{l}-0.180 \\
(0.097)\end{array}$ & $\begin{array}{l}-0.190 \\
(0.104)\end{array}$ & $\begin{array}{l}-0.079 \\
(0.132)\end{array}$ & \\
\hline PCE & $\begin{array}{l}0.464^{*} \\
(0.226)\end{array}$ & $\begin{array}{l}0.130 \\
(0.184)\end{array}$ & $\begin{array}{l}0.435 * \\
(0.205)\end{array}$ & $\begin{array}{l}-0.015 \\
(0.264)\end{array}$ & \\
\hline sust. concern & $\begin{array}{l}0.282 \\
(0.216)\end{array}$ & $\begin{array}{l}-0.065 \\
(0.178)\end{array}$ & $\begin{array}{l}0.650^{* *} \\
(0.209)\end{array}$ & $\begin{array}{l}0.166 \\
(0.265)\end{array}$ & \\
\hline informed cons. & $\begin{array}{l}0.615^{* *} \\
(0.224)\end{array}$ & $\begin{array}{l}-0.281 \\
(0.187)\end{array}$ & $\begin{array}{l}0.195 \\
(0.207)\end{array}$ & $\begin{array}{l}-0.223 \\
(0.267)\end{array}$ & \\
\hline _constant & $\begin{array}{l}0.660^{* *} \\
(0.239)\end{array}$ & $\begin{array}{l}1.110^{* * *} \\
(0.203)\end{array}$ & $\begin{array}{l}0.866^{* * *} \\
(0.208)\end{array}$ & $\begin{array}{l}-0.464 \\
(0.320)\end{array}$ & \\
\hline
\end{tabular}


A very strong positive change in the RSPO certified coefficient can be observed for the "palm oil avoiders", so the label of this class might be questioned now. However, they still show clearly stronger preferences for $P O$-free cookies, which even increased compared to part 1 . A higher PO objection value increases the likelihood of being a "palm oil avoider" compared to the reference. In general, this class is not against sustainability certification, as indicated by the significant coefficients for the respective labels. The coefficient for certification support is now significantly positive for classes 1 to 4 . This means that respondents who support certification are less likely to be members of the "cheap shoppers", who still are the most price-sensitive class.

While in part 1, the "cheap shoppers" preferred RSPO mixed over RSPO certified, these preferences have now been reversed, and the coefficient for RSPO mixed is not significant anymore. The only class that now unexpectedly prefers RSPO mixed over RSPO certified are the "chocolate lovers". While this class still cares most about the chocolate content, they seem also indifferent between buying cookies and opting out. The "concerned consumers" are still the least price-sensitive and show the highest preferences for EU organic and Fairtrade certification. Despite the psychometric variables that reflect support for sustainability certification as compared to the reference class, "concerned consumers" still prefer PO-free over RSPO certified cookies. This is in line with the positive coefficient for PO objection.

The results of the latent class analysis confirm that preferences with respect to palm oil and other relevant attributes are heterogeneous among consumers. Before information provision, the large majority of more than 70 percent of the sample does not derive any significantly positive utility from certified sustainable palm oil, while 30 percent prefer palm-oil-free cookies. After information provision, all respondents except for the smallest segment derive utility from RSPO-certified palm oil, but still the majority prefers palm-oil-free cookies. In both parts, only one segment prefers mass balance (RSPO mixed) over segregation (RSPO certified). The considered socio-economic and psychometric characteristics can be considered potential sources of preference heterogeneity. It has to be considered that the membership variables' coefficients and their significance would differ if another class was used as reference.

\subsection{Willingness to Pay}

With respect to the interpretation of coefficients, it has to be emphasized that only the relative magnitude of utility (ordinal utility) matters, while the absolute coefficient values are not directly interpretable $[66,95]$. More meaningful odds ratios can be calculated by exponentiating the coefficients [71]. (Marginal) WTP can be calculated as the (negative) ratio of the respective attribute coefficient and the price coefficient. The lclogit 2 module for Stata provides a post-estimation command for calculating class-specific WTP [96]. However, WTP should only be calculated for variables that show significant coefficients [66]. This restriction makes a comparison of WTP values across classes difficult. For the sake of brevity and interpretability, WTP has been calculated for the mixed logit models presented in Table 4, using the post-estimation command developed by Hole [97]. Table 8 shows the mean WTP and the 95\% confidence intervals (CIs) for part 1 (before information provision) and part 2 (after information provision). The mean WTP for RSPO mixed in part 1 is italicized because the respective coefficient was not significant.

Table 8. Willingness to pay (WTP) for chocolate cookie attributes (mixed logit, preference space).

\begin{tabular}{ccccc}
\hline$(\boldsymbol{n}=\mathbf{9 5 6 )}$ & \multicolumn{2}{c}{ Part 1 } & \multicolumn{2}{c}{ Part 2 } \\
\hline $\mathbf{( € / 2 0 0}$ g Cookies) & Mean & $\mathbf{9 5 \% ~ C I ~}$ & Mean & $\mathbf{9 5 \% ~ C I ~}$ \\
\hline RSPO certified & 0.11 & {$[0.02-0.20]$} & 0.74 & {$[0.63-0.84]$} \\
RSPO mixed & 0.03 & {$[-0.06-0.12]$} & 0.37 & {$[0.27-0.46]$} \\
PO-free & 0.34 & {$[0.24-0.44]$} & 1.43 & {$[1.30-1.55]$} \\
EU organic & 0.31 & {$[0.26-0.37]$} & 0.28 & {$[0.23-0.34]$} \\
Fairtrade & 0.57 & {$[0.49-0.65]$} & 0.50 & {$[0.40-0.59]$} \\
$40 \%$ chocolate & 0.60 & {$[0.53-0.68]$} & 0.51 & {$[0.43-0.58]$} \\
\hline
\end{tabular}


The values can be interpreted in terms of price premiums compared to the reference level. For instance, in part 1, respondents are on average willing to pay a premium of $€ 0.11$ for a $200 \mathrm{~g}$ package of cookies that contain $100 \%$ RSPO-certified palm oil, as compared to cookies with conventional palm oil, all else being equal. After information provision, the premium rises to $€ 0.74$ on average. For palm-oil-free cookies, the results indicate a much higher average WTP: $€ 0.34$ before and $€ 1.43$ after information provision. To set these values into context: cookies without any label but with $40 \%$ chocolate content cost around $€ 0.79$ in German discounters.

\section{Discussion}

\subsection{Interpretation and Comparison of Results}

This article contributes to the literature on consumers' attitudes and preferences concerning palm oil by quantitatively assessing preferences for products containing either segregated or mass balance RSPO-certified palm oil, uncertified palm oil, or no palm oil. Overall, the results indicate that consumers in Germany prefer palm-oil-free products over products that contain certified sustainable palm oil. This finding is in line with the results of the study by Vergura et al. [16]. Confirming the findings by Gassler and Spiller [49], the "RSPO certified" label is, on average, preferred over the "RSPO mixed" label. However, although this study also conducted a latent class analysis based on a choice experiment involving a chocolate product with a quota-based sample in Germany, the results differ considerably. Gassler and Spiller [49] derive a mean WTP of $€ 0.85$ for "RSPO certified" and $€ 0.43$ for "RSPO mixed" palm oil per $100 \mathrm{~g}$ package of chocolate bars. In the present study, the mean WTP after information provision is $€ 0.74$ and $€ 0.37$, respectively, but it has to be considered that these premiums refer to a $200 \mathrm{~g}$ package of chocolate cookies. These differences might partly result from differences in the choice design, as Gassler and Spiller [49] focus only on RSPO certification and the price, whereas the present study includes additional relevant product attributes. Particularly interesting is that the WTP for palm-oil-free cookies is higher than for RSPO-certified cookies, both before and after information provision.

The aspect of information provision has not been tested by Gassler and Spiller [49], as all respondents received information on palm oil and certification prior to the choice experiment. The present study shows that information provision does indeed influence preferences, supporting findings from previous research $[53,57]$. The identified premiums before information provision are much lower than afterward. It can be argued that the WTP before information provision better reflects a real purchase situation in which there is usually no additional information provided at the point of sale. Moreover, it is more realistic to consider additional product attributes that are advertised on the package besides palm-oil-related claims. The significant price premiums for Fairtrade and EU organic certification are slightly reduced after information provision. This might be explained by the fact that both schemes are more popular in Germany than RSPO. While 86 percent of the sample indicated in the survey that they had never heard of RSPO before, this share was much smaller for EU organic $(37 \%)$ and Fairtrade $(10 \%)$. The brief information provided to respondents probably did not considerably increase knowledge about these schemes. The small reduction in the price premiums for these labels might be attributed to the increased relative importance of RSPO certification, as respondents had to deal with trade-offs.

This study also confirms previous findings related to the prevalence of preference heterogeneity (e.g., [47,50,52]). Particularly attitudinal characteristics, such as support of sustainability certification or concern about sustainability issues, are relevant for segmentation. Contradicting other studies [26,28,48,49], gender was not found to be a relevant factor, and also education does not seem to matter much. While Gassler and Spiller [49] found that the oldest segment was also the least price-sensitive, the present study indicates the opposite. Interestingly, after information provision, subjective knowledge on palm oil was not a significant factor for distinguishing classes from the reference anymore. This makes sense, as this aspect was assessed before information provision, which can be expected to reduce differences 
in knowledge. The inclusion of additional product attributes might be a relevant reason why the latent class analysis resulted in more classes compared to the study by Gassler and Spiller [49].

With respect to the indicated class shares, it needs to be considered that they represent the mean posterior probability of class membership. While some individuals have a very high probability of membership for one of the classes based on their preferences and characteristics, others are more difficult to allocate. To assess the allocation precision, it is useful to calculate the average of the maximum posterior membership probability over respondents [89], also known as the index of relative entropy [98]. For part 1, this value is 89 percent, for part 2, it is 93 percent, indicating high overall precision. To analyze the changes in class composition from part 1 to part 2 , it is possible to assign each respondent to the class for which his or her maximum posterior probability of class membership had been estimated.

\subsection{Limitations of the Study}

This study had several methodological limitations. There might be relevant product attributes that influence consumer preferences but were not considered in this study, such as the product brand. The product brand was found to be irrelevant in the study by Vergura et al. [16] that also focused on cookies. In Germany, chocolate cookies are typically offered by supermarkets' and discounters' own brands. Thus, it could be assumed that the brand does not play a major role for this product category.

For the "palm-oil-free"-labeled cookies, it was not further specified which alternative oil or fat should be assumed as an ingredient, and no information on the advantages and disadvantages of different alternatives was provided to reduce the cognitive burden. While purchasing RSPO-certified palm oil might be an option for consumers who are concerned about the sustainability of conventional palm oil cultivation, potential health concerns might probably not be resolved in this way. Although there is still a lack of robust scientific evidence on the adverse health effects of palm oil consumption [99-101], many consumers still perceive palm oil as unhealthy. Potential health concerns have not been assessed in this study, but previous research suggests that such concerns might positively influence preferences for "palm-oil-free" products (e.g., [48,50,52]). It might be assumed that providing additional information on these aspects would have an influence, probably reducing relative preferences for the "palm-oil-free" attribute.

The omission of potentially relevant product attributes or information might have led to an overestimation of the utility of the considered aspects [45]. Referring to the behavioral framework described in Section 2.1, additional aspects might influence preferences but have not been considered here, such as the (perceived) product availability, different values, or social norms [41,42]. As explained in Section 3.3, the psychometric instruments used in the analysis were assessed in different parts of the questionnaire. For instance, knowledge on palm oil was assessed before additional information was provided, while the scale on sustainability concerns was assessed toward the end of the survey, in order to reduce social desirability bias in the choice experiment. It has to be considered that the structure of the questionnaire and the timing of questions certainly have an influence on the results.

It has to be considered that the coding of variables as well as assumptions on the distribution of effects have an influence on the size of the coefficients, which also affects the resulting marginal WTP values and their interpretation. It has, therefore, been suggested to test the sensitivity of results using various model specifications in preference space or willingness-to-pay space [102]. For the sake of brevity, WTP was only estimated for the mixed logit models in preference space here. Considering the latent class models, some classes indicated a very high WTP for palm-oil-related attributes, particularly after information provision. The "palm oil avoiders", for instance, would supposedly be willing to pay a premium of around $€ 4$ to get palm-oil-free cookies, all else being equal. Considering the price level of a package of chocolate cookies, this value seems unrealistically high. This might be attributed to the fact that this study assessed stated preferences, not revealed preferences. Hypothetical bias and social desirability bias might contribute to the so-called attitude-behavior gap $[41,103,104]$. Although a "cheap talk" script was used to reduce hypothetical bias, this issue might not have been completely 
eliminated. In this regard, the study by Gassler and Spiller [49] was more incentive-compatible than this study, as it involved a randomly determined real purchase for one-third of the sample.

\subsection{Recommendations}

Preferences for palm-oil-free products as compared to products containing RSPO-certified palm oil identified in the present study are problematic in so far as palm-oil-free products contain alternative oils or fats that are not necessarily more sustainable, considering efficiency in terms of land use and productivity [20-22]. Guadalupe et al. [54] suggest that the food industry should replace palm oil to meet consumers' preferences. Taking the relative advantages of palm oil compared to alternatives into account, this advice should not be supported. Instead, public and private efforts to source sustainably produced commodities should be strengthened. While sustainability certification is an important instrument to achieve sustainability targets, it will most likely not be sufficient and needs to be complemented by other policy measures $[105,106]$. The governments of Germany and other European countries already declared their commitment to support the development of sustainable and deforestation-free supply chains [34,107]. Other palm oil importing countries should be encouraged to follow this example, in order to reduce the risk of leakage effects $[108,109]$. Reductions in the overall consumption of palm oil and other vegetable oils in the European Union and other countries would be required to reduce the risk of further conversion of rainforests [110].

Policy interventions suitable for supporting sustainable consumption involve the provision of information and incentives [44]. Consumer involvement might be stimulated by focusing on the communication of positive socio-economic and environmental effects of consuming certified sustainable palm oil [41]. However, the results of this study indicate that providing information on RSPO certification to consumers might not be sufficient to convince them to buy certified products, if palm-oil-free alternatives are available. Considering previous research, consumers' preferences for palm-oil-free products might be attributable to concerns about potential health issues of palm oil consumption, and/or a lack of trust in sustainability certification. Therefore, it would be recommendable for policymakers to implement a general information campaign that explicitly focuses on explaining misconceptions with respect to adverse health effects and on communicating the benefits of palm oil compared to alternative oils. Information campaigns have also been suggested in previous studies [49,57].

However, Disdier et al. [57] have argued that such campaigns might be difficult to implement, as many aspects would need to be communicated to provide full information. It will probably not be sufficient to provide information at the point of sale. Lange and Cormans [51] have shown that providing information to consumers does not automatically mean that consumers read and process this information. Results from focus group discussions indicate that consumers are often in a hurry when shopping for groceries and tend to focus on product information that can be quickly processed [59]. Thus, initiatives such as the German FONAP should be further encouraged to inform consumers in situations in which they are actively looking for information. FONAP, for instance, has been involved in the International Green Week, a popular annual trade fair organized in Berlin, which is not only visited by business actors, but also by many consumers.

The results of the latent class analysis suggest that the consumption preferences of different consumer groups might be influenced by various aspects. Knowledge on the issue is one relevant factor that also might be interlinked with different attitudinal variables that are more or less pronounced in different groups. In general, more research is needed on the relationships between different influence factors, particularly on the direct and indirect effects of knowledge on attitudes. Many studies trying to quantify consumer preferences for certain product attributes have been conducted in a fictitious online or laboratory setting. Incentive-compatible experiments and real-life observations are expensive and difficult to implement, but would reduce potential biases and provide more realistic results with respect to revealed preferences. Previous field experiments focusing on preferences for Fairtrade certification are interesting examples [111,112]. As food manufacturers and retailers would also benefit 
from improving consumer acceptance of certified palm oil, it might be a good idea to involve them in research projects to exchange insights and improve access to data.

To raise awareness of certified sustainable palm oil, private sector stakeholders should consider increasing the use of RSPO labels on product packaging, also to counterbalance the prevalence of palm-oil-free claims. Further research should focus on other types of products, particularly non-food products. In this regard, it has to be considered that within the European Union the type of vegetable oil used as an ingredient has to be declared only for food products [113], which might have a relevant influence on awareness among consumers.

\section{Conclusions}

This study contributes to research on consumer attitudes and preferences by considering trade-offs between conventional palm oil, certified sustainable palm oil, and alternatives to palm oil advertised through "palm-oil-free" labels. A discrete choice experiment was implemented as part of a web-based survey in Germany to investigate these trade-offs as well as potential sources of preference heterogeneity. The results suggest that, on average, consumers prefer palm-oil-free cookies over cookies with palm oil certified according to RSPO standards, which again is preferred over conventional, uncertified palm oil. After providing further information on palm oil and certification, preferences for RSPO-certified palm oil are stronger, but palm-oil-free alternatives are still preferred. A latent class analysis identifies different consumer segments that can be characterized according to their preferences and certain socio-demographic and psychometric attributes. This analysis reveals that a large share of respondents does not care much about palm oil if they are just presented with the product and no additional information. Therefore, previous studies providing detailed information before assessing preferences might have produced overestimated results. These findings are particularly relevant for policymakers, manufacturers, and retailers that aim to increase the uptake of certified sustainable palm oil as one measure to resolve sustainability issues linked to global supply chains. Considering attitudinal factors, information campaigns might be targeted to certain consumer segments that still lack knowledge and could be convinced of the benefits of certified palm oil compared to alternatives. Further research should apply incentive-compatible methods to reduce biases and focus also on non-food products that may contain palm oil.

Author Contributions: Conceptualization, C.H.; methodology, C.H.; validation, C.H. and I.C.-S.; formal analysis, C.H.; investigation, C.H.; resources, C.H. and I.C.-S.; data curation, C.H.; writing-original draft preparation, C.H.; writing-review and editing, C.H. and I.C.-S.; visualization, C.H.; supervision, I.C.-S.; project administration, C.H. All authors have read and agreed to the published version of the manuscript.

Funding: This research received no external funding.

Conflicts of Interest: The authors declare no conflict of interest.

\section{Appendix A. Cheap Talk Script}

The following cheap talk script was presented to the respondents prior to part 1 of the choice experiment (translated from German; bold formatted parts as in the original survey):

"Please read the following information carefully:

In the following, please imagine yourself situated in a supermarket, aiming to buy a package of chocolate cookies. There are two different products available. These differ according to the following characteristics: price, ingredients, and certification. The price is indicated below the product and refers to a package size of $\mathbf{2 0 0} \mathrm{g}$.

Studies have shown that people act differently in surveys compared to "real" decisions. For instance, some people indicate in surveys that they are willing to buy a product at a certain price, although they would not pay that price in the supermarket.

Please imagine that your decision is constrained by your usual grocery shopping budget. If you choose a product, your budget available for other groceries is reduced by its price. You also have the 
option to choose neither of the two products that are presented to you, if they are both not appealing to you. Please make your choice as you would choose a product in a real shopping situation."

\section{Appendix B. Information Provided after Part 1 of the Choice Experiment}

The following information on palm oil and the different certification labels was presented to the respondents after part 1 of the choice experiment (translated from German, bold formatted parts as in the original survey). For the explanation of the labels, each label was presented next to its description. These images (as shown in Figure 1) are omitted here for the sake of brevity.

"Please read the following information carefully! This information is relevant for the subsequent tasks.

Palm oil is predominantly produced in Indonesia and Malaysia. For some palm oil plantations, rainforests have been cleared. The loss of rainforests is problematic for the environment and the local species. Deforestation contributes to climate change.

The Roundtable on Sustainable Palm Oil (German: "Runder Tisch für nachhaltiges Palmöl”; RSPO) is an organization of different actors (e.g., environmental conservation agencies, private companies) that have developed sustainability standards particularly for palm oil. The implementation of these standards aims at having positive effects on the palm oil production, meaning amongst other aspects:

- reduced consumption of resources (soil, water, energy) and reduced utilization of fertilizers and pesticides, for instance

- reduced pollution of water and air; reduced greenhouse gas emissions

- improved conservation of ecosystems

- $\quad$ safe and adequate working conditions

- improved income security for producers

RSPO labels on final products differ according to whether certified palm oil is separated from uncertified palm oil along the whole supply chain (transportation and processing):

RSPO certified: The product contains certified sustainable palm oil. "Certified" means that the product contains only palm oil that has been certified according to the RSPO sustainability standards. There should not be any blending with uncertified palm oil.

RSPO mixed: "Mixed" means that certified and uncertified palm oil are allowed to be mixed. It is not clear how much of the palm oil contained in the "mixed" labeled product is actually certified. According to the RSPO, the product contributes to the production of sustainable palm oil.

Apart from these RSPO labels, some of the chocolate cookies presented to you in the previous decision situations also showed the following labels:

palm-oil-free: This product does not contain any palm oil, but instead contains an alternative oil or fat. Vice versa, this means for the decision situations presented to you that a product not carrying this label does contain palm oil.

EU organic: This product has been certified according to organic standards of the European Union. At least $95 \%$ of the ingredients have been produced in organic agriculture.

Fairtrade: This product has been certified according to Fairtrade standards that aim at contributing to fair trade conditions. Amongst other aspects, a minimum price is guaranteed to producers, and an additional premium is awarded to the community to finance social projects."

\section{Appendix C. Survey Items Included in the Principal Component Analysis}

Tables A1-A3 show all items that have been included in the PCA described in Section 4.2. The items were presented in German, but here the English translation is shown. All items were assessed by the respondents on a labeled 7-point Likert scale (1: strongly disagree; 2: disagree; 3: somewhat disagree; 4: neither agree nor disagree; 5 : somewhat agree; 6: agree; 7 : strongly agree). The items were presented in different blocks within the survey, and the order of items was randomized. For the sake of comprehension, Table A1 shows the items ordered according to the factors identified in the PCA 
(see also Table 3 in Section 4.2). For some (negatively worded) items, the coding was reversed prior to conducting the PCA.

Table A1. Survey items: statements developed by the authors.

\begin{tabular}{|c|c|c|}
\hline \multicolumn{3}{|c|}{$\begin{array}{l}\text { Instructions: Please indicate your agreement/disagreement with the following statements. } \\
\text { (7-point Likert scale) }\end{array}$} \\
\hline No. & Item & Retained Factor \\
\hline 1 & $\begin{array}{l}\text { When I trust a sustainability label, I am willing to pay more for } \\
\text { a product carrying this label. }\end{array}$ & \multirow{4}{*}{ certification support } \\
\hline 2 & Sustainability certification is the first step in the right direction. & \\
\hline 3 & I usually try to buy products carrying a sustainability label. & \\
\hline 4 & $\begin{array}{c}\text { Products with sustainability label are usually more sustainable } \\
\text { than products without such a label. }\end{array}$ & \\
\hline 5 & $\begin{array}{l}\text { I don't trust in sustainability certification because the } \\
\text { standards and criteria are not transparent to consumers. }\end{array}$ & \multirow{4}{*}{ certification skepticism } \\
\hline 6 & $\begin{array}{l}\text { I don't think that sustainability certification really contributes } \\
\text { to sustainability. }\end{array}$ & \\
\hline 7 & $\begin{array}{l}\text { Sustainability labeling is only a marketing strategy of } \\
\text { the industry. }\end{array}$ & \\
\hline 8 & $\begin{array}{l}\text { I tend to trust uncertified products by small, regional } \\
\text { producers more than certified products by large, } \\
\text { multinational corporations. }\end{array}$ & \\
\hline 9 & $\begin{array}{l}\text { I tend to consider the ingredients of food products more } \\
\text { frequently than I consider the ingredients of other products } \\
\text { that I buy. }\end{array}$ & \multirow{7}{*}{ informed consumption } \\
\hline 10 & $\begin{array}{l}\text { When I frequently purchase a product, I tend to look for } \\
\text { information on its ingredients. }\end{array}$ & \\
\hline 11 & $\begin{array}{l}\text { I would appreciate it if there was a more explicit mandatory } \\
\text { labeling requirement for products containing palm oil. }\end{array}$ & \\
\hline 12 & $\begin{array}{l}\text { I have searched for information about which alternatives to } \\
\text { palm oil might be better. }\end{array}$ & \\
\hline 13 & $\begin{array}{c}\text { I have searched for information about palm oil prior to } \\
\text { participating in this survey. }\end{array}$ & \\
\hline 14 & $\begin{array}{l}\text { I don't care whether a product contains palm oil or not, as long } \\
\text { as it tastes good. (coding reversed) }\end{array}$ & \\
\hline 15 & $\begin{array}{l}\text { Palm-oil-free products are not any better than products } \\
\text { containing palm oil. (coding reversed) }\end{array}$ & \\
\hline 16 & $\begin{array}{l}\text { Palm oil is not necessarily bad, it depends on the production } \\
\text { conditions. (coding reversed) }\end{array}$ & \multirow{4}{*}{ palm oil objection } \\
\hline 17 & Palm oil is unhealthy. & \\
\hline 18 & Palm oil is cheap and therefore it can't be high-quality. & \\
\hline 19 & $\begin{array}{l}\text { Palm oil can't be sustainable because it has to be transported } \\
\text { long distances. }\end{array}$ & \\
\hline
\end{tabular}

Table A2. Survey items: perceived consumer effectiveness (PCE).

\begin{tabular}{|c|c|}
\hline \multicolumn{2}{|c|}{ Instructions: Please indicate your agreement/disagreement with the following statements. (7-point Likert scale) } \\
\hline No. & Item \\
\hline 1 & $\begin{array}{l}\text { It is useless for the individual consumer to do anything about environmental problems. } \\
\text { (coding reversed) }\end{array}$ \\
\hline 2 & When I buy products, I try to consider how my use of them will affect the environment. \\
\hline 3 & When I buy products, I try to consider how my use of them will affect other people. \\
\hline 4 & $\begin{array}{l}\text { Since one person cannot have any effect upon the exploitation of natural resources, it doesn't } \\
\text { make any difference what I do. (coding reversed) }\end{array}$ \\
\hline 5 & $\begin{array}{c}\text { Each consumer's behavior can contribute to sustainability by purchasing products sold by } \\
\text { socially responsible companies. }\end{array}$ \\
\hline
\end{tabular}

Note: This scale has been adopted and slightly modified from reference [43]. 
Table A3. Survey items: concern about sustainability issues.

\begin{tabular}{cc}
\hline $\begin{array}{c}\text { Instructions: } \\
\text { following topics in the context of food. (7-point Likert scale) }\end{array}$ \\
\hline No. & Item \\
\hline 1 & The use of child labor in food production \\
2 & Deforestation of rainforests for food production \\
3 & Starvation and malnutrition in the world population \\
4 & The use of pesticides in food production \\
5 & The abuse of animals in food production \\
6 & Environmental damage caused by food production \\
7 & Food waste \\
8 & Overexploitation of natural resources for food production \\
9 & Poor working conditions for food producers \\
10 & Low wages for food producers \\
11 & Packaging that is not recyclable \\
12 & The amount of packaging used for food products \\
13 & Greenhouse gas emissions caused by food production \\
14 & Energy consumption in food transport \\
15 & Energy consumption in food processing \\
\hline
\end{tabular}

Note: This scale has been adopted and slightly modified from reference [45].

\section{References}

1. Qaim, M.; Sibhatu, K.T.; Siregar, H.; Grass, I. Environmental, economic, and social consequences of the oil palm boom. Annu. Rev. Resour. Econ. 2020, 12. [CrossRef]

2. FAO. FAOSTAT: Production Quantity of Palm Oil in 2018. Available online: http://www.fao.org/faostat/ (accessed on 3 June 2020).

3. Oil World. Oil World Annual 2019; ISTA Mielke GmbH: Hamburg, Germany, 2019.

4. Miettinen, J.; Shi, C.; Liew, S.C. Land cover distribution in the peatlands of Peninsular Malaysia, Sumatra and Borneo in 2015 with changes since 1990. Glob. Ecol. Conserv. 2016, 6, 67-78. [CrossRef]

5. Vijay, V.; Pimm, S.L.; Jenkins, C.N.; Smith, S.J. The impacts of oil palm on recent deforestation and biodiversity loss. PLoS ONE 2016, 11, e0159668. [CrossRef] [PubMed]

6. Koh, L.P.; Miettinen, J.; Liew, S.C.; Ghazoul, J. Remotely sensed evidence of tropical peatland conversion to oil palm. Proc. Natl. Acad. Sci. USA 2011, 108, 5127-5132. [CrossRef]

7. Miettinen, J.; Shi, C.; Liew, S.C. Two decades of destruction in Southeast Asia's peat swamp forests. Front. Ecol. Environ. 2012, 10, 124-128. [CrossRef]

8. Wilcove, D.S.; Koh, L.P. Addressing the threats to biodiversity from oil-palm agriculture. Biodivers. Conserv. 2010, 19, 999-1007. [CrossRef]

9. Koh, L.P.; Wilcove, D.S. Is oil palm agriculture really destroying tropical biodiversity? Conserv. Lett. 2008, 1, 60-64. [CrossRef]

10. Grass, I.; Kubitza, C.; Krishna, V.V.; Corre, M.D.; Mußhoff, O.; Pütz, P.; Drescher, J.; Rembold, K.; Ariyanti, E.S.; Barnes, A.D.; et al. Trade-offs between multifunctionality and profit in tropical smallholder landscapes. Nat. Commun. 2020, 11, 1186. [CrossRef]

11. Guillaume, T.; Kotowska, M.M.; Hertel, D.; Knohl, A.; Krashevska, V.; Murtilaksono, K.; Scheu, S.; Kuzyakov, Y. Carbon costs and benefits of Indonesian rainforest conversion to plantations. Nat. Commun. 2018, 9, 2388. [CrossRef]

12. Meijide, A.; La Rua, C.D.; Guillaume, T.; Röll, A.; Hassler, E.; Stiegler, C.; Tjoa, A.; June, T.; Corre, M.D.; Veldkamp, E.; et al. Measured greenhouse gas budgets challenge emission savings from palm-oil biodiesel. Nat. Commun. 2020, 11, 1089. [CrossRef]

13. Cramb, R.; Curry, G.N. Oil palm and rural livelihoods in the Asia-Pacific region: An overview. Asia Pac. Viewp. 2012, 53, 223-239. [CrossRef] 
14. McCarthy, J.F.; Vel, J.A.C.; Afiff, S. Trajectories of land acquisition and enclosure: Development schemes, virtual land grabs, and green acquisitions in Indonesia's Outer Islands. J. Peasant Studies 2012, 39, 521-549. [CrossRef]

15. Riganelli, C.; Marchini, A. Governance and quality disclosure: The palm oil issue. Br. Food J. 2017, 119, 1718-1731. [CrossRef]

16. Vergura, D.T.; Zerbini, C.; Luceri, B. "Palm oil free" vs "sustainable palm oil": The impact of claims on consumer perception. Br. Food J. 2019, 121, 2027-2035. [CrossRef]

17. RSPO. Principles and Criteria for the Production of Sustainable Palm Oil 2018. 2018. Available online: https://rspo.org/principles-and-criteria-review (accessed on 29 May 2020).

18. RSPO. RSPO Rules on Market Communications and Claims. Approved by the Board of Governors November 2016. Revised in January 2019. 2019. Available online: http://www.rspo.org/publications/download/ 663b24e7a3900e5 (accessed on 29 May 2020).

19. RSPO. RSPO Supply Chain Certification Standard. For organizations Seeking or Holding Certification. 2020. Available online: https://rspo.org/certification/supply-chains (accessed on 29 May 2020).

20. Rival, A.; Levang, P. Palms of Controversies. Oil Palm and Development Challenges. 2014. Available online: https://www.cifor.org/library/4860/ (accessed on 6 November 2018).

21. Parsons, S.; Raikova, S.; Chuck, C.J. The viability and desirability of replacing palm oil. Nat. Sustain. 2020. [CrossRef]

22. WWF. Auf der Ölspur. Berechnungen zu Einer Palmölfreieren Welt. 2016. Available online: http://www.wwf. de/fileadmin/fm-wwf/Publikationen-PDF/WWF-Studie_Auf_der_OElspur.pdf (accessed on 4 November 2017).

23. Schmidt, J.H. Life cycle assessment of five vegetable oils. J. Clean. Prod. 2015, 87, 130-138. [CrossRef]

24. RSPO. RSPO Impact Report 2018. 2018. Available online: https://rspo.org/resources/rspo-reports/impactreports (accessed on 22 March 2019).

25. RSPO. RSPO Impact Update 2019. 2019. Available online: https://www.rspo.org/library/lib_files/download/ 976 (accessed on 7 April 2020).

26. Ostfeld, R.; Howarth, D.; Reiner, D.; Krasny, P. Peeling back the label—Exploring sustainable palm oil ecolabelling and consumption in the United Kingdom. Environ. Res. Lett. 2019, 14, 14001. [CrossRef]

27. Larsen, R.K.; Osbeck, M.; Dawkins, E.; Tuhkanen, H.; Nguyen, H.; Nugroho, A.; Gardner, T.A.; Zulfahm; Wolvekamp, P. Hybrid governance in agricultural commodity chains: Insights from implementation of 'No Deforestation, No Peat, No Exploitation' (NDPE) policies in the oil palm industry. J. Clean. Prod. 2018, 183, 544-554. [CrossRef]

28. Giam, X.; Mani, L.; Koh, L.P.; Tan, H.T.W. Saving tropical forests by knowing what we consume. Conserv. Lett. 2016, 9, 267-274. [CrossRef]

29. Sundaraja, C.S.; Hine, D.W.; Lykins, A. Confronting the palm oil crisis: Identifying behaviours for targeted interventions. Environ. Sci. Policy 2020, 103, 99-106. [CrossRef]

30. European Commission. The Impact of EU Consumption on Deforestation; Technical Report 2013-063; European Commission: Brussels, Belgium, 2013. Available online: http://ec.europa.eu/environment/forests/pdf/1. \%20Report\%20analysis\%20of\%20impact.pdf (accessed on 12 October 2017).

31. European Commission. Communication from the Commission to the European Parliament, the Council, the European Economic and Social Committee and the Committee of the Regions. Stepping up EU Action to Protect and Restore the World's Forests. 2019. Available online: https:/ec.europa.eu/info/sites/info/files/ communication-eu-action-protect-restore-forests_en.pdf (accessed on 3 July 2020).

32. ADP. The Amsterdam Declaration in Support of a Fully Sustainable Palm Oil Supply Chain by 2020. 2015. Available online: https://ad-partnership.org/wp-content/uploads/2018/10/Amsterdam-DeclarationDeforestation-Palm-Oil-v2017-0612.pdf (accessed on 12 June 2020).

33. ADP. Towards Eliminating Deforestation from Agricultural Commodity Chains with European Countries. 2015. Available online: https://ad-partnership.org/wp-content/uploads/2018/10/Amsterdam-DeclarationDeforestation-Palm-Oil-v2017-0612.pdf (accessed on 12 June 2020).

34. IDH. The Urgency of Action to Tackle Tropical Deforestation. Protecting Forests and Fostering Sustainable Agriculture. 2020. Available online: https://www.idhsustainabletrade.com/publication/the-urgency-ofaction-to-tackle-tropical-deforestation/ (accessed on 6 February 2020). 
35. Monticelli, L.; Della Porta, D. The successes of political consumerism as a social movement. In The Oxford Handbook of Political Consumerism; Boström, M., Micheletti, M., Oosterveer, P., Monticelli, L., Della Porta, D., Eds.; Oxford University Press: Oxford, UK, 2019; pp. 772-792, ISBN 9780190629038.

36. Ajzen, I. The theory of planned behavior. Organ. Behav. Hum. Decis. Process. 1991, 50, 179-211. [CrossRef]

37. Ajzen, I. From intentions to actions: A theory of planned behavior. In Action Control; Kuhl, J., Beckmann, J., Eds.; Springer: Berlin/Heidelberg, Germany, 1985; pp. 11-39, ISBN 978-3-642-69748-7.

38. McFadden, D. The choice theory approach to market research. Mark. Sci. 1986, 5, 275-297. [CrossRef]

39. Darby, M.R.; Karni, E. Free competition and the optimal amount of fraud. J. Law Econ. 1973, 16, 67-88. [CrossRef]

40. Thøgersen, J.; Haugaard, P.; Olesen, A. Consumer responses to ecolabels. Eur. J. Mark. 2010, 44, 1787-1810. [CrossRef]

41. Vermeir, I.; Verbeke, W. Sustainable food consumption: Exploring the consumer "attitude-behavioral intention" gap. J. Agric. Environ. Ethics 2006, 19, 169-194. [CrossRef]

42. Vermeir, I.; Verbeke, W. Sustainable food consumption among young adults in Belgium: Theory of planned behaviour and the role of confidence and values. Ecol. Econ. 2008, 64, 542-553. [CrossRef]

43. Roberts, J.A. Green consumers in the 1990s: Profile and implications for advertising. J. Bus. Res. 1996, 36, 217-231. [CrossRef]

44. Stern, P.C. Information, incentives, and proenvironmental consumer behavior. J. Consum. Policy 1999, 22, 461-478. [CrossRef]

45. Grunert, K.G.; Hieke, S.; Wills, J. Sustainability labels on food products: Consumer motivation, understanding and use. Food Policy 2014, 44, 177-189. [CrossRef]

46. Thøgersen, J. Psychological determinants of paying attention to eco-labels in purchase decisions: Model development and multinational validation. J. Consum. Policy 2000, 23, 285-313. [CrossRef]

47. Borrello, M.; Annunziata, A.; Vecchio, R. Sustainability of palm oil: Drivers of consumers' preferences. Sustainability 2019, 11, 4818. [CrossRef]

48. Capecchi, S.; Amato, M.; Sodano, V.; Verneau, F. Understanding beliefs and concerns towards palm oil: Empirical evidence and policy implications. Food Policy 2019, 89, 101785. [CrossRef]

49. Gassler, B.; Spiller, A. Is it all in the MIX? Consumer preferences for segregated and mass balance certified sustainable palm oil. J. Clean. Prod. 2018, 195, 21-31. [CrossRef]

50. Hartmann, C.; Hieke, S.; Taper, C.; Siegrist, M. European consumer healthiness evaluation of 'free-from' labelled food products. Food Qual. Prefer. 2018, 68, 377-388. [CrossRef]

51. Lange, F.; Coremans, L. The role of consumer knowledge in reducing the demand for palm oil. Environ. Conserv. 2020, 38, 1-5. [CrossRef]

52. Verneau, F.; La Barbera, F.; Amato, M.; Sodano, V. Consumers' concern towards palm oil consumption. Br. Food J. 2019, 121, 1982-1997. [CrossRef]

53. Bateman, I.J.; Fisher, B.; Fitzherbert, E.; Glew, D.; Naidoo, R. Tigers, markets and palm oil: Market potential for conservation. Oryx 2010, 44, 230. [CrossRef]

54. Guadalupe, G.A.; Lerma-García, M.J.; Fuentes, A.; Barat, J.M.; Bas, M.d.C.; Fernández-Segovia, I. Presence of palm oil in foodstuffs: Consumers' perception. Br. Food J. 2019, 121, 2148-2162. [CrossRef]

55. Aguiar, L.K.; Martinez, D.C.; Caleman, S.M.Q. Consumer awareness of palm oil as an ingredient in food and non-food products. J. Food Prod. Mark. 2018, 24, 297-310. [CrossRef]

56. Reardon, K.; Padfield, R.; Salim, H.K. "Consumers don't see tigers dying in palm oil plantations": A cross-cultural comparative study of UK, Malaysian and Singaporean consumer views of palm oil. Asian Geogr. 2019, 36, 117-141. [CrossRef]

57. Disdier, A.-C.; Marette, S.; Millet, G. Are consumers concerned about palm oil? Evidence from a lab experiment. Food Policy 2013, 43, 180-189. [CrossRef]

58. Wansink, B.; Chandon, P. Can "low-fat" nutrition labels lead to obesity? J. Mark. Res. 2006, 43, 605-617. [CrossRef]

59. Hinkes, C.; Christoph-Schulz, I. Consumer attitudes toward palm oil: Insights from focus group discussions. J. Food Prod. Mark. 2019, 25, 875-895. [CrossRef]

60. Thøgersen, J.; Pedersen, S.; Aschemann-Witzel, J. The impact of organic certification and country of origin on consumer food choice in developed and emerging economies. Food Qual. Prefer. 2019, 72, 10-30. [CrossRef] 
61. Andorfer, V.A.; Liebe, U. Research on fair trade consumption-A review. J. Bus. Ethics 2012, 106, 415-435. [CrossRef]

62. Schmitt, J.B.; Schneider, F.M.; Weinmann, C.; Roth, F.S. Saving tiger, orangutan \& co: How subjective knowledge and text complexity influence online information seeking and behavior. Inf. Commun. Soc. 2019, 22, 1193-1211. [CrossRef]

63. Lancaster, K.J. A new approach to consumer theory. J. Political Econ. 1966, 74, 132-157. [CrossRef]

64. McFadden, D. Conditional logit analysis of qualitative choice behavior. In Frontiers in Econometrics: Economic Theory and Mathematical Economics; Zarembka, P., Ed.; Academic Press: New York, NY, USA; London, UK, 1974; pp. 105-142.

65. Luce, R.D. Individual Choice Behavior. A Theoretical Analysis; Wiley: New York, NY, USA, 1959.

66. Hensher, D.A.; Rose, J.M.; Greene, W.H. Applied Choice Analysis, 2nd ed.; Cambridge University Press: Cambridge, UK, 2015; ISBN 978-1-107-46592-3.

67. Dhar, R.; Simonson, I. The effect of forced choice on choice. J. Mark. Res. 2003, 40, 146-160. [CrossRef]

68. Veldwijk, J.; Lambooij, M.S.; Bekker-Grob, E.W.D.; Smit, H.A.; Wit, G.A.D. The effect of including an opt-out option in discrete choice experiments. PLoS ONE 2014, 9, e111805. [CrossRef]

69. Boxall, P.C.; Adamowicz, W.L. Understanding heterogeneous preferences in random utility models: A latent class approach. Environ. Resour. Econ. 2002, 23, 421-446. [CrossRef]

70. Swait, J. A structural equation model of latent segmentation and product choice for cross-sectional revealed preference choice data. J. Retail. Consum. Serv. 1994, 1, 77-89. [CrossRef]

71. Collins, L.M.; Lanza, S.T. Latent Class and Latent Transition Analysis. With Applications in the Social, Behavioral, and Health Sciences; Wiley: Hoboken, NJ, USA, 2010; ISBN 0470228393.

72. Daly, A.; Dekker, T.; Hess, S. Dummy coding vs effects coding for categorical variables: Clarifications and extensions. J. Choice Model. 2016, 21, 36-41. [CrossRef]

73. ChoiceMetrics. Ngene 1.2 User Manual \& Reference Guide; ChoiceMetrics Pty Ltd.: Sydney, Australia, 2018.

74. Cummings, R.G.; Taylor, L.O. Unbiased value estimates for environmental goods: A cheap talk design for the contingent valuation method. Am. Econ. Rev. 1999, 89, 649-665. [CrossRef]

75. Murphy, J.J.; Allen, P.G.; Stevens, T.H.; Weatherhead, D. A meta-analysis of hypothetical bias in stated preference valuation. Environ. Resour. Econ. 2005, 30, 313-325. [CrossRef]

76. De-Magistris, T.; Gracia, A.; Nayga, R.M. On the use of honesty priming tasks to mitigate hypothetical bias in choice experiments. Am. J. Agric. Econ. 2013, 95, 1136-1154. [CrossRef]

77. Tonsor, G.T.; Shupp, R.S. Cheap talk scripts and online choice experiments: "Looking beyond the mean". Am. J. Agric. Econ. 2011, 93, 1015-1031. [CrossRef]

78. Howard, G.; Roe, B.E.; Nisbet, E.C.; Martin, J.F. Hypothetical bias mitigation techniques in choice experiments: Do cheap talk and honesty priming effects fade with repeated choices? J. Assoc. Environ. Resour. Econ. 2017, 4, 543-573. [CrossRef]

79. Destatis. GENESIS-Online Database. Available online: https://www-genesis.destatis.de/genesis/online (accessed on 31 October 2019).

80. Blom, A.G.; Bosnjak, M.; Cornilleau, A.; Cousteaux, A.-S.; Das, M.; Douhou, S.; Krieger, U. A comparison of four probability-based online and mixed-mode panels in Europe. Soc. Sci. Comput. Rev. 2016, 34, 8-25. [CrossRef]

81. Hair, J.F.; Black, W.C.; Babin, B.J.; Anderson, R.E. Multivariate Data Analysis, 8th ed.; Cengage Learning EMEA: Andover, Hampshire, 2019; ISBN 978-1-4737-5654-0.

82. Kaiser, H.F.; Rice, J. Little Jiffy, Mark IV. Educ. Psychol. Meas. 1974, 34, 111-117. [CrossRef]

83. Tavakol, M.; Dennick, R. Making sense of Cronbach's alpha. Int. J. Med. Educ. 2011, 2, 53-55. [CrossRef]

84. Kaiser, B. RHAUSMAN: Stata Module to Perform Robust Hausman Specification Test. Available online: https://ideas.repec.org/c/boc/bocode/s457909.html (accessed on 12 June 2020).

85. Hausman, J.; McFadden, D. Specification tests for the multinomial logit model. Econometrica 1984, 52, 1219. [CrossRef]

86. Hole, A.R. Fitting mixed logit models by using maximum simulated likelihood. Stata J. 2007, 7, 388-401. [CrossRef]

87. Bech, M.; Gyrd-Hansen, D. Effects coding in discrete choice experiments. Health Econ. 2005, 14, 1079-1083. [CrossRef] [PubMed] 
88. Yoo, H.I. LCLOGIT2: Stata Module to Estimate Latent Class Conditional Logit Models. Available online: https://ideas.repec.org/c/boc/bocode/s458616.html (accessed on 12 June 2020).

89. Pacifico, D.; Yoo, H.I. Lclogit: A Stata command for fitting latent-class conditional logit models via the expectation-maximization algorithm. Stata J. 2013, 13, 625-639. [CrossRef]

90. Bhat, C.R. An Endogenous Segmentation Mode Choice Model with an Application to Intercity Travel. Transp. Sci. 1997, 31, 34-48. [CrossRef]

91. Schwarz, G. Estimating the dimension of a model. Ann. Stat. 1978, 6, 461-464. [CrossRef]

92. Bozdogan, H. Model selection and Akaike's Information Criterion (AIC): The general theory and its analytical extensions. Psychometrika 1987, 52, 345-370. [CrossRef]

93. Nylund, K.L.; Asparouhov, T.; Muthén, B.O. Deciding on the number of classes in latent class analysis and growth mixture modeling: A Monte Carlo simulation study. Struct. Equ. Model. Multidiscip. J. 2007, 14, 535-569. [CrossRef]

94. Akaike, H. A new look at the statistical model identification. IEEE Trans. Autom. Contr. 1974, 19, 716-723. [CrossRef]

95. Hauber, A.B.; González, J.M.; Groothuis-Oudshoorn, C.G.M.; Prior, T.; Marshall, D.A.; Cunningham, C.; IJzerman, M.J.; Bridges, J.F.P. Statistical methods for the analysis of discrete choice experiments: A report of the ISPOR Conjoint Analysis Good Research Practices Task Force. Value Health 2016, 19, 300-315. [CrossRef]

96. Yoo, H.I. lclogit2: An enhanced module to estimate latent class conditional logit models. SSRN J. 2019. [CrossRef]

97. Hole, A.R. WTP: Stata Module to Estimate Confidence Intervals for Willingness to Pay Measures. Available online: https://ideas.repec.org/c/boc/bocode/s456808.html (accessed on 20 June 2020).

98. Masyn, K.E. Chapter 25: Latent class analysis and finite mixture modeling. In The Oxford Handbook of Quantitative Methods, Vol. 2: Statistical Analysis; Little, T.D., Ed.; Oxford University Press USA: Oxford, UK, 2013; pp. 551-611, ISBN 978-0-19-993489-8.

99. Zulkiply, S.H.; Balasubramaniam, V.; Abu Bakar, N.A.; Abd Rashed, A.; Ismail, S.R. Effects of palm oil consumption on biomarkers of glucose metabolism: A systematic review. PLoS ONE 2019, 14, e0220877. [CrossRef] [PubMed]

100. Ismail, S.R.; Maarof, S.K.; Siedar Ali, S.; Ali, A. Systematic review of palm oil consumption and the risk of cardiovascular disease. PLoS ONE 2018, 13, e0193533. [CrossRef]

101. Mancini, A.; Imperlini, E.; Nigro, E.; Montagnese, C.; Daniele, A.; Orrù, S.; Buono, P. Biological and nutritional properties of palm oil and palmitic acid: Effects on Health. Molecules 2015, 20, 17339-17361. [CrossRef] [PubMed]

102. Hole, A.R.; Kolstad, J.R. Mixed logit estimation of willingness to pay distributions: A comparison of models in preference and WTP space using data from a health-related choice experiment. Empir. Econ. 2012, 42, 445-469. [CrossRef]

103. Young, W.; Hwang, K.; McDonald, S.; Oates, C.J. Sustainable consumption: Green consumer behaviour when purchasing products. Sustain. Dev. 2009, 37, 20-31. [CrossRef]

104. Fisher, R.J. Social desirability bias and the validity of indirect questioning. J. Consum. Res. 1993, 20, 303. [CrossRef]

105. Lambin, E.F.; Meyfroidt, P.; Rueda, X.; Blackman, A.; Börner, J.; Cerutti, P.O.; Dietsch, T.; Jungmann, L.; Lamarque, P.; Lister, J.; et al. Effectiveness and synergies of policy instruments for land use governance in tropical regions. Glob. Environ. Chang. 2014, 28, 129-140. [CrossRef]

106. Lambin, E.F.; Gibbs, H.K.; Heilmayr, R.; Carlson, K.M.; Fleck, L.C.; Garrett, R.D.; le Polain de Waroux, Y.; McDermott, C.L.; McLaughlin, D.; Newton, P.; et al. The role of supply-chain initiatives in reducing deforestation. Nat. Clim. Chang. 2018, 8, 109-116. [CrossRef]

107. ADP. Strategy AD Partnership. 2016. Available online: https://ad-partnership.org/wp-content/uploads/2018/ 10/AD-Partnership-Implementation-Strategy-v1Dec2016.pdf (accessed on 17 February 2020).

108. Wilman, E.A. Market redirection leakage in the palm oil market. Ecol. Econ. 2019, 159, 226-234. [CrossRef]

109. Henders, S.; Persson, U.M.; Kastner, T. Trading forests: Land-use change and carbon emissions embodied in production and exports of forest-risk commodities. Environ. Res. Lett. 2015, 10, 125012. [CrossRef]

110. Koh, L.P.; Lee, T.M. Sensible consumerism for environmental sustainability. Biol. Conserv. 2012, 151, 3-6. [CrossRef] 
111. Hainmueller, J.; Hiscox, M.J.; Sequeira, S. Consumer demand for fair trade: Evidence from a multistore field experiment. Rev. Econ. Stat. 2015, 97, 242-256. [CrossRef]

112. Andorfer, V.A.; Liebe, U. Do information, price, or morals influence ethical consumption? A natural field experiment and customer survey on the purchase of Fair Trade coffee. Soc. Sci. Res. 2015, 52, 330-350. [CrossRef] [PubMed]

113. European Union. Regulation (EU) No 1169/2011 on the Provision of Food Information to Consumers. 2011. Available online: http://eur-lex.europa.eu/legal-content/en/ALL/?uri=CELEX:32011R1169 (accessed on 5 August 2019).

(C) 2020 by the authors. Licensee MDPI, Basel, Switzerland. This article is an open access article distributed under the terms and conditions of the Creative Commons Attribution (CC BY) license (http://creativecommons.org/licenses/by/4.0/). 


\subsection{Traceability matters: A conceptual framework for deforestation-free supply chains applied to soy certification}

Cordula Hinkes, Günter Peter

Sustainability Accounting, Management and Policy Journal (2020), 11(7): 1159-1187.

DOI: https://doi.org/10.1108/SAMPJ-04-2019-0145

Permission to reproduce this article as part of this dissertation has been granted by the publisher Emerald Publishing Limited according to the Author rights. This is the "author accepted manuscript" (AAM) version of the article published by Emerald Publishing Limited in Sustainability Accounting, Management and Policy Journal (SAMPJ) on February 3, 2020.

The final Version of Record is available online: https://doi.org/10.1108/SAMPJ-04-2019-0145.

\section{Declaration of originality:}

The idea for this article was developed by the author based on an earlier working paper that was written by the author and Dr. Günter Peter in joint collaboration with colleagues of the Thünen Institute of International Forestry and Forest Economics (Hargita et al., 2018), which has undergone a minor revision after publication that does not affect the results of this article (Hargita et al., 2019). All tasks related to literature review, document analysis, framework development, drafting and revising the manuscript were mainly performed by the author. Dr. Günter Peter contributed his advice and expertise on supply chains and regulatory issues related to the genetic modification of soy. He helped to develop the manuscript by reviewing an earlier version that was (unsuccessfully) submitted to another journal. 


\title{
Traceability matters: A conceptual framework for deforestation-free supply chains applied to soy certification
}

\author{
Cordula Hinkes $^{\mathrm{a} *}$ and Günter Peter ${ }^{\mathrm{a}}$ \\ ${ }^{a}$ Thuenen Institute of Market Analysis, Bundesallee 63, 38116 Braunschweig, Germany \\ *corresponding author \\ e-mail: cordula.hinkes@thuenen.de
}

\begin{abstract}
Purpose - Sustainability certification of agricultural commodities might be one measure to ensure deforestation-free supply chains. The purpose of this article is to add to previous assessments of soy certification systems with respect to "zero deforestation" criteria by focusing on the aspect of traceability.
\end{abstract}

Design/methodology/approach - A conceptual framework for assessing certification systems is proposed based on a literature review. This concept is applied to 16 soy certification systems, considering previous studies and available chain-of-custody certification options.

Findings - Among the sample, five certification systems may contribute to ensuring deforestationfree soy supply chains, as they have relatively high "zero deforestation" and assurance requirements, and support at least segregation. Other chain-of-custody systems are insufficient in terms of traceability, but still dominate the market.

Research limitations/implications - The assessment considers only certification systems that have been benchmarked according to criteria developed by the European feed industry. Regular updates and further assessments of certification systems for other commodities are recommended.

Practical implications - Supply chain actors and policymakers are informed about certification systems that may ensure deforestation-free sourcing. However, different factors influence the implementation of zero deforestation commitments, such as adverse effects, economic tradeoffs, and new certification and traceability concepts.

Social implications - The implementation of deforestation-free supply chains should contribute to achieving sustainable development goals. Potential adverse social effects need to be considered. 
Originality/value - This study focuses on the so far rather neglected but essential aspect of traceability, which is required for ensuring deforestation-free sourcing along the whole supply chain.

Keywords chain-of-custody certification, deforestation, supply chain, sustainability, traceability

\section{Introduction}

Deforestation results in a loss of important ecosystem services, such as the provision of timber, biodiversity conservation, the regulation of ecological functions, and climate change mitigation. Until the beginning of the twentieth century, deforestation occurred mainly in temperate forests, driven by agricultural production and economic development in Asia, Europe and North America. Approximately since the 1920s, deforestation has been prevailing in tropical forests (FAO, 2012). Net deforestation rates have been slowing down from $0.20 \%$ annually between 1990 and 2000 to 0.08\% annually between 2010 and 2015 (FAO, 2015). Nevertheless, global forest area still decreased by $3.1 \%$ to around 4 billion hectares between 1990 and 2015 (FAO, 2015, 2018). Among a sample of 112 countries, Brazil reported the largest annual net loss of forest area for the period from 2010 to 2015 (FAO, 2015).

Recent studies have identified land-use change for the expansion of commercial and subsistence agriculture as one important driver of deforestation. Tropical rainforests of Southeast Asia and in the Amazon region are particularly affected (Angelsen \& Rudel, 2013; Busch \& FerrettiGallon, 2017; Geist \& Lambin, 2002; Henders et al., 2015; Pfaff et al., 2013). Increasing international demand for food, feed and fuels provides incentives for agricultural expansion. In terms of international trade and imports into the European Union (EU), especially soy, palm oil, cocoa, and beef are relevant "forest-risk" commodities (Brack \& Bailey, 2013; European Commission, 2013; Henders et al., 2015; Neeff \& Linhares-Juvenal, 2017).

The global production of soy for instance has more than doubled over the last two decades (FAO, 2019). Major producer countries for soy in terms of harvested area and production volumes are the United States of America (USA), Brazil, and Argentina (FAO, 2019; Mielke, 2018; Oil World, 2018). For 2017, the USA reported a harvested area of 36 million hectares (Mha), followed by Brazil with 34 Mha, and Argentina with 17 Mha (FAO, 2019). Genetically modified (GM) soy accounts for around $80 \%$ of the area used for soybean production globally (Tillie \& Rodríguez-Cerezo, 2015). Soy is traded in the form of soybeans, soy oil and soy meal. Brazil is currently the largest exporter of soybeans globally, while the EU is the largest importer of soy meal and the second largest importer of soybeans, after China (Oil World, 2018). Around $70 \%$ of 
globally produced soy are used as soy meal to feed animals (Lernoud et al., 2018). The remaining volume is used for the production of food and biofuels. Especially demand for biodiesel has recently become more important (European Commission, 2013), while less than five percent of soybeans and soy oil used in the EU are directly consumed by humans (IDH \& IUCN NL, 2019).

Public and private stakeholders in both soy producing and soy importing countries have committed themselves to support sustainable soy production. One exemplary measure is the Brazilian Soy Moratorium, a demand-driven pledge to stop purchasing soy from recently deforested areas in the biodiversity-rich Brazilian Amazon from 2006 onwards. The Soy Moratorium has been complemented by national deforestation control programs and policies, incentive-based instruments, and improved law enforcement. Recent studies identified empirical evidence for the decoupling of soy production and deforestation in Brazil in the past few years. However, it is difficult to identify which factors contributed to what extent to this favorable development (Gibbs et al., 2015; Kastens et al., 2017; Macedo et al., 2012; Nepstad et al., 2014; Rausch \& Gibbs, 2016).

Recent studies have identified strong indirect land-use change (ILUC) effects of soy expansion (Arima et al., 2011; Richards et al., 2014). The Soy Moratorium does neither cover the protection of other valuable ecosystems, such as the Cerrado savanna, nor other agricultural activities (Gibbs et al., 2015; Godar et al., 2016). To reduce displacement and leakage risks, private sector "zero deforestation" commitments (ZDCs) in Brazil have been expanded to beef supply chains via a so-called Cattle Agreement since 2009, and geographically through the Cerrado Manifesto since 2017 (Gibbs et al., 2016; Macedo et al., 2012; Nepstad et al., 2014; WWF, 2018). Nevertheless, positive effects of these initiatives might be limited by increasing demand for soy and beef as well as by deficiencies in land registration, policy definition, implementation and monitoring, and potentially corruption (Gibbs et al., 2015; Gibbs et al., 2016; Macedo et al., 2012; Nepstad et al., 2006; Nepstad et al., 2014).

On the consumption side, governments and companies have pledged to develop deforestation-free supply chains. Industry initiatives such as the Consumer Goods Forum (CGF) acknowledge that deforestation is a major problem to be addressed from the point of view of corporate social responsibility (CSR) (Donofrio et al., 2017; Garrett et al., 2019). With the New York Declaration on Forests (NYDF) in 2014, many governments, companies, NGOs and indigenous communities declared the goal to halve the loss of forests by 2020 , and to end it completely by 2030. In December 2015, a group of European countries signed the so-called Amsterdam Declarations, which aim at supporting the private sector in achieving deforestation-free supply chains by 2020. But these declarations are non-legally binding, and a lack of transparency currently impedes the achievement of "zero deforestation" targets (Godar et al., 2016). 
Private voluntary certification systems have become a popular CSR instrument (Bendell et al., 2011), particularly for ensuring the sustainability of agricultural products (Lernoud et al., 2018; Mol \& Oosterveer, 2015). Such certification systems typically consist of sustainability standards, assurance procedures, labels or claims, and traceability systems, sometimes complemented by capacity building measures (Komives \& Jackson, 2014). Certification of palm oil for instance is dominated by the Roundtable on Sustainable Palm Oil (RSPO), which supports the use of labels to advertise certified sustainable palm oil to end consumers (Garrett et al., 2016; Gassler \& Spiller, 2018; Lernoud et al., 2018). For soy, the systems of the Round Table on Responsible Soy (RTRS) and ProTerra are most prevalent (Lernoud et al., 2018). However, there are several other, more or less ambitious certification systems for soy (FEFAC, 2016; Hargita et al., 2018; Kusumaningtyas \& van Gelder, 2019).

Policymakers and supply chain actors supporting the development of sustainable, deforestation-free soy supply chains need to know which certification systems should be implemented to reach this goal (Bendell et al., 2011; Hargita et al., 2018). Governments for instance might implement sustainable public procurement policies to influence the uptake of soy certified according to certain systems (D'Hollander \& Marx, 2014). Norway is the first country that established "zero deforestation" targets as part of their public procurement policy (CDP, 2018). It could also be decided to make certain private standards mandatory (Henson \& Humphrey, 2010). Not only environmental standards for cultivation have to be assessed for this purpose. Soy and other "forest-risk" commodities are traded along complex international supply chains that involve many actors and transformation processes. From a supply chain perspective, the tracking and tracing of these commodities is required to verify sustainable, deforestation-free production conditions.

Research on the use of traceability systems in the context of sustainable agricultural supply chains is sparse (Mol \& Oosterveer, 2015). Previous comparative studies on soy certification systems either ignored the aspect of traceability completely (Kusumaningtyas \& van Gelder, 2019), or indicated the necessity to analyze this aspect in more detail (Hargita et al., 2018). The aim of this article is therefore to contribute to answering the following research questions (RQs) that are relevant for supply chain actors and policymakers committed to deforestation-free supply chains:

RQ 1: Which soy certification systems may ensure the sourcing of deforestation-free soy?

RQ 2: Which factors influence the implementation of deforestation-free soy supply chains?

The remainder of this article proceeds as follows. Theoretical background information relevant for the assessment of soy certification systems is provided in section 2 . Section 3 describes the qualitative methods used and justifies the selection of the sample of certification 
systems. A conceptual assessment framework is proposed and results for the research questions are presented in section 4 . In section 5, results and limitations of the study are discussed and ideas for further research are provided, before the findings are summarized with final conclusions in section 6 .

\section{Theoretical background and literature review}

\subsection{Global soy supply chains}

Soy is a homogeneous bulk product (Heron et al., 2018; Thakur \& Donnelly, 2010), which is traded internationally in large volumes (AMI, 2017; Oil World, 2018). The diagram in Figure 1 visualizes a simplified soy supply chain. After harvest, soybeans are stored in elevators before they are transported to crushing and refining facilities, if they are not directly used for food manufacturing. According to IDH \& IUCN NL (2019), the crushing of soybeans results in around $78.5 \%$ soy meal and $18.5 \%$ soy oil, while the rest is hulls. Soy meal is used as an ingredient for animal feed, particularly for pork and poultry (Heron et al., 2018), but also for aquaculture (Mariojouls et al., 2019). "Embedded" in meat and fish products, soy is mainly indirectly consumed by humans. Compared to other agricultural products, such as palm oil, soy is therefore usually not visible as a product ingredient to the end consumer (Heron et al., 2018; IDH \& IUCN NL, 2019). The origin and production conditions of soy are difficult to identify due to complex trade relationships, nonlinear supply paths, and the lack of visible brands and labels (Heron et al., 2018; Rueda et al., 2017). The transformation of soy in the form of merging or splitting of batches is possible at each stage of the supply chain, which increases the difficulty to keep track of a certain batch (Olsen \& Borit, 2018; Thakur \& Donnelly, 2010).

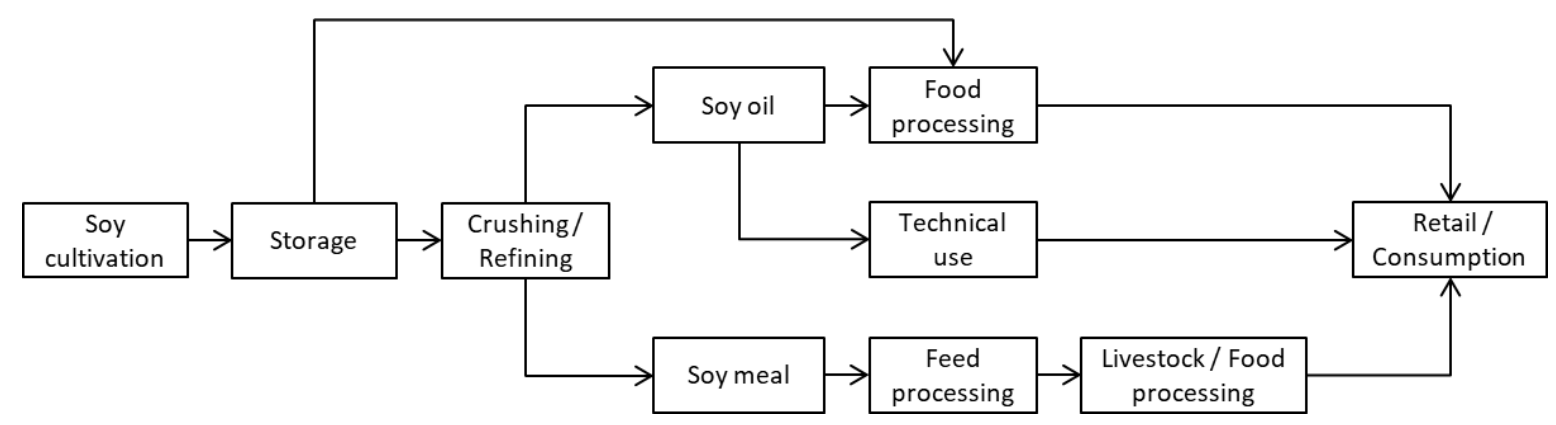

Figure 1. Simplified soy supply chain

Source: adapted from IDH \& IUCN NL (2019)

Depending on the individual case, different actors may be directly involved in soy supply chains: soy producers and cooperatives at the stage of cultivation, collectors and elevators at the storage stage, processors, traders, providers of transport and logistics, as well as feed and food 
manufacturers. Applying the concept of governance of global value chains ${ }^{20}$ (Gereffi et al., 2005) to the case of soy, Heron et al. (2018) argue that powerful actors are located at both ends of the chain, while retailers have less control compared to other agricultural value chains. The largest traders for soy globally are Archer Daniels Midland (ADM), Amaggi, Bunge, Cargill, and Louis Dreyfus. Multi-stakeholder initiatives and third-party certifiers have emerged as external actors influencing supply chain relations. The implementation of product and process standards as well as traceability systems affects supply chain governance (Gardner et al., 2019; Ghozzi et al., 2018; Mol \& Oosterveer, 2015).

\subsection{Traceability concepts and systems}

Grounded in institutional economics, the transaction cost economics (TCE) framework suggests that supply chain actors choose certain governance structures and contractual arrangements to minimize costs related to transaction risks (Williamson, 1979). Different forms of supply chain governance can be implemented to mitigate internal and exogenous and to increase supply chain transparency. One relevant example is the use of traceability systems to reduce food safety risks (Gardner et al., 2019; Ghozzi et al., 2016; Ghozzi et al., 2018; Stranieri et al., 2017). Apart from consumer concerns on food safety and quality, other relevant drivers for the development of food traceability systems are regulatory requirements, concerns on sustainability, and potential competitive advantages (Karlsen et al., 2013; van Rijswijk et al., 2008).

With respect to regulatory requirements, the General Food Law (GFL) (Regulation (EC) No 178/2002) for instance requires basic traceability for food products to reduce food safety risks in the EU. However, the GFL does not demand detailed information about the origin of ingredients or the production process. In addition, Regulation (EC) No. 1829/2003 legally requires labeling of food and feed in the EU if more than $0.9 \%$ of ingredients have been genetically modified (Ghozzi et al., 2016; Ghozzi et al., 2018; Peter \& Krug, 2016; Tillie \& Rodríguez-Cerezo, 2015). Examples in the United States are the Bioterrorism Act, which requires the registration of companies and data recording for the food and feed industry, and the Food Safety Modernization Act (FSMA), which provides guidelines for controls and compliance with regulations (Ringsberg, 2015; Thakur \& Donnelly, 2010).

A major difficulty related to research on traceability arises from the lack of a generally accepted definition, which might be attributed to the fact that traceability is relevant for different purposes, economic sectors, and research disciplines (Garcia-Torres et al., 2019; Karlsen et al.,

\footnotetext{
${ }^{20}$ The terms "supply chain", "value chain", and "chain of custody" are used interchangeably by different actors, depending on the perspective. Supply chain usually focuses on the movement of supplied materials between actors, while value chain emphasizes the value added at different stages, and chain of custody points to the control of information along the chain.
} 
2013; McEntire, 2019; Olsen \& Borit, 2013). Olsen and Borit (2013) reviewed and evaluated different traceability definitions. They conclude that no existing definition considers all relevant aspects of traceability and therefore suggest that traceability should be defined as "the ability to access any or all information relating to that which is under consideration, throughout its entire life cycle, by means of recorded identifications" (Olsen \& Borit, 2013, p. 148). Moe (1998) coined the term "traceable resource units" (TRUs) for any objects to be traced, and suggested a distinction between "internal traceability" within the operations of one organization and "chain traceability" along the whole supply chain.

Information recordings have to be linked to TRUs via unique identifiers (Olsen \& Borit, 2013). According to Olsen and Borit (2018), food traceability systems usually consist of three main components: mechanisms for identifying TRUs, for the documentation of transformations, and for the recording of TRU attributes. For the exchange of information along the supply chain, it is important to develop and implement non-proprietary electronic data exchange standards (Storøy et al., 2013; Thakur \& Donnelly, 2010). A broad range of possible implementation mechanisms for traceability is available, depending on resources and ambition and the type of information to be recorded (Bosona \& Gebresenbet, 2013; Mol \& Oosterveer, 2015; Sterling et al., 2015). Examples exist in different sectors, such as the online platform respect-code.org developed to ensure traceability in the apparel industry via so-called Quick Response (QR) codes (Cornelius, 2018), or radio-frequency identification (RFID) and e-pedigrees used in the pharmaceuticals industry (Choi et al., 2015).

Trade-offs between costs and benefits of traceability need to be considered (de Oliveira \& Alvim, 2017; Mol \& Oosterveer, 2015). Potential economic benefits of traceability are access to international or premium markets, improved operational efficiency leading to reduced production costs, and a reduction in market, operational and reputational risks. Such economic benefits have for instance been identified for timber (Halalisan et al., 2019), livestock (Kim et al., 2017), and fish products (Lallemand et al., 2016). Among major barriers to implementation are resource constraints, especially in terms of financial and technological resources, but also in the form of knowledge and human capacities (Bosona \& Gebresenbet, 2013; Sterling et al., 2015). It needs to be evaluated whether a traceability system reduces overall transaction costs because uncertainty is reduced, or whether it rather increases transaction costs due to the required physical separation and documentation (Banterle \& Stranieri, 2008; Bosona \& Gebresenbet, 2013).

\subsection{Chain-of-custody certification}

Credence qualities of a product can hardly be assessed by consumers, even after purchase and consumption (Darby \& Karni, 1973). Genetic modification is one example for a credence quality of 
soy, and a highly debated issue (Hilbeck et al., 2015; Qaim, 2009). Previous studies suggest environmental, social and economic benefits of genetically modified crops (Klümper \& Qaim, 2014; Qaim, 2009; Zilberman, Holland, \& Trilnick, 2018). But uncertainty remains, and many consumers are still concerned about health and safety of genetically modified organisms (GMO) and rather prefer GMO-free products (Costa-Font et al., 2008; Nielsen et al., 2003; Sax \& Doran, 2016). Potential effects of soy production on deforestation are another example of a credence quality. In contrast to the GMO-free status, "deforestation-free" is an immaterial attribute that cannot be verified by laboratory examination (Lippert, 2009). Traceability systems for food should also provide information on such product properties that are not analytically verifiable (Olsen \& Borit, 2013).

Voluntary sustainability certification is a popular instrument used to reduce information asymmetry with respect to sustainability-related credence qualities (Henson \& Humphrey, 2010; Mol \& Oosterveer, 2015; Stranieri et al., 2017; Zilberman, Kaplan, \& Gordon, 2018). Traceability systems linked to third-party verified certification shall provide credibility and transparency on different process and product qualities (Mol \& Oosterveer, 2015), thereby mitigating transaction risks along supply chains (Ghozzi et al., 2018). Certification is used as "common proxy for eliminating deforestation from supply chains" (Neeff \& Linhares-Juvenal, 2017, p. 2). In the context of certification, traceability systems are often referred to as chain-of-custody (CoC) systems (ISEAL Alliance, 2016; Komives \& Jackson, 2014). CoC certification has originally been developed for the forest sector and wood products (Wingate \& McFarlane, 2005). It provides the opportunity to certify the whole supply chain and is often an optional feature of certification systems. CoC systems differ in terms of traceability requirements and consequently in the wording of sustainability claims that may be attached to final products (ISEAL Alliance, 2016; Komives \& Jackson, 2014). The four most common forms of CoC systems for agricultural supply chains are visualized in Figure 2 in descending order according to the degree of traceability: identity preservation, segregation, mass balance, and book \& claim (ISEAL Alliance, 2016; Komives \& Jackson, 2014; Mol \& Oosterveer, 2015).

Soy certified as "identity preserved" or "segregated" is kept physically separated from non-certified soy along the whole supply chain. In contrast to identity preservation, segregation allows for the mixing of certified soy from different sources. Under the mass balance approach, it is allowed to mix certified with non-certified soy. The respective quantities have to be controlled along the chain, so that the input-output ratio is kept constant. Different forms of mass balance are possible, depending on the level at which the blending of certified and non-certified material takes place (e.g., batch level, site level, group level), as indicated by the boxes of blended material in Figure 2. Book \& claim is an approach that facilitates the trading of certificates independently 
of the certified products. Market participants may buy certificates or credits from certified producers via trading platforms, similarly to the more popular case of carbon credits.

\section{Identity preservation}

(c) $\rightarrow$ (c) $\rightarrow$ (c) $\rightarrow$ (c) $\rightarrow$ (c)

(c) $\rightarrow$ (c) $\rightarrow$ (c) $\rightarrow$ (c) $\rightarrow$ (c)

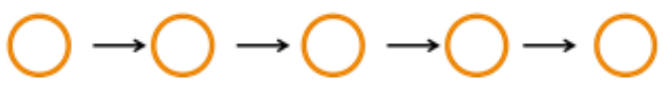

3. Mass balance

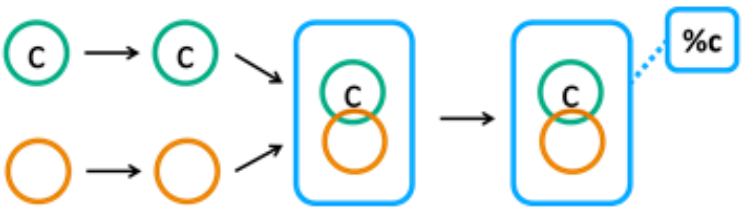

\section{Segregation}

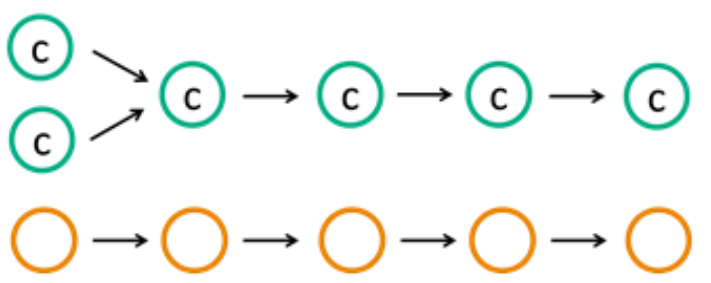

4. Book \& claim

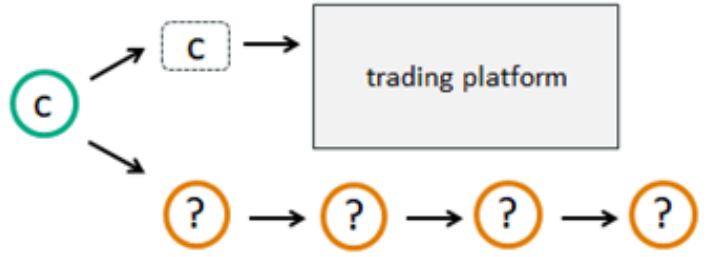

\section{Legend:}

(C) certified material

C certificate

non-certified material ? material without certificate

blended material

Figure 2. Common types of chain-of-custody systems

Sources: own contribution, adapted from ISEAL Alliance (2016); Komives and Jackson (2014); Mol and Oosterveer (2015)

\section{Methods and data}

In order to provide answers to the research questions defined in the introduction, (i) a literature review and (ii) a qualitative analysis of different standard documents and previous assessments were conducted. The literature review followed methodological guidance provided by Torraco (2005) on integrative literature reviews. According to Torraco (2005), integrative literature reviews involve the review, critique and synthesis of literature and thereby support the development of conceptual frameworks that facilitate a better understanding of relatively new and unexplored topics. The search engine Google Scholar was used to identify relevant articles published in scientific journals by using keywords like certification, chain-of-custody, deforestation-free, soy, standards, supply chain, sustainability, traceability, and various combinations thereof.

Additional articles were identified by using a form of backward snowballing, defined as the use of an article's reference list to search for potentially relevant publications (Wohlin, 2014). 
Working papers and reports not published in scientific journals were mainly retrieved in this way, and by using Google Search. As Torraco (2005) does not specify a concrete method for analyzing the identified literature, guidelines for conducting a qualitative document analysis according to Bowen (2009) have been considered. Document analysis is understood as an iterative process of skimming, reading and interpretation of texts. It combines aspects of thematic analysis and content analysis and results in the identification of categories and themes relevant for answering the respective research questions (Bowen, 2009). Although it is sometimes suggested to use specific software for computer-assisted qualitative data analysis to code the material (e.g., Kuckartz, 2016), this was not regarded necessary for the purpose of this study. An overview of the topics, subthemes and the main relevant literature identified in the review is provided in the Appendix.

Based on the literature review, the theoretical background information on soy supply chains, traceability, and chain-of-custody certification was provided in section 2 . This background information is relevant for the traceability assessment of soy certification systems presented in the following section 4 . The focus has been set on traceability systems associated with voluntary sustainability certification systems. With respect to RQ1, a conceptual framework for the identification of certification systems that allow for the sourcing of deforestation-free commodities is proposed based on the literature review. This framework is then applied to assess a sample of soy certification systems according to different criteria. The sample consists of those certification systems that have been benchmarked as compliant with minimum sustainability requirements defined in the Soy Sourcing Guidelines (SSG) published by the European Feed Manufacturer's Federation (FEFAC, 2016). The focus on this sample of certification systems is justified by the importance of the European Union as the largest import market for soy meal and the second largest import market for soybeans, as well as by the relevance of feed as the main designated use of soy globally. The benchmarked systems are particularly important for European policymakers supporting ZDCs according to the Amsterdam Declarations.

Information on the benchmarking of certification systems is provided by the FEFAC Sourcing Guidelines Tool developed by the International Trade Centre (ITC) in collaboration with FEFAC (ITC, 2019a). This tool also provides information on systems that have failed to meet the SSG requirements so far and therefore do not have to be considered. For the assessment, relevant information on sustainability standards and assurance provisions has been extracted from previous assessments (Hargita et al., 2018; Kusumaningtyas \& van Gelder, 2019) and updated accounting for changes in standards that had been published in the meantime. Due to a lack of previous research, the aspect of traceability has been assessed in detail by analyzing standard requirements in a document analysis, last updated in August and September 2019. 
Additional relevant scientific literature on traceability and chain-of-custody certification identified in the literature review has been considered.

Answers to RQ 2 are mainly based on the literature review and document analysis of scientific articles. This analysis identified three major factors currently influencing the implementation of deforestation-free soy supply chains. The following section 4 presents the results of the overall analysis, structured according to the two research questions.

\section{Results}

\subsection{Which soy certification systems may ensure the sourcing of deforestation-free soy?}

An overview of the sample of FEFAC SSG-compliant certification systems, the organizations behind these systems, as well as the geographical and product-related scope are provided in Table 1. It also shows which document versions of the standards have been considered in the analysis. The Belgian Feed Association (BFA) collaborates with Cefetra and adopts their standards. For the SSG-compliant certification systems of Bunge PRO-S, Cargill Triple S, COAMO and Louis Dreyfus, standard documentation was not publicly available during the assessment period. Therefore, these systems have been excluded from further analysis and are not shown in Table 1.

Table 1. Overview of FEFAC SSG-compliant soy certification systems

\begin{tabular}{|c|c|c|c|c|c|}
\hline $\begin{array}{c}\text { Standard or } \\
\text { program }\end{array}$ & $\begin{array}{c}\text { Reference to } \\
\text { document version }\end{array}$ & Organization & $\begin{array}{c}\text { Type of } \\
\text { organization }\end{array}$ & $\begin{array}{l}\text { Geographical } \\
\text { scope }\end{array}$ & $\begin{array}{c}\text { Product } \\
\text { range }\end{array}$ \\
\hline $\begin{array}{l}\text { ADM Responsible } \\
\text { Soybean Standard } \\
\text { (RSS) }\end{array}$ & ADM (2018) & $\begin{array}{l}\text { Archer Daniels } \\
\text { Midland } \\
\text { (ADM) }\end{array}$ & private company & $\begin{array}{l}\text { globally } \\
\text { produced }\end{array}$ & $\begin{array}{l}\text { soy (food } \\
\text { and feed) }\end{array}$ \\
\hline $\begin{array}{l}\text { Agricultura } \\
\text { Sustenable } \\
\text { Certificada (ASC) }\end{array}$ & Aapresid (2017) & Aapresid & $\begin{array}{l}\text { non- } \\
\text { governmental } \\
\text { organization } \\
\text { (NGO) }\end{array}$ & $\begin{array}{l}\text { produced in } \\
\text { Argentina }\end{array}$ & $\begin{array}{l}\text { different } \\
\text { agricultural } \\
\text { products }\end{array}$ \\
\hline $\begin{array}{l}\text { Amaggi } \\
\text { Responsible } \\
\text { Standard (ARS) }\end{array}$ & Amaggi (2016) & $\begin{array}{l}\text { Grupo André } \\
\text { Maggi } \\
\text { (Amaggi) }\end{array}$ & private company & $\begin{array}{l}\text { globally } \\
\text { produced (so far } \\
\text { only Brazil) }\end{array}$ & $\begin{array}{l}\text { soy (food } \\
\text { and feed) }\end{array}$ \\
\hline $\begin{array}{l}\text { Belgian Feed } \\
\text { Association (BFA) }\end{array}$ & $\begin{array}{l}\text { refers to Cefetra } \\
\text { (2018); no own } \\
\text { certification }\end{array}$ & $\begin{array}{l}\text { Belgian Feed } \\
\text { Association } \\
\text { (BFA) }\end{array}$ & $\begin{array}{l}\text { industry } \\
\text { association }\end{array}$ & $\begin{array}{l}\text { produced in } \\
\text { Brazil and } \\
\text { Argentina }\end{array}$ & $\begin{array}{l}\text { crops for } \\
\text { feed }\end{array}$ \\
\hline $\begin{array}{l}\text { Cefetra Certified } \\
\text { Responsible Soya } \\
\text { (CRS) }\end{array}$ & Cefetra (2018) & Cefetra & private company & $\begin{array}{l}\text { globally } \\
\text { produced (so far } \\
\text { only Brazil and } \\
\text { Argentina) }\end{array}$ & $\begin{array}{l}\text { soy (food } \\
\text { and feed) }\end{array}$ \\
\hline Donau Soja & $\begin{array}{l}\text { Donau Soja } \\
\text { Association (2019) }\end{array}$ & $\begin{array}{l}\text { Donau Soja } \\
\text { Association }\end{array}$ & $\begin{array}{l}\text { multi- } \\
\text { stakeholder } \\
\text { partnership }\end{array}$ & $\begin{array}{l}\text { produced in the } \\
\text { Danube region }\end{array}$ & $\begin{array}{l}\text { soy (food } \\
\text { and feed) }\end{array}$ \\
\hline Europe Soya & $\begin{array}{l}\text { Donau Soja } \\
\text { Association (2019) }\end{array}$ & $\begin{array}{l}\text { Donau Soja } \\
\text { Association }\end{array}$ & $\begin{array}{l}\text { multi- } \\
\text { stakeholder } \\
\text { partnership }\end{array}$ & $\begin{array}{l}\text { produced in } \\
\text { Europe }\end{array}$ & $\begin{array}{l}\text { soy (food } \\
\text { and feed) }\end{array}$ \\
\hline $\begin{array}{l}\text { Feed Materials } \\
\text { Assurance } \\
\text { Scheme (FEMAS) }\end{array}$ & $\operatorname{AIC}(2015,2019)$ & $\begin{array}{l}\text { Agricultural } \\
\text { Industries } \\
\text { Confederation } \\
\text { (AIC) }\end{array}$ & $\begin{array}{l}\text { industry } \\
\text { association }\end{array}$ & $\begin{array}{l}\text { globally } \\
\text { produced }\end{array}$ & $\begin{array}{l}\text { different } \\
\text { agricultural } \\
\text { products }\end{array}$ \\
\hline ISCC EU & ISCC (2018) & $\begin{array}{l}\text { International } \\
\text { Sustainability }\end{array}$ & $\begin{array}{l}\text { multi- } \\
\text { stakeholder }\end{array}$ & $\begin{array}{l}\text { produced for the } \\
\text { EU market }\end{array}$ & $\begin{array}{l}\text { biofuels in } \\
\text { the EU }\end{array}$ \\
\hline
\end{tabular}




\begin{tabular}{|c|c|c|c|c|c|}
\hline & & $\begin{array}{l}\text { and Carbon } \\
\text { Certification } \\
\text { (ISCC) GmbH }\end{array}$ & partnership & & \\
\hline ISCC PLUS & ISCC (2018) & ISCC GmbH & $\begin{array}{l}\text { multi- } \\
\text { stakeholder } \\
\text { partnership }\end{array}$ & $\begin{array}{l}\text { globally } \\
\text { produced } \\
\text { (biofuels for non- } \\
\text { EU markets) }\end{array}$ & $\begin{array}{l}\text { food, feed, } \\
\text { bio-based } \\
\text { products, } \\
\text { energy, } \\
\text { biofuels } \\
\text { outside EU }\end{array}$ \\
\hline ProTerra & ProTerra (2018) & $\begin{array}{l}\text { ProTerra } \\
\text { Foundation }\end{array}$ & NGO & $\begin{array}{l}\text { globally } \\
\text { produced }\end{array}$ & $\begin{array}{l}\text { different } \\
\text { agricultural } \\
\text { products }\end{array}$ \\
\hline RTRS & RTRS (2018) & $\begin{array}{l}\text { Round Table } \\
\text { on } \\
\text { Responsible } \\
\text { Soy (RTRS) }\end{array}$ & $\begin{array}{l}\text { multi- } \\
\text { stakeholder } \\
\text { partnership }\end{array}$ & $\begin{array}{l}\text { globally } \\
\text { produced }\end{array}$ & $\begin{array}{l}\text { soy (food, } \\
\text { feed, } \\
\text { biofuels) }\end{array}$ \\
\hline $\begin{array}{l}\text { Sustainable } \\
\text { Farming } \\
\text { Assurance } \\
\text { Programme } \\
\text { (SFAP) } \\
\end{array}$ & ProAgros (2017) & ProAgros & private company & $\begin{array}{l}\text { globally } \\
\text { produced (focus } \\
\text { on South } \\
\text { America) }\end{array}$ & $\begin{array}{l}\text { crops for } \\
\text { feed }\end{array}$ \\
\hline $\begin{array}{l}\text { SFAP Non- } \\
\text { Conversion }\end{array}$ & ProAgros (2018) & ProAgros & private company & see above & see above \\
\hline $\begin{array}{l}\text { Sustainable Feed } \\
\text { Standard (SFS) }\end{array}$ & SFS (2017) & CKade SFS BV & private company & $\begin{array}{l}\text { globally } \\
\text { produced (so far } \\
\text { Brazil and } \\
\text { Argentina) }\end{array}$ & $\begin{array}{l}\text { crops for } \\
\text { feed }\end{array}$ \\
\hline $\begin{array}{l}\text { U.S. Soy } \\
\text { Sustainability } \\
\text { Assurance } \\
\text { Protocol (U.S. } \\
\text { SSAP) }\end{array}$ & USSEC (2018) & $\begin{array}{l}\text { U.S. Soybean } \\
\text { Export Council } \\
\text { (USSEC) }\end{array}$ & $\begin{array}{l}\text { public-private } \\
\text { partnership } \\
\text { (PPP) }\end{array}$ & $\begin{array}{l}\text { produced in the } \\
\text { USA }\end{array}$ & $\begin{array}{l}\text { soy (food } \\
\text { and feed) }\end{array}$ \\
\hline
\end{tabular}

\subsubsection{Conceptual framework for the assessment of deforestation-free certification systems}

As mentioned in the introduction, voluntary sustainability certification systems usually consist of different components (Komives \& Jackson, 2014). For the assessment of their ability to ensure deforestation-free sourcing, three main aspects have to be considered: sustainability standards, assurance, and chain-of-custody certification. The following conceptual framework summarized in Figure 3 includes these aspects and is proposed for comparative assessments of certification systems for "forest-risk" commodities. In sections 4.1.2 and 4.1.3, this framework is applied to the case of soy.

First, at the stage of production, the implementation of environmental standards needs to ensure that no forests are converted for agricultural production. Certification systems also include social - and sometimes economic - standards, but these are less relevant for the focus on deforestation-free production. This focus requires a closer look on how "zero deforestation" is defined in the respective standards. In the literature it is usually distinguished between zero illegal deforestation, zero net deforestation, and zero gross deforestation. Zero illegal deforestation refers to regulatory requirements in the respective producer countries, which often allow for a certain amount of deforestation. Zero net deforestation allows for compensating deforestation 
with afforestation elsewhere. Zero gross deforestation is most stringent, meaning that no compensation for deforestation is allowed (Brown \& Zarin, 2013; Meyer \& Miller, 2015; Neeff \& Linhares-Juvenal, 2017).

While the CGF and most private sector ZDCs refer to zero net deforestation (CDP, 2018; Jopke \& Schoneveld, 2018), the NYDF does not specify whether zero net or zero gross deforestation should be achieved (Climate Focus, 2015). The requirement for zero illegal deforestation - although in line with the FEFAC SSG criteria - can be regarded as insufficient to achieve zero deforestation targets due to loopholes and deficiencies in national legislation and enforcement (e.g., Gibbs et al., 2015; Hargita et al., 2018; Kusumaningtyas \& van Gelder, 2019).

These definitions also depend on the perception of what counts as forest. Forest definitions may be quantitative, referring to area, tree height and tree crown cover, or qualitative, focusing for instance either on primary forests only or using concepts such as High Conservation Value (HCV) or High Carbon Stock (HCS). Moreover, different certification systems apply different cut-off dates for deforestation and timeframes for the implementation of ZDCs. The focus might also be extended from avoiding deforestation to avoiding the conversion of other types of valuable ecosystems (Hargita et al., 2018; Kusumaningtyas \& van Gelder, 2019). Systems that require the conservation of other valuable ecosystems and apply HCV or HCS approaches are more comprehensive and inclusive than systems that focus only on the conservation of (primary) forests. Earlier cut-off dates for deforestation impose stronger restrictions on land used for cultivation.

Second, assurance of compliance with sustainability standards is required. First-party controls are related to internal control systems and self-assessments by the entity to be controlled. Second-party controls are performed by actors that have direct trade relations with the entity to be controlled. Third-party controls are performed by independent certification bodies. Some certification systems require accreditation of third-party auditors to ensure competence and integrity. Audit frequency and the validity period of certificates also differ between certification systems. It can be assumed that - other things being equal - the higher the frequency of controls, the lower is the risk that non-compliance remains undetected. This risk is further reduced if a system requires unannounced audits.

Third, CoC systems need to be sufficiently stringent to ensure traceability of certified soy along the supply chain. In section 2.3 , the most common CoC certification systems relevant for agricultural commodities have been introduced. With identity preservation systems it is possible to trace soy back to the producer or even to identify the exact production batch, depending on the definition in the respective certification standard. Segregation ensures that soy purchased downstream the supply chain has been certified, although it is not possible to track certified soy 
back to the producer, as batches get mixed. As mass balance claims only ensure a certain ratio of certified to non-certified soy, this system is not suitable for ensuring compliance with certain standards for a given supply chain. Finally, traceability is not possible at all with book \& claim systems, as certification claims are completely decoupled from physical products. While effectively only identity preservation ensures traceability of soy batches back to the stage of production, this is not necessarily required to ensure the sourcing of certified, deforestation-free soy. For this purpose, segregation of certified from uncertified soy should be sufficient. A certification system that does not offer at least segregation might still have high sustainability standards and assurance at the stage of production, but cannot prevent blending with uncertified produce.

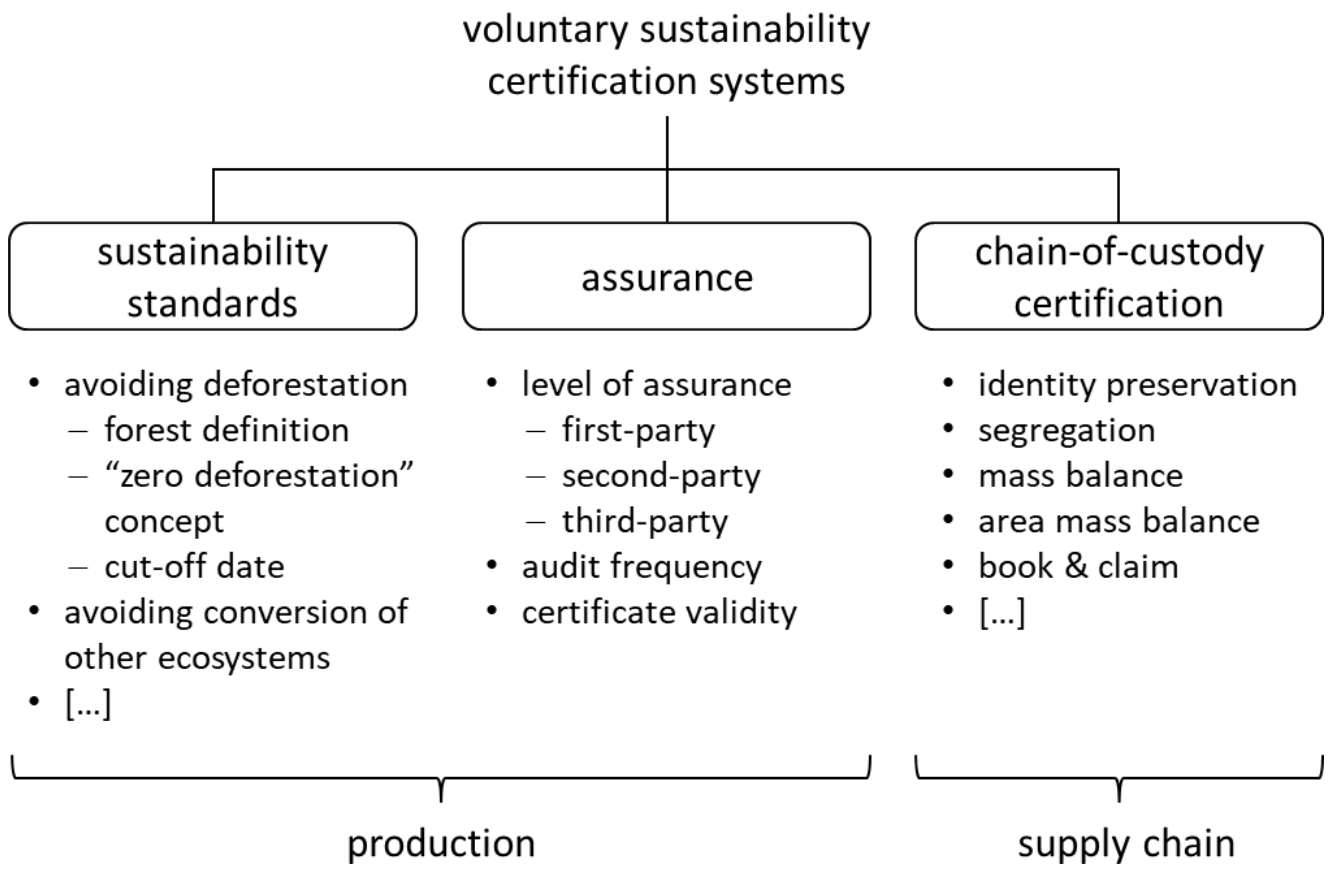

Figure 3. Certification criteria relevant for achieving "zero deforestation" targets

Source: own contribution

\subsubsection{Sustainability standards and assurance}

For the case of soy certification systems, the literature review identified two previous assessments (Hargita et al., 2018; Kusumaningtyas \& van Gelder, 2019). These studies also focused on FEFAC SSG-compliant certification systems, but the sample was not exactly the same due to different periods of analysis. Kusumaningtyas and van Gelder (2019) did not consider the SSG-compliant ISCC EU system, without providing an explanation for this exclusion. Instead, the recently established Sustainable Farming Assurance Programme (SFAP) has been included in two versions: SFAP and SFAP Non-Conversion, which had not yet existed when the assessment by Hargita et al. (2018) was conducted. SFAP Non-Conversion differs from SFAP in terms of additional 
requirements for avoiding the conversion of certain ecosystems. Both studies provide useful information with respect to "zero deforestation" criteria, but information on traceability is insufficient in the study by Hargita et al. (2018) and completely missing in the study by Kusumaningtyas and van Gelder (2019). The most important results of these assessments with respect to sustainability standards and assurance are summarized as follows.

Concerning sustainability standards, Hargita et al. (2018) and Kusumaningtyas and van Gelder (2019) found that the certification systems of ADM, Amaggi, ASC, FEMAS, SFAP, SFS, and U.S. SSAP refer only to national legislation with respect to zero deforestation criteria. These systems can therefore be regarded as insufficient. The remaining certification systems require zero gross deforestation, mostly using 2008 or 2009 as cut-off dates. Among these systems, ISCC EU and ISCC PLUS, followed by ProTerra and RTRS, have the highest standards with respect to avoiding conversion of HCV areas and other valuable ecosystems. Donau Soja, Europe Soya, Cefetra CRS and BFA are found to be less comprehensive, but at least include criteria on the conservation of wetlands ${ }^{21}$.

Concerning the aspect of assurance, all FEFAC SSG-compliant certification systems require independent third-party verification. Not all systems require the accreditation of the certification body, though. There are further differences in terms of audit frequency, the validity period of the certificate, and the option of unannounced audits. RTRS and Amaggi have the most stringent assurance provisions. Considering both sustainability standards and assurance together, ISCC EU and ISCC PLUS as well as ProTerra look best (Kusumaningtyas \& van Gelder, 2019).

\subsubsection{Chain-of-custody certification requirements}

CoC certification is not mandatory according to the FEFAC SSG. Nevertheless, FEFAC states that "in the longer term, area mass balance and mass balance should be considered as preferred supply chain models" (FEFAC, 2016, p. 6). Area mass balance is a relatively new CoC system for soy originally defined by Cefetra, which has been adopted by other systems as well. It combines elements of mass balance and book \& claim. Certificates are traded independently of the physical product, while it has to be assured that both are sourced from the same regional area. Thus, mass balance can be applied at a regional level, where some farms are certified and others are not (Cefetra, 2018). Area mass balance can therefore be ranked between mass balance and book \& claim in terms of traceability.

\footnotetext{
${ }^{21}$ The Donau Soja Association recently criticized this aspect of the assessment by Hargita et al. (2018) because according to Donau Soja and Europe Soya standards, soy cultivation is only allowed on areas that have been designated for agricultural land use even prior to 2008. Thus, deforestation or indirect landuse change should be effectively impossible, and forest definitions would in this case be redundant. The two certification systems should therefore receive a higher rating in this category (personal communication with Donau Soja Association in November 2019).
} 
Table 2 provides an overview of the available $\mathrm{CoC}$ certification options for each of the different certification systems listed in Table 1. If a CoC certification option is available for the respective system, it is marked with an " $\mathrm{X}$ ". In case the system clearly specifies a mandatory minimum level for $\mathrm{CoC}$ certification, the respective CoC system is marked with an " $\mathrm{X}$ ". For some systems CoC certification is covered in optional modules (e.g., FEMAS, RTRS). For other systems the documentation does not clearly indicate whether it is compulsory or optional (e.g., ADM RSS, ARS). Certification according to the ASC standards is only applicable to the level of production, so no chain-of-custody certification is available at all.

Table 3. Chain-of-custody options offered by different certification systems for soy

\begin{tabular}{|c|c|c|c|c|c|}
\hline \multirow[b]{2}{*}{ Certification system } & \multicolumn{5}{|c|}{ Chain-of-custody certification options } \\
\hline & $\begin{array}{c}\text { Identity } \\
\text { preservation }\end{array}$ & Segregation & Mass balance & $\begin{array}{c}\text { Area mass } \\
\text { balance }\end{array}$ & $\begin{array}{c}\text { Book \& } \\
\text { claim }\end{array}$ \\
\hline ADM RSS & & $\mathrm{x}$ & & $\mathrm{x}$ & $\mathrm{x}$ \\
\hline \multicolumn{6}{|l|}{ ASC } \\
\hline ARS & & & $x$ & & \\
\hline BFA (refers to Cefetra CRS) & & & & $x$ & $x^{R}$ \\
\hline Cefetra CRS & & & & $x$ & $x^{R}$ \\
\hline Donau Soja & $x^{R}$ & & & & \\
\hline Europe Soya & $\mathrm{x}$ & & $(X)^{R}$ & & \\
\hline FEMAS & & $x$ & $x$ & & $(X)$ \\
\hline ISCC EU \& ISCC PLUS & $x$ & $x$ & $x^{R}$ & & \\
\hline ProTerra & $x$ & $x^{R}$ & & & \\
\hline RTRS & & $\mathrm{x}$ & $x$ & & $x$ \\
\hline SFAP \& SFAP Non-Conversion & & & & $x$ & $x^{R}$ \\
\hline SFS & & & & & $\mathrm{x}$ \\
\hline U.S. SSAP & & & $x^{R}$ & & \\
\hline
\end{tabular}

ProTerra strictly prohibits the use of genetic modification, a highly contested issue in the context of soy cultivation (de Oliveira \& Alvim, 2017). ProTerra-certified soy is therefore not allowed to be mixed with non-certified genetically modified soy and requires at least segregation (ProTerra, 2018). According to Lernoud et al. (2018), all ProTerra-certified products imported to Europe follow identity preservation. Apart from ProTerra, only Donau Soja and Europe Soya prohibit the certification of genetically modified soy, while ISCC PLUS recommends abstaining from genetic modification without prohibiting its use. Other systems, such as RTRS or FEMAS, offer optional non-GM soy certificates that require segregation.

Donau Soja and Europe Soya share the same production standards but slightly differ in terms of their traceability requirements, apart from the different geographical scope of production. Donau Soja has the strictest requirements in terms of traceability, as the system requires the implementation of a $\mathrm{CoC}$ system that ensures identity preservation, in line with the 
"Guideline on the Definition of 'GMO-free Production' of Food and its Labelling" published in the Austrian Food Codex. According to this guideline, controls are required along the whole supply chain from the farmer to the primary processor (e.g., mills, food or feed processors). Soy farmers are required to register with the elevator (here: agricultural collector), and lot-based certificates are issued. All involved supply chain actors have to comply with the standards and agree to implement controls and to be subject to audits by independent certification bodies (Donau Soja Association, 2019).

Europe Soya additionally offers a so-called "quantity equivalence system", a type of mass balance that allows for blending with soy that has been approved by Europe Soya. To achieve this approval, specific criteria have to be fulfilled, such as the non-GM requirements and the geographic origin according to the Europe Soya standard. However, no further sustainability criteria are specified for the approved soy. The respective supply chain actors also have to sign contracts with and become a member of the Donau Soja Association. Referring to the EU General Food Law, the Donau Soja Association claims the right to trace approved soy batches "one step back in the value chain", starting from the primary processor (e.g., the mill), so effectively traceability is ensured until the stage of storage or collection of soy beans from producers after harvest (Donau Soja Association, 2019). If this CoC option is chosen, the level of traceability is lower compared to Donau Soja. Moreover, the lack of sustainability requirements for approved soy impedes deforestation-free sourcing.

RTRS offers optional CoC certification. The different options (segregation, mass balance, book \& claim) are described in a separate standard document. While ISCC EU and ISCC PLUS cover different markets and uses of soy, they refer to the same requirements in terms of traceability. ISCC PLUS includes ISCC EU requirements, plus additional specific requirements and voluntary add-ons. ISCC systems, particularly ISCC EU, are used for the certification of commodities that are used as feedstock for biofuels in the EU and need to comply with the EU Renewable Energy Directive (RED) 2009/28/EC and the Fuel Quality Directive (FQD) 2009/30/EC and their respective amendments. Based on these regulations, both systems require at least mass balance. Some organizations, such as Amaggi and Cefetra, regard compliance with their own system as the first achievement in a step-wise approach to certification for their suppliers, promoting continuous improvement of standards (Amaggi, 2016; Cefetra, 2018; Garrett et al., 2013). There are different approaches to collaboration between certification systems. Several of the organizations listed in Table 1 are also members of the RTRS.

Overall, Table 2 shows that ADM RSS, Donau Soja and Europe Soya, FEMAS, ISCC PLUS and ISCC EU, ProTerra, as well as RTRS offer at least segregation and/or identity preservation as CoC certification options. Donau Soja and ProTerra are most stringent in terms of traceability because 
they require at least segregation, with Donau Soja even prescribing identity preservation. Taking into account the results of section 4.1.2, the certification systems of ISCC PLUS and ISCC EU, ProTerra, Donau Soja and Europe Soya, as well as RTRS should be more suitable to ensure the deforestation-free sourcing of soy compared to other systems considered in the assessment.

\subsection{Which factors influence the implementation of deforestation-free supply chains?}

"Zero deforestation" targets are currently far from being reached (Garrett et al., 2019). Concerning traceability, mass balance remains the dominant CoC certification system applied in agricultural supply chains so far (Jopke \& Schoneveld, 2018) - which is insufficient as argued in section 4.1. The effective implementation of deforestation-free supply chains is influenced by different factors identified in the literature review, such as potential adverse effects, trade-offs between transaction and implementation costs, and the development of new approaches to certification and traceability.

\subsubsection{Adverse effects of "zero deforestation" commitments}

Many private sector ZDCs are still not linked to adequate implementation mechanisms and transparency. They often lack concrete definitions of forest and deforestation as well as specified cut-off dates and timelines, which makes it difficult to hold companies accountable for their commitments (Jopke \& Schoneveld, 2018; Lambin et al., 2018). Recent evidence has shown that deforestation continues in spite of certification. One reason might lie in weak standards and insufficient enforcement (van der Ven et al., 2018). The protection of certain forest areas or the focus on certain commodities such as soy might lead to ILUC effects (Arima et al., 2011; Richards et al., 2014) as well as displacement and leakage effects between commodities or production areas (Delacote et al., 2016; Lambin et al., 2018; le Polain de Waroux et al., 2019). It has been argued that if the EU or European buyers impose stricter requirements on soy sustainability, suppliers from Brazil might switch to countries with less strict requirements, such as China or India (da Silva Júnior et al., 2016; van der Ven et al., 2018). The currently ongoing "trade war" between the United States and China has already changed global trade flows of soy. A high tariff imposed on soy imported from the United States has motivated China to source more soy from Brazil instead. To satisfy the increasing demand, large-scale land use change at the expense of forests is expected for Brazil (Fuchs et al., 2019).

The implementation of ZDCs might also have adverse social effects. Producers not able to comply with higher production standards are likely to be excluded from supply chains. This would most likely affect smallholders who lack capacities and resources to adapt to new requirements. While this aspect might be less relevant for the soy sector, palm oil supply chains might be more 
affected due to the much higher number of smallholders in the supply base. ILUC effects might also lead to land rights conflicts and food security issues, if land previously used for food crop cultivation is converted for the production of feed crops or biofuel feedstock (DeFries et al., 2017; Jopke \& Schoneveld, 2018; Lambin et al., 2018).

\subsubsection{Trade-offs between transaction costs and implementation costs}

Referring to the TCE framework mentioned in section 2.2, traceability systems are often implemented to reduce transaction costs. Potential benefits expected from increased traceability - such as efficiency gains, risk reduction and consumer trust- need to outweigh the expected costs of implementation. As the implementation of more complex traceability systems is - other things being equal - more expensive, it can be expected that companies decide for these options only if they can pass on the costs along the supply chain (Kalaitzandonakes et al., 2018; Peter \& Krug, 2016). Mass balance and book \& claim approaches require less effort, so large-scale certification can be achieved at relatively low costs. Thus, they are attractive options for complex international supply chains for soy or other commodities. Book \& claim is particularly flexible, as in case of a demand gap certificates can be stored and sold later. RTRS certificates for instance are valid for five years. On the downside, the lack of traceability associated with mass balance and book \& claim implies a higher risk of fraud (Mol \& Oosterveer, 2015).

CoC certification options that allow for a high degree of traceability, such as identity preservation and segregation, are so far rather used for products for which sustainability is demanded by end consumers ( $\mathrm{Mol} \&$ Oosterveer, 2015), or if regulatory compliance requires the assurance of certain product characteristics. For the case of soy, which is predominantly used for feed production and thus indirectly consumed by humans, sustainability labeling with strict claims is less relevant, because feed is not visible on the list of ingredients of meat products (Heron et al., 2018; IDH \& IUCN NL, 2019; Wesseler, 2014). However, regulations in the European Union as an important market for non-GM feed effectively require segregation systems (Peter \& Krug, 2016; Tillie \& Rodríguez-Cerezo, 2015). Also the increasing consumer demand for organic livestock products leads to an increasing demand for segregated non-GM soy for feed (Lernoud et al., 2018).

Access to premium markets and higher prices received for segregated soy might outweigh costs for the implementation of traceability systems. Identity preserved or segregated non-GM soybean meal achieves significant price premiums on the market as compared to the price for non-segregated soy (Garrett et al., 2019; Peter \& Krug, 2016; Tillie \& Rodríguez-Cerezo, 2015). Garrett et al. (2013) identified price premiums of $5-10 \%$ for non-GM soy as compared to conventional GM soy. If non-GM soy is additionally certified by ProTerra, the premium is even 
higher. One possible strategy for supply chain actors aiming at achieving deforestation-free soy supply chains might therefore be to support non-GM soy certification systems in order to target premium markets that compensate for traceability implementation costs. But currently, the major part of global soy production is still not certified according to any sustainability standards (Heron et al., 2018; Lernoud et al., 2018), and a large share of certified produce is sold as uncertified, indicating that buyers are often not willing to pay a premium (Potts et al., 2014; RTRS, 2017). High costs still remain a major barrier to the implementation of sophisticated traceability systems (Godar et al., 2016).

\subsubsection{New approaches to certification and traceability}

The current development of certification and traceability systems shows a trend towards aggregation to leverage economies of scale. So-called landscape or jurisdictional approaches are developed to upscale certification and to achieve deforestation-free supply chains (Ghazoul et al., 2009; Godar et al., 2016; Meyer \& Miller, 2015; Tscharntke et al., 2015; van Noordwijk et al., 2017). Moving from supply chain approaches to territorial approaches is expected to save costs, as compared to the tracking and tracing of individual batches (Nepstad et al., 2014). Also the risk of leakage to other commodities or adjacent areas might be reduced (Lambin et al., 2018). However, upscaling initiatives bear the non-negligible risk of a so-called "race to the bottom" in sustainability standards, as the certification of landscapes against one-fits-all standards provides room for errors and fraud (Meyer \& Miller, 2015).

Different tools have been developed to improve supply chain transparency. One example is the "Trase" project by the Stockholm Environment Institute (SEI) and the environmental organization Global Canopy. The idea behind this project is to increase public transparency on the jurisdictional level by combining customs data with cross-border analyses of trade material flows (Godar et al., 2016). A publicly accessible web-based tool includes trade data and visualizes supply chains that are currently available for selected production regions and supply chains of soy, beef, and palm oil (Trase, 2019). Another example is the "Agroideal" initiative that involves NGOs, research institutes, but also private companies. The "Agroideal" tool provides information on socio-environmental risks in production regions and should serve as a decision support system for private investors in soy and beef supply chains (TNC, 2019). Such tools might support supply chain actors in implementing preferential sourcing strategies depending on area-based risk assessments.

Finally, the development of new information technologies might play an important role in improving traceability. Distributed ledger technologies based on so-called "blockchains" might offer new opportunities for supply chain transparency and traceability (Francisco \& Swanson, 
2018). Transactions along the supply chain could be tracked using digital "tokens" and storing information in a database which is shared in a peer-to-peer network. In January 2018, the first blockchain-supported agricultural trade was reported: a shipment of soybeans from the United States to China. Significant improvements in documentation efficiency have been observed by involved actors (Hunt, 2018).

\section{Discussion}

Kusumaningtyas and van Gelder (2019, p. 5) stated that "[...] without a good level of assurance, responsible soy (covering either illegal or deforestation) can never be guaranteed". The present article goes even further and argues that sustainability standards and assurance are still insufficient if the aspect of traceability is neglected. Traceability systems are required to ensure that information on product and process characteristics does not get lost along complex international supply chains for "forest-risk" commodities such as soy. The main focus of traceability efforts with respect to soy supply chains has been mostly related to non-GMO soy so far. This situation might change with increasing relevance of ZDCs. However, many private sector ZDCs still lack concrete targets with respect to traceability (Jopke \& Schoneveld, 2018). Moreover, not all concepts that are commonly labeled as traceability systems can effectively ensure traceability. To account for these aspects and to contribute to research on supply chain governance and traceability, a conceptual framework for the qualitative assessment of deforestation-free certification systems has been proposed and applied to the case of soy. This framework might be applied and potentially further developed to assess certification systems for other relevant commodities such as palm oil or cocoa as well.

The results of the assessment presented in section 4.1 suggest that among the sample, ISCC EU and ISCC PLUS, ProTerra, Donau Soja and Europe Soya as well as RTRS have relatively high standards for the conservation of forests and other valuable ecosystems, sufficient assurance provisions, and provide chain-of-custody options that allow for traceability along the supply chain. In contrast to the assessment by Kusumaningtyas and van Gelder (2019), the systems of BFA, CRS and SFAP Non-Conversion have not been found to be sufficiently stringent, as they do not allow for segregation. The recently published "European Soy Monitor" report, which is based on the assessment by Kusumaningtyas and van Gelder (2019), estimates that only $13 \%$ of soy used in Europe in 2017 could be regarded as deforestation-free (IDH \& IUCN NL, 2019). Taking traceability requirements into account, this share would probably be even lower. Interestingly, the report argues that the bottleneck is not supply of deforestation-free soy, but demand.

ProTerra, Donau Soja and Europe Soya are among the most demanding certification systems. These three certification systems also prohibit the use of GMOs, although empirical 
evidence so far indicates environmental, economic, social and even potential health benefits of GM crops (Klümper \& Qaim, 2014; Qaim, 2009; Zilberman, Holland, \& Trilnick, 2018). It remains to be assessed to what extent prohibiting GMOs is consistent with the Sustainable Development Goals (SDGs), particularly as GM crops might contribute to food security in developing countries (Adenle \& Ammann, 2015). But in general, more research is needed to understand the long-term risks and benefits of genetic modification and to adequately address consumers' concerns. In Europe, soy certified according to the systems of Donau Soja and Europe Soya might become more important, considering potential outcomes of the new European strategy for the promotion of protein crops (European Parliament, 2018). The main aim of this strategy is to reduce the existing "protein gap" of the EU and the resulting dependency on soy imports. To what extent this strategy might influence trade relations and potentially lead to adverse effects with respect to deforestation in other regions is a question that requires further research.

For several years the ProTerra standard dominated the market for certified soy but it is expected to be outperformed by RTRS, which realizes higher growth rates (Lernoud et al., 2018; Potts et al., 2014). One possible reason might be that RTRS offers more flexibility in terms of CoC options and associated product claims, in addition to the fact that RTRS allows for genetic modification (Garrett et al., 2013). Considering trade-offs between transaction costs and implementation costs, it might therefore be assumed that lower implementation costs in this case outweigh the benefits obtained from improved traceability. More empirical studies are needed to assess actual costs and benefits of different traceability systems.

This study has relevant limitations that need to be considered. The scope of the assessment has been limited to the sample of soy certification systems that have been successfully benchmarked against the baseline criteria provided in the FEFAC Soy Sourcing Guidelines. It can be argued that additional certification systems that have participated in the ITC/FEFAC benchmarking do not need to be included in more detailed assessments because they failed to meet the Soy Sourcing Guideline's minimum requirements. As of August 2019, the FEFAC Sourcing Guidelines Tool provided information on 39 certification systems in total. Still, there might be compliant systems that have not been assessed because standard owners have to voluntarily register the certification systems for benchmarking. It also has to be considered that most standards are updated on a more or less regular basis. The results of this study are based on the status of standard development indicated by the document versions presented in Table 2. Regular updates of the assessment would be required to account for further development with respect to standards and traceability systems. The proposed conceptual framework should be useful for this case, also to ensure comparability of assessments.

A limitation of the conceptual framework and the conducted assessment is that criteria 
which are not directly relevant for achieving "zero deforestation" targets are currently not considered. Particularly the lack of consideration of social sustainability standards might be problematic, considering potential adverse social effects mentioned in section 4.2.1. Hargita et al. (2018) considered environmental and social sustainability criteria, but this assessment was based on information retrieved from the ITC Sustainability Map (ITC, 2019b). This information is reported to the ITC by the certification system owners themselves. Future research might benefit from extending the proposed conceptual framework to include further sustainability criteria and to consider trade-offs and potential reciprocal effects.

Despite progress in terms of including "zero deforestation" criteria into sustainability standards, traceability still needs to be improved by shifting market share of CoC systems in favor of segregation and identity preservation - or by implementing other measures besides certification. Another governance option is vertical integration of different stages of the supply chain, thereby improving internal traceability and reducing transaction risks. Direct sourcing is possible if all intermediaries are integrated. Cargill is one example for the implementation of vertical integration (Heron et al., 2018). Bunge reported 92\% direct sourcing from soy farms and 100\% traceability to the elevator in high-deforestation risk areas in Brazil for 2018 (Bunge, 2018). These governance options to increase traceability were not in focus of this study but deserve further investigation. Currently, barriers related to the availability of data and resources still have to be overcome in order to implement transparency initiatives such as "Trase" on a larger scale (Godar et al., 2016). In the future, new technologies such as blockchain-based traceability systems might help to reduce implementation costs of traceability systems. For further research, it would be recommendable to conduct interviews or surveys with different supply chain actors and standard-setting organizations to verify the proposed conceptual framework and to analyze to what extent traceability systems are used that are not linked to third-party certification.

Sustainability certification remains limited - not only in the case of soy, but also regarding other agricultural forest-risk commodities (Lernoud et al., 2018). Palm oil might be regarded as a positive example with $19 \%$ of global production certified according to RSPO standards (RSPO, 2018), but it remains to be assessed to what extent these standards might effectively ensure "zero deforestation". In this regard, it would also be recommendable to conduct field visits to soybean growing areas certified according to different standards. Overall, it can be concluded that further upscaling is required to achieve ZDCs. It has therefore been argued that voluntary marketbased instruments need to be complemented by policies and regulations in producer countries (Busch \& Ferretti-Gallon, 2017; Jopke \& Schoneveld, 2018; Lambin et al., 2018). The recent development of jurisdictional approaches and area-based certification systems provides opportunities for upscaling and might reduce potential adverse effects of conventional 
sustainability certification, if monitoring and enforcement in producer countries are ensured and risks are appropriately addressed. Lessons learned from successful national-level approaches in the forest sector, so-called Voluntary Partnership Agreements (VPAs) based on the EU Forest Law Enforcement, Governance and Trade (FLEGT) Action Plan, might be utilized to transfer these concepts to agricultural sectors (EU FLEGT Facility, 2017). However, it needs to be considered that VPAs ensure only zero illegal deforestation according to producer country regulations. For achieving ZDCs, it will be required to go beyond legality.

\section{Conclusions}

One possible measure to achieve ZDCs is the certification of agricultural commodities according to voluntary sustainability standards. But certification systems largely differ in terms of definitions and requirements. Thus, it is difficult for supply chain actors and policymakers to evaluate which systems are suitable to achieve their targets. This paper argues that the hitherto focus on sustainability standards and assurance procedures is insufficient, as it covers only the level of production but not the whole supply chain, which requires traceability.

Focusing on the case of soy, different certification systems relevant for the European market have been assessed on the basis of their suitability to ensure deforestation-free supply chains. For this purpose a conceptual framework has been proposed, taking into account relevant sustainability standards, assurance provisions, and traceability options. With respect to traceability, it has been explained that among the relevant chain-of-custody systems only identity preservation and segregation can ensure traceability and thereby support compliance with ZDCs. The results of the assessment suggest that ISCC EU and ISCC PLUS, ProTerra, Donau Soja and Europe Soya as well as RTRS may contribute to the implementation of deforestation-free soy supply chains, provided that the recommended chain-of-custody systems are applied.

In practice, however, certified and segregated soy rather serves niche markets, taking into account overall certification rates. Also the success of other initiatives to achieve deforestationfree supply chains seems limited so far. Several challenges still need to be overcome. Adverse effects such as ILUC, leakage and displacement, as well as the marginalization of smallholders need to be avoided. Benefits received from the implementation of stringent traceability systems need to outweigh implementation costs, which mostly seems not to be the case yet. The development of new approaches to certification and traceability might provide opportunities for upscaling and cost reduction. Although voluntary certification is an important tool to initiate change and define best practices, stricter regulations and enforcement mechanisms in producer countries are needed as well. These findings imply the need for further research, not only with 
respect to assessments of certification systems, but also regarding additional or alternative measures in support of deforestation-free supply chains.

\section{Acknowledgements}

The authors gratefully thank colleagues of the Thuenen Institute of International Forestry and Forest Economics for previous collaboration and knowledge exchange on the subject of assessing certification systems, and the anonymous reviewers for their constructive feedback and suggestions that significantly helped to improve the manuscript. An earlier version of this article was presented as a poster at the 58th annual conference of the German Society of Economic and Social Sciences in Agriculture (GEWISOLA) in Kiel, Germany, September 12-14, 2018.

\section{Declarations of interest}

The authors have no conflicts of interest to declare.

\section{Funding}

This research did not receive any specific grant from funding agencies.

\section{References}

Aapresid (2017). Protocolo del sistema de gestión de la calidad y prácticas productivas sustenables: Revisión 3. Rosario, Argentina: Aapresid. Retrieved from https://www.aapresid.org.ar/wp-content/uploads/2018/09/Protocolo-ASC-Revisi\%C3\%B3n-3Formato2018-Marzo-2017.pdf on September 29, 2018.

ADM (2018). ADM Responsible Soybean Standard: Version 2. Chicago, Illinois, USA: Archer Daniels Midland (ADM). Retrieved from https://assets.adm.com/Sustainability/ADM-Sustainable-SoyStandard_180911_120112.pdf on September 21, 2018.

AIC (2015). FEMAS module for responsible sourcing of agricultural \& natural products. Peterborough, UK: Agricultural Industries Confederation (AIC). Retrieved from https://www.aictradeassurance.org.uk/latest-documents/femas-module-for-responsiblesourcing/ on November 30, 2018.

AIC (2019). FEMAS standard 2019. Peterborough, UK: Agricultural Industries Confederation (AIC). Retrieved from https://www.aictradeassurance.org.uk/latest-documents/femas-standard2019/ on August 26, 2019.

Adenle, A. A., \& Ammann, K. (2015). Role of modern biotechnology in sustainable development; addressing social-political dispute of GMOs that influences decision-making in developing countries. Brief for Global Sustainable Development Report (GSDR). New York City, USA: United Nations Department of Economic and Social Affairs (UNDESA). Retrieved from https://sustainabledevelopment.un.org/topics/science/crowdsourcedbriefs on September 16, 2019. 
Amaggi (2016). Amaggi Responsible Soy Standard. Certification guide. São Miguel do Iguaçu, Brasil: Amaggi. Retrieved from https://www.amaggi.com.br/wpcontent/uploads/2019/01/Guia_ARS_en.pdf on September 3, 2019.

AMI. (2017). AMI Markt Bilanz: Getreide, Ölsaaten, Futtermittel 2017. Bonn, Germany: Agrarmarkt Informations-Gesellschaft mbH (AMI).

Angelsen, A., \& Rudel, T. K. (2013). Designing and implementing effective REDD+ policies: A forest transition approach. Review of Environmental Economics and Policy, 7(1), 91-113. https://doi.org/10.1093/reep/res022.

Arima, E. Y., Richards, P., Walker, R., \& Caldas, M. M. (2011). Statistical confirmation of indirect land use change in the Brazilian Amazon. Environmental Research Letters, 6(2), Article 24010. https://doi.org/10.1088/1748-9326/6/2/024010.

Banterle, A., \& Stranieri, S. (2008). The consequences of voluntary traceability system for supply chain relationships. An application of transaction cost economics. Food Policy, 33(6), 560-569. https://doi.org/10.1016/j.foodpol.2008.06.002.

Bendell, J., Miller, A., \& Wortmann, K. (2011). Public policies for scaling corporate responsibility standards. Sustainability Accounting, Management and Policy Journal, 2(2), 263-293. https://doi.org/10.1108/20408021111185411.

Bosona, T., \& Gebresenbet, G. (2013). Food traceability as an integral part of logistics management in food and agricultural supply chain. Food Control, 33(1), 32-48. https://doi.org/10.1016/j.foodcont.2013.02.004.

Bowen, G. A. (2009). Document analysis as a qualitative research method. Qualitative Research Journal, 9(2), 27-40. https://doi.org/10.3316/QRJ0902027.

Brack, D., \& Bailey, R. (2013). Ending global deforestation: Policy options for consumer countries. London: Chatham House. Retrieved from https://www.chathamhouse.org/publications/papers/view/194247 on October 31, 2018.

Brown, S., \& Zarin, D. (2013). Environmental science. What does zero deforestation mean? Science, 342(6160), 805-807. https://doi.org/10.1126/science.1241277.

Bunge (2018). Non-deforestation policy - Grains \& oilseeds progress report. White Plains, New York, USA. Retrieved from https://www.bunge.com/sites/default/files/nondeforestation_progressreport_mar2018.pdf on August 22, 2019.

Busch, J., \& Ferretti-Gallon, K. (2017). What drives deforestation and what stops it? A metaanalysis. Review of Environmental Economics and Policy, 11(1), 3-23. https://doi.org/10.1093/reep/rew013.

CDP (2018). Analysing European public and private actions to tackle imported deforestation: A guide for European policymakers and companies. Policy Briefing March 2018. London: Carbon Disclosure Project (CDP). Retrieved from https://www.cdp.net/en/reports/downloads/3270 on August 26, 2019.

Cefetra (2018). Certified Responsible Soy (CRS): Normative Document. Rotterdam, The Netherlands: Cefetra. Retrieved from http://www.certifiedsoya.com/wpcontent/uploads/2018/10/20180712-CRS_Normative-document.pdf on September 4, 2019.

Choi, S. H., Yang, B., Cheung, H. H., \& Yang, Y. X. (2015). RFID tag data processing in manufacturing for track-and-trace anti-counterfeiting. Computers in Industry, 68, 148-161. https://doi.org/10.1016/j.compind.2015.01.004. 
Climate Focus (2015). Progress on the New York Declaration on Forests - An Assessment Framework and Initial Report. Amsterdam, The Netherlands: Climate Focus. Retrieved from http://forestdeclaration.org/wp-content/uploads/2015/10/NYDF-Progress-Report.pdf on August 26, 2018.

Cornelius, R. (2018). Traceability: The Respect-Code solution. In A.-M. Schneider \& S. Jastram (Eds.), Management for professionals. Sustainable fashion: Governance and new management approaches (pp. 129-137). Cham, Switzerland: Springer. https://doi.org/10.1007/978-3-31974367-7_12.

Costa-Font, M., Gil, J. M., \& Traill, W. B. (2008). Consumer acceptance, valuation of and attitudes towards genetically modified food: Review and implications for food policy. Food Policy, 33(2), 99-111. https://doi.org/10.1016/j.foodpol.2007.07.002.

da Silva Júnior, A. G., Zanasi, C., de Souza Júnior, \& Gutierrez Ajonas, J. V. (2016). Matching Brazilian soybean production to the EU sustainability standards' requirements. Compliance of the Sojaplus management program with the FEFAC guidelines. Proceedings in System Dynamics and Innovation in Food Networks 2016, 349-356. https://doi.org/10.18461/pfsd.2016.1637.

Darby, M. R., \& Karni, E. (1973). Free competition and the optimal amount of fraud. The Journal of Law and Economics, 16(1), 67-88. https://doi.org/10.1086/466756.

de Oliveira, A. L.R., \& Alvim, A. M. (2017). The supply chain of Brazilian maize and soybeans: The effects of segregation on logistics and competitiveness. International Food and Agribusiness Management Review, 20(1), 45-61. https://doi.org/10.22434/IFAMR2016.0084.

DeFries, R. S., Fanzo, J., Mondal, P., Remans, R., \& Wood, S. A. (2017). Is voluntary certification of tropical agricultural commodities achieving sustainability goals for small-scale producers? A review of the evidence. Environmental Research Letters, 12(3), Article 33001. https://doi.org/10.1088/1748-9326/aa625e.

Delacote, P., Robinson, E. J.Z., \& Roussel, S. (2016). Deforestation, leakage and avoided deforestation policies: A spatial analysis. Resource and Energy Economics, 45, 192-210. https://doi.org/10.1016/j.reseneeco.2016.06.006.

D'Hollander, D., \& Marx, A. (2014). Strengthening private certification systems through public regulation. Sustainability Accounting, Management and Policy Journal, 5(1), 2-21. https://doi.org/10.1108/SAMPJ-04-2013-0016.

Donau Soja Association (2019). Donau Soja guidelines. Vienna: Donau Soja Association. Retrieved from https://www.donausoja.org/fileadmin/user_upload/Downloads/Donau_Soja_Guidelines/Engli sh/Donau_Soja_Guidelines.pdf on September 2, 2019.

Donau Soja Association (2019). Europe Soya guidelines. Vienna: Donau Soja Association. Retrieved from

https://www.donausoja.org/fileadmin/user_upload/Downloads/Europe_Soya_Guidelines/Engl ish/Europe_Soya_Guidelines.pdf on September 2, 2019.

Donofrio, S., Rothrock, P., \& Leonard, J. (2017). Supply Change: Tracking corporate commitments to deforestation-free supply chains. Washington, DC: Forest Trends. Retrieved from https://www.forest-trends.org/wp-content/uploads/2017/03/2017SupplyChange_FINAL.pdf on October 31, 2018.

EU FLEGT Facility (2017). Achieving zero-deforestation commitments: Lessons from FLEGT Voluntary Partnership Agreements (Briefing). Barcelona, Spain: EU FLEGT Facility. Retrieved 
from http://www.euflegt.efi.int/publications/achieving-zero-deforestation-commitments on September 17, 2019.

European Commission (2013). The impact of EU consumption on deforestation. Technical Report 2013-063. Brussels: European Commission. Retrieved from http://ec.europa.eu/environment/forests/pdf/1.\%20Report\%20analysis\%20of\%20impact.pdf on October 12, 2017.

European Parliament (2018). Report on a European strategy for the promotion of protein crops Encouraging the production of protein and leguminous plants in the European agriculture sector (2017/2116(INI)). Retrieved from http://www.europarl.europa.eu/doceo/document/A8-2018-0121_EN.html on September 15, 2019.

FAO (2012). State of the World's Forests 2012. Rome: Food and Agriculture Organization of the United Nations (FAO). Retrieved from http://www.fao.org/3/i3010e/i3010e.pdf on September 3, 2019.

FAO (2015). Global Forest Resources Assessment 2015: How are the world's forests changing? Rome: Food and Agriculture Organization of the United Nations (FAO). Retrieved from http://www.fao.org/3/a-i4808e.pdf on September 3, 2019.

FAO (2018). The State of the World's Forests: Forests pathways to sustainable development. Rome: Food and Agriculture Organization of the United Nations (FAO). Retrieved from http://www.fao.org/3/ca0188en/ca0188en.pdf on September 3, 2019.

FAO (2019). FAOSTAT. Rome: Food and Agriculture Organization of the United Nations (FAO). http://www.fao.org/faostat/.

FEFAC (2016). FEFAC Soy Sourcing Guidelines. Towards a mainstream transition to responsible soy. Brussels: European Feed Manufacturers' Federation (FEFAC). Retrieved from http://www.fefac.eu/file.pdf?FileID=65744 on January 14, 2018.

Francisco, K., \& Swanson, D. (2018). The supply chain has no clothes: Technology adoption of blockchain for supply chain transparency. Logistics, $2(1), 2$. https://doi.org/10.3390/logistics2010002.

Fuchs, R., Alexander, P., Brown, C., Cossar, F., Henry, R. C., \& Rounsevell, M. (2019). Why the USChina trade war spells disaster for the Amazon. Nature, 567(7749), 451-454. https://doi.org/10.1038/d41586-019-00896-2.

Garcia-Torres, S., Albareda, L., Rey-Garcia, M., \& Seuring, S. (2019). Traceability for sustainability literature review and conceptual framework. Supply Chain Management: An International Journal, 24(1), 85-106. https://doi.org/10.1108/SCM-04-2018-0152.

Gardner, T. A., Benzie, M., Börner, J., Dawkins, E., Fick, S., Garrett, R., Godar, J., Grimard, A., Lake, S., Larsen, R. K., Mardas, N., McDermott, C. L., Meyfroidt, P., Osbeck, M., Persson, M., Sembres, T., Suavet, C., Strassburg, B., Trevisan, A., ... Wolvekamp, P. (2019). Transparency and sustainability in global commodity supply chains. World Development, 121, 163-177. https://doi.org/10.1016/j.worlddev.2018.05.025.

Garrett, R. D., Levy, S., Carlson, K. M., Gardner, T. A., Godar, J., Clapp, J., Dauvergne, P., Heilmayr, R., Le Polain de Waroux, Y., Ayre, B., Barr, R., Døvre, B., Gibbs, H. K., Hall, S., Lake, S., Milder, J. C., Rausch, L. L., Rivero, R., Rueda, X., ... Villoria, N. (2019). Criteria for effective zerodeforestation commitments. Global Environmental Change, 54, 135-147. https://doi.org/10.1016/j.gloenvcha.2018.11.003. 
Garrett, R. D., Carlson, K. M., Rueda, X., \& Noojipady, P. (2016). Assessing the potential additionality of certification by the Round table on Responsible Soybeans and the Roundtable on Sustainable Palm Oil. Environmental Research Letters, 11(4), Article 45003. https://doi.org/10.1088/1748-9326/11/4/045003.

Garrett, R. D., Rueda, X., \& Lambin, E. F. (2013). Globalization's unexpected impact on soybean production in South America: Linkages between preferences for non-genetically modified crops, eco-certifications, and land use. Environmental Research Letters, 8(4), Article 44055. https://doi.org/10.1088/1748-9326/8/4/044055.

Gassler, B., \& Spiller, A. (2018). Is it all in the MIX? Consumer preferences for segregated and mass balance certified sustainable palm oil. Journal of Cleaner Production, 195, 21-31. https://doi.org/10.1016/j.jclepro.2018.05.039.

Geist, H. J., \& Lambin, E. F. (2002). Proximate causes and underlying driving forces of tropical deforestation. BioScience, 52(2), 143-150. https://doi.org/10.1641/00063568(2002)052[0143:PCAUDF]2.0.CO;2.

Gereffi, G., Humphrey, J., \& Sturgeon, T. (2005). The governance of global value chains. Review of International Political Economy, 12(1), 78-104. https://doi.org/10.1080/09692290500049805.

Ghazoul, J., Garcia, C., \& Kushalappa, C. G. (2009). Landscape labelling: A concept for nextgeneration payment for ecosystem service schemes. Forest Ecology and Management, 258(9), 1889-1895. https://doi.org/10.1016/j.foreco.2009.01.038.

Ghozzi, H., Platoni, S., Tillie, P., \& Soregaroli, C. (2018). TCE determinants and governance forms in the EU "Non-GMO" soybean supply chain. Food Policy, 78, 68-80. https://doi.org/10.1016/j.foodpol.2018.02.011.

Ghozzi, H., Soregaroli, C., Boccaletti, S., \& Sauvée, L. (2016). Impacts of non-GMO standards on poultry supply chain governance: Transaction cost approach vs resource-based view. Supply Chain Management: An International Journal, 21(6), 743-758. https://doi.org/10.1108/SCM03-2016-0089.

Gibbs, H. K., Rausch, L., Munger, J., Schelly, I., Morton, D. C., Noojipady, P., Barreto, P., Micol, L., Walker, N. F., Amazon, B., \& Cerrado, E. (2015). Brazil's Soy Moratorium. Science, 347(6220), 377-378. https://doi.org/10.1126/science.aaa0181.

Gibbs, H. K., Munger, J., L'Roe, J., Barreto, P., Pereira, R., Christie, M., Amaral, T., \& Walker, N. F. (2016). Did ranchers and slaughterhouses respond to zero-deforestation agreements in the Brazilian Amazon? Conservation Letters, 9(1), 32-42. https://doi.org/10.1111/conl.12175.

Godar, J., Suavet, C., Gardner, T. A., Dawkins, E., \& Meyfroidt, P. (2016). Balancing detail and scale in assessing transparency to improve the governance of agricultural commodity supply chains. Environmental Research Letters, 11(3), Article 35015. https://doi.org/10.1088/17489326/11/3/035015.

Halalisan, A. F., Popa, B., Heras-Saizarbitoria, I., loras, F., \& Abrudan, I. V. (2019). Drivers, perceived benefits and impacts of FSC chain of custody certification in a challenging sectoral context: The case of Romania. International Forestry Review, 21(2), 195-211. https://doi.org/10.1505/146554819826606595.

Hargita, Y., Hinkes, C., Bick, U., \& Peter, G. (2018). Entwaldungsfreie Agrarrohstoffe - Analyse relevanter Soja-Zertifizierungssysteme für Futtermittel. Thünen Working Paper No. 98. Braunschweig, Germany: Johann Heinrich von Thünen-Institut. Retrieved from https://literatur.thuenen.de/digbib_extern/dn059838.pdf on September 3, 2019. 
Henders, S., Persson, U. M., \& Kastner, T. (2015). Trading forests: Land-use change and carbon emissions embodied in production and exports of forest-risk commodities. Environmental Research Letters, 10(12), Article 125012. https://doi.org/10.1088/1748-9326/10/12/125012.

Henson, S., \& Humphrey, J. (2010). Understanding the complexities of private standards in global agri-food chains as they impact developing countries. The Journal of Development Studies, 46(9), 1628-1646. https://doi.org/10.1080/00220381003706494.

Heron, T., Prado, P., \& West, C. (2018). Global value chains and the governance of 'embedded' food commodities: The case of soy. Global Policy, 9(3), 29-37. https://doi.org/10.1111/17585899.12611.

Hilbeck, A., Binimelis, R., Defarge, N., Steinbrecher, R., Székács, A., Wickson, F., Antoniou, M., Bereano, P. L., Clark, E. A., Hansen, M., Novotny, E., Heinemann, J., Meyer, H., Shiva, V., \& Wynne, B. (2015). No scientific consensus on GMO safety. Environmental Sciences Europe, 27(4), 1-6. https://doi.org/10.1186/s12302-014-0034-1.

Hunt, N. (2018). U.S. soy cargo to China traded using blockchain. Reuters. Retrieved from https://www.reuters.com/article/grains-blockchain/u-s-soy-cargo-to-china-traded-usingblockchain-idUSL8N1PGOVJ on February 7, 2018.

IDH \& IUCN NL (2019). European Soy Monitor: Insights on the European supply chain and the use of responsible and deforestation-free soy in 2017. Utrecht/Amsterdam, The Netherlands: IDH \& IUCN NL. Retrieved from https://www.idhsustainabletrade.com/uploaded/2019/04/EuropeanSoy-Monitor.pdf on September 3, 2019.

ISCC (2018). Traceability and chain of custody: Version 3.1. Cologne, Germany: ISCC GmbH. Retrieved from https://www.iscc-system.org/wp-content/uploads/2017/02/SystemDocument-203-Traceability-and-Chain-of-Custody.pdf on September 2, 2019.

ISEAL Alliance (2016). Chain of custody models and definitions: A reference document for sustainability standard systems, and to complement ISEAL's Sustainability Claims Good Practice Guide. London: ISEAL Alliance. Retrieved from https://www.isealalliance.org/sites/default/files/resource/201711/ISEAL_Chain_of_Custody_Models_Guidance_September_2016.pdf on June 22, 2018.

ITC (2019a). FEFAC Sourcing Guidelines Tool. Geneva, Switzerland: International Trade Centre (ITC). Retrieved from http://www.standardsmap.org/fefac/ on September 9, 2019.

ITC (2019b). ITC Sustainability Map. Geneva, Switzerland: International Trade Centre (ITC). Retrieved from https://sustainabilitymap.org/standards on September 15, 2019.

Jopke, P., \& Schoneveld, G. C. (2018). Corporate commitments to zero deforestation: An evaluation of externality problems and implementation gaps. Occasional paper No. 181. Bogor, Indonesia: Center for International Forestry Research (CIFOR). Retrieved from http://www.cifor.org/publications/pdf_files/OccPapers/OP-181.pdf on September 11, 2019.

Kalaitzandonakes, N., Lusk, J., \& Magnier, A. (2018). The price of non-genetically modified (nonGM) food. Food Policy, 78, 38-50. https://doi.org/10.1016/j.foodpol.2018.02.005.

Karlsen, K. M., Dreyer, B., Olsen, P., \& Elvevoll, E. O. (2013). Literature review: Does a common theoretical framework to implement food traceability exist? Food Control, 32(2), 409-417. https://doi.org/10.1016/j.foodcont.2012.12.011. 
Kastens, J. H., Brown, J. C., Coutinho, A. C., Bishop, C. R., \& Esquerdo, J. C. D.M. (2017). Soy moratorium impacts on soybean and deforestation dynamics in Mato Grosso, Brazil. PLOS ONE, 12(4), e0176168. https://doi.org/10.1371/journal.pone.0176168.

Kim, M.-K., Ukkestaad, C. M., Tejeda, H. A., \& Bailey, D. (2017). Benefits of an animal traceability system for a food-and-mouth disease outbreak: A supply-driven social accounting matrix approach. Journal of Agricultural and Applied Economics, 49(3), 438-466. https://doi.org/10.1017/aae.2017.7.

Klümper, W., \& Qaim, M. (2014). A meta-analysis of the impacts of genetically modified crops. PLOS ONE, 9(11), e111629. https://doi.org/10.1371/journal.pone.0111629.

Komives, K., \& Jackson, A. (2014). Introduction to voluntary sustainability standard systems. In C. Schmitz-Hoffmann, M. Schmidt, B. Hansmann, \& D. Palekhov (Eds.), Voluntary standard systems: A contribution to sustainable development (pp. 3-19). Berlin: Springer-Verlag.

Kuckartz, U. (2016). Qualitative Inhaltsanalyse: Methoden, Praxis, Computerunterstützung (3rd ed.). Grundlagentexte Methoden. Weinheim, Germany: Beltz Juventa.

Kusumaningtyas, R., \& van Gelder, J. W. (2019). Setting the bar for deforestation-free soy in Europe: A benchmark to assess the suitability of voluntary standard systems. Amsterdam, The Netherlands: Profundo. Retrieved from https://profundo.nl/download/iucn1906 on September 3, 2019.

Lallemand, P., Bergh, M., Hansen, M., \& Purves, M. (2016). Estimating the economic benefits of MSC certification for the South African hake trawl fishery. Fisheries Research, 182, 98-115. https://doi.org/10.1016/j.fishres.2016.02.003.

Lambin, E. F., Gibbs, H. K., Heilmayr, R., Carlson, K. M., Fleck, L. C., Garrett, R. D., le Polain de Waroux, Y., McDermott, C. L., McLaughlin, D., Newton, P., Nolte, C., Pacheco, P., Rausch, L. L., Streck, C., Thorlakson, T., \& Walker, N. F. (2018). The role of supply-chain initiatives in reducing deforestation. Nature Climate Change, 8(2), 109-116. https://doi.org/10.1038/s41558-0170061-1.

le Polain de Waroux, Y., Garrett, R. D., Graesser, J., Nolte, C., White, C., \& Lambin, E. F. (2019). The restructuring of South American soy and beef production and trade under changing environmental regulations. World Development, 121, 188-202. https://doi.org/10.1016/j.worlddev.2017.05.034.

Lernoud, J., Potts, J., Sampson, G., Schlatter, B., Huppe, G., Voora, V., Willer, H., Wozniak, J., \& Dang, D. (2018). The state of sustainable markets 2018: Statistics and emerging trends.

Geneva, Switzerland: International Trade Centre (ITC). Retrieved from http://www.intracen.org/publication/The-State-of-Sustainable-Markets-2018-Statistics-andEmerging-Trends/ on May 27, 2019.

Lippert, C. (2009). Fraud and free riding in tropical forests - On the potential for certification to enforce sustainable resource use indirectly. Agrarwirtschaft, 58(3), 144-154.

Macedo, M. N., DeFries, R. S., Morton, D. C., Stickler, C. M., Galford, G. L., \& Shimabukuro, Y. E. (2012). Decoupling of deforestation and soy production in the southern Amazon during the late 2000s. Proceedings of the National Academy of Sciences, 109(4), 1341-1346. https://doi.org/10.1073/pnas.1111374109.

Mariojouls, C., Le Gouvello, R., \& Simard, F. (2019). Feed and feeding in certification schemes of sustainable aquaculture. In T. Komatsu, H.-J. Ceccaldi, J. Yoshida, P. Prouzet, \& Y. Henocque 
(Eds.), Oceanography Challenges to Future Earth (Vol. 341, pp. 387-397). Cham, Switzerland: Springer International Publishing. https://doi.org/10.1007/978-3-030-00138-4_30.

McEntire, J. (2019). Chapter 1: Introducing the drivers and complexities to tracing foods. In J. McEntire \& A. W. Kennedy (Eds.), Food traceability: From binders to blockchain (pp. 1-12). Cham, Switzerland: Springer International Publishing.

Meyer, C., \& Miller, D. (2015). Zero deforestation zones: The case for linking deforestation-free supply chain initiatives and jurisdictional REDD+. Journal of Sustainable Forestry, 34(6-7), 559580. https://doi.org/10.1080/10549811.2015.1036886.

Mielke, T. (2018). World markets for vegetable oils and animal fats: Dynamics of global production, trade flows, consumption and prices. In M. Kaltschmitt \& U. Neuling (Eds.), Biokerosene: Status and prospects (pp. 147-188). Berlin: Springer.

Moe, T. (1998). Perspectives on traceability in food manufacture. Trends in Food Science \& Technology, 9(5), 211-214. https://doi.org/10.1016/S0924-2244(98)00037-5.

Mol, A., \& Oosterveer, P. (2015). Certification of markets, markets of certificates: Tracing sustainability in global agro-food value chains. Sustainability, 7(9), 12258-12278. https://doi.org/10.3390/su70912258.

Neeff, T., \& Linhares-Juvenal, T. (2017). Zero deforestation initiatives and their impacts on commodity supply chains: Discussion paper prepared for the 57th Session of the FAO Advisory Committee on Sustainable Forest-based Industries. Rome: Food and Agriculture Organization of the United Nations (FAO). Retrieved from http://www.fao.org/3/a-i6857e.pdf on November 1, 2018.

Nepstad, D. C., McGrath, D., Stickler, C., Alencar, A., Azevedo, A., Swette, B., Bezerra, T., DiGiano, M., Shimada, J., Seroa da Motta, R., Armijo, E., Castello, L., Brando, P., Hansen, M. C., McGrathHorn, M., Carvalho, O., \& Hess, L. (2014). Slowing Amazon deforestation through public policy and interventions in beef and soy supply chains. Science, 344(6188), 1118-1123. https://doi.org/10.1126/science.1248525.

Nepstad, D. C., Stickler, C. M., \& Almeida, O. T. (2006). Globalization of the Amazon soy and beef industries: Opportunities for conservation. Conservation Biology, 20(6), 1595-1603. https://doi.org/10.1111/j.1523-1739.2006.00510.x.

Nielsen, C. P., Thierfelder, K., \& Robinson, S. (2003). Consumer preferences and trade in genetically modified foods. Journal of Policy Modeling, 25(8), 777-794. https://doi.org/10.1016/j.jpolmod.2003.07.001.

Oil World. (2018). Oil World Annual 2018. Hamburg, Germany: ISTA Mielke GmbH.

Olsen, P., \& Borit, M. (2013). How to define traceability. Trends in Food Science \& Technology, 29(2), 142-150. https://doi.org/10.1016/j.tifs.2012.10.003.

Olsen, P., \& Borit, M. (2018). The components of a food traceability system. Trends in Food Science \& Technology, 77, 143-149. https://doi.org/10.1016/j.tifs.2018.05.004.

Peter, G., \& Krug, O. (2016). Die Verfügbarkeit von nicht-gentechnisch verändertem Soja aus Brasilien: Stellungnahme für BMEL. Braunschweig, Germany: Johann Heinrich von ThünenInstitut. Retrieved from https://www.bmel.de/SharedDocs/Downloads/Landwirtschaft/Pflanze/GrueneGentechnik/TIn ichtgentSojaBrasilien.html on September 7, 2018. 
Pfaff, A., Amacher, G. S., \& Sills, E. O. (2013). Realistic REDD: Improving the forest impacts of domestic policies in different settings. Review of Environmental Economics and Policy, 7(1), 114-135. https://doi.org/10.1093/reep/res023.

Potts, J., Lynch, M., Wilkings, A., Huppé, G., Cunningham, M., \& Voora, V. (2014). The state of sustainability initiatives review 2014: Standards and the green economy. International Institute for Sustainable Development (IISD). Retrieved from https://www.iisd.org/pdf/2014/ssi_2014.pdf on November 1, 2018.

ProAgros (2017). The Sustainable Farming Assurance Programme (SFAP): Version 3, October 2017. Amersfoort, The Netherlands: ProAgros. Retrieved from https://www.sustainableassurance.com/\#sfap on October 3, 2018.

ProAgros (2018). The Sustainable Farming Assurance Programme Non-Conversion (SFAP NonConversion): Version 3, November 2018. Amersfoort, The Netherlands: ProAgros. Retrieved from https://www.sustainableassurance.com/\#sfap-non-conversion on June 10, 2019.

ProTerra (2018). ProTerra Standard: Social responsibility and environmental sustainability. Bilthoven, The Netherlands: ProTerra Foundation. Retrieved from http://www.proterrafoundation.org/wp-content/uploads/2019/02/ProTerra-Standard-V04final-26-02.pdf on September 3, 2019.

Qaim, M. (2009). The economics of genetically modified crops. Annual Review of Resource Economics, 1(1), 665-694. https://doi.org/10.1146/annurev.resource.050708.144203.

Rausch, L., \& Gibbs, H. (2016). Property arrangements and soy governance in the Brazilian state of Mato Grosso: Implications for deforestation-free production. Land, 5(2), 7. https://doi.org/10.3390/land5020007.

Richards, P. D., Walker, R. T., \& Arima, E. Y. (2014). Spatially complex land change: The indirect effect of Brazil's agricultural sector on land use in Amazonia. Global Environmental Change, 29, 1-9. https://doi.org/10.1016/j.gloenvcha.2014.06.011.

Ringsberg, H. A. (2015). Implementation of global traceability standards: Incentives and opportunities. British Food Journal, 117(7), 1826-1842. https://doi.org/10.1108/BFJ-10-20140353.

RSPO (2018). RSPO Impact Report 2018. Kuala Lumpur: Roundtable on Sustainable Palm Oil (RSPO). Retrieved from https://rspo.org/resources/rspo-reports/impact-reports on March 22, 2019.

RTRS (2017). RTRS Management Report 2016. Zurich, Switzerland: Round Table on Responsible Soy (RTRS). Retrieved from http://www.responsiblesoy.org/wpcontent/uploads/2017/07/InformeGestion-ING.pdf on January 26, 2018.

RTRS (2018). RTRS Chain of Custody Standard: Version 2.2. Zurich, Switzerland: Round Table on Responsible Soy (RTRS). Retrieved from http://www.responsiblesoy.org/wpdm-package/rtrschain-of-custody-standard-pdf/?lang=en on October 3, 2018.

Rueda, X., Garrett, R. D., \& Lambin, E. F. (2017). Corporate investments in supply chain sustainability: Selecting instruments in the agri-food industry. Journal of Cleaner Production, 142, 2480-2492. https://doi.org/10.1016/j.jclepro.2016.11.026.

Sax, J. K., \& Doran, N. (2016). Food labeling and consumer associations with health, safety, and environment. The Journal of Law, Medicine \& Ethics, 44(4), 630-638. https://doi.org/10.1177/1073110516684805. 
SFS (2017). Sustainable Feed Standard - Book \& Claim. Rotterdam, The Netherlands: CKade SFS BV. Retrieved from https://www.sustainablefeedstandard.com/traceability on October 3, 2018.

Sterling, B., Gooch, M., Dent, B., Marenick, N., Miller, A., \& Sylvia, G. (2015). Assessing the value and role of seafood traceability from an entire value-chain perspective. Comprehensive Reviews in Food Science and Food Safety, 14(3), 205-268. https://doi.org/10.1111/15414337.12130.

Storøy, J., Thakur, M., \& Olsen, P. (2013). The TraceFood framework - Principles and guidelines for implementing traceability in food value chains. Journal of Food Engineering, 115(1), 41-48. https://doi.org/10.1016/j.jfoodeng.2012.09.018.

Stranieri, S., Orsi, L., \& Banterle, A. (2017). Traceability and risks: An extended transaction cost perspective. Supply Chain Management: An International Journal, 22(2), 145-159. https://doi.org/10.1108/SCM-07-2016-0268.

Thakur, M., \& Donnelly, K. A.-M. (2010). Modeling traceability information in soybean value chains. Journal of Food Engineering, 99(1), 98-105. https://doi.org/10.1016/j.jfoodeng.2010.02.004.

Tillie, P., \& Rodríguez-Cerezo, E. (2015). Markets for non-genetically modified, identity-preserved soybean in the EU. Luxemburg: European Commission. Retrieved from http://publications.jrc.ec.europa.eu/repository/bitstream/JRC95457/report.pdf on October $31,2018$.

TNC (2019). Agroideal: Territorial intelligence. Arlington County, Virginia, USA: The Nature Conservancy (TNC). Retrieved from https://agroideal.org/en/ on September 9, 2019.

Torraco, R. J. (2005). Writing integrative literature reviews: Guidelines and examples. Human Resource Development Review, 4(3), 356-367. https://doi.org/10.1177/1534484305278283

Trase (2019). Transparent supply chains for sustainable economies. Trase. Retrieved from https://trase.earth/ on September 9, 2019.

Tscharntke, T., Milder, J. C., Schroth, G., Clough, Y., DeClerck, F., Waldron, A., Rice, R., \& Ghazoul, J. (2015). Conserving biodiversity through certification of tropical agroforestry crops at local and landscape scales. Conservation Letters, 8(1), 14-23. https://doi.org/10.1111/conl.12110.

USSEC (2018). U.S. Soy Sustainability Assurance Protocol (U.S. SSAP). Chesterfield, USA: U.S. Soybean Export Council (USSEC). Retrieved from https://ussec.org/resources/ssap-2/ on October 3, 2018.

van der Ven, H., Rothacker, C., \& Cashore, B. (2018). Do eco-labels prevent deforestation? Lessons from non-state market driven governance in the soy, palm oil, and cocoa sectors. Global Environmental Change, 52, 141-151. https://doi.org/10.1016/j.gloenvcha.2018.07.002.

van Noordwijk, M., Dewi, S., Minang, P., \& Simons, T. (2017). Deforestation-free claims: scams or substance? In ETFRN (Ed.), ETFRN News: Vol. 58. Zero deforestation: A commitment to change. Wageningen, The Netherlands: European Tropical Forest Research Network (ETFRN).

van Rijswijk, W., Frewer, L. J., Menozzi, D., \& Faioli, G. (2008). Consumer perceptions of traceability: A cross-national comparison of the associated benefits. Food Quality and Preference, 19(5), 452-464. https://doi.org/10.1016/j.foodqual.2008.02.001. 
Wesseler, J. (2014). Biotechnologies and agrifood strategies: Opportunities, threats and economic implications. Bio-Based and Applied Economics, 3(3), 187-204. https://doi.org/10.13128/BAE15017.

Williamson, O. E. (1979). Transaction-cost economics: The governance of contractual relations. Journal of Law and Economics, 22(2), 233-261. https://doi.org/10.1086/466942.

Wingate, K. G., \& McFarlane, P. N. (2005). Chain of custody and eco-labelling of forest products: a review of the requirements of the major forest certification schemes. International Forestry Review, 7(4), 342-347. https://doi.org/10.1505/ifor.2005.7.4.342.

Wohlin, C. (2014). Guidelines for snowballing in systematic literature studies and a replication in software engineering. In M. Shepperd, T. Hall, \& I. Myrtveit (Eds.), ICPS, EASE 2014: The 18th International Conference on Evaluation and Assessment in Software Engineering : London, May 12th-14th, 2014 (pp. 1-10). New York City, USA: Association for Computing Machinery. https://doi.org/10.1145/2601248.2601268.

WWF (2018). Sixty-one meat and soybean purchasing companies in Brazil have committed to combating deforestation in the Cerrado. Brasília: World Wide Fund for Nature (WWF) Brazil. Retrieved from https://www.wwf.org.br/informacoes/english/?65083/Sixty-one-companiesin-Brazil-have-committed-to-combating-deforestation-in-the-Cerrado on September 15, 2018.

Zilberman, D., Holland, T., \& Trilnick, I. (2018). Agricultural GMOs-What we know and where scientists disagree. Sustainability, 10(5), Article 1514. https://doi.org/10.3390/su10051514.

Zilberman, D., Kaplan, S., \& Gordon, B. (2018). The political economy of labeling. Food Policy, 78, 6-13. https://doi.org/10.1016/j.foodpol.2018.02.008.

\section{Appendix}

Table A1. Overview of selected publications identified in the literature review

\begin{tabular}{|c|c|c|}
\hline Topics & Subthemes & Main literature \\
\hline \multirow[t]{3}{*}{ deforestation } & general & $\begin{array}{l}\text { Angelsen and Rudel (2013), Busch and Ferretti-Gallon } \\
\text { (2017), Delacote et al. (2016), Geist and Lambin } \\
\text { (2002), Henders et al. (2015), Pfaff et al. (2013) }\end{array}$ \\
\hline & $\begin{array}{l}\text { forest-risk commodities / } \\
\text { deforestation-free } \\
\text { supply chains }\end{array}$ & $\begin{array}{l}\text { Brack and Bailey (2013), Brown and Zarin (2013), CDP } \\
\text { (2018), Climate Focus (2015), Donofrio et al. (2017), } \\
\text { European Commission (2013), Garrett et al. (2019), } \\
\text { Gibbs et al. (2015), Godar et al. (2016), Henders et al. } \\
\text { (2015), Jopke and Schoneveld (2018), Lambin et al. } \\
\text { (2018), Meyer and Miller (2015), Neeff and Linhares- } \\
\text { Juvenal (2017), van der Ven et al. (2018) }\end{array}$ \\
\hline & soy and deforestation & $\begin{array}{l}\text { Arima et al. (2011), da Silva Júnior et al. (2016), Fuchs } \\
\text { et al. (2019), Gibbs et al. (2015, 2016), Godar et al. } \\
\text { (2016), Kastens et al. (2017), Lambin et al. (2018), le } \\
\text { Polain de Waroux et al. (2019), Macedo et al. (2012), } \\
\text { Nepstad et al. (2006, 2014), Rausch and Gibbs (2016), } \\
\text { Richards et al. (2014), WWF (2018) }\end{array}$ \\
\hline $\begin{array}{l}\text { global soy } \\
\text { supply chains }\end{array}$ & $\mathrm{n} / \mathrm{a}$ & $\begin{array}{l}\text { Gardner et al. (2019), Gereffi et al. (2005), Heron et } \\
\text { al. (2018), IDH \& IUCN NL (2019), Lernoud et al. } \\
\text { (2018), Mariojouls et al. (2019), Mol and Nepstad et } \\
\text { al. (2014), Olsen and Borit (2018), Oosterveer (2015), } \\
\text { Rueda et al. (2017), Thakur and Donnelly (2010) }\end{array}$ \\
\hline
\end{tabular}




\begin{tabular}{|c|c|c|}
\hline \multirow[t]{3}{*}{$\begin{array}{l}\text { traceability } \\
\text { concepts and } \\
\text { systems }\end{array}$} & traceability systems & $\begin{array}{l}\text { Garcia-Torres et al. (2019), Karlsen et al. (2013), } \\
\text { McEntire (2019), Moe (1998), Olsen and Borit (2013, } \\
\text { 2018) } \\
\text { Bosona and Gebresenbet (2013), Choi et al. (2015), } \\
\text { Cornelius (2018), Francisco and Swanson (2018), Mol } \\
\text { and Oosterveer (2015), Sterling et al. (2015), Storøy et } \\
\text { al. (2013), Thakur and Donnelly (2010) }\end{array}$ \\
\hline & $\begin{array}{l}\text { food traceability } \\
\text { (drivers) }\end{array}$ & $\begin{array}{l}\text { Gardner et al. (2019), Ghozzi et al. (2016, 2018), } \\
\text { Karlsen et al. (2013), Mol and Oosterveer (2015), } \\
\text { Peter and Krug (2016), Ringsberg (2015), Stranieri et } \\
\text { al. (2017), Thakur and Donnelly (2010), Tillie and } \\
\text { Rodríguez-Cerezo (2015), van Rijswijk et al. (2008) }\end{array}$ \\
\hline & economics of traceability & $\begin{array}{l}\text { Banterle and Stranieri (2008), Bosona and } \\
\text { Gebresenbet (2013), de Oliveira and Alvim (2017), } \\
\text { Garrett et al. (2013, 2019), Ghozzi et al. (2018), Godar } \\
\text { et al. (2016), Halalisan et al. (2019), Kalaitzandonakes } \\
\text { et al. (2018), Kim et al. (2017), Lallemand et al. (2016), } \\
\text { Mol and Oosterveer (2015), Nepstad et al. (2014), } \\
\text { Peter and Krug (2016), Sterling et al. (2015), Tillie and } \\
\text { Rodríguez-Cerezo (2015), Williamson (1979) }\end{array}$ \\
\hline \multirow[t]{2}{*}{$\begin{array}{l}\text { genetic } \\
\text { modification }\end{array}$} & $\begin{array}{l}\text { genetically modified } \\
\text { crops }\end{array}$ & $\begin{array}{l}\text { Adenle and Ammann (2015), Hilbeck et al. (2015), } \\
\text { Kalaitzandonakes et al. (2018), Klümper and Qaim } \\
\text { (2014), Peter and Krug (2016), Qaim (2009), Tillie and } \\
\text { Rodríguez-Cerezo (2015), Wesseler (2014), Zilberman } \\
\text { et al. (2018a) }\end{array}$ \\
\hline & $\begin{array}{l}\text { public concerns / } \\
\text { consumer attitudes }\end{array}$ & $\begin{array}{l}\text { Costa-Font et al. (2008), Lernoud et al. (2018), Nielsen } \\
\text { et al. (2013), Sax and Doran (2016) }\end{array}$ \\
\hline \multirow[t]{5}{*}{$\begin{array}{l}\text { voluntary } \\
\text { sustainability } \\
\text { certification }\end{array}$} & general & $\begin{array}{l}\text { Bendell et al. (2011), De Fries et al. (2017), Garrett et } \\
\text { al. (2016), Gassler and Spiller (2018), Komives and } \\
\text { Jackson (2014), Lernoud et al. (2018), Mol and } \\
\text { Oosterveer (2015), Neeff and Linhares-Juvenal (2017), } \\
\text { Potts et al. (2014), van der Ven et al. (2018) }\end{array}$ \\
\hline & credence qualities & $\begin{array}{l}\text { Darby and Karni (1973), Henson and Humphrey } \\
\text { (2010), Lippert (2009), Mol and Oosterveer (2015), } \\
\text { Qaim (2009), Stranieri et al. (2017), Zilberman et al. } \\
\text { (2018b) }\end{array}$ \\
\hline & $\begin{array}{l}\text { chain-of custody (CoC) } \\
\text { certification }\end{array}$ & $\begin{array}{l}\text { ISEAL Alliance (2016), Komives and Jackson (2014), } \\
\text { Mol and Oosterveer (2015), Wingate and McFarlane } \\
\text { (2005) }\end{array}$ \\
\hline & $\begin{array}{l}\text { benchmarking/assessme } \\
\text { nts of soy certification } \\
\text { systems }\end{array}$ & $\begin{array}{l}\text { FEFAC (2016), Hargita et al. (2018), IDH \& IUCN NL } \\
\text { (2019), ITC (2019a,b), Kusumaningtyas and van Gelder } \\
\text { (2019) } \\
\text { The list of certification systems and documents } \\
\text { considered in this study is provided in Table } 1 .\end{array}$ \\
\hline & $\begin{array}{l}\text { landscape approaches / } \\
\text { jurisdictional approaches }\end{array}$ & $\begin{array}{l}\text { Ghazoul et al. (2009), Godar et al. (2016), Meyer and } \\
\text { Miller (2015), Tscharntke et al. (2015), van Noordwijk } \\
\text { et al. (2017) }\end{array}$ \\
\hline
\end{tabular}




\section{Discussion}

In this section, the contribution of this dissertation to policy-relevant research on deforestationfree supply chains is discussed. Section 5.1 comprises a discussion of the main findings of the four articles in the context of the three overarching research questions posed in section 1.4. In section 5.2, limitations of the articles and their scope are discussed, which leads to suggestions for future research.

\subsection{Contribution to the research on deforestation-free supply chains}

This dissertation contributes to the research on deforestation-free supply chains by studying the instrument of voluntary sustainability certification from different perspectives. In section 1.4, three overarching research questions that are important for policy-relevant research on deforestation-free supply chains have been identified, and the research focus of this dissertation with respect to these research questions has been outlined. In this section, the main results of the four studies conducted as part of this dissertation will be summarized and discussed in a broader context in order to explain how these findings contribute to answering each of the research questions.

\section{To what extent is the development of deforestation-free supply chains supported by policy measures in the EU?}

The development of deforestation-free supply chains may be facilitated by an enabling policy environment that complements voluntary zero-deforestation initiatives (e.g., Bager et al., 2020; Garrett et al., 2019; Schmitz et al., 2015). In section 1.2, background information on the development of public zero-deforestation initiatives has been provided. However, most of these are voluntary initiatives or non-binding declarations of support, such as the New York Declaration on Forests (NYDF, 2014) or the Amsterdam Declarations (ADP, 2015a, 2015b). The research project on which this dissertation is based started in October 2017. At that time, concrete policy development in Europe had just begun, following the initiative by the ADP countries. The most recent development of EU policy measures dealing with forest-risk commodities was expressed in two policy documents: the European Parliament (EP) resolution of 4 April 2017 on palm oil and deforestation of rainforests (European Parliament, 2017), and the new EU Renewable Energy Directive (RED II) (European Union, 2018). This Directive can be regarded as an update to the first Renewable Energy Directive (RED) (European Union, 2009) from 2021 onwards, which adds additional sustainability criteria. This process of policy development in the EU explicitly focused on palm oil. 
Diverging public discourses on the risks and benefits of palm oil production, consumption, and certification had already existed and discussed before (e.g., Cheyns, 2014; Dauvergne, 2018; Henders et al., 2015; Rival \& Levang, 2014). Nevertheless, it was not clear to what extent the recent EU policy development had been influenced by discourses, and - vice versa - to what extent this development might contribute to the development of discourses, which might also (negatively) affect trade relations and thereby hinder the achievement of zero-deforestation targets in the EU. To close this research gap, a policy discourse analysis focusing on the two previously mentioned policy documents was conducted and published in article (1). It was found that the EU policy development led to an intensification of discursive struggles between the EU and the main palm oil producing countries, Indonesia and Malaysia, which was expressed in various media, public statements, and speeches. Within the following discussion, the focus lies on the results of the study that are particularly relevant for answering RQ I and less on the identified discourses.

The EP resolution - which is also not a binding regulation itself but rather an appeal to the European Commission to take action - acknowledges the advantages of palm oil in terms of versatility and efficiency, but also emphasizes the adverse environmental effects of unsustainable palm oil consumption, particularly by framing palm oil as a forest-risk commodity. Thus, instead of promoting alternatives to palm oil, the EP takes up the ADP's commitment to source only certified, deforestation-free sustainable palm oil by 2020 (ADP, 2015a). In this regard, the EP resolution claims that existing sustainability certification systems for palm oil are inadequate for ensuring deforestation-free sourcing of palm oil, referring to both voluntary certification systems (i.e., RSPO) as well as producer countries' national mandatory certification systems (i.e., ISPO, MSPO). Only a stricter version of the RSPO standards, called RSPO NEXT, was found to be sufficiently stringent by the EP. In this regard, it has to be stressed that the RSPO has revised its principles and criteria in 2018 to include the stricter zero-deforestation criteria of RSPO NEXT (RSPO, 2018), so RSPO certification should be acceptable by the EP as of today. The EP resolution calls for the development of a mandatory sustainability certification scheme for palm oil imported into the EU, though. With respect to the specific use of palm oil as a biofuel, the EP suggests to phase out biofuels made from forest-risk crops in general.

This proposal directly refers to the RED II, which was still in the process of being developed when the EP resolution was published in April 2017. In its final version adopted in December 2018, the RED II mandated to gradually phase out biofuels made from crops with high risk of causing ILUC for the purpose of accounting toward the new renewable energy targets of the EU. ILUC cannot be directly measured, but has to be estimated using land-use models based on assumptions (Valin et al., 2015). A delegated act adopted in March 2019 specified criteria for 
determining whether a crop is regarded as having high ILUC-risk or not. One of the relevant criteria is the share of production expansion into high carbon stock areas. According to the definition used in the delegated act, a commodity is classified as "high ILUC-risk" if this share exceeds a threshold of ten percent. Among the commodities considered in the RED II, only palm oil was found to be a "high ILUC-risk" commodity based on this threshold (European Union, 2019).

Nevertheless, ILUC is also relevant for the case of soy (Macedo et al., 2012; Nepstad et al., 2019), and the amount of deforestation linked to soy imported to the EU has been found to exceed the amount of deforestation linked to palm oil in a study commissioned by the European Commission itself (European Commission, 2013). Still, according to the data provided in the annex to the delegated act, the share of production expansion of soy into high carbon stock areas amounts to eight percent, thus just missing the defined threshold. Some further criteria are defined to allow for exceptional re-classification of palm oil as "low ILUC-risk" commodity, but it remains unclear how the fulfillment of these criteria should be verified.

Article (1) finds that the EP resolution and the RED II have contributed to the intensification of discursive struggles between the $\mathrm{EU}$ and the main palm oil producing countries. As discussed in the article, palm oil is still not "banned" from the EU, not even for the use as biofuel, which has been misunderstood by several political actors from Indonesia and Malaysia. However, such misinterpretations as well as the perception that palm oil has been unfairly singled out by EU policymakers has led to impaired trade relations with the palm oil producing countries, which threatened the EU with WTO complaints (Keating, 2019; Suroyo \& Nangoy, 2019) and trade boycotts (Reuters, 2018; Tan, 2019).

Apart from article (1), only few other studies have focused on this topic more recently (Mitchell \& Merriman, 2020; Oosterveer, 2020; Webster, 2020). Oosterveer (2020) also deals with discourses related to EU policy development focusing on palm oil, referring to article (1) in several instances and agreeing that discourses on palm oil have been intensified in the context of EU policy development. He emphasizes the problematic distinction between palm oil used for biofuels and palm oil used for food and other purposes that is obviously made in EU policies and related discussions. Webster (2020) appreciates the EU's initiative in setting sustainability standards in the context of the RED and RED II because of expected positive effects on sustainability due to transnational bioenergy governance. Although the EU cannot directly influence the production conditions in other regions, pressure can be exercised via standards that effectively regulate market access. However, Mitchell and Merriman (2020) assessed the RED II in the context of Indonesia's complaints with respect to WTO law violations in detail and arrived at the conclusion that the RED II measures might indeed not be in line with WTO rules. According to their legal analysis, the WTO panel would presumably regard palm-oil-based biofuels and biofuels 
made from other crops as so-called "like" products, which need to receive the same treatment in international trade.

Regarding RQ I, this analysis has shown that the EP resolution and the RED II have been designed to support the development of deforestation-free supply chains in the $\mathrm{EU}$, which can be regarded as a first step in the right direction. To what extent the proposed measures will be successful remains an open question, though. Risks of leakage and displacement remain relevant on the global scale, if other relevant palm oil consuming countries - particularly in Asia - do not impose similar sustainability requirements. In the EU, mandatory sustainability requirements have been implemented only for biofuels so far. Moreover, it seems that palm oil producing countries have not been sufficiently involved in this policy development process. Besides palm oil, other forest-risk commodities will require more attention. Concrete zero-deforestation policy measures, such as mandatory supply chain due diligence or deforestation-free public procurement, are currently still in the process of negotiation and development in the EU.

\section{Which factors influence the demand for certified sustainable, deforestation-free products?}

In order to achieve deforestation-free supply chains by means of voluntary sustainability certification, sufficient demand for certified products is necessary. Contributing to RQ II, a sequential mixed methods study on consumer attitudes and preferences toward palm oil in food products (i.e., hazelnut spread and chocolate cookies) was conducted in Germany. Article (2) covers the qualitative analysis of several face-to-face and online focus group discussions. Article (3) deals with the quantitative analysis of a discrete choice experiment conducted as part of an online survey. In particular, trade-offs between RSPO-certified products, palm-oil-free products, and products containing conventional palm oil have been analyzed, which - to the knowledge of the author - had not been done in any quantitative analysis before. The consideration of the role of information on preferences is another relevant contribution to the existing research body. The two articles are complementary, and no relevant discrepancies could be identified with respect to their results. The main findings with respect to RQ II are summarized and discussed in the following. Some additional results of the online survey are considered, which have not been mentioned in article (3), which focuses primarily on the choice experiment.

The findings from articles (2) and (3) suggest that attitudes toward palm oil are rather deprecatory. The focus group discussions revealed that respondents were better informed about the disadvantages of palm oil with respect to environmental sustainability, particularly referring to deforestation, than about its advantages compared to alternatives. Media reports, documentaries, NGO campaigns and information by friends and family members were named by 
several respondents as sources of information on palm oil that have influenced their attitudes. This seems plausible, as particularly the Greenpeace anti-palm-oil campaigns focusing on the destructions of rainforests have received much attention (D'Antone \& Spencer, 2015; Greenpeace, 2010, 2018). In addition, the discourse analysis conducted in article (1) has shown that EU policies rather promote the view that palm oil cannot be regarded as sustainable, which might also influence public perceptions.

Despite the RSPO's aim to promote certified sustainable palm oil, the results of the mixed methods study indicate that palm-oil-free products are generally preferred over RSPO-certified products in Germany. Segregation ("RSPO certified") is preferred over the mass balance approach ("RSPO mixed"), other things being equal. There are different possible reasons for these general preferences that are relevant to discuss, before looking more closely into differences between the identified consumer segments.

One major reason is that the "palm-oil-free" claim is self-explanatory, while RSPO labels are not. The meaning of "RSPO certified" or "RSPO mixed" is unclear if the respective certification systems and their standards are not known. Findings from the mixed methods study indicate that RSPO certification is not well known in Germany. Only three focus group participants stated that they might have seen an RSPO label before, but they had no concrete idea about its meaning. Prior to the choice experiment, $86 \%$ of the survey respondents stated that they had never heard of certification by the RSPO. Around four percent of the sample claimed to know the RSPO label. Also, four percent claimed to know the requirements of the RSPO standards. Three percent stated that they deliberately purchase RSPO-certified products. ${ }^{22}$ These numbers are roughly comparable with findings from the previous German survey by Gassler and Spiller (2018), in which $80 \%$ of the sample had indicated to be unfamiliar with RSPO labels. However, it might be questioned whether these numbers are realistic. Ostfeld et al. (2019) used a similar item-based approach to let survey respondents in the United Kingdom assess their recognition of different sustainability labels. Five percent of the respondents claimed to know the RSPO label, but the same share also claimed to know a fictitious label included as a plausibility check. Thus, knowledge of RSPO certification might have been overstated and is probably negligible.

Despite the large volumes of certified palm oil imported to Europe, RSPO labels are unknown among consumers because RSPO labels are often not used on products that contain RSPO-certified palm oil. Major food processors and manufacturers suspect that consumers would rather avoid RSPO-labeled products because the labels signalize that palm oil is an ingredient

\footnotetext{
${ }^{22}$ Those respondents who claimed to know the name of RSPO (14\%) were asked to indicated whether they: a) know the label; b) know the requirements of the standards; c) deliberately purchase RSPO-certified products. Multiple choice was allowed. If none of the three options was applicable, respondents had to choose the option "none of the three statements is applicable“, which was selected by around five percent of the sample.
} 
(Larsen et al., 2018). The Ferrero Group is one prominent example. Although Ferrero uses only RSPO-certified and segregated palm oil for its products and achieves the best ranking among manufacturers on WWF's "Palm Oil Buyers Scorecard" (WWF, 2020), RSPO labels are not shown on their products, such as the popular hazelnut spread Nutella. However, many consumers are aware that Nutella contains palm oil, because this product has been frequently used as an emblem in anti-palm-oil campaigns and related discourses (Cova \& D'Antone, 2016). Moreover, the list of ingredients of food products in the EU has to specify which vegetable oil has been used (European Union, 2011). In the focus group discussions, which used hazelnut spread as an example, many respondents knew that Nutella contains palm oil. But several persons indicated that they would still rather buy Nutella than a palm-oil-free alternative, because they prefer its taste and are loyal toward the brand. This brand loyalty is consistent with the findings from a qualitative analysis conducted in France (Cova \& D'Antone, 2016). Whether Ferrero and other companies would gain or lose customers if they used RSPO labels remains an open question. Either way, it might help to increase recognition and awareness of the labels, which is a prerequisite for the consideration of sustainability labels in consumers' decision making process (Thøgersen, 2000; Thøgersen et al., 2010).

In order to study the influence of information on preferences, the choice experiment was divided into two parts: before and after information on palm oil and different certification systems was provided to the respondents. Besides the two RSPO labels ("RSPO certified" for segregated palm oil and "RSPO mixed" for mass balance), two additional labels were included in the choice experiment: "EU organic" and "Fairtrade". The survey results indicate that both are significantly better known than the RSPO labels ${ }^{23}$, and both received statistically significant and economically relevant positive utility values before information provision. The respective coefficient for the "RSPO certified" label was much smaller and only significant at the $5 \%$ level, while the "RSPO mixed" coefficient was found to be insignificant. After information provision, the utility of the "RSPO certified" label became quite strong, and also the "RSPO mixed" label seemed to provide significantly positive utility now, while the coefficients for the other two sustainability labels only slightly decreased. Still, the preference for palm-oil-free products became even stronger and outweighed the preference for RSPO-certified products. This finding suggests that the information about palm oil production, which included information on adverse effects, increased respondents' awareness for palm oil, and that the negative aspects were perceived as overall more relevant than the sustainability standards of RSPO certification. In both parts,

\footnotetext{
${ }^{23}$ Only $10 \%$ of the survey respondents stated that they had never heard of "Fairtrade" certification, while $37 \%$ had never heard of "EU organic" certification.
} 
consumers preferred cheaper products, other product attributes (i.e., certification and chocolate content) being equal.

Health concerns with respect to palm oil consumption are another relevant reason for prevailing preferences for palm-oil-free products. Health concerns were not in the main focus of the two studies, and no information on health aspects was provided in the choice experiment. Still, several participants in the focus group discussions described palm oil as unhealthy, with some persons referring to saturated fats, others to potential carcinogenic risk factors. At the very end of the survey they were asked whether they regard RSPO-certified or palm-oil-free products as healthier. Almost 55\% opted for palm-oil-free products, while around one third of the sample was unsure and the remainder chose RSPO-certified products. Thus, health concerns might indeed have played a role. This finding is also in line with previous studies that considered the relevance of health concerns (Borrello et al., 2019; Disdier et al., 2013; Hartmann et al., 2018; Verneau et al., 2019). Thus, palm-oil-free claims might have a "health halo effect", as consumers might suspect that the declared absence of palm oil is per se better for their health, as in "sugar-free" or "free from harmful substances" - although this might actually not be the case (Borrello et al., 2019; Hartmann et al., 2018). Similarly, palm-oil-free products might be perceived as generally more sustainable. For this reason, palm-oil-free claims are regarded as discriminatory by producers and policymakers in palm oil producing countries, as discussed in article (1). Several participants in the focus group discussions admitted that they had never really thought about whether alternatives to palm oil are really better in terms of sustainability and health aspects, or whether they are suitable to replace palm oil at all. In the choice experiment, the alternative oil or fat used in the palm-oil-free products was not specified.

As mentioned before, the preferences for product attributes discussed so far refer to mean utility values for the whole sample. A latent class analysis was conducted in order to get a better understanding of the sources of the identified preference heterogeneity among the respondents. As the differences between the latent classes (or segments) are explained in more detail in article (3), only the most relevant aspects with respect to RQ II will be emphasized here. Before information provision (part 1), six consumer segments have been identified: "palm oil avoiders" (14\% of the sample), "palm oil neutrals" (20\%), "concerned consumers" (16\%), "cheap shoppers" (11\%), "plain cookie eaters" (32\%), and "chocolate lovers" (7\%). Among these segments, only the "concerned consumers" show convincing support for RSPO-certified palm oil, but still prefer palm-oil-free products.

The provision of information clearly affects preferences. After information provision (part 2), the latent class analysis identifies five segments for the second part of the choice experiment. By analyzing their preferences and characteristics, it is concluded that the segment of 
"palm oil neutrals" has dissolved. It seems that the information helped the "palm oil neutrals" to overcome their indifference toward palm oil. This segments' members have switched to other segments, particularly to the "palm oil avoiders" (now 21\% of the sample) and the "concerned consumers" (now almost 28\%). Now all segments show preferences for RSPO certification to some extent, even the "palm oil avoiders". Still, the preferences for palm-oil-free products outweigh these preferences for all segments except for the "plain cookie eaters" (32\%), which is the only segment that still seems to have no interest in palm-oil-free cookies.

Assuming that the survey sample is sufficiently representative of the population and that potential biases are negligible, it can be concluded that the market demand for RSPO-certified palm oil in Germany is clearly not sufficient. With respect to market shares, only around one third of German consumers would prefer RSPO-certified cookies over palm-oil-free cookies, provided that they receive information on the certification systems at the point of sale. This can be regarded as a rather unrealistic scenario. Without any additional information, only a rather small population share of concerned consumers might choose RSPO-certified cookies, but possibly only if palm-oil-free alternatives are not available. Many consumers would rather not care much about palm oil as a product ingredient when making purchase decisions. Instead, they would rather care about the price and often choose the cheaper alternative. This is in line with findings from the focus group discussions described in article (2).

Concerning the willingness to pay a premium for certified palm oil as compared to uncertified palm oil, it has to be considered that a large share of the overall sample was highly price-sensitive. While the estimated mean WTP before information provision might be realistic, the mean WTP after information provision seems unrealistically high, considering real product prices. Thus, as discussed in article(3), WTP values should be treated with caution, also considering that segment-specific WTP values would be even higher for some segments. In the study by Gassler and Spiller (2018), the estimated WTP for a similar product (chocolate bars) was even significantly higher, considering the same product weight. Gassler and Spiller (2018) provided information to consumers before the choice experiment and did neither include a palmoil-free option nor other product attributes besides RSPO certification and the price. The inclusion of additional product attributes and additional attitudinal variables is probably also the reason why in article (3), more consumer segments were identified than in the study by Gassler and Spiller (2018), who identified only three segments. Due to the consideration of additional product attributes, additional certification systems, and the choice situation without information provision, the choice experiment analyzed in article (3) reproduces more complex decisionmaking environments. 
Going back to RQ II, the results of articles (2) and (3) suggest that various factors might influence the demand and the willingness to pay for certified sustainable, deforestation-free palm oil. The latent class analysis described in article (3) indicates that several attitudinal factors are relevant, particularly concern about sustainability issues, certification support, as well as the perceived importance of information and respondents' information-seeking behavior. Trust in the credibility and effectiveness of certification systems has also been mentioned as relevant by the focus group participants in article (2). Prior knowledge about palm oil might also influence attitudes and preferences. As indicated by results from articles (1) and (2), public discourses on negative health effects and sustainability issues might influence consumers' attitudes toward palm oil. Article (3) has shown that information about palm oil and certification systems provided to consumers might help to increase the demand for RSPO-certified palm oil to some extent.

However, participants in the focus group discussions mentioned other factors as more relevant for their purchase decisions: Relevant product attributes are for instance the product price, the brand, and other ingredients. Personal factors, such as taste, habits, and the budget also play a role. In this regard, the latent class analysis showed that the "concerned consumers" tend to have a significantly higher income than the reference class, the "cheap shoppers". Also situational factors at the point of sale are relevant, such as the time for information search and the product availability. Overall, the results illustrate that the trade-off between RSPO-certified and palm-oil-free products is an important one. Ignoring palm-oil-free options that are increasingly advertised in supermarkets leads to an overestimation of the market potential of RSPO-certified products, particularly if RSPO labels are not shown on products no information is provided. Insufficient market demand for sustainable, deforestation-free products shows that supporting polices involving mandatory sustainability requirements are required, as discussed in the context of RQI.

\section{Which sustainability certification systems should be supported to ensure deforestation- free supply chains?}

In the focus group discussions on palm oil analyzed in article (2), several respondents expressed distrust in sustainability labels. They stressed that there are too many different labels, which makes it very difficult to assess which certification systems are ambitious and which are rather used for "greenwashing" purposes. On the one hand, different labels and claims used on products lead to information overload. On the other hand, the labels themselves usually do not provide any concrete information about the underlying standards. Similar findings with respect to information overload and the identified lack of trust in certification among consumers were made in previous studies (e.g., Grunert, 2011; Sirieix et al., 2013; Thøgersen et al., 2010). But not only consumers 
lack knowledge and are uncertain which certification systems they should support. Also policymakers and supply chain actors need some guidance in this regard because they face reputational risks related to their activities (e.g., Bullock \& van der Ven, 2020; Chkanikova \& Sroufe, 2020). This is particularly relevant in the context of zero-deforestation commitments, because - as explained in section 1.2 - there are different concepts of zero deforestation. Thus, a common understanding of which certification systems can be regarded as suitable for ensuring deforestation-free supply chains is required.

In order to contribute to RQ III, a conceptual framework for sustainability certification systems focusing on zero-deforestation criteria has been developed and applied to a sample of soy certification systems in article (4). While FEFAC has established sustainability criteria for soy that are relevant for the European feed market (FEFAC, 2016), these can be only regarded as minimum benchmarking criteria. For instance, the FEFAC SSG only require compliance with zero illegal deforestation, referring to the respective producer countries' regulations. Thus, the FEFAC benchmarking (ITC, 2019) has only been used to preselect the sample of soy certification systems to be assessed. Two previous assessments had focused on FEFAC SSG-compliant certifications before (Hargita et al., 2018; Kusumaningtyas \& van Gelder, 2019). ${ }^{24}$ In this context, the main contribution of article (4) is the development of the conceptual assessment framework, which is simple but comprehensive, and the focus on $\mathrm{CoC}$ certification systems to ensure traceability. While the assessment by Kusumaningtyas and van Gelder (2019) does not consider CoC certification at all, the assessment by Hargita et al. (2018) considers this aspect but does not discuss which systems are actually required for ensuring traceability. Article (4) argues that traceability is essential if the ambition is to ensure that a product sold to final consumers does not contain any ingredients that have been linked to deforestation.

Thus, the conceptual framework developed in article (4) considers all relevant elements of certifications systems: sustainability standards, assurance systems, and chain-of-custody certification systems (Komives \& Jackson, 2014). With respect to assurance systems and the zerodeforestation criteria covered in sustainability standards, the results of the two previous assessment studies (Hargita et al., 2018; Kusumaningtyas \& van Gelder, 2019) were considered as a basis for the assessment. The FEFAC benchmarking (ITC, 2019) had been updated since the publication of the two previous studies, and some of the certification systems had published updates to their standards in the meantime. To account for these updates, the most recent standard versions have been considered in article (4). With regard to the use of CoC systems, it is argued that only identity preservation and segregation can ensure that a final product contains

\footnotetext{
${ }^{24}$ The revised version of the assessment by Hargita et al. (2018) had been published right before article (4) was accepted for publication (Hargita et al., 2019). Thus, the update has not been considered, but also would neither have changed the results or the discussion of article (4), nor made it less relevant.
} 
only certified soy (or certified commodities in general). This is because other CoC systems cannot effectively ensure that the certified commodity is not mixed with uncertified produce. Thus, while other popular systems, such as mass balance and book \& claim can help to contribute to deforestation-free production, they cannot ensure deforestation-free supply chains from the beginning to the end.

The result of the assessment described in article (4) suggests that among the 16 systems analyzed, the following systems are suitable to ensure deforestation free supply chains: ISCC EU, ISCC PLUS, ProTerra, Donau Soja and Europe Soya as well as RTRS. While all of these six provide at least the option for identity preservation and/or segregation, only two require this level of CoC certification: Donau Soja (identity preservation) and ProTerra (segregation). Thus, it can be argued that these two represent the strictest systems. Europe Soya is in most aspects identical to Donau Soja (except for the geographic scope), but allows also for the mixing with "approved" soy from other sources, a specific form of mass balance. It can be concluded that the identified six systems are recommendable in terms of supporting the achievement of zero-deforestation targets, provided that at least segregation is used as a CoC system. As Donau Soja, Europe Soya and ProTerra also prohibit genetic modification, it needs to be considered whether this requirement might fit to supply chain actors' and policymakers' aims. Overall, the assessment might also motivate standard setting organizations to improve their certification systems in order to pass similar assessments in the future, which might help them to gain reputation and market share.

The assessment by Kusumaningtyas and van Gelder (2019) identified three additional certification systems as adequate for ensuring deforestation-free supply chains: the systems by the Belgian Feed Association (BFA) and Cefetra - which use the same standards - and SFAP NonConversion. However, these systems do not provide the option to certify the supply chain according to segregation. The most recent reports by IDH on the state of deforestation-free soy consumption in Europe (IDH, 2020a, 2020b) refer to the assessment by Kusumaningtyas and van Gelder (2019). The consideration of the three additional certification systems in these reports might be problematic for two main reasons: First, the share of deforestation-free soy might be overestimated. Second, certification systems that are not ambitious enough might be promoted.

For the European Soy Monitor (IDH, 2020a), data on certified soy volumes were collected from FEFAC member associations and the respective standard owners. But no numbers on volumes certified according to the different certification systems are reported, so it is difficult to estimate the share of deforestation-free soy considering only the six systems identified in article (4). The report also acknowledges that data availability has been difficult so far, and a data break-down was not available in many cases. It is also reported that "more soy was certified than 
sold as certified" (IDH, 2020a, p. 102) - the same demand gap issue that has been discussed for the case of palm oil before.

Referring to the case of palm oil, article (2) and (3) studied consumer preferences for RSPO-certified palm oil, considering two different CoC certification options: segregation ("RSPO certified") and mass balance ("RSPO mixed"). In line with article (4), support for sustainable, deforestation-free palm oil should particularly focus on increasing the amount of segregated palm oil. Moreover, as the focus group discussions in article (2) indicate, consumers might regard mass balance as "greenwashing", as the product they purchase and consume might not even contain certified palm oil at all. This skepticism toward mass balance certification as compared to segregation is also reflected in the stated preferences analyzed in article (3). Thus, consumer acceptance is another relevant aspect in favor of segregation.

Ostfeld et al. (2019) even recommend to supply chain actors to purchase only identity preserved palm oil, but it might be questionable whether this is a realistic target for the short to medium term, as supply chains are complex and traceability systems still need to be improved, as argued in article (4). In this regard, transaction costs play an important role, and the market demand for certified products needs to increase. As mentioned in section 1.3, it has to be considered that voluntary certification tends to be used by actors who find it rather easy to comply with the respective standards (Lambin et al., 2018; van der Ven et al., 2018). Hence, it might be unlikely that ambitious standards would be voluntarily implemented in supply chains that are linked to severe sustainability issues. A large-scale transformation toward sustainability would probably not be achieved through voluntary measures alone. This is particularly relevant for the case of soy. As soy is primarily used for feed, certification labels are not shown on (animal) products sold in supermarkets. Therefore, demand will rather not be stimulated by final consumers' willingness to pay a premium for certified soy.

To summarize, RQ III can be answered in two ways: by referring to the conceptual framework that is applicable to forest-risk commodities in general, and by referring to the six certification systems that meet the frameworks' criteria for the specific case of soy. In general, certification systems need to comprise standards that are stringent enough to protect forests and other ecosystems with high conservation value. Zero gross deforestation is required, and a strict cut-off date (e.g., no later than 2008 or 2009) needs to be set. With respect to assurance, independent third-party audits and corrective measures for the case of non-compliance should be mandatory. Concerning traceability, the certification system needs to offer chain-of-custody certification in the form of segregation or identity preservation. Only certification systems fulfilling these criteria should be supported. Referring to the policy development discussed in the 
context of RQ I, it might make sense to use stringent voluntary certification systems as a tool to verify compliance with mandatory sustainability requirements that are being developed in the EU.

\subsection{Limitations and suggestions for future research}

Considering the contribution of this dissertation to the research on deforestation-free supply chains, several limitations have to be taken into account, particularly with respect to the methods and the scope. General advantages and disadvantages of the methods used in this dissertation have been briefly mentioned in section 2 , while the specific methodological limitations of the studies conducted as part of this dissertation have been discussed in more detail in the respective articles presented in section 4 . The most relevant aspects are summarized as follows:

The discourse analysis described in article (1) focuses on two specific EU policy documents and the discourses developing around this policy development that was topical in 2017 and 2018. In this context, the delegated act supplementing the RED II, which was adopted in March 2019, is the most recent document that has been included in the analysis. Subsequent policy development has not been considered. Moreover, the discourse analysis concentrates particularly on the positions of policymakers and supply chain actors in the EU, Indonesia and Malaysia. The consideration of speeches held at the European Palm Oil Conference (EPOC) in 2017 sets the focus to actors participating at this industry-driven event. Opinions of certain stakeholder groups, for instance environmental and social NGOs, have probably been insufficiently considered. Although some NGOs participated in the EPOC, private sector organizations were stronger represented. Unfortunately, there was no similar event with a stronger engagement of NGOs organized around that time. In general, the selection of the data material and the interpretation by the responsible researcher had certainly a significant influence on the results of the analysis. However, other scientific articles that analyze discourses on palm oil from different perspectives have been considered in the preparatory literature review process, and relevant references are provided in article (1).

With respect to the mixed methods research covered in articles (2) and (3), the main methodological limitation is that the information gained from both studies is based on stated preferences, not revealed preferences observed in real markets. As explained in section 2.2.3, potential biases, such as hypothetical bias and social desirability bias, might have led to an overestimation of preferences and WTP for certain product attributes used in the choice experiment (Breidert, 2006, p. 38ff.; Louviere et al., 2000, p. 228ff.). In this regard, the choice experiment conducted by Gassler and Spiller (2018) was probably more realistic, as respondents were randomly selected to buy a real chocolate bar based on a randomly selected choice task using money they had earned in an effort task prior to the choice experiment. However, it has 
been argued that the choice experiment described in article (3) considers a larger number of relevant product attributes, and particularly the important trade-off between palm-oil-free claims and RSPO labels, which had not been considered by Gassler and Spiller (2018).

Other relevant limitations are associated with sampling error, as mentioned in section 2.2.1. The participants in both studies were recruited from an online panel of a market research company according to certain socio-economic quota, so the sample was not randomly selected. With respect to the quota, participants with a higher level of education were overrepresented, which might have influenced the results. Moreover, the age limit was set to 70 years, so preferences of older people have not been considered.

It is also important to consider that the psychometric variables included in the latent class analysis are based on items that have been assessed only at one point in time, respectively. In order to reduce potential response biases, different aspects have been assessed in different sections of the questionnaire: Items related to knowledge on and attitudes toward certification have been assessed before the choice experiment. Items related to knowledge on and attitudes toward palm oil have been assessed before information on palm oil was provided, after the first part of the choice experiment. Further psychometric items have been assessed after the second part of the choice experiment. Although response biases might have been reduced, they certainly could not be eliminated in this way. Moreover, the different timing of the assessment makes it difficult to compare values across variables. And importantly, it is not possible to assess to what extent the provision of information might have affected the attitudinal variables, as these have not been assessed both before and after information provision.

Concerning the assessment of certification systems described in article (4), limitations are related to the selection of the sample. The assessment was limited to those soy certification systems that comply with the FEFAC SSG. This means that systems that are not compliant and systems that have not even participated in the voluntary benchmarking against the FEFAC SSG have not been considered. However, it can be argued that those systems with ambitious criteria probably registered for the benchmarking in order to gain reputation, so this should not be a major limitation with respect to answering RQ III. Another relevant limitation is related to the fact that several certification systems are continuously being further developed, so the assessment is only a snap-shot and might be outdated quite soon. Thus, similar assessments would need to be performed on a regular basis.

With respect to the conceptual framework developed for the assessment, it has to be acknowledged that the focus lies primarily on zero-deforestation criteria and less on environmental and social standards that are relevant for achieving other sustainability targets. These aspects have been considered by Hargita et al. $(2018,2019)$, but based on standard setting 
organizations' self-reported information retrieved from ITC (2020) as of September 2019. A more comprehensive assessment should verify this information by considering the respective standard documentation as a primary source.

Apart from these methodological limitations, there are further relevant limitations with respect to the scope of the dissertation defined in section 1.4. It has to be acknowledged that the three overarching research questions cannot be fully answered based on the findings of the four articles. Thus, further research is required in several areas.

This dissertation focuses on only two forest-risk commodities, namely palm oil and soy, while other forest-risk commodities are not covered. Cocoa for instance has also been prioritized by the ADP (2016) due to its relevance for the European market. According to IDH (2020b), 63\% of globally traded cocoa are imported to Europe, but so far, the share of sustainable sourcing remains unknown. Similar to the cases of palm oil and soy, a demand gap has also been identified for certified cocoa. Referring to Fountain and Huetz-Adams (2018), IDH (2020b) reports that between $20 \%$ and $60 \%$ of certified cocoa are not being sold as certified. Thus, cocoa is a commodity that clearly deserves further research in the context of deforestation-free supply chains. Other relevant commodities are for instance timber, coffee, rubber, and beef (European Commission, 2013; IDH, 2020b).

While rainforests in South America and Southeast Asia have been in the focus of researchers and policymakers so far, emerging "deforestation hotspots" (IDH, 2020b) in Africa should not be ignored. For the period from 2010 to 2020, the largest net forest loss per year has been observed in Africa (FAO, 2020d). Cocoa and palm oil are among the most relevant forest-risk commodities produced in Africa. More than half of the global cocoa production is located in Côte d'Ivoire and Ghana (FAO, 2020a). Nigeria is the fourth largest producer of palm oil globally, and also Cameroon and Ghana are among the "top 10" palm oil producing countries in terms of volumes (FAO, 2020b). It is expected that oil palm cultivation in Africa will significantly expand, with detrimental effects on biodiversity (Strona et al., 2018; Vijay et al., 2016).

Concerning the question to what extent the development of deforestation-free supply chains is supported by policy development in the EU (RQI), future research should focus on analyzing the more recent development of European policies. In this regard, the European Commission's communication on "stepping up EU action to protect and restore the world's forests" (European Commission, 2019a) and the new European Parliament resolution on the development of an "EU legal framework to halt and reverse EU-driven global deforestation" (European Parliament, 2020) are particularly relevant. Moreover, as suggested in article (4), the European strategy for the promotion of protein crops (European Parliament, 2018) deserves further investigation. 
As discussed in section 5.1, voluntary sustainability certification alone will most likely not solve all problems, as this measure tends to be implemented only where the required effort is comparably low and economic incentives are sufficiently high. Previous studies suggest that regulations in producer and consumer countries are needed as complementary measures (Bager et al., 2020; Busch \& Ferretti-Gallon, 2017; Jopke \& Schoneveld, 2018; Lambin et al., 2014; Lambin et al., 2018; Sundaraja et al., 2020). Among various policy options to support the development of deforestation-free supply chains, mandatory due diligence requirements and multi-stakeholder fora have been assessed as particularly feasible (Bager et al., 2020). The development of an EU supply chain regulation requiring companies to implement due diligence checks is currently being discussed in the context of the European Green Deal and the Farm to Fork Strategy (European Commission, 2019b, 2020b; European Parliament, 2020). A relevant question is which role sustainability certification should play in this regulatory context.

Further research is required with respect to different policy options and their (potential) effectiveness. In this regard, it would also be recommendable that researchers participate in stakeholder consultation processes initiated by the European Commission in order to share their knowledge and to highlight areas that require further analysis. In October 2020, the EU launched a global multi-stakeholder platform to accompany the policy development process. This platform shall also involve stakeholders from other countries that produce and/or consume forest-risk commodities (European Commission, 2020a). Concerning international collaboration, also potential effects of international trade agreements on deforestation need to be further investigated. Kehoe et al. (2020) for instance have argued that the EU-Mercosur trade agreement does not sufficiently consider sustainability aspects.

With respect to the market demand for certified sustainable and deforestation-free products (RQ II), this dissertation focuses only on German consumers' preferences for certified palm oil in food products. Previous research on palm-oil-related consumer preferences has also focused mainly on food products and on consumers in different European countries (e.g., Hartmann et al., 2018; Lange \& Coremans, 2020; Ostfeld et al., 2019; Verneau et al., 2019). Further research is required with respect to non-food products, such as cosmetics. However, palm oil is often not visible on the list of ingredients of non-food products, as this information must be provided only on food products in the EU (European Union, 2011).

Concerning the role of information, it might be interesting to investigate whether the provision of information on health aspects of palm oil consumption as compared to alternatives might help to reduce the persisting aversion to palm oil. Also, consumer preferences for other forest-risk commodities and respective sustainability certification require further exploration. However, it needs to be considered that soy for instance is mainly indirectly consumed in the 
form of animal products and is therefore probably less in the focus of consumers. Although the EU is an important consumer of deforestation-free commodities, the role of demand from emerging markets - particularly China and India - should not be ignored in future research (IDH, 2020b; TFA, 2018; zu Ermgassen et al., 2020). According to Poore and Nemecek (2018), demand for RSPO-certified palm oil in Asia is still negligible.

Globally, a significant market share of certified products needs to be achieved to avoid leakage to less stringent producer or consumer markets (Garrett et al., 2019). Besides the discussed demand gaps, there is still a lack of knowledge with respect to the market shares of various certification systems, even for the European market (IDH, 2020a, 2020b). In this regard, more research in collaboration with standard setting organizations and the private sector is required, as they have to collect and share relevant data. Research collaboration with retailers might be useful in order to implement more realistic experiments and to get data on revealed consumer preferences. For instance, an interesting study is currently being implemented in Germany as a collaboration between the discounter Penny and researchers of the University of Augsburg. The researchers had calculated the "true costs" associated with externalities of production of several own-brand consumer products. In one of its branches, the discounter now shows these costs as a second price in addition to the actual market price for the respective products. While consumers still have to pay the usual price, the researchers aim to find out whether the "true cost" label influences consumers' purchase decisions (Awater-Esper, 2020). In general, retailers often have significant power within the supply chain and thus can influence the market uptake of certified products (Waldman \& Kerr, 2014). Their strategies differ widely: The British retailer Tesco for instance has committed to use only RSPO-certified palm oil for its ownbrand products (Tesco, 2020). REWE Austria adopts a mixed approach and sources RSPO-certified palm oil in general, while its organic own-brand line "Ja! Natürlich" offers and promotes only palm-oil-free products (REWE Group, 2019).

Further research is also required in order to decide which sustainability certification systems should be supported to ensure deforestation-free supply chains (RQ III). Apart from certification systems for soy, further certification systems for other forest-risk commodities should be assessed, for instance by using the conceptual framework proposed in article (4). Palm oil certification systems had been assessed in earlier studies (Fry et al., 2018; McInnes, 2017), but as certification systems have been updated in the meantime, new assessments would be recommendable. Moreover, article (4) deals only with the theoretical effectiveness of certification systems. So far, the evidence for their actual effectiveness in terms of sustainability in general and stopping deforestation in particular is less clear (Carlson et al., 2018; Cazzolla Gatti et al., 2019; Lambin et al., 2014; Lambin et al., 2018; Morgans et al., 2018; van der Ven et al., 2018). 
With respect to socio-economic sustainability, economic incentives and the effects of certification on smallholder livelihoods are relevant topics that should be further explored. Smallholders often experience financial and technical barriers to certification and therefore might be excluded from international markets that establish sustainability requirements. Premiums for certified sustainable palm oil for instance are not fixed and generally too small to compensate for compliance and certification costs (Fry et al., 2018; Gallemore \& Jespersen, 2019; Ostfeld et al., 2019). As discussed before, certified commodities often have to be sold at regular market prices for uncertified products due to a lack of demand (IDH, 2020b).

Potential leakage, ILUC, and spillover effects of certification and forest conservation policies need to be further investigated, as the results of previous studies in this regard suggest (Heilmayr et al., 2020; Taheripour et al., 2019). As discussed in article (4), there are still relevant economic barriers that hinder the large-scale implementation of certification and traceability along the supply chain, which is needed to protect forests. Recently, pilot projects have been initiated to test the implementation of so-called landscape or jurisdictional approaches to certification, which have been suggested as a potential cost-efficient solution for achieving largescale certification (EU REDD Facility, 2016; Meyer \& Miller, 2015; Neeff \& Linhares-Juvenal, 2017; Tscharntke et al., 2015). Such approaches might also help to reduce the amount of different certification systems and to avoid potential disadvantages of multiple certification and labeling (Tebbe \& von Blanckenburg, 2018; Vanderhaegen et al., 2018). Research will be needed to investigate the effects of jurisdictional certification on different sustainability indicators and on the market uptake. Finally, more research is needed on new information technologies, for instance based on blockchains (Ge et al., 2017; Kamilaris et al., 2019), that might help to close persisting data gaps and to increase supply chain transparency and traceability. 


\section{Conclusions and policy recommendations}

By now, it has become clear that the target to achieve deforestation-free agricultural supply chains by 2020, as declared for instance by the Consumer Goods Forum (CGF, 2010) and the Amsterdam Declaration Partnership (ADP, 2015b), has not been achieved in time (IDH, 2020b). Thus, further efforts will be required by public and private actors to overcome remaining barriers in the coming years. The findings of this dissertation shall support these actors in their decisionmaking processes. This is particularly relevant, as related policies are still being negotiated and developed in the EU. The aim of this final section of the dissertation is to derive conclusions and policy recommendations for the EU based on the results discussed in section 5 . In this context, recent policy development is also considered and briefly discussed.

In the context of zero-deforestation commitments, this dissertation has analyzed the instrument of sustainability certification from different perspectives, focusing on palm oil and soy as relevant forest-risk commodities. Thereby, this dissertation contributes to answering three overarching research questions:

I. To what extent is the development of deforestation-free supply chains supported by policy measures in the EU?

II. Which factors influence the demand for certified sustainable, deforestation-free products?

III. Which sustainability certification systems should be supported to ensure deforestationfree supply chains?

With respect to RQ I, it can be concluded that the EU has clearly taken initiative in drafting policies to support the development of deforestation-free supply chains. Nevertheless, there is still a lack of comprehensive regulations affecting all relevant commodities and uses, which hampers progress with respect to achieving zero-deforestation targets. One of the two Amsterdam Declarations aims at achieving sustainable palm oil supply chains (ADP, 2015a), while there are no equivalent declarations dealing with sustainability certification for other forest-risk commodities. Also the European Parliament resolution on palm oil and deforestation of rainforests requests the development of a mandatory sustainability certification system only for palm oil (European Parliament, 2017). The revised RED II (European Union, 2018) is so far the only legally binding policy that explicitly deals with forest-risk commodities. However, mandatory sustainability requirements are only defined for commodities used for bioenergy, while other uses have not yet been sufficiently considered. According to the RED II and its supplementary delegated act, palm oil is so far the only "high ILUC-risk" commodity, and therefore the only commodity that will be phased out in the context of the renewable energy targets of the EU. 
Concerning other uses and other commodities, the EU has focused on expressing support for private sector initiatives and voluntary sustainability certification, thereby leaving the main responsibility to market actors. Consequences might be leakage effects (e.g., if producers switch from palm oil to other commodities) as well as conflicts with palm oil producing countries because of perceived unfair treatment. In order to avoid these problems, it will be important for the EU to develop legally binding policies that are applicable to several relevant deforestation drivers.

Concerning RQ II, it first has to be stressed that the European market demand for certified sustainable commodities, such as palm oil, soy, and cocoa, is insufficient and lagging behind supply. To be clear, this does not mean that the overall demand for these commodities is low, but that large volumes of certified products are sold as conventional, unlabeled products, without a premium. This suggests that final consumers probably do not express sufficient demand for sustainability certification and respective product labels. For the case of palm oil consumption in Germany, the results of two studies conducted as part of this dissertation lead to relevant conclusions on consumers' attitudes and preferences.

Overall, a large share of consumers seems not to care much about palm oil. Discussions with consumers revealed that other product attributes (e.g., price, brand), situational factors (e.g., time, availability) and personal factors (e.g., habits, taste, budget) are regarded as more important. Those consumers who care about palm oil tend to prefer palm-oil-free products over products containing certified sustainable palm oil. Prevailing preferences for palm-oil-free products might be attributable to several main reasons: First, consumers regard alternatives to palm oil as healthier and/or more sustainable than palm oil, irrespective of certification. Second, the most common certification system for palm oil - RSPO - is basically unknown among consumers, also because RSPO labels are often not shown on certified products. Third, information overload caused by too many different labels as well as "greenwashing" attempts might lead to distrust toward certification. Fourth, the product labels themselves are not selfexplanatory.

Consumers who derive utility from RSPO certification further distinguish between products that contain only segregated certified palm oil ("RSPO certified") and products that might also contain an (unknown) share of uncertified palm oil ("RSPO mixed"). The former option is preferred over the latter. The results of focus group discussions indicate that mass balance certification ("RSPO mixed") might be regarded as "greenwashing". Several attitudinal factors have been identified as relevant for characterizing consumers who prefer RSPO-certified over uncertified palm oil. These consumers tend to be concerned about sustainability aspects and supportive of certification in general. They also tend to actively search for information before making purchase and consumption decisions. With respect to socio-economic aspects, these 
consumers have a comparably high household income. Apart from the income, other socioeconomic factors seem to be less relevant for distinguishing consumer segments.

As previous research suggests, information not only affects knowledge, but also might influence attitudinal and motivational factors that are relevant in the decision-making process (e.g., Thøgersen, 2000). The provision of relevant information might therefore help to increase the demand for certified sustainable, deforestation-free products among consumers who care about sustainability and who are generally supportive toward certification. But it is crucial to carefully decide which kind of information is provided, as information provision might also have unintended effects. In the case of the implemented choice experiment, the provision of information (about palm oil production and certification) stimulated the willingness to pay a premium for RSPO-certified products, as compared to products containing conventional palm oil. However, the willingness to pay a premium for palm-oil-free products increased even further. Even after information provision, only a rather small share of consumers would prefer RSPOcertified products over palm-oil-free products. It remains to be further explored which effects information about health effects of palm oil consumption or information about alternatives to palm oil might have on preferences.

In the context of RQII, this dissertation focused on analyzing consumer preferences for palm oil in Germany. Further research is required with respect to the demand for other (certified) forest-risk commodities, such as soy and cocoa. Also the demand for such products in other countries, particularly outside of the EU, needs to be further explored. In other countries and other contexts, different factors might be relevant in purchase and consumption decisions.

To answer RQ III, a conceptual framework for the assessment of certification systems focusing on zero-deforestation requirements has been developed and applied to a sample of soy certification systems. According to this conceptual framework, the three main elements of certification systems (i.e., sustainability standards, assurance, and CoC certification) have to fulfill certain criteria to be suitable for ensuring that supply chains are deforestation-free. The aspect of traceability, which is addressed with CoC certification, had not been sufficiently considered in previous studies. However, traceability is crucial for the verification that uncertified commodities are not mixed with certified commodities along the supply chain. This can only be achieved by two CoC certification systems: identity preservation and segregation.

Among 16 soy certification systems, only six have been assessed as adequate according to all three elements of the conceptual framework: ISCC EU, ISCC PLUS, ProTerra, Donau Soja, Europe Soya, and RTRS. With respect to traceability, these systems offer either identity preservation or segregation as CoC certification options. But ISCC EU, ISCC PLUS, Europe Soya, and RTRS also allow for choosing a less stringent option, such as mass balance or book \& claim. Thus, 
it is not only important to use an adequate certification system, but also to choose a sufficiently stringent $\mathrm{CoC}$ certification option within this system, if it is not mandatory. As discussed in the context of RQ II, it can be expected that consumers also prefer segregation over mass balance.

Taking these considerations into account, the six adequate soy certification systems should be supported by public and private actors to increase the market uptake in Europe. Also other certification systems that pass the assessment according to the conceptual framework should be supported. In this regard, similar assessments need to be conducted for other forest risk commodities and repeated on a regular basis to account for updates in sustainability standards. To monitor progress, it is necessary to improve the data availability, as there is still a lack of detailed information on the volumes certified according to each of the certification systems, for instance. If the implementation of stringent chain-of-custody systems remains a voluntary decision by supply chain actors, progress will likely depend on a reduction in transaction costs that might be achieved through technological advancement.

These findings lead to the overall conclusion that zero-deforestation goals can hardly be achieved by focusing on voluntary sustainability certification alone, although certification is an important instrument that should be further improved and applied. This conclusion is supported by previous research (e.g., Bager et al., 2020; Jopke \& Schoneveld, 2018; Lambin et al., 2018). Certification systems that fulfill the criteria of the conceptual framework could be used as a reference for mandatory sustainability requirements that might be established in the EU. Mandatory sustainability requirements would probably be more effective than mandatory labeling of products containing forest-risk commodities. ${ }^{25}$ Palm oil for instance is often just one of many ingredients of processed products, and it might be difficult to justify why it should be singled out by introducing mandatory labeling. Moreover, mandatory labeling would probably solve neither the problem of perceived information overload nor the problem that consumers tend to prefer palm-oil-free products. Thus, it remains questionable whether such a measure would help to increase incentives for voluntary certification.

In this regard, it is important to remember that substituting forest-risk commodities might have adverse effects, if the alternatives for instance require more land for the equivalent amount of output. To achieve a reduction in the overall consumption of forest-risk commodities, it is crucial to reduce the consumption of processed products (which often contain palm oil), to reduce the consumption of dairy products and meat from soy-fed animals, and to reduce food loss and waste (Green et al., 2019; Koh \& Lee, 2012; Poore \& Nemecek, 2018; Springmann et al., 2018).

\footnotetext{
${ }^{25}$ Mandatory labeling could for instance mean that a product label has to indicate whether the product contains a certain forest-risk commodity, and - if it does - to what extent this ingredient can be regarded as sustainable based on voluntary certification, if applicable.
} 
Considering the discussion of the results presented in section 5 , the following five main recommendations are provided to policymakers at the EU level and at the national level in the EU member states:

1. Establish clear zero-deforestation targets for the period from 2021 to 2030. Moreover, establish monitoring and reporting systems that provide and improve access to data, for instance on the origin and traceability of products and on the market uptake of certified sustainable commodities.

2. Support further scientific research in order to close the identified knowledge gaps and to assess the effectiveness of different policy options.

3. Develop more stringent policy measures involving sustainability requirements that are applicable to several forest-risk commodities and different uses, and that consider the aspect of traceability.

4. Engage with relevant producer and consumer countries to develop joint solutions with respect to sustainability requirements that ensure the inclusion of small-scale producers and reduce risks of leakage, displacement, and trade conflicts.

5. Further promote the market uptake of certified sustainable commodities by engaging in multistakeholder initiatives, and by providing information on relevant forest-risk commodities, potential substitutes, and relevant sustainability certification systems to the public.

Due to the limited timeframe, the analysis of EU policy measures described in article (1) of this dissertation did not consider the policy development after the adoption of the delegated act supplementing the RED II, which was adopted in March 2019. Thus, major aspects of more recent policy development in the EU should be considered in order to identify potential remaining gaps in the context of the derived conclusions and policy recommendations. In this regard, answers to RQ I can be complemented.

The European Commission's communication on "Stepping up EU action to protect and restore the world's forests" published in July 2019 suggests to facilitate "close cooperation with producer and consumer countries as well as business and civil society" (European Commission, 2019a, p. 6). Moreover, incentive mechanisms for smallholders to adopt sustainable practices shall be developed (European Commission, 2019a, p. 11). These suggestions relate to policy recommendations 4 and 5 . The communication further suggests that sustainability standards and certification systems should be strengthened, and systems should be assessed according to different criteria. The latter aspect has been addressed in article (4) of this dissertation. Furthermore, it is proposed to "integrate deforestation considerations within the EU Ecolabel, green public procurement and other initiatives in the context of the circular economy" (European Commission, 2019a, p. 9). Information on forest-risk products shall be disseminated to influence 
consumer demand (European Commission, 2019a, p. 9), which relates to recommendation 5. Also recommendations 1 and 2 are partly addressed, as the communication suggests to "support the availability of, quality of, and access to information on forests and commodity supply chains" and to "support research and innovation" (European Commission, 2019a, p. 15).

The European Commission's communication on the European Green Deal published in December 2019 sets the overarching goal to achieve climate neutrality in the EU by 2050 (European Commission, 2019b). A "carbon border adjustment mechanism" shall be developed to account for emissions linked to imported products, thereby reducing leakage risks (European Commission, 2019b, p. 5). Moreover, greenwashing shall be addressed by requiring companies to provide proof for "green claims" on products, using a standard methodology to be developed (European Commission, 2019b, p. 8). These suggestions relate to recommendations 3 and 5. The European Green Deal is accompanied by the Farm to Fork Strategy to support sustainability in agricultural supply chains (European Commission, 2020b). This strategy proposes several important policy measures, such as mandatory sustainability criteria for public food procurement, tax adjustments to reflect externalities of food production, and the inclusion of sustainability requirements in trade agreements. Also the importance of international collaboration, research, and the sharing of data and knowledge is stressed (European Commission, 2020b, p. 14ff.). Two announcements are particularly important: First, a legislative proposal and additional measures to reduce EU imports of forest-risk commodities shall be presented in 2021. Second, an "EU sustainable food labeling framework" shall be established and sustainability standards shall be promoted to increase the uptake of certified products (European Commission, 2020b, p. 18f.) Thus, all five policy recommendations are addressed to some extent in the Farm to Fork Strategy.

In October 2020, the European Parliament adopted a resolution to propose the development of an "EU legal framework to halt and reverse EU-driven global deforestation" (European Parliament, 2020). This resolution introduces the term "forest and ecosystem-risk commodities" (FERCs) to underline that not only forests need to be protected. It is emphasized that "a policy measure that is dependent solely on consumer choice unduly shifts the responsibility to purchase deforestation-free products to consumers, which is insufficient in its effectiveness to mainstream more sustainable production" (European Parliament, 2020, p. 10). Thus, a legal framework shall establish mandatory due diligence requirements for any operators placing FERCs on the EU market. This means that public and private actors need to ensure that sustainability requirements are met along the supply chain.

In this context, it is also stressed that traceability plays an important role. Existing voluntary sustainability certification systems shall be assessed based on minimum criteria to be developed. Certification systems that pass the benchmarking assessment shall be supported and 
used as part of the mandatory due diligence systems. As a complementary measure, information campaigns on FERCs and their impacts shall be developed to raise public awareness (European Parliament, 2020). Interestingly, the resolution also asks for a reassessment of soy data in the context of "high ILUC-risk" criteria defined in the RED II (European Parliament, 2020), thereby taking up a relevant aspect discussed in section 5.1 of this dissertation. Overall, this resolution particularly tackles relevant aspects of recommendations 3 and 5 .

Considering the recent policy development in the EU, it can be concluded that there are significant overlaps with the conclusions and policy recommendations that have been derived based on the results of this dissertation. It can be expected that several legally binding policy measures will be implemented, while voluntary sustainability certification will continue to play an important supporting role. However, it seems that clear, binding zero-deforestation targets have not yet been established. Although the importance of traceability has been emphasized, it remains to be further specified how exactly it should be achieved. Concerning the suggested assessment of certification systems with respect to zero-deforestation criteria, it might make sense to utilize and refine the conceptual framework developed as part of this dissertation. 


\section{References}

Adamowicz, W. L., Louviere, J. J., \& Swait, J. D. (1998). Introduction to attribute-based stated choice models: Final report. Washington, D.C.: Resource Valuation Branch, Damage Assessment Center, NOAA, U.S. Department of Commerce.

ADP (2015a). The Amsterdam Declaration in support of a fully sustainable palm oil supply chain by 2020. Amsterdam, The Netherlands: Amsterdam Declarations Partnership (ADP). Retrieved from https://ad-partnership.org/wp-content/uploads/2018/10/Amsterdam-DeclarationDeforestation-Palm-Oil-v2017-0612.pdf on June 12, 2020.

ADP (2015b). Towards eliminating deforestation from agricultural commodity chains with European countries. Amsterdam, The Netherlands: Amsterdam Declarations Partnership (ADP). Retrieved from https://ad-partnership.org/wp-content/uploads/2018/10/AmsterdamDeclaration-Deforestation-Palm-Oil-v2017-0612.pdf on June 12, 2020.

ADP (2016). Strategy AD Partnership. Leiden, The Netherlands: Amsterdam Declarations Partnership (ADP). Retrieved from https://ad-partnership.org/wpcontent/uploads/2018/10/AD-Partnership-Implementation-Strategy-v1Dec2016.pdf on February 17, 2020.

AFi (2020). Accountability Framework. Accountability Framework initiative (AFi). Retrieved from https://accountability-framework.org/ on October 13, 2020.

Alix-Garcia, J., \& Gibbs, H. K. (2017). Forest conservation effects of Brazil's zero deforestation cattle agreements undermined by leakage. Global Environmental Change, 47, 201-217. https://doi.org/10.1016/j.gloenvcha.2017.08.009.

Allwood, C. M. (2012). The distinction between qualitative and quantitative research methods is problematic. Quality \& Quantity, 46(5), 1417-1429. https://doi.org/10.1007/s11135-011-94558.

Arima, E. Y., Richards, P. D., Walker, R. T., \& Caldas, M. M. (2011). Statistical confirmation of indirect land use change in the Brazilian Amazon. Environmental Research Letters, 6(2), Article 024010. https://doi.org/10.1088/1748-9326/6/2/024010.

Awater-Esper, S. (2020). Wahre Kosten von Lebensmitteln sind höher als ihr Preis. Münster, Germany: top agrar. Retrieved from https://www.topagrar.com/management-undpolitik/news/wahre-kosten-von-lebensmitteln-sind-hoeher-als-ihr-preis-12337968.html on November 9, 2020.

Bager, S., Persson, M., \& Reis, T. N. (2020). Reducing commodity-driven tropical deforestation: Political feasibility and 'theories of change' for EU policy options. SSRN Electronic Journal. Advance online publication. https://doi.org/10.2139/ssrn.3624073.

Barrios, E. X., \& Costell, E. (2004). Review: Use of methods of research into consumers' opinions and attitudes in food research. Food Science and Technology International, 10(6), 359-371. https://doi.org/10.1177/1082013204049386.

Betts, M. G., Wolf, C., Ripple, W. J., Phalan, B., Millers, K. A., Duarte, A., Butchart, S. H. M., \& Levi, T. (2017). Global forest loss disproportionately erodes biodiversity in intact landscapes. Nature, 547(7664), 441-444. https://doi.org/10.1038/nature23285.

Bhat, C. R. (1997). An endogenous segmentation mode choice model with an application to intercity travel. Transportation Science, 31(1), 34-48. https://doi.org/10.1287/trsc.31.1.34. 
Bliemer, M. C. J., \& Rose, J. M. (2011). Experimental design influences on stated choice outputs: An empirical study in air travel choice. Transportation Research Part A: Policy and Practice, 45(1), 63-79. https://doi.org/10.1016/j.tra.2010.09.003.

Borrello, M., Annunziata, A., \& Vecchio, R. (2019). Sustainability of palm oil: Drivers of consumers' preferences. Sustainability, 11(18), Article 4818. https://doi.org/10.3390/su11184818.

Bowen, G. A. (2009). Document analysis as a qualitative research method. Qualitative Research Journal, 9(2), 27-40. https://doi.org/10.3316/QRJ0902027.

Boxall, P. C., \& Adamowicz, W. L. (2002). Understanding heterogeneous preferences in random utility models: A latent class approach. Environmental and Resource Economics, 23(4), 421446. https://doi.org/10.1023/A:1021351721619.

Brack, D., \& Bailey, R. (2013). Ending global deforestation: Policy options for consumer countries. London: Chatham House. Retrieved from https://www.chathamhouse.org/publications/papers/view/194247 on October 31, 2018.

Brandão Jr., A., Rausch, L. L., Paz Durán, A., Costa Jr., C., Spawn, S. A., \& Gibbs, H. K. (2020). Estimating the potential for conservation and farming in the Amazon and Cerrado under four policy scenarios. Sustainability, 12(3), Article 1277. https://doi.org/10.3390/su12031277.

Braun, V., \& Clarke, V. (2006). Using thematic analysis in psychology. Qualitative Research in Psychology, 3(2), 77-101. https://doi.org/10.1191/1478088706qp063oa.

Braun, V., Clarke, V., Hayfield, N., \& Terry, G. (2019). Thematic analysis. In P. Liamputtong (Ed.), Handbook of research methods in health social sciences (pp. 843-860). Singapore: Springer. https://doi.org/10.1007/978-981-10-5251-4_103.

Breidert, C. (2006). Estimation of willingness-to-pay: Theory, measurement, application. (1. Aufl.). Gabler Edition Wissenschaft. Wiesbaden, Germany: Deutscher Universitäts-Verlag (DUV).

Brockerhoff, E. G., Barbaro, L., Castagneyrol, B., Forrester, D. I., Gardiner, B., GonzálezOlabarria, J. R., Lyver, P. O., Meurisse, N., Oxbrough, A., Taki, H., Thompson, I. D., van der Plas, F., \& Jactel, H. (2017). Forest biodiversity, ecosystem functioning and the provision of ecosystem services. Biodiversity and Conservation, 26(13), 3005-3035. https://doi.org/10.1007/s10531-017-1453-2.

Brown, S., \& Zarin, D. (2013). Environmental science. What does zero deforestation mean? Science, 342(6160), 805-807. https://doi.org/10.1126/science.1241277.

Brüggen, E., \& Willems, P. (2009). A critical comparison of offline focus groups, online focus groups and e-Delphi. International Journal of Market Research, 51(3), 1-15. https://doi.org/10.1177/147078530905100301.

Bullock, G., \& van der Ven, H. (2020). The shadow of the consumer: Analyzing the importance of consumers to the uptake and sophistication of ratings, certifications, and eco-labels. Organization \& Environment, 33(1), 75-95. https://doi.org/10.1177/1086026618803748.

Busch, J., \& Ferretti-Gallon, K. (2017). What drives deforestation and what stops it? A metaanalysis. Review of Environmental Economics and Policy, 11(1), 3-23. https://doi.org/10.1093/reep/rew013.

Carlson, K. M., Heilmayr, R., Gibbs, H. K., Noojipady, P., Burns, D. N., Morton, D. C., Walker, N. F., Paoli, G. D., \& Kremen, C. (2018). Effect of oil palm sustainability certification on deforestation and fire in Indonesia. Proceedings of the National Academy of Sciences, 115(1), 121-126. https://doi.org/10.1073/pnas.1704728114. 
Carrasco, L. R., Le Nghiem, T. P., Chen, Z., \& Barbier, E. B. (2017). Unsustainable development pathways caused by tropical deforestation. Science Advances, 3(7), e1602602.

https://doi.org/10.1126/sciadv.1602602.

Cazzolla Gatti, R., Liang, J., Velichevskaya, A., \& Zhou, M. (2019). Sustainable palm oil may not be so sustainable. The Science of the Total Environment, 652, 48-51.

https://doi.org/10.1016/j.scitotenv.2018.10.222.

CGF (2010). Consumer goods industry announces initiatives on climate protection. Paris: The Consumer Goods Forum (CGF). Retrieved from https://www.theconsumergoodsforum.com/press_releases/consumer-goods-industryannounces-initiatives-on-climate-protection/ on September 14, 2020.

Cheyns, E. (2014). Making "minority voices" heard in transnational roundtables: The role of local NGOs in reintroducing justice and attachments. Agriculture and Human Values, 31(3), 439453. https://doi.org/10.1007/s10460-014-9505-7.

Chkanikova, O., \& Sroufe, R. (2020). Third-party sustainability certifications in food retailing: Certification design from a sustainable supply chain management perspective. Journal of Cleaner Production, (in press), 124344. https://doi.org/10.1016/j.jclepro.2020.124344.

Collins, L. M., \& Lanza, S. T. (2010). Latent class and latent transition analysis: With applications in the social, behavioral, and health sciences. Wiley Series in Probability and Statistics: Vol. 718. Hoboken, New Jersey, USA: Wiley.

Corciolani, M., Gistri, G., \& Pace, S. (2019). Legitimacy struggles in palm oil controversies: An institutional perspective. Journal of Cleaner Production, 212, 1117-1131. https://doi.org/10.1016/j.jclepro.2018.12.103.

Cotton, M., Rattle, I., \& van Alstine, J. (2014). Shale gas policy in the United Kingdom: An argumentative discourse analysis. Energy Policy, 73, 427-438. https://doi.org/10.1016/j.enpol.2014.05.031.

Couper, M. P. (2000). Web Surveys: A review of issues and approaches. Public Opinion Quarterly, 64(4), 464-494. https://doi.org/10.1086/318641.

Cova, B., \& D'Antone, S. (2016). Brand iconicity vs. anti-consumption well-being concerns: The Nutella palm oil conflict. Journal of Consumer Affairs, 50(1), 166-192. https://doi.org/10.1111/joca.12082.

Creswell, J. W. (2009). Research design: Qualitative, quantitative, and mixed methods approaches. (3rd ed.). Thousand Oaks, California, USA: SAGE Publications.

Creswell, J. W., \& Plano Clark, V. L. (2011). Designing and conducting mixed methods research. (2nd ed.). Thousand Oaks, California, USA: SAGE Publications.

Curtis, P. G., Slay, C. M., Harris, N. L., Tyukavina, A., \& Hansen, M. C. (2018). Classifying drivers of global forest loss. Science, 361(6407), 1108-1111. https://doi.org/10.1126/science.aau3445.

Cyr, J. (2016). The pitfalls and promise of focus groups as a data collection method. Sociological Methods \& Research, 45(2), 231-259. https://doi.org/10.1177/0049124115570065.

D'Antone, S., \& Spencer, R. (2015). Organising for sustainable palm oil consumption: A marketbased approach. Consumption Markets \& Culture, 18(1), 55-71. https://doi.org/10.1080/10253866.2014.899217.

Darby, M. R., \& Karni, E. (1973). Free competition and the optimal amount of fraud. The Journal of Law and Economics, 16(1), 67-88. https://doi.org/10.1086/466756. 
Dauvergne, P. (2018). The global politics of the business of "sustainable" palm oil. Global Environmental Politics, 18(2), 34-52. https://doi.org/10.1162/glep_a_00455.

de-Magistris, T., Gracia, A., \& Nayga, Rodolfo M., Jr. (2013). On the use of honesty priming tasks to mitigate hypothetical bias in choice experiments. American Journal of Agricultural Economics, 95(5), 1136-1154. https://doi.org/10.1093/ajae/aat052.

Disdier, A.-C., Marette, S., \& Millet, G. (2013). Are consumers concerned about palm oil? Evidence from a lab experiment. Food Policy, 43, 180-189. https://doi.org/10.1016/j.foodpol.2013.09.003.

Donofrio, S., Rothrock, P., \& Leonard, J. (2017). Supply Change: Tracking corporate commitments to deforestation-free supply chains. Washington, DC: Forest Trends. Retrieved from https://www.forest-trends.org/wp-content/uploads/2017/03/2017SupplyChange_FINAL.pdf on October 31, 2018.

EIA (2019). Indonesia's moratorium on clearing forests and peatlands now permanent - but excludes vast areas. London: Environmental Investigation Agency (EIA). Retrieved from https://eia-international.org/news/indonesias-moratorium-on-clearing-forests-and-peatlandsnow-permanent-but-excludes-vast-areas/ on October 28, 2020.

Elgert, L. (2012). Certified discourse? The politics of developing soy certification standards. Geoforum, 43(2), 295-304. https://doi.org/10.1016/j.geoforum.2011.08.008.

EPOA (2020). Monitoring sustainable deforestation-free palm oil in Europe: Edition March 2020. Zoetermeer, The Netherlands: European Palm Oil Alliance (EPOA). Retrieved from https://palmoilalliance.eu/wp-content/uploads/2020/03/EPOA-facts-and-figures-2018-A5digital-DEF.pdf on September 16, 2020.

ESPO (2015). Commitment to support: 100\% sustainable palm oil in Europe by 2020. Amsterdam, The Netherlands: European Sustainable Palm Oil (ESPO) secretariat. Retrieved from https://www.idhsustainabletrade.com/uploaded/2016/06/commitment-to-supportsustainable-palm-oil-in-europe.pdf on October 28, 2020.

ESPO (2017). Making sustainable palm oil the norm in Europe: Progress report on the import and use of sustainable palm oil in Europe. Zoetermeer, the Netherlands: European Sustainable Palm Oil (ESPO) secretariat. Retrieved from http://www.mvo.nl/media/making_sustainable_palm_oil_the_norm_in_europe__progress_report_2017.pdf on February 22, 2018.

EU REDD Facility (2016). Deforestation-free commodity trade - Scaling-up implementation with jurisdictions. Barcelona, Spain: EU REDD Facility. Retrieved from http://www.euredd.efi.int/publications/deforestation-free-commodity-trade on October 11, 2017.

European Commission (2013). The impact of EU consumption on deforestation. Technical Report 2013-063. Brussels: European Commission. Retrieved from http://ec.europa.eu/environment/forests/pdf/1.\%20Report\%20analysis\%20of\%20impact.pdf on October 12, 2017.

European Commission (2019a). Communication from the Commission to the European Parliament, the Council, the European Economic and Social Committee and the Committee of the Regions: Stepping up EU action to protect and restore the world's forests. Brussels: European Commission. Retrieved from https://ec.europa.eu/info/sites/info/files/communication-euaction-protect-restore-forests_en.pdf on July 3, 2020. 
European Commission (2019b). Communication from the Commission to the European Parliament, the Council, the European Economic and Social Committee and the Committee of the Regions: The European Green Deal. Brussels: European Commission. Retrieved from https://eurlex.europa.eu/legal-content/EN/TXT/?qid=1588580774040\&uri=CELEX:52019DC0640 on October 10, 2020.

European Commission (2020a). Commission launches global cooperation platform to fight deforestation. Brussels: European Commission. Retrieved from https://ec.europa.eu/environment/news/commission-launches-global-cooperation-platformfight-deforestation-2020-10-02_de on November 11, 2020.

European Commission (2020b). Farm to Fork Strategy: For a fair, healthy and environmentallyfriendly food system. Brussels: European Commission. Retrieved from https://ec.europa.eu/food/sites/food/files/safety/docs/f2f_action-plan_2020_strategyinfo_en.pdf on October 10, 2020.

European Parliament (2017). European Parliament resolution of 4 April 2017 on palm oil and deforestation of rainforests (2016/2222(INI)). Strasbourg: European Parliament. Retrieved from http://www.europarl.europa.eu/sides/getDoc.do?type=TA\&reference=P8-TA-20170098\&language=EN\&ring=A8-2017-0066 on March 13, 2019.

European Parliament (2018). European Parliament resolution of 17 April 2018 on a European strategy for the promotion of protein crops - encouraging the production of protein and leguminous plants in the European agriculture sector (2017/2116(INI)). Strasbourg: European Parliament. Retrieved from https://www.europarl.europa.eu/doceo/document/TA-8-20180095_EN.html on October 15, 2020.

European Parliament (2020). European Parliament resolution of 22 October 2020 with recommendations to the Commission on an EU legal framework to halt and reverse EU-driven global deforestation (2020/2006(INL)). Brussels: European Parliament. Retrieved from https://www.europarl.europa.eu/doceo/document/TA-9-2020-0285_EN.pdf on October 30, 2020.

European Union (2009). Directive 2009/28/EC of the European Parliament and of the Council of 23 April 2009 on the promotion of the use of energy from renewable sources and amending and subsequently repealing Directives 2001/77/EC and 2003/30/EC. European Union. Retrieved from https://eur-lex.europa.eu/legal-content/DE/ALL/?uri=CELEX\%3A32009L0028 on October 17, 2017.

European Union (2011). Regulation (EU) No 1169/2011 on the provision of food information to consumers. European Union. Retrieved from http://eur-lex.europa.eu/legalcontent/en/ALL/?uri=CELEX:32011R1169 on April 20, 2018.

European Union (2018). Directive (EU) 2018/2001 of the European Parliament and of the Council of 11 December 2018 on the promotion of the use of energy from renewable sources. Retrieved from https://eur-lex.europa.eu/legalcontent/EN/TXT/?uri=uriserv:OJ.L_.2018.328.01.0082.01.ENG\&toc=OJ:L:2018:328:TOC on December 18, 2018.

European Union (2019). Commission delegated regulation (EU) 2019/807 of 13 March 2019: supplementing Directive (EU) 2018/2001 of the European Parliament and of the Council as regards the determination of high indirect land-use change-risk feedstock for which a significant expansion of the production area into land with high carbon stock is observed and 
the certification of low indirect land-use change-risk biofuels, bioliquids and biomass fuels. European Union. Retrieved from https://eur-lex.europa.eu/legalcontent/EN/TXT/PDF/?uri=CELEX:32019R0807\&from=EN on May 5, 2019.

Evans, J. R., \& Mathur, A. (2018). The value of online surveys: A look back and a look ahead. Internet Research, 28(4), 854-887. https://doi.org/10.1108/IntR-03-2018-0089.

FAO (2020a). FAOSTAT: Production quantity of cocoa in 2018. Rome: Food and Agriculture Organization of the United Nations (FAO). Retrieved from http://www.fao.org/faostat/ on November 21, 2020.

FAO (2020b). FAOSTAT: Production quantity of palm oil in 2018. Rome: Food and Agriculture Organization of the United Nations (FAO). Retrieved from http://www.fao.org/faostat/ on June 3, 2020.

FAO (2020c). FAOSTAT: Production quantity of soybeans in 2018. Rome: Food and Agriculture Organization of the United Nations (FAO). Retrieved from http://www.fao.org/faostat/ on September 12, 2020.

FAO (2020d). Global Forest Resources Assessment 2020. Rome: Food and Agriculture Organization of the United Nations (FAO). Retrieved from http://www.fao.org/3/ca9825en/CA9825EN.pdf on September 1, 2020.

FAO \& UNEP (2020). The State of the World's Forests 2020: Forests, Biodiversity and People. Rome: Food and Agriculture Organization of the United Nations (FAO); United Nations Environment Programme (UNEP). Retrieved from https://doi.org/10.4060/ca8642en on August 31,2020 .

FEFAC (2016). FEFAC Soy Sourcing Guidelines. Towards a mainstream transition to responsible soy. Brussels: European Feed Manufacturers' Federation (FEFAC). Retrieved from http://www.fefac.eu/file.pdf?FileID=65744 on January 14, 2018.

Feindt, P. H., \& Oels, A. (2005). Does discourse matter? Discourse analysis in environmental policy making. Journal of Environmental Policy \& Planning, 7(3), 161-173. https://doi.org/10.1080/15239080500339638.

Ferns, G., \& Amaeshi, K. (2017). Struggles at the summits: Discourse coalitions, field boundaries, and the shifting role of business in sustainable development. Business \& Society, 58(8), 15331571. https://doi.org/10.1177/0007650317701884.

Finch, H., \& Lewis, J. (2003). Focus groups. In J. Ritchie \& J. Lewis (Eds.), Qualitative research practice: A guide for social science students and researchers (pp. 170-198). London: SAGE Publications.

Fountain, A., \& Huetz-Adams, F. (2018). Cocoa Barometer 2018. Bonn: VOICE Network; Südwind Institut. Retrieved from http://www.cocoabarometer.org on March 25, 2019.

Franklin, K. K., \& Lowry, C. (2001). Computer-mediated focus group sessions: Naturalistic inquiry in a networked environment. Qualitative Research, 1(2), 169-184. https://doi.org/10.1177/146879410100100204.

Fricker, R.D., Jr. (2008). Sampling methods for web and e-mail surveys. In Fielding, N., Lee, R.M., Blank, G. (Ed.), The SAGE handbook of online research methods (pp. 195-216). London: SAGE Publications.

Fry, J., Sheane, R., Schreiber, W., Royston, S., McGill, J., Barthel, M., Jennings, S., \& Khor, Y. L. (2018). Study on the environmental impact of palm oil consumption and on existing 
sustainability standards. Brussels: Publications Office of the European Union. Retrieved from https://op.europa.eu/en/publication-detail/-/publication/89c7f3d8-2bf3-11e8-b5fe01aa75ed71a1 on March 9, 2020.

Gaiser, T. J. (2008). Online focus groups. In Fielding, N., Lee, R.M., Blank, G. (Ed.), The SAGE handbook of online research methods (pp. 290-306). London: SAGE Publications.

Gallemore, C., \& Jespersen, K. (2019). Offsetting, insetting, or both? Current trends in sustainable palm oil certification. Sustainability, 11(19), Article 5393. https://doi.org/10.3390/su11195393.

Gardner, T. A., Benzie, M., Börner, J., Dawkins, E., Fick, S., Garrett, R. D., Godar, J., Grimard, A., Lake, S., Larsen, R. K., Mardas, N., McDermott, C. L., Meyfroidt, P., Osbeck, M., Persson, M., Sembres, T., Suavet, C., Strassburg, B., Trevisan, A., . . Wolvekamp, P. (2019). Transparency and sustainability in global commodity supply chains. World Development, 121, 163-177. https://doi.org/10.1016/j.worlddev.2018.05.025.

Garrett, R. D., Carlson, K. M., Rueda, X., \& Noojipady, P. (2016). Assessing the potential additionality of certification by the Round table on Responsible Soybeans and the Roundtable on Sustainable Palm Oil. Environmental Research Letters, 11(4), Article 045003. https://doi.org/10.1088/1748-9326/11/4/045003.

Garrett, R. D., Levy, S., Carlson, K. M., Gardner, T. A., Godar, J., Clapp, J., Dauvergne, P., Heilmayr, R., le Polain de Waroux, Y., Ayre, B., Barr, R., Døvre, B., Gibbs, H. K., Hall, S., Lake, S., Milder, J. C., Rausch, L. L., Rivero, R., Rueda, X., . . Villoria, N. (2019). Criteria for effective zero-deforestation commitments. Global Environmental Change, 54, 135-147. https://doi.org/10.1016/j.gloenvcha.2018.11.003.

Gassler, B., \& Spiller, A. (2018). Is it all in the MIX? Consumer preferences for segregated and mass balance certified sustainable palm oil. Journal of Cleaner Production, 195, 21-31. https://doi.org/10.1016/j.jclepro.2018.05.039.

Ge, L., Brewster, C., Spek, J., Smeenk, A., Top, J., van Diepen, F., Klaase, B., Graumans, C., \& Ruyter Wildt, M. de. (2017). Blockchain for agriculture and food: Findings from the pilot study. Wageningen Economic Research Report: 2017-112. Wageningen, the Netherlands: Wageningen Economic Research. https://doi.org/10.18174/426747.

Gibbs, H. K., Munger, J., L'Roe, J., Barreto, P., Pereira, R., Christie, M., Amaral, T., \& Walker, N. F. (2016). Did ranchers and slaughterhouses respond to zero-deforestation agreements in the Brazilian Amazon? Conservation Letters, 9(1), 32-42. https://doi.org/10.1111/conl.12175.

Gibbs, H. K., Rausch, L. L., Munger, J., Schelly, I., Morton, D. C., Noojipady, P., Barreto, P., Micol, L., Walker, N. F., Amazon, B., \& Cerrado, E. (2015). Brazil's Soy Moratorium. Science, 347(6220), 377-378. https://doi.org/10.1126/science.aaa0181.

Gifford, R. (2014). Environmental psychology matters. Annual Review of Psychology, 65, 541-579. https://doi.org/10.1146/annurev-psych-010213-115048.

Glasbergen, P. (2018). Smallholders do not eat certificates. Ecological Economics, 147, 243-252. https://doi.org/10.1016/j.ecolecon.2018.01.023.

Global Forest Watch (2020). Global primary forest loss. Global Forest Watch. Retrieved from https://www.globalforestwatch.org/dashboards/global/ on September 9, 2020.

Godar, J., Suavet, C., Gardner, T. A., Dawkins, E., \& Meyfroidt, P. (2016). Balancing detail and scale in assessing transparency to improve the governance of agricultural commodity supply chains. 
Environmental Research Letters, 11(3), Article 035015. https://doi.org/10.1088/17489326/11/3/035015.

Grant, M. J., \& Booth, A. (2009). A typology of reviews: An analysis of 14 review types and associated methodologies. Health Information and Libraries Journal, 26(2), 91-108. https://doi.org/10.1111/j.1471-1842.2009.00848.x.

Grass, I., Kubitza, C., Krishna, V. V., Corre, M. D., Mußhoff, O., Pütz, P., Drescher, J., Rembold, K., Ariyanti, E. S., Barnes, A. D., Brinkmann, N., Brose, U., Brümmer, B., Buchori, D., Daniel, R., Darras, K. F. A., Faust, H., Fehrmann, L., Hein, J., . . Wollni, M. (2020). Trade-offs between multifunctionality and profit in tropical smallholder landscapes. Nature Communications, 11(1), 1186. https://doi.org/10.1038/s41467-020-15013-5.

Green, J. M. H., Croft, S. A., Durán, A. P., Balmford, A. P., Burgess, N. D., Fick, S., Gardner, T. A., Godar, J., Suavet, C., Virah-Sawmy, M., Young, L. E., \& West, C. D. (2019). Linking global drivers of agricultural trade to on-the-ground impacts on biodiversity. Proceedings of the National Academy of Sciences, 116(46), 23202-23208. https://doi.org/10.1073/pnas.1905618116.

Greenpeace (2006). Eating up the Amazon. Amsterdam, The Netherlands: Greenpeace International. Retrieved from https://www.greenpeace.org/usa/wpcontent/uploads/legacy/Global/usa/report/2010/2/eating-up-the-amazon.pdf on September $12,2020$.

Greenpeace (2010). Have a break? [Video]. YouTube (March 17, 2010). Retrieved from https://www.youtube.com/watch?v=VaJjPRwExO8 on December 18, 2018.

Greenpeace (2018). Rang-tan: the story of dirty palm oil [Video]. Youtube (August 13, 2018). Retrieved from https://www.youtube.com/watch?v=TQQXstNh45g on December 18, 2018.

Grunert, K. G. (2011). Sustainability in the food sector: A consumer behaviour perspective. International Journal on Food System Dynamics, 2(3), 207-218. https://doi.org/10.18461/ijfsd.v2i3.232.

Grunert, K. G., Hieke, S., \& Wills, J. (2014). Sustainability labels on food products: Consumer motivation, understanding and use. Food Policy, 44, 177-189. https://doi.org/10.1016/j.foodpol.2013.12.001.

Hair, J. F., Black, W. C., Babin, B. J., \& Anderson, R. E. (2019). Multivariate data analysis. (8th ed.). Andover, Hampshire, UK: Cengage Learning EMEA.

Hajer, M. A. (1995). The politics of environmental discourse: Ecological modernization and the policy process. Oxford, UK: Oxford University Press.

Hajer, M. A., \& Versteeg, W. (2005). A decade of discourse analysis of environmental politics: Achievements, challenges, perspectives. Journal of Environmental Policy \& Planning, 7(3), 175184. https://doi.org/10.1080/15239080500339646.

Hargita, Y., Hinkes, C., Bick, U., \& Peter, G. (2018). Entwaldungsfreie Agrarrohstoffe - Analyse relevanter Soja-Zertifizierungssysteme für Futtermittel. Thünen Working Paper No. 98. Braunschweig, Germany: Johann Heinrich von Thünen-Institut. Retrieved from https://literatur.thuenen.de/digbib_extern/dn059838.pdf on September 3, 2019.

Hargita, Y., Hinkes, C., Bick, U., \& Peter, G. (2019). Entwaldungsfreie Agrarrohstoffe - Analyse relevanter Soja-Zertifizierungssysteme für Futtermittel. Thünen Working Paper No. 98 (korrigierte Auflage). Braunschweig, Germany: Johann Heinrich von Thünen-Institut. Retrieved from https://literatur.thuenen.de/digbib_extern/dn061690.pdf on September 17, 2020. 
Hartmann, C., Hieke, S., Taper, C., \& Siegrist, M. (2018). European consumer healthiness evaluation of 'free-from' labelled food products. Food Quality and Preference, 68, 377-388. https://doi.org/10.1016/j.foodqual.2017.12.009.

Hauber, A. B., González, J. M., Groothuis-Oudshoorn, C. G. M., Prior, T., Marshall, D. A., Cunningham, C., IJzerman, M. J., \& Bridges, J. F. P. (2016). Statistical methods for the analysis of discrete choice experiments: A report of the ISPOR Conjoint Analysis Good Research Practices Task Force. Value in Health, 19(4), 300-315. https://doi.org/10.1016/j.jval.2016.04.004.

Heilmayr, R., Carlson, K. M., \& Benedict, J. J. (2020). Deforestation spillovers from oil palm sustainability certification. Environmental Research Letters, 15(7), Article 075002. https://doi.org/10.1088/1748-9326/ab7f0c.

Henders, S., \& Ostwald, M. (2014). Accounting methods for international land-related leakage and distant deforestation drivers. Ecological Economics, 99, 21-28. https://doi.org/10.1016/j.ecolecon.2014.01.005.

Henders, S., Persson, U. M., \& Kastner, T. (2015). Trading forests: Land-use change and carbon emissions embodied in production and exports of forest-risk commodities. Environmental Research Letters, 10(12), Article 125012. https://doi.org/10.1088/1748-9326/10/12/125012.

Hensher, D. A., Rose, J. M., \& Greene, W. H. (2015). Applied choice analysis. (2nd ed.). Cambridge, UK: Cambridge University Press.

Henson, S., \& Humphrey, J. (2010). Understanding the complexities of private standards in global agri-food chains as they impact developing countries. The Journal of Development Studies, 46(9), 1628-1646. https://doi.org/10.1080/00220381003706494.

Heron, T., Prado, P., \& West, C. D. (2018). Global value chains and the governance of 'embedded' food commodities: The case of soy. Global Policy, 9(3), 29-37. https://doi.org/10.1111/17585899.12611.

Hinkes, C. (2020). Key aspects to consider when conducting synchronous text-based online focus groups - A research note. International Journal of Social Research Methodology, (in press), 17. https://doi.org/10.1080/13645579.2020.1801277.

Hoffman, S. D., \& Duncan, G. J. (1988). Multinomial and conditional logit discrete-choice models in demography. Demography, 25(3), 415. https://doi.org/10.2307/2061541.

Holt, A. (2010). Using the telephone for narrative interviewing: A research note. Qualitative Research, 10(1), 113-121. https://doi.org/10.1177/1468794109348686.

Hosonuma, N., Herold, M., Sy, V. de, Fries, R. S. de, Brockhaus, M., Verchot, L., Angelsen, A., \& Romijn, E. (2012). An assessment of deforestation and forest degradation drivers in developing countries. Environmental Research Letters, 7(4), Article 044009. https://doi.org/10.1088/17489326/7/4/044009.

Hospes, O. (2014). Marking the success or end of global multi-stakeholder governance? The rise of national sustainability standards in Indonesia and Brazil for palm oil and soy. Agriculture and Human Values, 31(3), 425-437. https://doi.org/10.1007/s10460-014-9511-9.

Howard, G., Roe, B. E., Nisbet, E. C., \& Martin, J. F. (2017). Hypothetical bias mitigation techniques in choice experiments: Do cheap talk and honesty priming effects fade with repeated choices? Journal of the Association of Environmental and Resource Economists, 4(2), 543-573. https://doi.org/10.1086/691593. 
Hsieh, H.-F., \& Shannon, S. E. (2005). Three approaches to qualitative content analysis. Qualitative Health Research, 15(9), 1277-1288. https://doi.org/10.1177/1049732305276687.

IDH (2020a). European Soy Monitor: Insights on European responsible and deforestation-free soy consumption in 2018. Utrecht, The Netherlands: IDH. Retrieved from https://www.idhsustainabletrade.com/uploaded/2020/05/IDH-European-Soy-Monitor-v2.pdf on September 13, 2020.

IDH (2020b). The urgency of action to tackle tropical deforestation: Protecting forests and fostering sustainable agriculture. Utrecht, The Netherlands: IDH. Retrieved from https://www.idhsustainabletrade.com/publication/the-urgency-of-action-to-tackle-tropicaldeforestation/ on February 6, 2020.

IDH \& IUCN NL (2019). European Soy Monitor: Insights on the European supply chain and the use of responsible and deforestation-free soy in 2017. Utrecht/Amsterdam, The Netherlands: IDH \& IUCN NL. Retrieved from https://www.idhsustainabletrade.com/uploaded/2019/04/EuropeanSoy-Monitor.pdf on September 3, 2019.

ITC (2019). FEFAC Sourcing Guidelines Tool. Geneva, Switzerland: International Trade Centre (ITC). Retrieved from http://www.standardsmap.org/fefac/ on September 9, 2019.

ITC (2020). ITC Sustainability Map. Geneva, Switzerland: International Trade Centre (ITC). Retrieved from https://sustainabilitymap.org/standards on October 12, 2020.

Janßen, D., \& Langen, N. (2017). The bunch of sustainability labels - Do consumers differentiate? Journal of Cleaner Production, 143, 1233-1245. https://doi.org/10.1016/j.jclepro.2016.11.171.

Jesson, J. K., Matheson, L., \& Lacey, F. M. (2011). Doing your literature review: Traditional and systematic techniques. London: SAGE Publications.

Johnson, R. F., Lancsar, E., Marshall, D. A., Kilambi, V., Mühlbacher, A., Regier, D. A., Bresnahan, B. W., Kanninen, B., \& Bridges, J. F. P. (2013). Constructing experimental designs for discrete-choice experiments: Report of the ISPOR Conjoint Analysis Experimental Design Good Research Practices Task Force. Value in Health, 16(1), 3-13. https://doi.org/10.1016/j.jval.2012.08.2223.

Johnson, R. B., Onwuegbuzie, A. J., \& Turner, L. A. (2007). Toward a definition of mixed methods research. Journal of Mixed Methods Research, 1(2), 112-133. https://doi.org/10.1177/1558689806298224.

Jong, H. N. (2019). RSPO questions effectiveness of Indonesian palm plantation moratorium. Mongabay. Retrieved from https://news.mongabay.com/2019/11/rspo-indonesia-palm-oilplantations-moratorium/ on October 10, 2020.

Jopke, P., \& Schoneveld, G. C. (2018). Corporate commitments to zero deforestation: An evaluation of externality problems and implementation gaps. Occasional paper No. 181. Bogor, Indonesia: Center for International Forestry Research (CIFOR). Retrieved from http://www.cifor.org/publications/pdf_files/OccPapers/OP-181.pdf on September 11, 2019.

Kaiser, H. F., \& Rice, J. (1974). Little Jiffy, Mark IV. Educational and Psychological Measurement, 34(1), 111-117. https://doi.org/10.1177/001316447403400115.

Kamilaris, A., Fonts, A., \& Prenafeta-Boldú, F. X. (2019). The rise of blockchain technology in agriculture and food supply chains. Trends in Food Science \& Technology, 91, 640-652. https://doi.org/10.1016/j.tifs.2019.07.034. 
Kastens, J. H., Brown, J. C., Coutinho, A. C., Bishop, C. R., \& Esquerdo, J. C. D. (2017). Soy moratorium impacts on soybean and deforestation dynamics in Mato Grosso, Brazil. PLOS ONE, 12(4), e0176168. https://doi.org/10.1371/journal.pone.0176168.

Keating, D. (2019). EU labels biofuel from palm oil as unsustainable, bans subsidies. Forbes. Retrieved from https://www.forbes.com/sites/davekeating/2019/03/14/eu-labels-biofuelfrom-palm-oil-as-unsustainable-bans-subsidies/ on July 5, 2019.

Kehoe, L., dos Reis, T. N., Meyfroidt, P., Bager, S., Seppelt, R., Kuemmerle, T., Berenguer, E., Clark, M., Davis, K. F., Ermgassen, E. K. zu, Farrell, K. N., Friis, C., Haberl, H., Kastner, T., Murtough, K. L., Persson, U. M., Romero-Muñoz, A., O'Connell, C., Schäfer, V. V., . . . Kiesecker, J. (2020). Inclusion, transparency, and enforcement: How the EU-Mercosur trade agreement fails the sustainability test. One Earth, 3(3), 268-272. https://doi.org/10.1016/j.oneear.2020.08.013.

Koh, L. P., \& Lee, T. M. (2012). Sensible consumerism for environmental sustainability. Biological Conservation, 151(1), 3-6. https://doi.org/10.1016/j.biocon.2011.10.029.

Komives, K., \& Jackson, A. (2014). Introduction to voluntary sustainability standard systems. In C. Schmitz-Hoffmann, M. Schmidt, B. Hansmann, \& D. Palekhov (Eds.), Voluntary standard systems: A contribution to sustainable development (pp. 3-19). Berlin: Springer-Verlag.

Kuckartz, U. (2014). Mixed Methods: Methologie, Forschungsdesigns und Analyseverfahren. Wiesbaden, Germany: Springer Fachmedien.

Kuckartz, U. (2016). Qualitative Inhaltsanalyse: Methoden, Praxis, Computerunterstützung. (3rd ed.). Grundlagentexte Methoden. Weinheim, Germany: Beltz Juventa.

Kusumaningtyas, R., \& van Gelder, J. W. (2019). Setting the bar for deforestation-free soy in Europe: A benchmark to assess the suitability of voluntary standard systems. Amsterdam, The Netherlands: Profundo. Retrieved from https://profundo.nl/download/iucn1906 on September 3, 2019.

Lambin, E. F., Gibbs, H. K., Heilmayr, R., Carlson, K. M., Fleck, L. C., Garrett, R. D., le Polain de Waroux, Y., McDermott, C. L., McLaughlin, D., Newton, P., Nolte, C., Pacheco, P., Rausch, L. L., Streck, C., Thorlakson, T., \& Walker, N. F. (2018). The role of supply-chain initiatives in reducing deforestation. Nature Climate Change, 8(2), 109-116. https://doi.org/10.1038/s41558-0170061-1.

Lambin, E. F., Meyfroidt, P., Rueda, X., Blackman, A., Börner, J., Cerutti, P. O., Dietsch, T., Jungmann, L., Lamarque, P., Lister, J., Walker, N. F., \& Wunder, S. (2014). Effectiveness and synergies of policy instruments for land use governance in tropical regions. Global Environmental Change, 28, 129-140. https://doi.org/10.1016/j.gloenvcha.2014.06.007.

Lambin, E. F., \& Thorlakson, T. (2018). Sustainability standards: Interactions between private actors, civil society, and governments. Annual Review of Environment and Resources, 43(1), 369-393. https://doi.org/10.1146/annurev-environ-102017-025931.

Lamnek, S. (2010). Qualitative Sozialforschung. (5th ed.). Weinheim, Germany: Beltz Verlag. Lancaster, K. J. (1966). A new approach to consumer theory. Journal of Political Economy, 74(2), 132-157. https://doi.org/10.1086/259131.

Lange, F., \& Coremans, L. (2020). The role of consumer knowledge in reducing the demand for palm oil. Environmental Conservation, 47(2), 84-88. https://doi.org/10.1017/\$0376892920000053. 
Larsen, R. K., Osbeck, M., Dawkins, E., Tuhkanen, H., Nguyen, H., Nugroho, A., Gardner, T. A., Zulfahm, \& Wolvekamp, P. (2018). Hybrid governance in agricultural commodity chains: Insights from implementation of 'No Deforestation, No Peat, No Exploitation' (NDPE) policies in the oil palm industry. Journal of Cleaner Production, 183, 544-554. https://doi.org/10.1016/j.jclepro.2018.02.125.

Lawrence, D., \& Vandecar, K. (2015). Effects of tropical deforestation on climate and agriculture. Nature Climate Change, 5(1), 27-36. https://doi.org/10.1038/nclimate2430.

le Polain de Waroux, Y., Garrett, R. D., Graesser, J., Nolte, C., White, C., \& Lambin, E. F. (2019). The restructuring of South American soy and beef production and trade under changing environmental regulations. World Development, 121, 188-202. https://doi.org/10.1016/j.worlddev.2017.05.034.

Lenzner, T., Neuert, C., \& Otto, W. (2016). Cognitive pretesting. GESIS Survey Guidelines. Mannheim, Germany: GESIS - Leibniz Institute for the Social Sciences. https://doi.org/10.15465/gesis-sg_en_010.

Lernoud, J., Potts, J., Sampson, G., Schlatter, B., Huppé, G., Voora, V., Willer, H., Wozniak, J., \& Dang, D. (2018). The state of sustainable markets 2018: Statistics and emerging trends. Geneva, Switzerland. Retrieved from http://www.intracen.org/publication/The-State-ofSustainable-Markets-2018-Statistics-and-Emerging-Trends/ on May 27, 2019.

Lobe, B. (2017). Best practices for synchronous online focus groups. In R. S. Barbour \& D. L. Morgan (Eds.), A new era in focus group research (Vol. 33, pp. 227-250). London: Palgrave Macmillan UK. https://doi.org/10.1057/978-1-137-58614-8_11.

Louviere, J. J., Hensher, D. A., Swait, J. D., \& Adamowicz, W. L. (2000). Stated choice methods: Analysis and applications. Cambridge, UK: Cambridge University Press.

Luce, R. D. (1959). Individual choice behavior: A theoretical analysis. New York: Wiley.

Lyons-White, J., \& Knight, A. T. (2018). Palm oil supply chain complexity impedes implementation of corporate no-deforestation commitments. Global Environmental Change, 50, 303-313. https://doi.org/10.1016/j.gloenvcha.2018.04.012.

Macdiarmid, J. I., Douglas, F., \& Campbell, J. (2016). Eating like there's no tomorrow: Public awareness of the environmental impact of food and reluctance to eat less meat as part of a sustainable diet. Appetite, 96, 487-493. https://doi.org/10.1016/j.appet.2015.10.011.

Macedo, M. N., DeFries, R. S., Morton, D. C., Stickler, C. M., Galford, G. L., \& Shimabukuro, Y. E. (2012). Decoupling of deforestation and soy production in the southern Amazon during the late 2000s. Proceedings of the National Academy of Sciences, 109(4), 1341-1346. https://doi.org/10.1073/pnas.1111374109.

Mayring, P. (2000). Qualitative content analysis. Forum: Qualitative Social Research, 1(2), Article 20. https://doi.org/10.17169/fqs-1.2.1089.

McFadden, D. (1974). Conditional logit analysis of qualitative choice behavior. In P. Zarembka (Ed.), Frontiers in econometrics: Economic theory and mathematical economics (pp. 105-142). New York: Academic Press.

McFadden, D. (1986). The choice theory approach to market research. Marketing Science, 5(4), 275-297. https://doi.org/10.1287/mksc.5.4.275. 
McFadden, D., \& Train, K. (2000). Mixed MNL models for discrete response. Journal of Applied Econometrics, 15(5), 447-470. https://doi.org/10.1002/1099-1255(200009/10)15:5<447::AIDJAE570>3.0.CO;2-1.

Mclnnes, A. (2017). A comparison of leading palm oil certification standards. Moreton-in-Marsh, England: Forest Peoples Programme. Retrieved from https://www.forestpeoples.org/en/responsible-finance-palm-oilrspo/report/2017/comparison-leading-palm-oil-certification-standards on November 14, 2018.

Meyer, C., \& Miller, D. (2015). Zero deforestation zones: The case for linking deforestation-free supply chain initiatives and jurisdictional REDD+. Journal of Sustainable Forestry, 34(6-7), 559580. https://doi.org/10.1080/10549811.2015.1036886.

Meyfroidt, P., Carlson, K. M., Fagan, M. E., Gutiérrez-Vélez, V. H., Macedo, M. N., Curran, L. M., DeFries, R. S., Dyer, G. A., Gibbs, H. K., Lambin, E. F., Morton, D. C., \& Robiglio, V. (2014). Multiple pathways of commodity crop expansion in tropical forest landscapes. Environmental Research Letters, 9(7), Article 074012. https://doi.org/10.1088/1748-9326/9/7/074012.

Meyfroidt, P., \& Lambin, E. F. (2011). Global forest transition: Prospects for an end to deforestation. Annual Review of Environment and Resources, 36(1), 343-371. https://doi.org/10.1146/annurev-environ-090710-143732.

Meyfroidt, P., Lambin, E. F., Erb, K.-H., \& Hertel, T. W. (2013). Globalization of land use: Distant drivers of land change and geographic displacement of land use. Current Opinion in Environmental Sustainability, 5(5), 438-444. https://doi.org/10.1016/j.cosust.2013.04.003.

Meyfroidt, P., Rudel, T. K., \& Lambin, E. F. (2010). Forest transitions, trade, and the global displacement of land use. Proceedings of the National Academy of Sciences, 107(49), 2091720922. https://doi.org/10.1073/pnas.1014773107.

Mielke, T. (2018). World markets for vegetable oils and animal fats: Dynamics of global production, trade flows, consumption and prices. In M. Kaltschmitt \& U. Neuling (Eds.), Biokerosene: Status and prospects (pp. 147-188). Berlin: Springer.

Mitchell, A. D., \& Merriman, D. (2020). Indonesia's WTO challenge to the European Union's Renewable Energy Directive: Palm oil \& indirect land-use change. SSRN Electronic Journal. Advance online publication. https://doi.org/10.2139/ssrn.3665463.

Mol, A. P., \& Oosterveer, P. (2015). Certification of markets, markets of certificates: Tracing sustainability in global agro-food value chains. Sustainability, 7(9), 12258-12278. https://doi.org/10.3390/su70912258.

Moreno-Peñaranda, R., Gasparatos, A., Stromberg, P., Suwa, A., Pandyaswargo, A. H., \& Puppim de Oliveira, J. A. (2015). Sustainable production and consumption of palm oil in Indonesia: What can stakeholder perceptions offer to the debate? Sustainable Production and Consumption, 4, 16-35. https://doi.org/10.1016/j.spc.2015.10.002.

Morgans, C. L., Meijaard, E., Santika, T., Law, E., Budiharta, S., Ancrenaz, M., \& Wilson, K. A. (2018). Evaluating the effectiveness of palm oil certification in delivering multiple sustainability objectives. Environmental Research Letters, 13(6), Article 064032. https://doi.org/10.1088/1748-9326/aac6f4.

Mori, A. S., Lertzman, K. P., \& Gustafsson, L. (2017). Biodiversity and ecosystem services in forest ecosystems: A research agenda for applied forest ecology. Journal of Applied Ecology, 54(1), 12-27. https://doi.org/10.1111/1365-2664.12669. 
Morse, J. M. (1991). Approaches to qualitative-quantitative methodological triangulation. Nursing Research, 40(2), 120-123. https://doi.org/10.1097/00006199-199103000-00014.

Munkin, M. K., \& Trivedi, P. K. (1999). Simulated maximum likelihood estimation of multivariate mixed-Poisson regression models, with application. The Econometrics Journal, 2(1), 29-48. https://doi.org/10.1111/1368-423X.00019.

Neeff, T., \& Linhares-Juvenal, T. (2017). Zero deforestation initiatives and their impacts on commodity supply chains: Discussion paper prepared for the 57th Session of the FAO Advisory Committee on Sustainable Forest-based Industries. Rome: Food and Agriculture Organization of the United Nations (FAO). Retrieved from http://www.fao.org/3/a-i6857e.pdf on November 1, 2018.

Nelson, P. (1970). Information and consumer behavior. Journal of Political Economy, 78(2), 311329. https://doi.org/10.1086/259630.

Nelson, P. (1974). Advertising as information. Journal of Political Economy, 82(4), 729-754. https://doi.org/10.1086/260231.

Nepstad, D. C., McGrath, D., Stickler, C. M., Alencar, A., Azevedo, A. A., Swette, B., Bezerra, T., DiGiano, M., Shimada, J., Seroa da Motta, R., Armijo, E., Castello, L., Brando, P., Hansen, M. C., McGrath-Horn, M., Carvalho, O., \& Hess, L. (2014). Slowing Amazon deforestation through public policy and interventions in beef and soy supply chains. Science, 344(6188), 1118-1123. https://doi.org/10.1126/science.1248525.

Nepstad, L. S., Gerber, J. S., Hill, J. D., Dias, L. C. P., Costa, M. H., \& West, P. C. (2019). Pathways for recent Cerrado soybean expansion: Extending the soy moratorium and implementing integrated crop livestock systems with soybeans. Environmental Research Letters, 14(4), Article 044029. https://doi.org/10.1088/1748-9326/aafb85.

NYDF (2014). New York Declaration on Forests: Declaration and Action Agenda. Climate Summit 2014. New York City, USA: United Nations Development Programme (UNDP). Retrieved from http://www.undp.org/content/dam/undp/library/Environment\%20and\%20Energy/Forests/Ne w\%20York\%20Declaration\%20on\%20Forests_DAA.pdf on December 18, 2018.

NYDF Assessment Partners (2019). Protecting and restoring forests: A story of large commitments yet limited progress: New York Declaration on Forests five-year assessment report. Amsterdam, The Netherlands: Climate Focus. Retrieved from https://www.climatefocus.com/sites/default/files/2019NYDFReport.pdf on September 1, 2020.

Oil World. (2019). Oil World Annual 2019. Hamburg, Germany: ISTA Mielke GmbH.

Okereke, C., \& Stacewicz, I. (2018). Stakeholder perceptions of the environmental effectiveness of multi-stakeholder initiatives: Evidence from the palm oil, soy, cotton, and timber programs. Society \& Natural Resources, 31(11), 1302-1318. https://doi.org/10.1080/08941920.2018.1482037.

Oosterveer, P. (2020). Sustainability of palm oil and its acceptance in the EU. Journal of Oil Palm Research, 32(3), 365-376. https://doi.org/10.21894/jopr.2020.0039.

Orsato, R. J., Clegg, S. R., \& Falcão, H. (2013). The political ecology of palm oil production. Journal of Change Management, 13(4), 444-459. https://doi.org/10.1080/14697017.2013.851916. 
Ostfeld, R., Howarth, D., Reiner, D., \& Krasny, P. (2019). Peeling back the label - exploring sustainable palm oil ecolabelling and consumption in the United Kingdom. Environmental Research Letters, 14(1), Article 014001. https://doi.org/10.1088/1748-9326/aaf0e4.

Pacifico, D., \& Yoo, H. I. (2013). Lclogit: A Stata command for fitting latent-class conditional logit models via the expectation-maximization algorithm. The Stata Journal, 13(3), 625-639. https://doi.org/10.1177/1536867X1301300312.

Palinkas, L. A., Horwitz, S. M., Green, C. A., Wisdom, J. P., Duan, N., \& Hoagwood, K. (2015). Purposeful sampling for qualitative data collection and analysis in mixed method implementation research. Administration and Policy in Mental Health and Mental Health Services Research, 42(5), 533-544. https://doi.org/10.1007/s10488-013-0528-y.

Pendrill, F., Persson, U. M., Godar, J., \& Kastner, T. (2019a). Deforestation displaced: Trade in forest-risk commodities and the prospects for a global forest transition. Environmental Research Letters, 14(5), Article 055003. https://doi.org/10.1088/1748-9326/ab0d41.

Pendrill, F., Persson, U. M., Godar, J., Kastner, T., Moran, D., Schmidt, S., \& Wood, R. (2019b). Agricultural and forestry trade drives large share of tropical deforestation emissions. Global Environmental Change, 56, 1-10. https://doi.org/10.1016/j.gloenvcha.2019.03.002.

Pirard, R., Fishman, A., Gnych, S., Obidzinski, K., \& Pacheco, P. (2015). Deforestation-free commitments: The challenge of implementation - An application to Indonesia. Working Paper No. 181. Bogor, Indonesia: Center for International Forestry Research (CIFOR). https://doi.org/10.17528/cifor/005572.

Poore, J., \& Nemecek, T. (2018). Reducing food's environmental impacts through producers and consumers. Science, 360(6392), 987-992. https://doi.org/10.1126/science.aaq0216.

Qaim, M., Sibhatu, K. T., Siregar, H., \& Grass, I. (2020). Environmental, economic, and social consequences of the oil palm boom. Annual Review of Resource Economics, 12(1). https://doi.org/10.1146/annurev-resource-110119-024922.

Rajão, R., Soares-Filho, B. S., Nunes, F., Börner, J., Machado, L., Assis, D., Oliveira, A., Pinto, L., Ribeiro, V., Rausch, L. L., Gibbs, H. K., \& Figueira, D. (2020). The rotten apples of Brazil's agribusiness. Science, 369(6501), 246-248. https://doi.org/10.1126/science.aba6646.

Reid, D. J., \& Reid, F. J. M. (2005). Online focus groups: An in-depth comparison of computermediated and conventional focus group discussions. International Journal of Market Research, 47(2), 131-162. https://doi.org/10.1177/147078530504700204.

Reuters (2018). European move to ban palm oil from biofuels is 'crop apartheid' - Malaysia. Kuala Lumpur: Reuters. Retrieved from https://www.reuters.com/article/malaysia-palmoileu/european-move-to-ban-palm-oil-from-biofuels-is-crop-apartheid-malaysia-idUSL3N1PD1NJ on December 20, 2018.

REWE Group (2019). REWE Group Nachhaltigkeitsbericht 2018. Cologne, Germany: REWE Group. Retrieved from https://rewe-group-nachhaltigkeitsbericht.de/2018/gri-bericht/produkte/gri204-fp1-fokusrohstoffe\%E2\%80\%93food/index.html on November 9, 2020.

Richards, P. D., Walker, R. T., \& Arima, E. Y. (2014). Spatially complex land change: The indirect effect of Brazil's agricultural sector on land use in Amazonia. Global Environmental Change, 29, 1-9. https://doi.org/10.1016/j.gloenvcha.2014.06.011. 
Richardson, T. (1996). Foucauldian discourse: Power and truth in urban and regional policy making. European Planning Studies, 4(3), 279-292.

https://doi.org/10.1080/09654319608720346.

Riganelli, C., \& Marchini, A. (2017). Governance and quality disclosure: The palm oil issue. British Food Journal, 119(8), 1718-1731. https://doi.org/10.1108/BFJ-11-2016-0566.

Rival, A., \& Levang, P. (2014). Palms of controversies: Oil palm and development challenges. Bogor, Indonesia: Center for International Forestry Research (CIFOR). Retrieved from https://www.cifor.org/library/4860/ on November 6, 2018.

RSPO (2018). Principles and criteria for the production of sustainable palm oil 2018. Kuala Lumpur: Roundtable on Sustainable Palm Oil (RSPO). Retrieved from https://rspo.org/principles-andcriteria-review on May 29, 2020.

RSPO (2019). RSPO rules on market communications and claims: Approved by the Board of Governors November 2016. Revised in January 2019. Kuala Lumpur: Roundtable on Sustainable Palm Oil (RSPO). Retrieved from http://www.rspo.org/publications/download/663b24e7a3900e5 on May 29, 2020.

RSPO (2020a). National commitments. Kuala Lumpur: Roundtable on Sustainable Palm Oil (RSPO). Retrieved from https://www.rspo.org/about/national-commitments on October 28, 2020.

RSPO (2020b). RSPO Impact Report 2019: Reflecting on a decade of growth. Kuala Lumpur: Roundtable on Sustainable Palm Oil (RSPO). Retrieved from https://rspo.org/resources/archive/1324 on October 15, 2020.

RTRS (2017). RTRS Standard for responsible soy production: Version 3.1. Zurich, Switzerland: Round Table on Responsible Soy (RTRS). Retrieved from https://responsiblesoy.org/documentos/rtrs-standard-for-responsible-soy-productionv31?lang=en on October 17, 2020.

Ruysschaert, D., \& Salles, D. (2014). Towards global voluntary standards: Questioning the effectiveness in attaining conservation goals. Ecological Economics, 107, 438-446. https://doi.org/10.1016/j.ecolecon.2014.09.016.

Saadun, N., Lim, E. A. L., Esa, S. M., Ngu, F., Awang, F., Gimin, A., Johari, I. H., Firdaus, M. A., Wagimin, N. I., \& Azhar, B. (2018). Socio-ecological perspectives of engaging smallholders in environmental-friendly palm oil certification schemes. Land Use Policy, 72, 333-340. https://doi.org/10.1016/j.landusepol.2017.12.057.

Salkind, N. (2010). Encyclopedia of research design. Thousand Oaks, California, USA: SAGE Publications. https://doi.org/10.4135/9781412961288.

Sarstedt, M., \& Mooi, E. (2019). A concise guide to market research. Berlin: Springer. https://doi.org/10.1007/978-3-662-56707-4.

Schmitz, C., Kreidenweis, U., Lotze-Campen, H., Popp, A., Krause, M., Dietrich, J. P., \& Müller, C. (2015). Agricultural trade and tropical deforestation: Interactions and related policy options. Regional Environmental Change, 15(8), 1757-1772. https://doi.org/10.1007/s10113-014-07002.

Schneider, S. J., Kerwin, J., Frechtling, J., \& Vivari, B. A. (2002). Characteristics of the discussion in online and face-to-face focus groups. Social Science Computer Review, 20(1), 31-42. https://doi.org/10.1177/089443930202000104. 
Schreier, M. (2014). Varianten qualitativer Inhaltsanalyse: Ein Wegweiser im Dickicht der Begrifflichkeiten. Forum: Qualitative Social Research, 15(1). https://doi.org/10.17169/fqs15.1.2043.

Sharp, L., \& Richardson, T. (2001). Reflections on Foucauldian discourse analysis in planning and environmental policy research. Journal of Environmental Policy \& Planning, 3(3), 193-209. https://doi.org/10.1002/jepp.88.

Sirieix, L., Delanchy, M., Remaud, H., Zepeda, L., \& Gurviez, P. (2013). Consumers' perceptions of individual and combined sustainable food labels: A UK pilot investigation. International Journal of Consumer Studies, 37(2), 143-151. https://doi.org/10.1111/j.1470-6431.2012.01109.x.

Soini, K., \& Birkeland, I. (2014). Exploring the scientific discourse on cultural sustainability. Geoforum, 51, 213-223. https://doi.org/10.1016/j.geoforum.2013.12.001.

Soterroni, A. C., Ramos, F. M., Mosnier, A., Fargione, J., Andrade, P. R., Baumgarten, L., Pirker, J., Obersteiner, M., Kraxner, F., Câmara, G., Carvalho, A. X. Y., \& Polasky, S. (2019). Expanding the Soy Moratorium to Brazil's Cerrado. Science Advances, 5(7), eaav7336. https://doi.org/10.1126/sciadv.aav7336.

Springmann, M., Clark, M., Mason-D'Croz, D., Wiebe, K., Bodirsky, B. L., Lassaletta, L., Vries, W. de, Vermeulen, S. J., Herrero, M., Carlson, K. M., Jonell, M., Troell, M., DeClerck, F., Gordon, L. J., Zurayk, R., Scarborough, P., Rayner, M., Loken, B., Fanzo, J., . . . Willett, W. (2018). Options for keeping the food system within environmental limits. Nature, 562(7728), 519-525. https://doi.org/10.1038/s41586-018-0594-0.

Stewart, D. W., \& Shamdasani, P. (2017). Online focus groups. Journal of Advertising, 46(1), 4860. https://doi.org/10.1080/00913367.2016.1252288.

Stewart, K., \& Williams, M. (2005). Researching online populations: The use of online focus groups for social research. Qualitative Research, 5(4), 395-416. https://doi.org/10.1177/1468794105056916.

Strona, G., Stringer, S. D., Vieilledent, G., Szantoi, Z., Garcia-Ulloa, J., \& A Wich, S. (2018). Small room for compromise between oil palm cultivation and primate conservation in Africa. Proceedings of the National Academy of Sciences, 115(35), 8811-8816. https://doi.org/10.1073/pnas.1804775115.

Sundaraja, C. S., Hine, D. W., \& Lykins, A. (2020). Confronting the palm oil crisis: Identifying behaviours for targeted interventions. Environmental Science \& Policy, 103, 99-106. https://doi.org/10.1016/j.envsci.2019.08.004.

Suroyo, G., \& Nangoy, F. (2019). Indonesia to challenge 'discriminative' EU directive on palm oil. Reuters. Retrieved from https://www.reuters.com/article/us-indonesia-eu-palmoilidUSKCN1PPOVW on July 5, 2019.

Swait, J. D. (1994). A structural equation model of latent segmentation and product choice for cross-sectional revealed preference choice data. Journal of Retailing and Consumer Services, 1(2), 77-89. https://doi.org/10.1016/0969-6989(94)90002-7.

Taheripour, F., Hertel, T. W., \& Ramankutty, N. (2019). Market-mediated responses confound policies to limit deforestation from oil palm expansion in Malaysia and Indonesia. Proceedings of the National Academy of Sciences, 116(38), 19193-19199.

https://doi.org/10.1073/pnas.1903476116. 
Tan, T. (2019). 'Stop palm oil discrimination'. Kuala Lumpur: The Star. Retrieved from https://www.thestar.com.my/news/nation/2019/03/21/stop-palm-oil-discrimination/ on July 5, 2019.

Tavakol, M., \& Dennick, R. (2011). Making sense of Cronbach's alpha. International Journal of Medical Education, 2, 53-55. https://doi.org/10.5116/ijme.4dfb.8dfd.

Tebbe, E., \& von Blanckenburg, K. (2018). Does willingness to pay increase with the number and strictness of sustainability labels? Agricultural Economics, 49(1), 41-53. https://doi.org/10.1111/agec.12394.

Tesco (2020). Sourcing palm oil responsibly. Cheshunt, Hertfordshire, UK: Tesco. Retrieved from https://www.tescoplc.com/sustainability/publications/policies/downloads/palm-oil-policy/ on November 9, 2020.

TFA (2018). Emerging market consumers \& deforestation: Risks and opportunities of growing demand for soft commodities in China \& beyond. Cologny/Geneva, Switzerland: Tropical Forest Alliance (TFA); World Economic Forum. Retrieved from https://www.tropicalforestalliance.org/assets/Uploads/47530_Emergingmarkets_consumers_and_deforestation_report_2018.pdf on November 9, 2020.

Thøgersen, J. (2000). Psychological determinants of paying attention to eco-labels in purchase decisions: Model development and multinational validation. Journal of Consumer Policy, 23(3), 285-313. https://doi.org/10.1023/A:1007122319675.

Thøgersen, J., Haugaard, P., \& Olesen, A. (2010). Consumer responses to ecolabels. European Journal of Marketing, 44(11/12), 1787-1810. https://doi.org/10.1108/03090561011079882.

Tonsor, G. T., \& Shupp, R. S. (2011). Cheap talk scripts and online choice experiments: "Looking beyond the mean". American Journal of Agricultural Economics, 93(4), 1015-1031. https://doi.org/10.1093/ajae/aar036.

Torraco, R. J. (2005). Writing integrative literature reviews: Guidelines and examples. Human Resource Development Review, 4(3), 356-367. https://doi.org/10.1177/1534484305278283.

Torraco, R. J. (2016). Writing integrative literature reviews: Using the past and present to explore the future. Human Resource Development Review, 15(4), 404-428. https://doi.org/10.1177/1534484316671606.

Trase (2020). Trase Yearbook 2020 Executive Summary: The state of forest-risk supply chains. Stockholm: Stockholm Environment Institute (SEI); Global Canopy. Retrieved from https://insights.trase.earth/yearbook/summary/ on September 9, 2020.

Tscharntke, T., Milder, J. C., Schroth, G., Clough, Y., DeClerck, F., Waldron, A., Rice, R., \& Ghazoul, J. (2015). Conserving biodiversity through certification of tropical agroforestry crops at local and landscape scales. Conservation Letters, 8(1), 14-23. https://doi.org/10.1111/conl.12110.

UNFCCC (2015). Paris Agreement. Bonn, Germany: United Nations Framework Convention on Climate Change (UNFCCC) Secretariat. Retrieved from https://unfccc.int/files/essential_background/convention/application/pdf/english_paris_agree ment.pdf on October 9, 2020.

UNGA (2015). Transforming our world: the 2030 Agenda for Sustainable Development. New York: United Nations General Assembly (UNGA). Retrieved from http://www.un.org/ga/search/view_doc.asp?symbol=A/RES/70/1\&Lang=E on October 9, 2020. 
Valin, H., Peters, D., van den Berg, M., Frank, S., Havlík, P., Forsell, N., \& Hamelinck, C. (2015). The land use change impact of biofuels consumed in the EU: Quantification of area and greenhouse gas impacts. Utrecht, The Netherlands: ECOFYS Netherlands B.V. Retrieved from https://ec.europa.eu/energy/sites/ener/files/documents/Final\%20Report_GLOBIOM_publicati on.pdf on February 22, 2018.

van der Ven, H., Rothacker, C., \& Cashore, B. (2018). Do eco-labels prevent deforestation? Lessons from non-state market driven governance in the soy, palm oil, and cocoa sectors. Global Environmental Change, 52, 141-151. https://doi.org/10.1016/j.gloenvcha.2018.07.002.

Vanderhaegen, K., Akoyi, K. T., Dekoninck, W., Jocqué, R., Muys, B., Verbist, B., \& Maertens, M. (2018). Do private coffee standards 'walk the talk' in improving socio-economic and environmental sustainability? Global Environmental Change, 51, 1-9. https://doi.org/10.1016/j.gloenvcha.2018.04.014.

Vehovar, V., \& Lozar Manfreda, K. (2008). Overview: Online Surveys. In Fielding, N., Lee, R.M., Blank, G. (Ed.), The SAGE handbook of online research methods (pp. 177-194). London: SAGE Publications.

Vermeir, l., \& Verbeke, W. (2006). Sustainable food consumption: Exploring the consumer "attitude - behavioral intention" gap. Journal of Agricultural and Environmental Ethics, 19(2), 169-194. https://doi.org/10.1007/s10806-005-5485-3.

Vermeir, I., \& Verbeke, W. (2008). Sustainable food consumption among young adults in Belgium: Theory of planned behaviour and the role of confidence and values. Ecological Economics, 64(3), 542-553. https://doi.org/10.1016/j.ecolecon.2007.03.007.

Verneau, F., La Barbera, F., Amato, M., \& Sodano, V. (2019). Consumers' concern towards palm oil consumption. British Food Journal, 121(9), 1982-1997. https://doi.org/10.1108/BFJ-10-20180659.

Vijay, V., Pimm, S. L., Jenkins, C. N., \& Smith, S. J. (2016). The impacts of oil palm on recent deforestation and biodiversity loss. PLOS ONE, 11(7), e0159668. https://doi.org/10.1371/journal.pone.0159668.

Waldman, K. B., \& Kerr, J. M. (2014). Limitations of certification and supply chain standards for environmental protection in commodity crop production. Annual Review of Resource Economics, 6(1), 429-449. https://doi.org/10.1146/annurev-resource-100913-012432.

Webster, E. (2020). Transnational legal processes, the EU and RED II: Strengthening the global governance of bioenergy. Review of European, Comparative \& International Environmental Law, 29(1), 86-94. https://doi.org/10.1111/reel.12315.

Wesseler, J. (2014). Biotechnologies and agrifood strategies: Opportunities, threats and economic implications. Bio-based and Applied Economics, 3(3), 187-204. https://doi.org/10.13128/BAE15017.

Widaman, K. F. (1993). Common factor analysis versus principal component analysis: Differential bias in representing model parameters? Multivariate Behavioral Research, 28(3), 263-311. https://doi.org/10.1207/s15327906mbr2803_1.

Winters, P., Kuo, H.-W., Niljinda, C., Chen, B., Alves-Pinto, H. N., Ongun, M., Daryanto, S., \& Newton, P. (2015). Voluntary certification design choices influence producer participation, stakeholder acceptance, and environmental sustainability in commodity agriculture sectors in tropical forest landscapes. Journal of Sustainable Forestry, 34(6-7), 581-604. https://doi.org/10.1080/10549811.2015.1017884. 
Woodyatt, C. R., Finneran, C. A., \& Stephenson, R. (2016). In-person versus online focus group discussions: A comparative analysis of data quality. Qualitative Health Research, 26(6), 741749. https://doi.org/10.1177/1049732316631510.

WWF (2016). Auf der Ölspur: Berechnungen zu einer palmölfreieren Welt. Berlin: World Wide Fund for Nature (WWF) Germany. Retrieved from http://www.wwf.de/fileadmin/fmwwf/Publikationen-PDF/WWF-Studie_Auf_der_OElspur.pdf on November 4, 2017.

WWF (2018). Sixty-one meat and soybean purchasing companies in Brazil have committed to combating deforestation in the Cerrado. Brasília: World Wide Fund for Nature (WWF) Brazil. Retrieved from https://www.wwf.org.br/informacoes/english/?65083/Sixty-one-companiesin-Brazil-have-committed-to-combating-deforestation-in-the-Cerrado on September 15, 2018.

WWF (2020). Palm oil buyers scorecard: Measuring the progress of palm oil buyers. Gland, Switzerland: World Wide Fund For Nature (WWF). Retrieved from https://palmoilscorecard.panda.org/file/WWF_Palm_Oil_Scorecard_2020.pdf on March 7, 2020.

Yoo, H. I. (2019). Iclogit2: An enhanced module to estimate latent class conditional logit models. SSRN Electronic Journal. Advance online publication. https://doi.org/10.2139/ssrn.3484429.

Zepeda, L., Sirieix, L., Pizarro, A., Corderre, F., \& Rodier, F. (2013). A conceptual framework for analyzing consumers' food label preferences: An exploratory study of sustainability labels in France, Quebec, Spain and the US. International Journal of Consumer Studies, 37(6), 605-616. https://doi.org/10.1111/ijcs.12041.

zu Ermgassen, E. K. H. J., Ayre, B., Godar, J., Bastos Lima, M. G., Bauch, S., Garrett, R. D., Green, J. M. H., Lathuillière, M. J., Löfgren, P., MacFarquhar, C., Meyfroidt, P., Suavet, C., West, C. D., \& Gardner, T. A. (2020). Using supply chain data to monitor zero deforestation commitments: An assessment of progress in the Brazilian soy sector. Environmental Research Letters, 15(3), Article 035003. https://doi.org/10.1088/1748-9326/ab6497. 


\section{Appendices}

\section{Appendix A: Further publications}

\section{Peer-reviewed scientific articles}

Hinkes, C. (2020). Key aspects to consider when conducting synchronous text-based online focus groups - A research note. International Journal of Social Research Methodology, (in press), 1-7. https://doi.org/10.1080/13645579.2020.1801277.

Hinkes, C., Schulze-Ehlers, B. (2018). Consumer attitudes and preferences toward pangasius and tilapia: The role of sustainability certification and the country of origin. Appetite, 127, 171-181. https://doi.org/10.1016/j.appet.2018.05.001.

\section{Peer-reviewed poster contributions}

Hinkes, C., Christoph-Schulz, I. (2020). Verbrauchereinstellungen zu Palmöl - Erkenntnisse aus Fokusgruppen in Deutschland. Schriften der Gesellschaft für Wirtschafts- und Sozialwissenschaften des Landbaues e.V., 55, 431-432. https://www.gewisola.de/files/GeWiSoLa_Bd55_2020.pdf.

Hinkes, C., Peter, G. (2019). Chain-of-custody certification for sustainable soy - Ensuring traceability along deforestation-free supply chains? Schriften der Gesellschaft für Wirtschaftsund Sozialwissenschaften des Landbaues e.V., 54, 351-353. https://www.gewisola.de/files/Schriften_der_GEWISOLA_Bd_54_2019.pdf.

\section{Reports}

Hargita, Y., Hinkes, C., Bick, U., Peter, G. (2019). Entwaldungsfreie Agrarrohstoffe - Analyse relevanter Soja-Zertifizierungssysteme für Futtermittel. Thünen Working Paper No. 98 (korrigierte Auflage). Braunschweig, Germany: Johann Heinrich von Thünen-Institut. https://literatur.thuenen.de/digbib_extern/dn061690.pdf.

\section{Book chapters}

Colozza, D., Pilling, D., Dudley, N., Hinkes, C. (2019). Chapter 2.5 - Livelihoods. In: Belanger, J., Pilling, D. (eds.) (2019). The State of the World's Biodiversity for Food and Agriculture, 41-48. Rome: Food and Agriculture Organization of the United Nations (FAO). http://www.fao.org/3/CA3129EN/CA3129EN.pdf.

Hinkes, C., Dudley, N. (2019). Chapter 8.5 - Research. In: Belanger, J., Pilling, D. (eds.) (2019). The State of the World's Biodiversity for Food and Agriculture, 410-412. Rome: Food and Agriculture Organization of the United Nations (FAO). http://www.fao.org/3/CA3129EN/CA3129EN.pdf.

Hinkes, C., Dudley, N., Garrett, L., Pilling, D. (2019). Chapter 8.6 - Valuation. In: Belanger, J., Pilling, D. (eds.) (2019). The State of the World's Biodiversity for Food and Agriculture, 412419. Rome: Food and Agriculture Organization of the United Nations (FAO). http://www.fao.org/3/CA3129EN/CA3129EN.pdf. 


\section{Cordula Hinkes}

born in Wiesbaden, Germany

\section{Education}

04/2018-03/2021

Doctoral studies for Agricultural Sciences in Göttingen (PAG), Graduate School Forest and Agricultural Sciences (GFA), Georg-August-Universität Göttingen Doctoral certificate program in Agricultural Economics Dissertation: "Sustainability certification for deforestation-free supply chains: the cases of palm oil and soy"

Master of Science in "Sustainability, Society and the Environment", Kiel University Thesis: "The market potential of pangasius and tilapia from Bangladesh in Germany - Exploring the role of sustainability in seafood consumption decisions"

09/2010-02/2011

Korea University Business School, Seoul semester abroad during Bachelor studies

$08 / 2008-06 / 2011$

Bachelor of Science in Business Administration, University of Mannheim

08/1999-06/2008

Abitur (higher education entrance qualification), Leibnizschule Wiesbaden

\section{Work experience}

$10 / 2017-03 / 2021$

$07 / 2016-09 / 2017$

Researcher at Johann Heinrich von Thuenen Institute, Institute of Market Analysis, Braunschweig

Development cooperation trainee at Deutsche Gesesellschaft für Internationale Zusammenarbeit (GIZ) GmbH in Bangkok, with secondments at the Food and Agriculture Organization of the United Nations (FAO), Rome, and the German Federal Ministry for Economic Cooperation and Development (BMZ), Berlin

$03 / 2015-08 / 2015$

$10 / 2013-02 / 2015$ \& $10 / 2015-05 / 2016$ Internship in the area of social and environmental standards for agricultural products at GIZ GmbH, Eschborn

08/2012-09/2013

Graduate Assistant (part-time) at the IT helpdesk of the computing center at Kiel University

Associate / Operational Risk \& Process Management Specialist at Commerzbank AG, Frankfurt am Main

$08 / 2011-07 / 2012$

$11 / 2009-07 / 2011$ Graduate trainee in the investment ban

Working student (part-time) at Commerzbank AG headquarters, Frankfurt am Main

06/2009-08/2009 Internship at Commerzbank AG headquarters, Frankfurt am Main 


\section{Appendix C: Acknowledgements}

Mein Dank gebührt an erster Stelle meinem Doktorvater PD Dr. Martin Banse für die motivierende Betreuung meiner Promotion, die Unterstützung meiner Forschungsideen, und die Ermöglichung der Teilnahme an Blockmodulen des Promotionskollegs Agrarökonomik sowie vielen interessanten Fachveranstaltungen und Konferenzen. Der regelmäßige Austausch über den Fortschritt meines Promotionsvorhabens hat mir dabei geholfen, Fragen zu klären, Prioritäten zu setzen, und meinen eigenen (manchmal zu ambitionierten) Zeitplan im Blick zu behalten. Ohne zusätzliche Finanzierung wäre die Durchführung der Gruppendiskussionen und der OnlineBefragung in dieser Form nicht möglich gewesen. Dafür danke ich herzlich auch Prof. Dr. Folkhard Isermeyer.

Prof. Dr. Achim Spiller danke ich für die Bereitschaft, das Zweitgutachten zu meiner Dissertation zu schreiben und mich zu prüfen. Außerdem danke ich für technische Unterstützung von Seiten des Lehrstuhls bei der Durchführung einer Vorstudie für meine Online-Befragung. Prof. Dr. Claudia Neu danke ich für die Bereitschaft, die Rolle der Drittprüferin in meiner Disputation zu übernehmen. Prof. Dr. Jan-Henning Feil danke ich für ein Korreferat im Rahmen des DARE Doktorandenseminars, das mir hilfreiche Impulse für meine Arbeit gegeben hat.

Dr. Günter Peter als ursprünglichem Projektleiter danke ich für die fachliche Betreuung und gute Zusammenarbeit, die leider viel zu kurz war, sowie für die Motivation, den Artikel zu Soja-Zertifizierungssystemen trotz Frustration und Ablehnungen nicht aufzugeben.

Mein besonderer Dank gilt Dr. Inken Christoph-Schulz für die methodische und organisatorische Betreuung meiner Untersuchungen im Arbeitsgebiet Verbraucherforschung sowie für das detaillierte und sehr hilfreiche Feedback zu meiner Doktorarbeit insgesamt. Ich danke insbesondere auch für die Unterstützung bei der Planung und Durchführung der Gruppendiskussionen sowie bei der Planung der Online-Befragung und der Überarbeitung des Fragebogens. Ich habe viel gelernt und auch sehr vom Austausch innerhalb der Arbeitsgruppe Verbraucherforschung profitiert.

In diesem Zusammenhang danke ich auch allen Kolleginnen und Kollegen, die mir im Rahmen der "Methodenwerkstatt" oder im Rahmen von Pretests hilfreiches Feedback zur Planung und Auswertung der Gruppendiskussionen und zum Entwurf des Online-Fragebogens gegeben haben. Dr. Anja-Karolina Rovers danke ich besonders für die spontane Unterstützung bei der Moderation einer Gruppendiskussion.

Prof. Dr. Michiel Bliemer und Dr. Collins Asante-Addo danke ich für methodische Ratschläge im Zusammenhang mit der Erstellung des Choice Designs mit Ngene. Prof. Dr. Hong II Yoo danke ich für die Unterstützung bei der Lösung von Problemen mit dem Stata-Modul Iclogit2. 
Der Graduiertenschule Forst- und Agrarwissenschaften (GFA) der Georg-AugustUniversität Göttingen danke ich insbesondere für die finanzielle Förderung meiner Teilnahme am 8. PhD-Workshop der European Association of Agricultural Economists (EAAE) in Uppsala. Außerdem danke ich den Mitarbeiter*innen der GFA und des Prüfungsamts Agrarwissenschaften für die stets freundliche und hilfsbereite Beratung bei organisatorischen Fragen zur Prüfungsordnung und meiner Promotion.

Ich danke herzlich allen Kolleginnen und Kollegen am Thünen-Institut (insbesondere am Institut für Marktanalyse) für die stets angenehme Arbeitsatmosphäre, die gegenseitige Unterstützung auf allen Ebenen und den Informationsaustausch zu fachlichen und weniger fachlichen Themen. Ich habe viele gute Tipps und Ratschläge sowie organisatorische und technische Unterstützung erhalten. Außerdem habe ich immer ein offenes Ohr gefunden, um Frust und Freuden der Promotionszeit zu teilen. Der regelmäßige Austausch war für mich sehr hilfreich; vor allem auch während der "Corona-Zeit".

Nicht zuletzt danke ich all den Menschen in meinem Leben, die mich auf verschiedenste Weise unterstützen und damit auch dazu beigetragen haben, dass ich dieses Projekt fertigstellen konnte. Danke, dass ihr mich auf diesem Weg begleitet habt! 